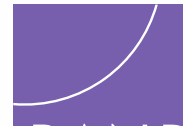

RAND EUROPE

\title{
The changing research landscape and reflections on national research assessment in the future
}

Sarah Parks, Daniela Rodriguez-Rincon,

Sarah Parkinson and Catriona Manville 
For more information on this publication, visit www.rand.org/t/RR3200

Published by the RAND Corporation, Santa Monica, Calif., and Cambridge, UK RAND ${ }^{\circledR}$ is a registered trademark.

RAND Europe is a not-for-profit research organisation that helps to improve policy and decision making through research and analysis. RAND's publications do not necessarily reflect the opinions of its research clients and sponsors.

(C) Copyright 2019 Research England

\section{Support RAND}

Make a tax-deductible charitable contribution at www.rand.org/giving/contribute

www.rand.org

www.randeurope.org 


\section{Preface}

Research England asked RAND Europe to conduct a landscaping study to understand the changing research landscape over the next 5 to 10 years, and the possible application of technology within the process of national research assessment. The aim of this study is to help Research England understand the direction of change within the research system in order to consider how national research assessments may need to adapt going forwards. It considers factors such as the international environment, technological advances and public policy developments.

This report provides an in-depth analysis of the views gathered from the sector and existing literature. It is intended for those who fund and evaluate research in the United Kingdom and internationally. It may also be of interest more broadly, for researchers and those who lead higher education institutions.
RAND Europe is an independent not-for-profit policy research organisation that aims to improve policy and decision making in the public interest through research and analysis. RAND Europe's clients include European governments, institutions, non-governmental organisations and firms with a need for rigorous, independent and multidisciplinary analysis. This report has been peer reviewed in accordance with RAND's quality assurance standards.

For more information about RAND Europe or this document, please contact:

Catriona Manville

RAND Europe

Westbrook Centre

Milton Road

Cambridge CB4 1YG

United Kingdom

Tel. +44 (1223) 353329

manville@rand.org 



\section{Executive Summary}

\begin{abstract}
A national retrospective assessment of research is carried out in the United Kingdom every five to seven years. This exercise assesses research in all disciplines across the country and is used to allocate funding to higher education institutions (HEls). While the preparation and execution of these exercises continues, the research landscape is changing as technology advances, public policy develops and the international environment shifts. Research England commissioned RAND Europe to conduct a study to understand the direction of change within the research system in order to explore how national research assessments may need to adapt. It considers factors such as the international environment, technological advances and public policy developments.
\end{abstract}

This report provides an in-depth analysis of the views gathered from the sector and existing literature. It is intended for the research community, those leading and managing HEls, and those funding and evaluating research in the United Kingdom and internationally.

\section{ES.1 What is this study about?}

The purpose of this study was to explore how the research landscape and research assessment may be affected by trends in the international environment, technological advances and public policy developments in the next 5 to 10 years. It considers the current system and possible changes to the research environment in the future in relation to the following questions:

- Why do we assess research and how might that change in the next 5 to 10 years?

- How do researchers expect the forms of output they are producing to change in the next 5 to 10 years?

- How do researchers expect the types of societal impact their research produces to change in the next 5 to 10 years?

- How do researchers expect the research environment they are in to change in the next 5 to 10 years?

- How could national research assessment exercises learn from developments in peer review?

The study used a mixed-methods approach to gather a wide range of evidence that could be triangulated. It consisted of four rapid evidence analyses of academic and grey literature (each focusing on a different theme); a survey of over 3,600 researchers from across England (see Figure ES.1 and Table ES.1 for the distribution of respondents by geography, career stage and discipline); views on the key questions from representative bodies across the sector associated with academic research; and three workshops with representatives from the government and national funding bodies, organisations that fund research, the 
higher education sector, academics, academic publishing houses, and experts in emerging technologies (with each workshop focussing on a different theme). The relationship between the methods used and the key questions is summarised in Table ES.2. A detailed explanation of the methods, including limitations, can be found in the full report.

Figure ES.1: Locations of researchers participating in the survey

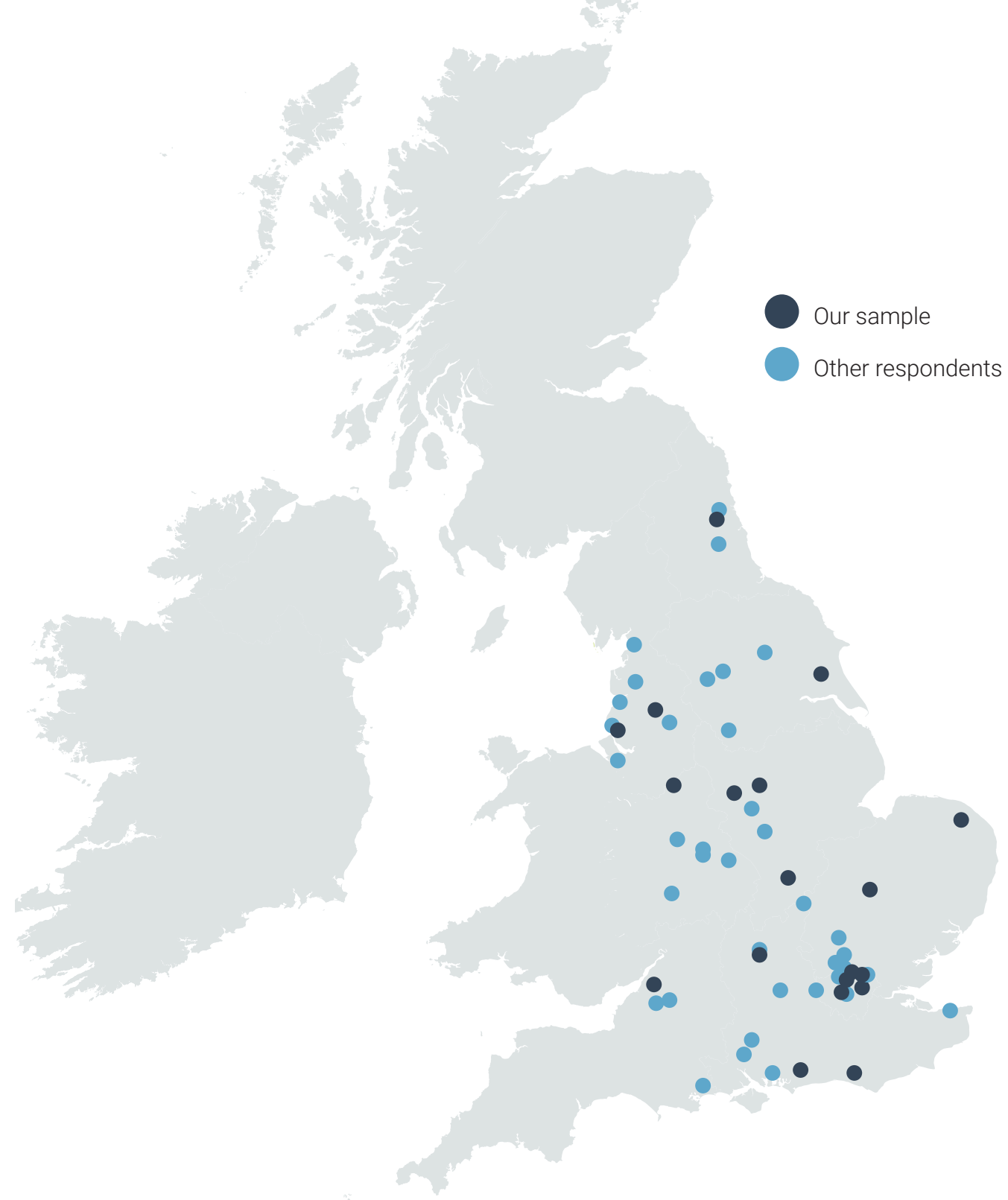


Table ES.1: Distribution of respondents participating in the survey by discipline and career stage

\begin{tabular}{|l|l|}
\hline Discipline & \multicolumn{1}{|c|}{$\begin{array}{l}\text { Number of } \\
\text { respondents }\end{array}$} \\
\hline $\begin{array}{l}\text { Medicine, health and life } \\
\text { sciences }\end{array}$ & 1,409 \\
\hline $\begin{array}{l}\text { Physical sciences, engineering } \\
\text { and mathematics }\end{array}$ & 955 \\
\hline Social sciences & 664 \\
\hline Arts and humanities & 582 \\
\hline Interdisciplinary & 126 \\
\hline Unknown & 32 \\
\hline
\end{tabular}

\begin{tabular}{|l|l|}
\hline Career stage & Number of \\
\hline PhD Student & 896 \\
\hline Early-career researcher & 1,045 \\
\hline Mid-career researcher & 804 \\
\hline Established researcher & 955 \\
\hline Retired or emeritus researcher & 47 \\
\hline Unknown & 21 \\
\hline
\end{tabular}

\section{ES.2 Why do we assess research and how might that change in the next 5 to 10 years?}

Key findings:

- The reasons for doing research assessment can be summarised by six 'A's: analysis, advocacy, allocation, accountability, acclaim and adaptation.

- The reasons for assessing research are understood and interpreted differently by different stakeholders.

- The rationale for, and emphasis of, research assessment is likely to evolve in the future.

There are many reasons for assessing research. This study expands on the four 'A's previously described in the literature ${ }^{3}$ - accountability, advocacy, analysis, and allocation - by adding two further 'A's: acclaim and adaptation (Box ES.1).

The reasons for research assessment are both implicit and explicit, which results in a varied understanding and interpretation by different stakeholders as to why research is assessed. Over time there has been a shift in the focus of the rationale behind assessment, possibly due to the legitimacy of the aims developing and the different aims gaining popularity or importance within the research system and wider society. Within the United Kingdom, while the explicit aims of the Research Excellence Framework (REF) are allocation, accountability and acclaim, the Stern review and recent research on the REF have illustrated that the effects of the assessment exercise went beyond these broad aims. For example, the inclusion of the impact element in REF 2014 has driven researchers and HEls to increase their focus on the wider societal impact of research (i.e. adaptation).

\footnotetext{
We used REF 2021 units of assessment (UOAs) and main panels as a proxy for disciplines by which to interrogate the analysis. Main Panel A: medicine, health and life sciences; Main Panel B: physical sciences, engineering and mathematics; Main Panel C: social sciences; and Main Panel D: arts and humanities. Respondents were assigned to a main panel based on the main UoA they reported that represented them. They are classified as interdisciplinary if they selected two main UoAs that spanned multiple main panels. 'Unknown' indicates that the respondent did not fill in this question

$2 \quad$ Career stage was self-reported. 'Unknown' indicates that the respondent did not fill in this question.

3 Morgan Jones, Molly \& Jonathan Grant. 2013. 'Making the Grade: Methodologies for Assessing and Evidencing Research Impact.' In 7 essays on impact. DESCRIBE Project Report for Jisc. Exeter: University of Exeter.
} 
Table ES.2: Methods used to address the key questions

\begin{tabular}{|c|c|c|c|c|c|c|}
\hline & \multicolumn{5}{|l|}{ Questions } \\
\hline & & $\begin{array}{l}\text { Why do } \\
\text { we assess } \\
\text { research and } \\
\text { how might } \\
\text { that change } \\
\text { in the next } 5 \\
\text { to } 10 \text { years? }\end{array}$ & $\begin{array}{l}\text { How do } \\
\text { researchers } \\
\text { expect the } \\
\text { forms of } \\
\text { output they } \\
\text { are producing } \\
\text { to change in } \\
\text { the next } 5 \text { to } \\
10 \text { years? }\end{array}$ & $\begin{array}{l}\text { How do } \\
\text { researchers } \\
\text { expect the } \\
\text { types of } \\
\text { societal impact } \\
\text { their research } \\
\text { produces to } \\
\text { change in the } \\
\text { next } 5 \text { to } 10 \\
\text { years? }\end{array}$ & $\begin{array}{l}\text { How do } \\
\text { researchers } \\
\text { expect the } \\
\text { research } \\
\text { environment } \\
\text { they are in to } \\
\text { change in the } \\
\text { next } 5 \text { to } 10 \\
\text { years? }\end{array}$ & $\begin{array}{l}\text { How could } \\
\text { national } \\
\text { research } \\
\text { assessment } \\
\text { exercises } \\
\text { learn from } \\
\text { developments } \\
\text { in peer review? }\end{array}$ \\
\hline \multirow{4}{*}{$\begin{array}{l}\text { Rapid } \\
\text { evidence } \\
\text { assessments }\end{array}$} & $\begin{array}{l}\text { Reasons for } \\
\text { research } \\
\text { assessment }\end{array}$ & $\checkmark$ & & & & \\
\hline & $\begin{array}{l}\text { The trends } \\
\text { and factors } \\
\text { changing } \\
\text { the research } \\
\text { landscape }\end{array}$ & & $\checkmark$ & $\checkmark$ & $\checkmark$ & \\
\hline & $\begin{array}{l}\text { The role, } \\
\text { process and } \\
\text { infrastructure } \\
\text { of peer review }\end{array}$ & & & & & $\checkmark$ \\
\hline & $\begin{array}{l}\text { Application } \\
\text { of emerging } \\
\text { technologies } \\
\text { in peer review } \\
\text { in various } \\
\text { contexts }\end{array}$ & & & & & $\checkmark$ \\
\hline \multicolumn{2}{|l|}{ Survey } & & $\checkmark$ & $\checkmark$ & $\checkmark$ & \\
\hline \multicolumn{2}{|c|}{ Sector view collection } & $\checkmark$ & $\checkmark$ & $\checkmark$ & $\checkmark$ & $\checkmark$ \\
\hline \multirow{3}{*}{ Workshops } & $\begin{array}{l}\text { 'Purpose } \\
\text { of research } \\
\text { assessment' } \\
\text { with } \\
\text { policymakers } \\
\text { and academics } \\
\text { in research } \\
\text { assessment }\end{array}$ & $\checkmark$ & & & & \\
\hline & $\begin{array}{l}\text { 'Peer review' } \\
\text { with publishers, } \\
\text { academics and } \\
\text { funders }\end{array}$ & & & & & $\checkmark$ \\
\hline & $\begin{array}{l}\text { 'Emerging } \\
\text { technology' } \\
\text { with technology } \\
\text { and data } \\
\text { specialists } \\
\text { from higher } \\
\text { education and } \\
\text { industry }\end{array}$ & & & & & $\checkmark$ \\
\hline
\end{tabular}




\section{Box ES.1: Definitions of the proposed six 'A's as reasons for research assessment}

$\begin{array}{ll}\text { Analysis } & \begin{array}{l}\text { To understand why, how and whether research is effective, and how it can be } \\ \text { better supported. }\end{array} \\ \text { Advocacy } & \text { To demonstrate the benefits of supporting research, and enhance the } \\ & \text { understanding of research and its processes among policymakers and the public. } \\ \text { Allocation } & \text { To determine how to distribute funding across the research system. } \\ \text { Accountability } & \text { To evidence that money and other resources have been used efficiently and } \\ & \text { effectively, and to hold stakeholders to account. } \\ \text { Acclaim } & \text { To compare and recognise the value of higher education institutions and the } \\ \text { Adaptation } & \text { Tosearch conducted within them. } \\ & \text { research activities and priorities. }\end{array}$

As the research landscape changes, the reasons for performing national research assessment are likely to continue to develop. Participants in the workshop on the reasons for research assessment noted that within the funding community in particular, additional emphasis was now placed on analysis (in the use of research assessment to inform higher education and funding strategies), and that for institutional stakeholders, acclaim has become increasingly important (in the ranking of universities and departments according to the research conducted within them). Given that the six 'A's are dynamic and interrelated elements for research assessment, they are likely to continue to evolve, and the weight and importance of each ' $A$ ' as a reason for assessment may continue to shift over time.

\section{ES.3 How do researchers expect the forms of output they are producing to change in the next 5 to 10 years?}

Key findings:

- Researchers currently produce a diversity of output forms.
- Researchers expect that they will produce a greater diversity of outputs in the future.

- Researchers expect to continue to produce journal articles and conference contributions, and that they will remain the dominant forms in many disciplines in the future.

- Many researchers expect to start to produce more diverse forms of output aimed at a wider audience.

- Researchers' decisions on which forms of output to produce are influenced by factors such as career progression and personal preference, as well as institutional incentives and funder requirements.

- Researchers from different disciplines currently produce different output forms, and researchers' expectations suggest that these differences will continue in the future.

The survey presented researchers with a list of forms of output (e.g. journal articles, books, conference proceedings, visualisations and code) and asked them which forms of output they were currently producing and expect to produce in the next 5 to 10 years. It is important to note that this captured the presence or absence of the creation of different 


\section{Figure ES.2: Number of different forms of output that researchers produce now (A) and expect to produce in the next 5 to 10 years (B)}

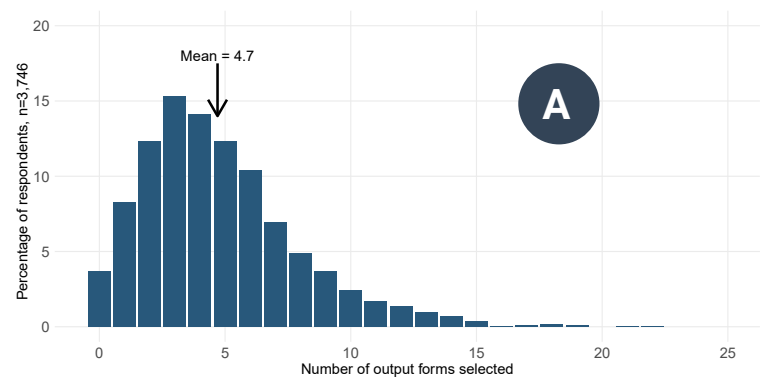

output forms by an individual researcher, rather than the volume of each output form that they produce. The number of forms of outputs produced by researchers is expected to increase, from the current average of 4.7 (Figure ES.2A) to 6.5 in the next 5 to 10 year period (Figure ES.2B).

The majority of researchers expect to continue to produce journal articles and conference contributions, which remain the dominant forms in many disciplines in the future. Currently, the only other forms of output produced by more than 50 per cent of respondents were chapters in books and authored books in arts and humanities. Individual researchers also expect to start to produce more diverse forms of output aimed at a wider audience. The forms of output with the greatest expected percentage increase in the number of researchers producing them over the next 5 to 10 years are books (authored books, chapters in book and edited books), non-confidential research reports for external bodies and openly published peer reviews.

The changes are driven in particular by an expectation of individual career progression, which brings with it the opportunity or requirement to produce different output forms (e.g. books). Other factors influencing the changes in output forms included desire to reach new audiences and create societal

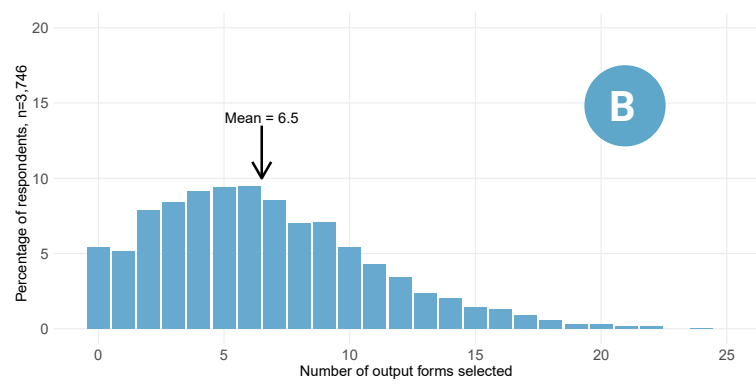

impact, changes controlled by external bodies (e.g. funding, open access requirements, REF) and wider changes that may influence the research landscape (e.g. societal changes and new technology).

There are significant differences in the forms of outputs being produced by researchers from different disciplines. For example, fewer arts and humanities researchers produce journal articles than researchers in other disciplines; while more researchers in the social sciences and arts and humanities produce book types (i.e. chapters in books, authored books, book reviews and edited books), social media, blogs, podcasts and working papers. More researchers in medicine, health and life sciences, and physical sciences, engineering and mathematics, produce peer review, code, research datasets, and databases and preprints than researchers from the social sciences and arts and humanities. Some outputs are also highly specific to certain disciplines, for example analysis plans are mainly produced in the disciplines of medicine, health and life sciences, and software is mainly produced in physical sciences, engineering and mathematics. Although there are some differences between career stages, these are relatively minor compared to discipline-level differences. These differences are expected to continue in the future. 


\section{Figure ES.3: Types of societal impact that respondents are producing now and expecting to produce in the next 5 to 10 years}

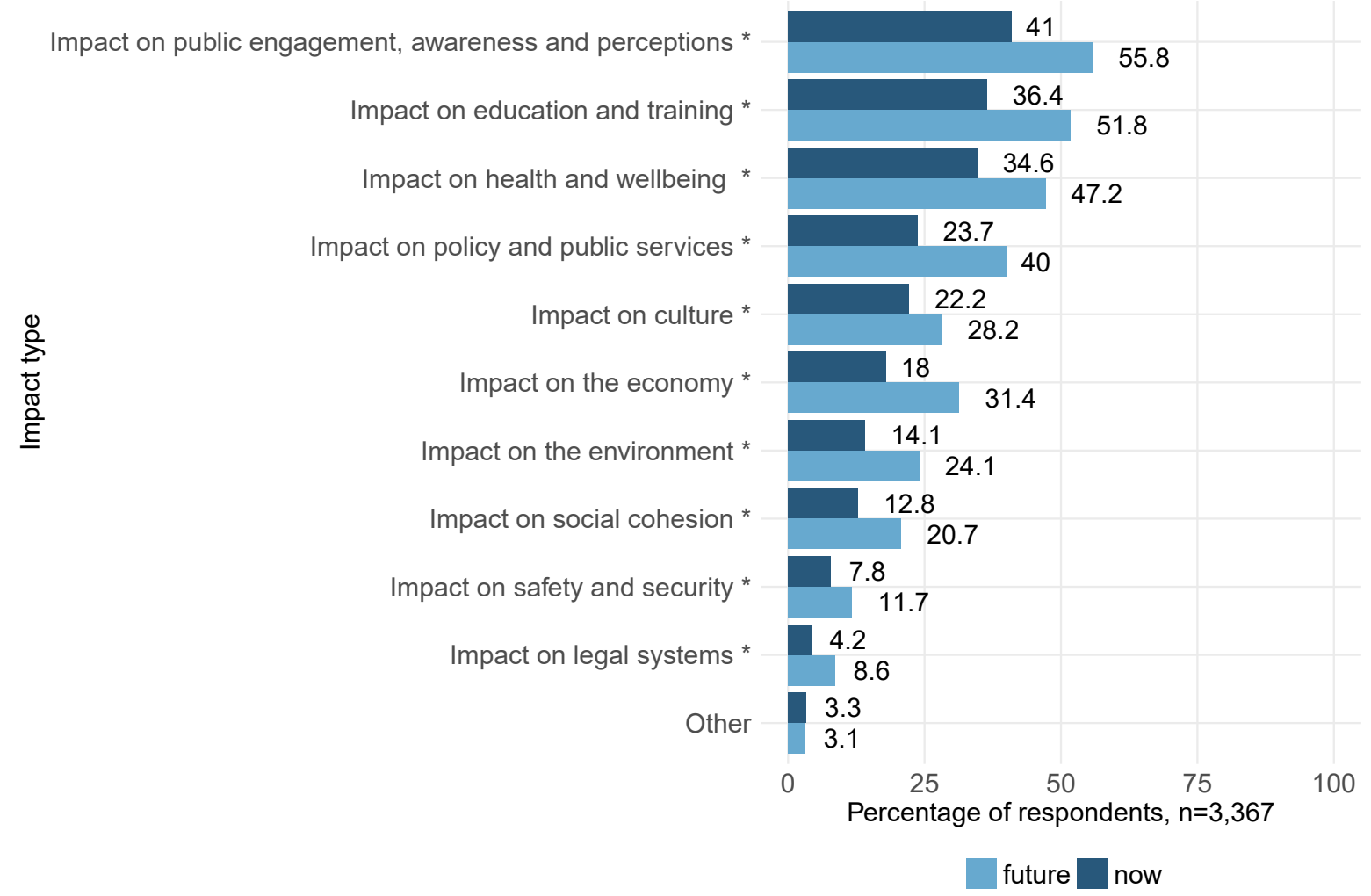

\section{ES.4 How do researchers expect the types of societal impact their research produces to change in the next 5 to 10 years?}

Key Findings:

- More researchers expect that there will be societal impacts from their research in the future, although the balance of types of impact is expected to remain largely the same.

- Societal impact types differ across disciplines, and this is not expected to change.

- Researchers expect that they will continue to focus the majority of their efforts in the future on producing outputs.
- Respondents had differing views as to whether the importance placed on societal impact should increase or decrease in the future, and the reasons for this change.

Some $77 \%$ of respondents currently expect their research to have societal impact, compared to $86 \%$ who expect their research to have societal impact in the future. Researchers also expect their research to lead to more types of societal impact in the future, with the mean number of types of societal impact produced from their research increasing from 2.2 to 3.2. Across respondents, the types of societal impact they expected to have did not alter, with only impact on culture and impact on the economy switching over in prevalence between now and the future (Figure ES.3). Societal impact type differs across disciplines, and this is expected to continue (Figure ES.4). 
Figure ES.4: Types of societal impact that respondents from each discipline are producing now and expecting to produce in the next 5 to 10 years (percentage)

\begin{tabular}{|c|c|c|c|c|c|c|c|c|}
\hline \multirow[b]{2}{*}{ Impact type } & \multicolumn{2}{|c|}{$\begin{array}{c}\text { Medicine, health and } \\
\text { life sciences } \\
n=1,252\end{array}$} & \multicolumn{2}{|c|}{$\begin{array}{c}\text { Physical sciences, } \\
\text { engineering and } \\
\text { mathematics } \\
n=812\end{array}$} & \multicolumn{2}{|c|}{$\begin{array}{c}\text { Social sciences } \\
\mathrm{n}=639\end{array}$} & \multicolumn{2}{|c|}{$\begin{array}{l}\text { Arts and humanities } \\
n=529\end{array}$} \\
\hline & Now & Future & Now & Future & Now & Future & Now & Future \\
\hline Impact on public engagement, awareness and perceptions & 38 & 54 & 29 & 44 & 51 & 66 & 52 & 65 \\
\hline Impact on education and training & 33 & 50 & 30 & 46 & 43 & 55 & 45 & 61 \\
\hline Impact on health and wellbeing & 63 & 79 & 19 & 33 & 18 & 28 & 10 & 16 \\
\hline Impact on policy and public services & 22 & 40 & 11 & 26 & 47 & 65 & 15 & 29 \\
\hline Impact on culture & 7 & 13 & 7 & 12 & 30 & 37 & 68 & 75 \\
\hline Impact on the economy & 11 & 27 & 30 & 50 & 21 & 31 & 10 & 15 \\
\hline Impact on the environment & 8 & 17 & 28 & 44 & 15 & 25 & 4 & 8 \\
\hline Impact on social cohesion & 6 & 13 & 2 & 6 & 31 & 43 & 21 & 33 \\
\hline Impact on safety and security & 5 & 7 & 16 & 24 & 8 & 11 & 2 & 3 \\
\hline Impact on legal systems & 2 & 6 & 2 & 6 & 12 & 20 & 3 & 6 \\
\hline
\end{tabular}

Percentages are shown in bold where there is a significant difference between now and in the future. Impact types are shown shaded in grey if there is a significant difference across disciplines now, and in bold if there is a significant difference expected in the future. Each cell is shaded from white to dark red according to the percentage of respondents reporting producing or expecting to produce each type of impact. The darker the red, the higher the percentage.

When asked about the distribution of balance of effort between producing research outputs and societal impact, researchers expect the majority of effort to remain on outputs in the future, but with a slight increase in effort spent producing impacts, mainly due to the continued emphasis on the impact agenda and its implications for funding at an individual and institutional level.

\section{ES.5 How do researchers expect the research environment they are in to change in the next 5 to 10 years?}

Key Findings:

- Researchers think that collaborating with other academics is the most important driver of change.

- There are significant differences across disciplines in the perceived importance of most of the drivers, although the three most important drivers are consistent.

- Overall, most drivers were seen as more important by PhD students and early-career researchers than by mid-career and established researchers, particularly open science.

- There are a range of views from researchers on how the research environment needs to adapt to change.

- Changes to support and drive developments need to happen at both an institutional and a sector level.

Researchers identified a large number of drivers as important for influencing the changes happening in the research system (Figure ES.5). Academic drivers such as the need to collaborate, in general and internationally, were seen as more important than drivers related to societal impact.

Across disciplines, the three most important drivers of change in the research system were consistently identified as collaborating with other academic researchers, collaborating globally with other academic researchers and the focus on multidisciplinary research. However, there were significant differences in the importance of most of the drivers further down the list. For example, open 
Figure ES.5: How respondents perceive the importance of potential drivers of change in the research environment

The value placed on research by society

The use of metrics (e.g. citation measures) in understanding research

Shift in global research balance

Open science

Increasing investment in some areas of research

Importance of collaborating with other academic researchers

Importance of collaborating with non-academic partners (excluding industry)

Importance of collaborating with industry

Importance of collaborating globally with other

Importance of being mobile as a researcher

Focus on the non-academic impact of research

Focus on research into global challenges

Focus on research integrity

Focus on multidisciplinary research

Focus on inclusion and diversity

Focus on accountability (e.g. demonstrating that publicly funded research is valuable)

Emergence of new professional roles in academia

Decreasing investment in some areas of research

Citizen science

Changes in how research is assessed

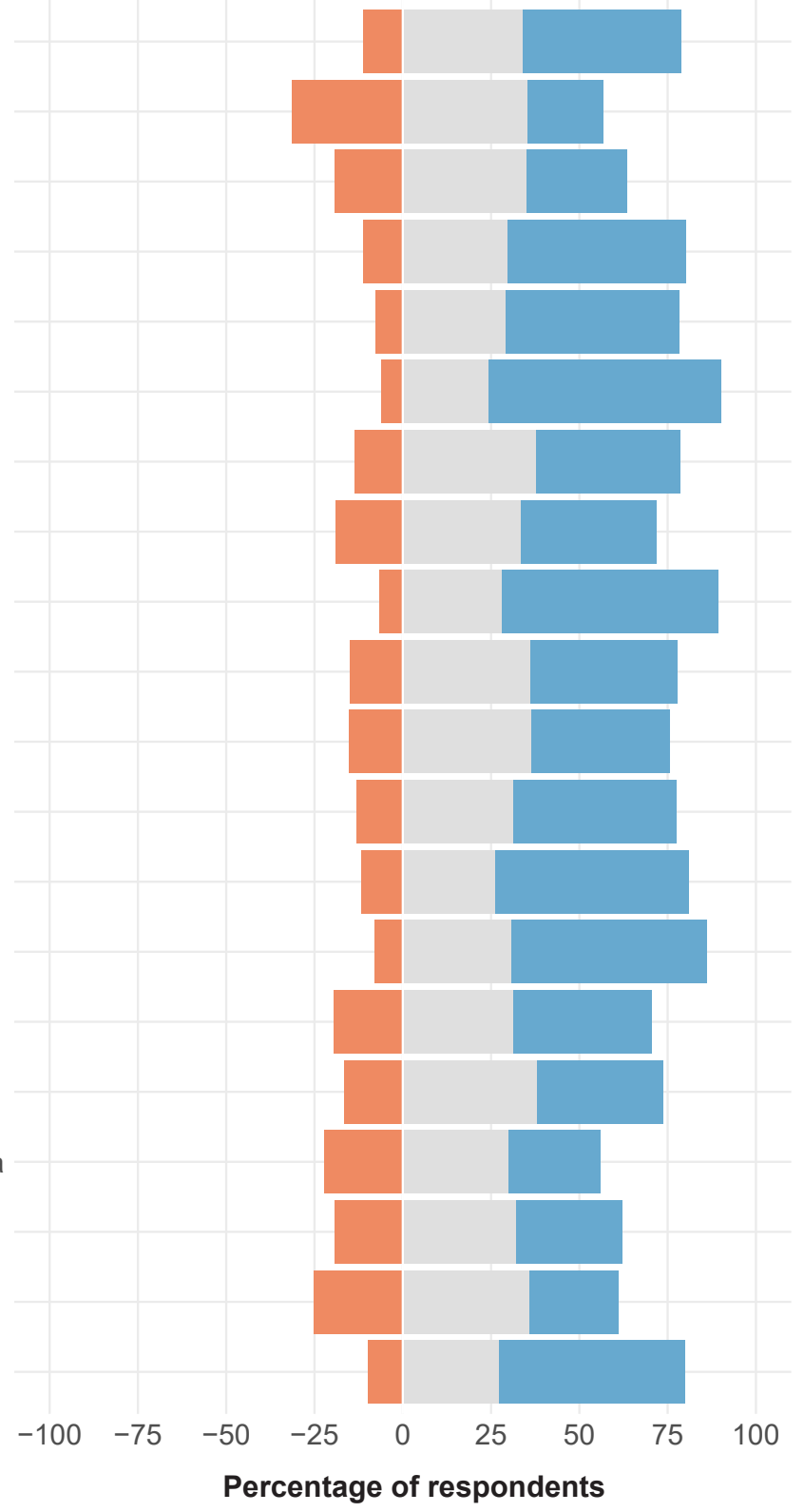

not important somewhat important very important science was ranked 4 th by respondents in medicine, health and life sciences, and 5th by respondents in physical sciences, engineering and mathematics; but it was ranked 10th by respondents in social sciences and 14th by those in arts and humanities. The importance of being mobile as a researcher was ranked 4 th by respondents in physical sciences, engineering and mathematics, but was less highly ranked by respondents from other disciplines. The importance of collaborating with non-academic partners (outside of industry) was ranked 4th by respondents in social sciences and arts and humanities, but 14th by respondents in physical 
sciences, engineering and mathematics. There are also differences across career stages, where most drivers were seen as more important by $\mathrm{PhD}$ students and early-career researchers than by mid-career and established researchers, this contrast was particularly pronounced for open science.

Researchers were asked about how the research environment needs to adapt to the changes they foresee in the outputs and societal impacts they produce. The range of topics discussed in the survey free text of how researchers would like the environment to change is presented in Box ES.2. To address these changes there is a need for support at an institutional and a sector level: respondents' suggestions in relation to this are provided in Box ES.3.

\section{Box ES.2: Factors identified by participants that will shape the research landscape over the next 5 to 10 years}

- Societal impact: both to increase and decrease the emphasis on this factor.

- Reducing pressure and incentives to produce a large number of research outputs in selective journals.

- Incentivising researchers to produce higher quality and new forms of output to engage a more diverse audience.

- Focusing on dissemination and engagement as routes to societal impact.

- Increasing collaborative research.

- Balancing basic and applied research.

- Making research accessible through open science and open access.

- Increasing support for interdisciplinary research

\section{Box ES.3: Types of support suggested by survey respondents}

- Funding to develop research that has societal impact.

- Valuing societal impact and engagement within HEl reward and recognition systems.

- Adjusting workload models and the creation of new roles to take into account work to develop societal impact.

- Changes to policy to address concerns about a culture of audit and the impact of the United Kingdom's changing relationship with the EU.

- Training to develop expertise in engagement, societal impact and new digital methodologies.

- Changes to the academic publishing system to increase openness and improve peer review.

- IT and infrastructure to support openness and collaboration on a global scale. 


\section{ES. 6 How could UK national research assessment learn from advances in other applications of peer review?}

Key findings:

- Peer review is the predominant method for research assessment in the United Kingdom, and there is no expectation that this will change.

- Technological approaches are expected to further support peer review in the future.

- Cultural shifts, as well as technological shifts, are both needed and happening.

Peer review is the predominant method for research assessment in the United Kingdom. It is used across many contexts, such as grant applications, journal publications, ex-post assessment and conference contributions, and while it has both strengths and weaknesses, there was no expectation from workshop participants that its predominance in research assessment will change.

However, there is an expectation that technological approaches, which already underpin many aspects of peer review, may further support peer review in the future. Attendees at the workshops on peer review and emerging technologies identified a number of technologies and approaches already being developed which span the entire pathway of peer review, from selecting reviewers and allocating items, to scoring, to calibration, moderation, validation and decision making, and incentives (Figure ES.6).

Figure ES.6: The peer review process and examples of technologies that can support the different stages

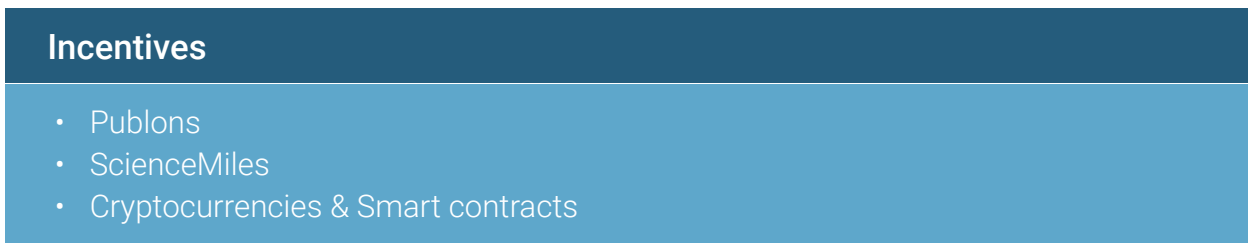

Parts of the process

Examples

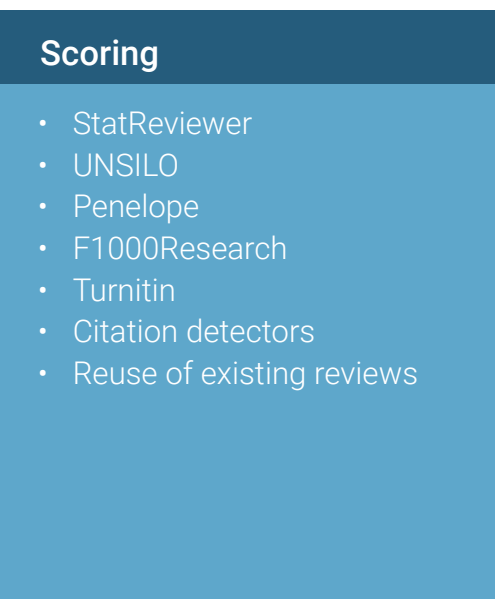

Calibration, moderation, validation and decision making

- Prediction software

- elife 
Although there are a variety of technologies potentially available to support the peer review process, it was noted that they are not necessarily aligned with all the underlying issues of peer review systems. For example, some of the issues that participants in the workshops on peer review and emerging technology felt most needed addressing, such as equality and diversity and the rewarding of reviewers, would not be exclusively solved by advances in technology, as currently imagined. A challenge for the sector is to not just be driven by technological advances, but to take advantage of the technology that does provide benefits. Additionally, improvements to peer review are likely to require cultural changes, such as the rise of open science, as well as technological changes, and may require additional approaches such as training and incentives.

\section{ES.7 Reflections on how national research assessment may need to adapt to changes in the research landscape}

Key considerations for the future:

- Research assessment needs to continue to consider the diversity of outputs produced by academic research.

- It is important to consider the needs of different disciplines when undertaking a nationwide assessment.

- Drivers that researchers perceive to be important are generally within the academic system.

- National research assessment is an important driver of behaviour for the sector.

Across these questions no disruptive changes that would indicate a large or immediate shift in the research landscape have been identified. Instead there are likely to continue to be gradual changes as current drivers within the system develop alongside developments in the external environments (e.g. technological developments). National research assessment is therefore likely to need to continue to remain engaged with the sector and respond to changes as they arise or can be anticipated. In particular, research assessment needs to continue to consider the diversity of outputs produced by academic research. Currently the vast majority of outputs submitted to the REF represent a small number of output types, largely journal articles. ${ }^{4}$ However, researchers want and expect to produce a greater diversity of types of output. If the increased diversity of output forms is considered valuable to the system then it may be necessary to consider suitable ways to encourage their submission. It will also be important to ensure appropriate capacity to both assess and ensure confidence in the assessment of these outputs.

Across outputs, societal impacts and drivers, there were more significant differences in the survey responses between disciplines than between career stages. This reinforces the importance of considering the needs of different disciplines when making decisions about and undertaking national research assessment.

While the majority of drivers were considered to be important in driving changes in the system, those that were seen as most important were more related to academic impact rather than societal impact. In particular, the top five drivers for change were (1) the need to collaborate with other academic researchers; (2) the need to collaborate globally with other academic researchers; (3) the need to focus on multidisciplinary research; (4) the 
need to focus on research integrity; and (5) a drive towards open science.

It is important to remember that national research assessment is an important driver of behaviour and practice in the sector at an individual and institution level, as well as a system level. For example, universities increasingly use the results of research assessment exercises to promote their work, enhance their reputation, and inform strategic approaches such as recruitment. When tweaking or changing assessments it is important to consider the potential effects or consequences. Continued research is needed to understand the incentives and effects and ensure that they encourage a positive research environment. 



\section{Table of contents}

Preface III

Executive Summary $\quad$ V

List of figures $\quad$ XXIII

List of tables $\quad$ XXV

List of boxes $\quad$ XXVII

Abbreviations $\quad$ XXIX

Acknowledgements $\quad$ XXXI

1. Introduction $\quad 1$

1.1. Introduction and aims of the study 1

1.2. How the research environment is changing 1

1.3. National research assessment in the United Kingdom 6

1.4. Overview of methodology 7

1.5. Outline of the report 12

2. Why do we assess research and how might that change in the next 5 to 10 years? $\quad 13$

2.1. The reasons for doing research assessment can be summarised by six 'A's 13

2.2. The reasons for assessing research are understood and interpreted differently by different audiences $\quad 21$

2.3. The rationale for, and emphasis of, research assessment is likely to evolve in the future 23

3. How do researchers expect the forms of output they are producing to change in the next 5 to 10 years?

3.1. Researchers currently produce a diversity of output forms 25

3.2. Researchers expect that they will produce a greater diversity of outputs in the future 26

3.3. Researchers expect to continue to produce journal articles and conference contributions, and that they will remain the dominant forms in many disciplines in the future

3.4. Many researchers expect to start to produce more diverse forms of output aimed at a wider audience 
3.5. Researchers' decisions on which forms of output to produce are influenced by factors such as career progression and personal preference, as well as institutional incentives and funder requirements

3.6. Researchers from different disciplines currently produce different output forms, and researchers' expectations suggest that these differences will continue in the future

4. How do researchers expect the types of societal impact their research produces to change in the next 5 to 10 years?

4.1. More researchers expect that there will be societal impacts from their research in the future, although the balance of types of impact is expected to remain largely the same

4.2. Societal impact types differ across disciplines, and this is not expected to change

4.3. Researchers expect that they will continue to focus the majority of their efforts in the future on producing outputs

4.4. Respondents had differing views as to whether the importance placed on societal impact should increase or decrease in the future, and the reasons for this change

5. How do researchers expect the research environment they are in to change in the next 5 to 10 years?

5.1. Researchers think that collaborating with other academics is the most important driver of change

5.2. There are significant differences across disciplines in the perceived importance of most of the drivers, although the three most important drivers are consistent

5.3. Overall, most drivers were seen as more important by PhD students and early-career researchers than by mid-career and established researchers, particularly open science

5.4. There are a range of views from researchers on how the research environment needs to adapt to change

5.5. Changes to support and drive developments need to happen at both an institutional and a sector level

6. How could national research assessment exercises learn from developments in peer review?

6.1. Peer review is the predominant method for research assessment in the United Kingdom, and there is no expectation that this will change

6.2. Technological approaches are expected to further support peer review in the future

6.3. Cultural shifts, as well as technological shifts, are both needed and happening

7. Reflections on how national research assessment may need to adapt to changes in the research landscape

7.1. Why assess research, and how might that change in the next 5 to 10 years?

7.2. How do researchers expect the forms of output they are producing to change in the next 5 to 10 years?

7.3. How do researchers expect the types of societal impact their research produces to change in the next 5 to 10 years?

7.4. How do researchers expect the research environment they are in to change in the next 5 to 10 years? 
7.5. How could UK national research assessment learn from advances in other applications of peer review?

7.6. Considerations for the future 94

References $\quad 99$

$\begin{array}{ll}\text { Annex A. Methodology } & 113\end{array}$

$\begin{array}{lll}\text { A.1. } & \text { Methodology overview } & 113\end{array}$

$\begin{array}{ll}\text { A.2. } & \text { Rapid evidence assessments } \\ & 115\end{array}$

$\begin{array}{ll}\text { A.3. } & \text { Workshops } \\ \text { A.4. }\end{array}$

$\begin{array}{lll}\text { A.4. Survey } & 118\end{array}$

A.5. Collection of sector views 121

$\begin{array}{ll}\text { A.6. } & \text { Analysis and reporting } \\ & 121\end{array}$

Annex B. Survey respondent demographics $\quad 123$

$\begin{array}{ll}\text { B.1. Career stage } & 123\end{array}$

$\begin{array}{ll}\text { B.2. Universities } & 123\end{array}$

$\begin{array}{ll}\text { B.3. } & \text { Disciplines } \\ \end{array}$

$\begin{array}{ll}\text { Annex C. Survey protocol } & 131\end{array}$

$\begin{array}{ll}\text { Annex D. Sectoral views questions } & 149\end{array}$

Annex E. Codebooks for open-ended questions in the survey 155

E.1. Codebook for expected outputs question 155

E.2. Codebook for ideal outputs question 158

E.3. Codebook for expected impacts question 160

E.4. Codebook for the research environment question 161

Annex F. REF 2021 Units of Assessment 169

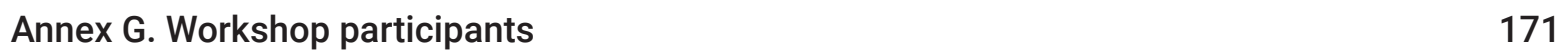





\section{List of figures}

Figure ES.1: Locations of researchers participating in the survey

Figure ES.2: Number of different forms of output that researchers produce now

(A) and expect to produce in the next 5 to 10 years (B) $X$

Figure ES.3: Types of societal impact that respondents are producing now and expecting to produce in the next 5 to 10 years

Figure ES.4: Types of societal impact that respondents from each discipline are producing now and expecting to produce in the next 5 to 10 years (percentage)

Figure ES.5: How respondents perceive the importance of potential drivers of change in the research environment

Figure ES.6: The peer review process and examples of technologies that can support the different stages

Figure 1.1: Methodology used in this study

Figure 1.2: Locations of researchers responding to the study 10

Figure 3.1: Number of output forms currently produced 26

Figure 3.2: The percentage of respondents currently producing each form of output 27

Figure 3.3: Number of output forms that researchers plan to produce in the next 5 to 10 years

Figure 3.4: The different forms of output respondents are producing now and expect to produce in the next 5 to 10 years

Figure 3.5: Percentage of respondents from each discipline who report producing each form of output now and who expect to do so in the future (in 5 to 10 years)

Figure 3.6: Percentage of respondents reporting producing the top 10 overall forms of output now and expecting to produce them in the future: Differences across career stages within disciplines

Figure 3.7: Percentage of respondents from each career stage reporting producing forms of output now and expecting to produce them in the future 
Figure 3.8: Percentage of respondents reporting producing the top 10 forms of output now and expecting to produce them in the future: Differences across disciplines within career stages

Figure 4.1: Types of impact that respondents are producing now and expecting to produce in the next 5 to 10 years

Figure 4.2: Types of societal impact that respondents from each discipline are producing now and expecting to produce in the next 5 to 10 years (percentage)

Figure 4.3: Types of societal impact that respondents from each career stage are producing now and expecting to produce in the next 5 to 10 years (percentage)

Figure 4.4: Percentage of respondents reporting producing each type of impact now and expecting to produce each type of impact in the next 5 to 10 years: Differences across disciplines within career stages

Figure 4.5: Percentage of respondents reporting producing each type of impact now and expecting to produce each type of impact in the next 5 to 10 years:

Differences across career stages within disciplines

Figure 4.6: Change in the balance of efforts spent on producing outputs and impacts between now and 5 to 10 years' time

Figure 5.1: How respondents perceive the importance of potential drivers of change in the research environment

Figure 5.2: Percentage of respondents who were unsure of importance of drivers of change (level of uncertainty)

Figure 5.3: How researchers perceive the importance of drivers of change, across disciplines

Figure 5.4: The top five ranked drivers of change in the research system, across disciplines 62

Figure 5.5: Percentage of respondents reporting a driver as important: Differences across career stages within disciplines

Figure 5.6: How researchers perceive the importance of drivers of change, across career stages

Figure 5.7: Top five ranked drivers of changes in the research system, by career stage

Figure 5.8: Percentage of respondents reporting a driver as important: Differences across disciplines within career stages

Figure 6.1: $\quad$ Settings in which peer review occurs 78

Figure 6.2: The stages of peer review

Figure 6.3: The peer review process and examples of technologies that can support the different stages

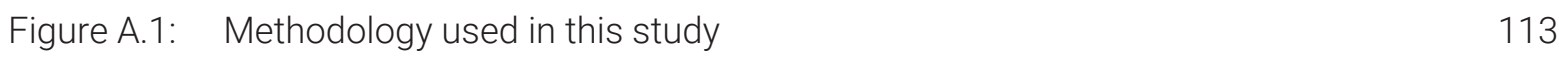

$\begin{array}{lll}\text { Figure B.1: } & \text { Career stage of respondents } & 124\end{array}$

Figure B.2: Geography of respondents 


\section{List of tables}

Table ES.1: Distribution of respondents participating in the survey by discipline and career stage

Table ES.2: Methods used to address the key questions VIII

Table 1.1: Methods used to address the key questions 8

Table 1.2: Distribution of respondents to the survey by discipline and career stage 11

Table 2.1: Examples of research assessment exercises linked to funding allocation 16

Table 3.1: $\quad$ Top 10 most frequently reported output forms being produced now and expected to be produced in 5 to 10 years' time

Table 3.2: Respondents who expect a change in the forms of output they produce in the next 5 to 10 years $(n=1,072)$

Table 3.3 Respondents who would ideally like to produce more or fewer books, monographs and journal articles $(n=640)$

Table 3.4: $\quad$ Top 10 output forms with greatest percentage increase in the number of respondents who plan to produce them in the next 5 to 10 years

Table 3.5: Broad categories of less common output forms that respondents expect to increase producing

Table 3.6: Less common output forms that respondents expect to increase producing 33

Table 3.7: $\quad$ Respondents who would ideally like to produce more of different output forms 34

Table 3.8: Reasons provided for why researchers expect to produce new output forms in the future

Table 3.9: $\quad$ Significant differences in outputs produced now and expected to be produced in the future, across disciplines

Table 3.10: Significant differences in outputs produced now and expected to be produced in the future, across career stages

Table 4.1: $\quad$ Expected shifts in effort between the production of outputs and impacts 52

Table 4.2: $\quad$ Average balance of efforts spent on outputs and impacts across career stages 52 
Table 4.3: $\quad$ Average balance of efforts spent on outputs and impacts across disciplines

Table 4.4: Reasons respondents gave for expecting different types of impact or an increase in impact in the future

Table 4.5: $\quad$ Reasons respondents gave for expecting the same or a reduction in the types of impact in the future

Table 4.6: Reasons respondents gave for being unsure of how impacts would change in the future

Table 5.1: Main forms of institutional and sectoral mechanisms to support changes in the research landscape, as suggested by respondents

Table 6.1: Views from the workshop on peer review on the areas most likely to change, and those that would be most beneficial to change, in the next 5 to 10 years

Table 6.2: Views from the workshop on technology on the areas most likely to change, and those that would be most beneficial to change, in the next 5 to 10 years

Table 7.1: The percentage of different output forms submitted to REF 2014 overall and by discipline

Table A.1: $\quad$ Methods used to address the key questions

Table A.2: $\quad$ Open response question coding

Table B.1: $\quad$ Number of respondents from each HEl within the sample 125

Table B.2: $\quad$ Number of respondents from HEls outside of the sample 125

$\begin{array}{lll}\text { Table B.3: } & \text { Respondents from each UOA } & 128\end{array}$

Table B.4: $\quad$ Percentage of respondents across career stages for each main panel 129

Table B.5: $\quad$ Gender distribution of respondents for each main panel 129

Table E.1: $\quad$ Codebook used in Excel for expected outputs question 155

Table E.2: $\quad$ Codebook used in Excel for ideal outputs question 158

Table E.3: $\quad$ Codebook used in Excel for expected impacts question 160

Table E.4: $\quad$ Codebook used in NVivo for the research environment question 161 


\section{List of boxes}

Box ES.1: Definitions of the proposed six 'A's as reasons for research assessment

Box ES.2: Factors identified by participants that will shape the research landscape over the next 5 to 10 years

Box ES.3: $\quad$ Types of support suggested by survey respondents XIV

Box 1.1: Definitions of the proposed six 'A's as reasons for research assessment 14

Box 6.1: Description of some current persistent identifiers 83

Box 6.2: Examples of software to support eligibility checks 85

Box 7.1: $\quad$ Factors identified by participants that will shape the research landscape over the next 5 to 10 years

Box 7.2: $\quad$ Types of support suggested by survey respondents 93

Box A.1: $\quad$ Search sequence for the rapid evidence assessments 116 



\section{Abbreviations}

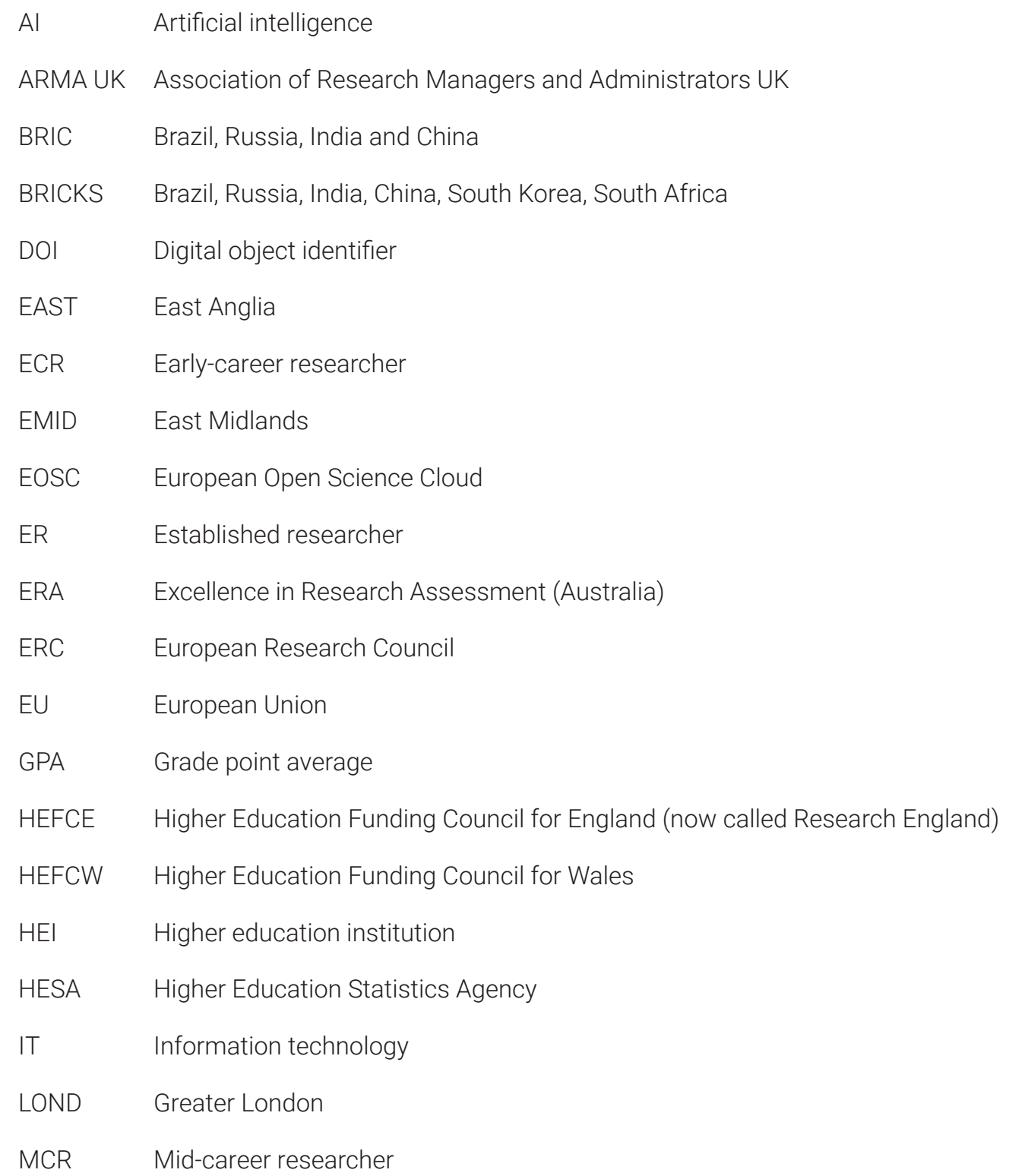




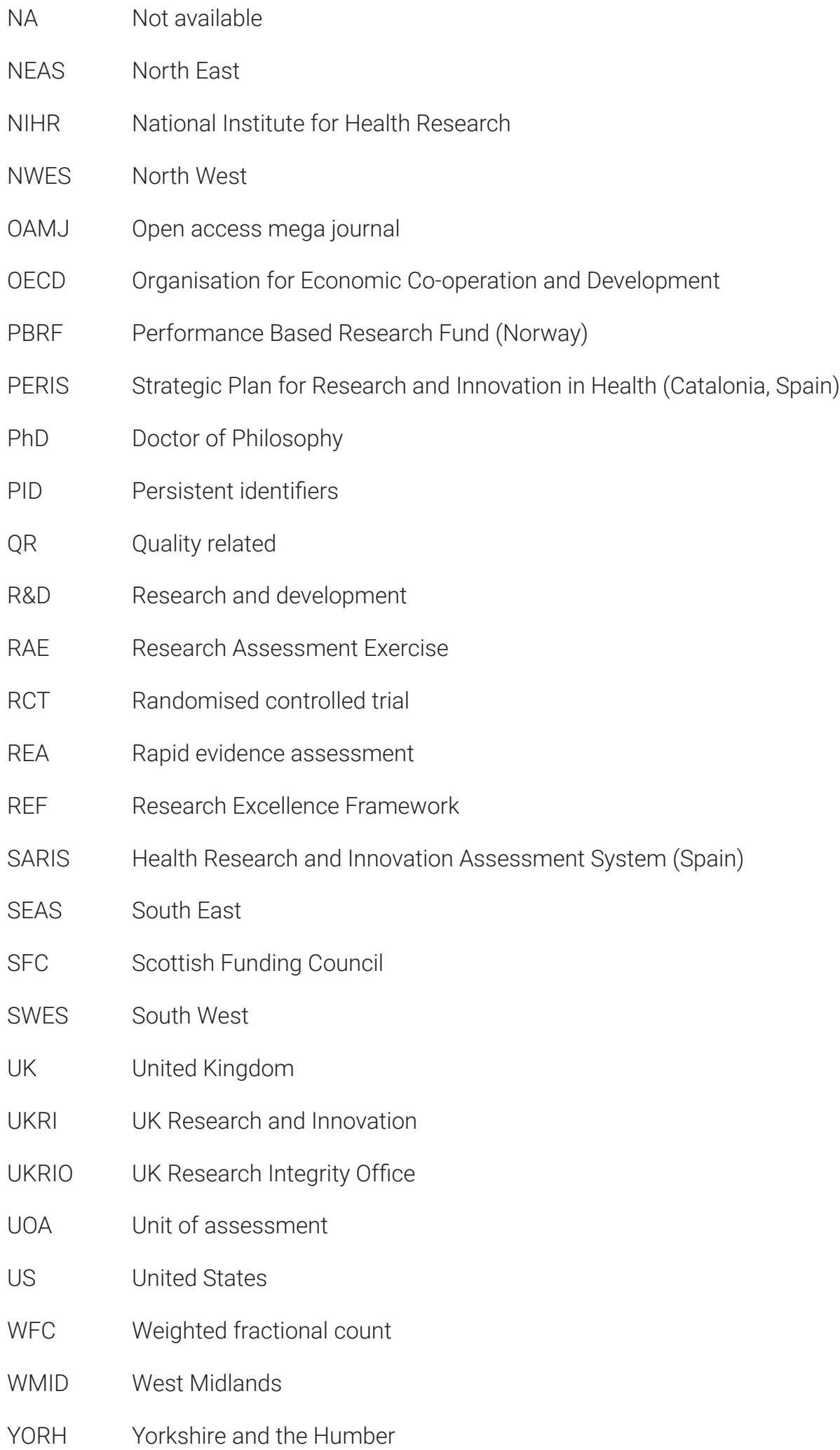




\section{Acknowledgements}

RAND Europe researchers would like to thank Dr Charlotte Lester, Adam Killey, Geoff Hill and Dr Steven Hill from Research England for their support throughout this project, as well as expertise from the advisory group (Dr Gemma Derrick, Professor Mark D'Inverno, Dr Emily Gale, Dr Daniel Hook, Professor Alis Oancea, Professor Mike Thelwall, Professor Jane
Winters and Professor Sarah De Rijcke) for their input and guidance.

We would also like to thank workshop participants and the research community who informed our research. Lastly, we thank Dr Susan Guthrie and Dr Catherine Lichten from RAND Europe for their quality assurance roles. 



\section{Introduction}

\subsection{Introduction and aims of the study}

Research England ${ }^{5}$ commissioned RAND Europe to conduct a scoping study to explore how the research landscape and research assessment may be affected by trends in the international environment, technological advances and public policy developments in the next 5 to 10 years. This study is based on perspectives from the sector around the direction of travel that is expected, rather than that desired by researchers and other members of the sector. This study considers changes in the next 5 to 10 years for three elements of national research assessment: why national research assessment is carried out, what is assessed, and how technology might affect the processes of national research assessment.

\subsection{How the research environment is changing}

Recent studies have looked at possible future scenarios to describe how the research landscape may shift (Elsevier \& Ipsos MORI 2019; Elsevier n.d.; Rhoods \& Babor 2018). Some future scenarios explored in these reports include the 'brave open world' scenario, characterised by the rise of the open access agenda; the 'tech titans' scenario, which centres around the growing influence and dominance of technology; and the 'eastern ascendance' scenario, characterised by the rise of China as a research power (Elsevier n.d.). Rhoods \& Babor have explored changes that may occur in the publishing industry, including the widespread use of emerging technologies such as artificial intelligence, machine learning and automation; developments in geopolitics (globalisation and nationalism); and socioeconomic shifts, including the growing distrust of experts (Rhoods \& Babor 2018). Some of these major trends, as well as other trends affecting the research system, are described in more detail below.

\subsubsection{The role of emerging research nations}

The international research landscape is changing as the global role and dominance of emerging nations shift, especially in fields that are highly relevant to industry. A report published by Nature Index, Nature's Database of Author Affiliation Information, focused on China's growth as a research nation in terms of research and development (R\&D) investment, research output, citation share and international collaboration with top research 
countries such as the United States and the United Kingdom. According to the report, China's total expenditure on R\&D grew at an average rate of 20\% per year from 2005-2015, which was a time when austerity affected most European countries. China's weighted fractional count (WFC) ${ }^{6}$ of articles is higher than any other country, especially in chemistry, which accounts for $61 \%$ of China's total WFC of articles (Zhou 2015).

Another report compared India's scientific productivity in terms of publications and citation-based indicators to a selection of advanced OECD countries ${ }^{7}$ and other BRICKS countries (Brazil, Russia, India, China, South Korea and South Africa). The report found that publications have grown significantly in India and South Korea, as well as in China (Bhattacharya \& Kaul 2015), and that the publication share of OECD countries is falling, while that of BRICKS countries is growing, even when China is excluded from the BRICKS country group (Bhattacharya \& Kaul 2015).

\subsubsection{The growing importance of international research collaborations}

A second global trend affecting the international landscape has been the growing importance of international research collaborations in producing high-quality and high-impact research, referred to in the literature as the 'fourth age of research' (Adams 2013; 2017). Globally, the number of international collaborations has been growing. A study looking at internationally co-authored papers in Web of Science from 2000 to 2015 found that the number of internationally collaborative papers grew from $10.7 \%$ of the total scientific output in 2000 to $21.3 \%$ in 2015 (Ribeiro et al. 2018). While the number of scientific outputs is growing internationally, the proportion of domestic outputs, or papers that list only authors from the country of publication, has fallen in the United States, the United Kingdom and western European countries over the past three decades (Adams 2013; 2017). A recent report by Elsevier found that the upward trend in UK research productivity may be due to a greater number of international collaborations, which tend to have a greater citation impact than outputs by a single author or by collaborations within a single country (Elsevier n.d.). International collaboration is also important to the productivity of individual researchers - a survey of researchers in Europe found that the average productivity of 'internationalists', or researchers involved in international collaborations, is consistently higher than the productivity of 'locals' or researchers not involved in international collaborations, in all fields and countries included in the study (Kwiek 2015).

\subsubsection{Increasing academic and industrial collaborations}

A third related trend is the growing international importance of higher education institution (HEI) and industry connections, and commercialisation (Abreu \& Grinevich 2013; Cervantes \& Meissner 2014; Tijssen et al. 2017). A recent study found that around $5.4 \%$ of all publications in the United Kingdom list an author affiliative address referring to a business rather than a university, and that university-industry co-authored publications

\footnotetext{
$6 \quad$ Weighted fractional count (WFC) is a measure of the number of articles published in a group of highly selective science journals (chosen by an independent group of active researchers), reported by Nature Index. WFC assigns fractional counts in the case of multiple authors in order to avoid counting the same article multiple times, and is weighted to account for the high volume of publications in astrophysics and astronomy. For more information see A Guide to the Nature Index (Nature Index 2018).

$7 \quad$ These were: France, Germany, Japan, the United Kingdom and the United States of America.
} 
and other interactions with industry have become increasingly important (Tijssen et al. 2017). The focus on societal impact and building connections between HEls and industry has led to the proliferation of new professional roles within academia, including the 'knowledge broker' role and other para-academic roles that look for ways to match research to impact opportunities (Lightowler \& Knight 2013). This emerging class of professionals is part of a wider shift in roles within academia that is leading to non-research staff increasingly taking on professional activities, such as administrative and management tasks, that were previously assigned to academic researchers. This change may alter the skills that academics are expected to have (Kehm 2015).

\subsubsection{Focusing on the societal impact of research}

There has also been an increased focus on the wider societal impacts of research. For example, in the United Kingdom, the 2014 Research Excellence Framework (REF) introduced the use of case studies to assess the wider societal impact of research. The REF is reflective of broader trends towards an accountability culture (Weingart 2013), which have also been apparent in the increased use of proxy measures of research productivity and quality in research management, such as bibliometrics and altmetrics. Quantitative metrics can contribute to the discussion about research productivity and quality; however, recent work has highlighted limitations in representation, coverage and robustness to manipulation (Wilsdon et al. 2015). Both within the United Kingdom and globally there are ongoing efforts to move away from the use of heuristic measures related to journal prestige to instead focus on the development of 'responsible' research metrics (San Francisco Declaration on Research Assessment 2012; Universities UK 2019; Wilsdon et al. 2015).

\subsubsection{The impact of emerging technologies on research}

New and emerging technologies have not only had an impact on how research is assessed, but also on how it is conducted. For example, Web $2.0^{8}$ and smart devices have dramatically increased the quantity and granularity of data that can be collected and analysed, which has contributed to ethical concerns about public and private data (Hesse-Biber \& Johnson 2013). Similarly, big data and cloud computing now allow researchers to collect, store, analyse and share large quantities of data throughout the research process rather than just when results are peer reviewed and published, which needs to be balanced against concerns around data quality, metadata and reproducibility (Rousidis et al. 2014). Disruptive technologies ${ }^{9}$ also have the potential to dramatically change how research is conducted, including by automating or partially automating parts of the research process. For example, research protocols can be written into 'stone' with distributed ledger technologies such as blockchain and smart contracts, which can automatically collect, encrypt and analyse data based on pre-specified instructions, potentially making research less susceptible to error and reducing the risk of intentional misrepresentation (van Rossum 2017).

\subsubsection{The rise of open science}

Within the United Kingdom and internationally, open science has the potential to change the

\footnotetext{
8 Web 2.0 refers to the move from a static web in which content is developed by a limited number of developers, to a more collaborative, responsive and interactive web in which users create content on an ongoing basis.

$9 \quad$ A disruptive technology is technology that displaces an established technology and shocks industry, or a product that creates a new industry ("What Is Disruptive Technology? - Definition from Whatls.Com" n.d.).
} 
research landscape in the next 5 to 10 years. Open science refers to a broad range of changes to increase transparency, accountability and collaboration in the research system, including open access to publications, openly available research data, open scientific codes and tools, open scholarly communications, open evaluation and peer review, and the widening participation in research through activities such as citizen science (Bonney et al. 2014; Fecher \& Friesike 2014)..$^{10}$ These changes are being driven by a variety of factors, including concerns around the replicability and reproducibility of published science (Siebert et al. 2015), and a desire to encourage a culture of transparency and to incentivise 'good' science as opposed to only innovative research or novel findings (Nosek et al. 2015). Open science practices also allow more datasets to be reused, particularly those that are expensive and hard to collect (Piwowar \& Vision 2013), which can potentially improve the efficiency of the research system in terms of how research funds are spent. Similarly, open access ensures that research outputs are available to the tax-paying public, which increases the accountability of the research system (Neylon 2013). Open access has been an area of particular growth, with activity taking place in this space (Cervantes \& Meissner 2014; Brown et al. 2015) since the 1970s. Activity increased around the turn of the century with the launch of open access journals and databases such as PubMed Central in 2000, Google Scholar in 2004 and PLoS ONE in 2006. ${ }^{11}$ The open access agenda has gained momentum over the past decade: in 2011, PLOS ONE became the largest peer reviewed journal in the world in terms of the number of publications that year, and in 2014, the four UK research funding bodies announced an open access policy for REF2021 (Symplectic 2019). The UK Research and Innovation (UKRI) and the European Commission have signed Plan S, which will mandate immediate open access for all cOAlition $S^{12}$ funded projects by 2020 (Schiltz 2018), ${ }^{13}$ and many third sector research funders in the United Kingdom have also moved towards open access requirements (Brown et al. 2015).

Open access trends have already led to significant changes in how research is conducted (Neylon 2013), and may lead to more significant changes in the future, possibly disrupting the traditional publishing model (Risnes 2018; Van Noorden 2013). For example, a survey of academics found that social media has already allowed for more open scholarly communications as researchers connect with one another, engage the public and discuss their work online through a process of 'conversational scholarship' (Lupton 2014). Researchers have also found that online repositories have changed their workflows by allowing for the publication of raw data, analysis plans and findings throughout the research process (Assante et al. 2015). The availability of these new types of output in repositories and other platforms online creates the potential for their evaluation by funders (Barbaro et al. 2014; Scanlon 2014); for researchers to receive commentary throughout the research process, rather than just at the end (Van Noorden 2014); and for data to be reused and validated (Piwowar \& Vision 2013).

10 See the European Commission's Open Science Policy Platform for more information (European Commission 2019a)

11 PLOS ONE is an open access peer reviewed journal with a belief that all rigorous science needs to be published and discoverable, widely disseminated and freely accessible to all.' See PLOS ONE for more information (PLOS ONE 2019)

12 'Plan S is an initiative for open access publishing that was launched in September 2018. The plan is supported by c0Alition $\mathrm{S}$, an international consortium of research funders. Plan S requires that, from 2020, scientific publications that result from research funded by public grants must be published in compliant open access journals or platforms' (COAlition S 2018). 
Open science has led to an increase in the quantity of published outputs and new ways of managing quality. Online journals are no longer restricted by physical space and can now accept more articles for publication, which has led to the growth of open access mega journals (OAMJs). This removes the need to consider utility, contribution or novelty as factors in the publication process. A recent literature review of OAMJs highlighted the diversity of opinions around them, ranging from viewing OAMJ's as the future of scientific communication to viewing them as 'career suicide' or an 'academic dumping ground' for research that was not accepted into highly selective traditional journals (Spezi et al. 2017). Regardless, open access journals have led to new kinds of research being published and new incentive structures within the research system (Nosek et al. 2015). A recent commentary highlighted that open access has reduced the risk associated with conducting replication studies, finding null or inconclusive results and finding results that contradict a widely held status quo, while also making it easier for new researchers to 'break into' a system in which publishing decisions are not based on previous publishing history or perceived prestige (Risnes 2018). As this area continues to develop, research assessment and reward systems may shift to reflect open science trends and the changing role of selective academic journals; there have already been developments in this direction through, for example, open peer review (Hodonu-Wusu 2018) and altmetrics (Haustein 2016).

\subsubsection{The changing role and practice of peer review}

Another trend in the academic publishing system has been the increasing acknowledgement of risks to the peer review system. Traditional peer review may have the potential for bias and abuse because of the differential power between researchers and reviewers. It has been criticised for its inability to reliably detect fraudulent research (Tennant et al. 2017) and the lack of incentives for reviewers to provide timely feedback (Jan 2018). Peer review is central to the research system, but is reliant on the cooperation of senior researchers. It is likely to be under increasing pressure in terms of the supply of reviewers as the number of outputs available online grows (Sabater-Mir et al. n.d.). These challenges to the traditional peer review system have led to a number of new models of peer review being put into place, including open peer review, 'peer review lite'14 and peer review that is decoupled from the publishing process (Tennant et al. 2017).

Different actors within the research landscape have different experiences of the changes to the research system. Early-career researchers, who are typically on temporary short-term contracts, have particularly precarious positions which can affect their experiences (Brechelmacher et al. 2015; Sigl 2016). Some literature has argued that the pressure to focus heavily on public engagement may be damaging to early-career researchers in particular, who may be unable to compete with academics that have been able to focus more heavily on research and publication than their younger peers (Watermeyer 2015). Recent literature has also argued that the movement towards open access may negatively affect early-career researchers, who may face career consequences from publishing in open access mega journals rather than traditional peer reviewed journals that convey prestige (Spezi et al. 2017).

14 'Peer review lite' refers to review processes that only assess whether a study was conducted according to a scientific process and whether conclusions are based on the results, rather than reviewing for potential contribution of an article or output. 
Research takes place in a wider social and political ecosystem that needs to be considered in terms of how the research landscape may evolve. The UK system has experienced, and is continuing to experience, social, political and legislative flux in a range of areas, particularly regarding the United Kingdom's upcoming exit from the EU. Questions remain about the medium- and long-term effects these wider changes will have on research investment, mobility and standards (Webb 2016). In particular, there is uncertainty around the United Kingdom's position in the global network of international research collaborations, the future potential for researcher mobility and exchange, and future access to research funding from Horizon 2020 and subsequent EU Framework Programmes (Adams 2017). A recent report looking at 47 large UK universities between 2009 and 2015 found that $24 \%$ of all universityindustry co-authored publications were through collaborations with companies in EU member states (Tijssen et al. 2017), which points to the potential impact that the United Kingdom's exit from the EU may have on the research system.

\subsection{National research assessment in the United Kingdom}

Research conducted around the world is assessed at many levels: at an individual level by institutions when considering researchers for new positions or promotions, at a programme level by funders when reviewing a portfolio or allocating awards and grants to individuals, and at a national level by national funders or governments. Research assessment measures different aspects of research depending on the aims of the assessment. These aspects can include the volume of research produced, the quality of research produced, the impact of research produced and the environment in which research is produced. A range of methods are used to assess and report research activity and outcomes, including bibliometrics and altmetrics, economic analyses, peer review, surveys, and case studies (Guthrie et al. 2013). Research can be assessed prospectively on its potential, for example when reviewing grant applications, or retrospectively, like in national exercises such as the United Kingdom's REF or the Australian Excellence in Research Assessment (ERA). This review focuses on the retrospective (ex post) assessments conducted at a national level.

National research assessment refers to exercises that monitor research outputs across a country. These exercises are carried out periodically in a number of countries worldwide. There are a range of reasons for carrying them out (discussed in Chapter 2), which include the allocation of funding and the ability to demonstrate the value of providing the funding.

National research assessment was first conducted in the United Kingdom in 1986 in an effort to 'adopt a more selective approach in allocation of research support among universities in order to ensure that resources are used to the best advantage' (Johnes \& Taylor 1992). Following the 1989 Research Selectivity Exercise (RSE), the Research Assessment Exercise (RAE) was then carried out approximately every three to five years (1992, 1996, 2001 and 2008), and was replaced by the REF in 2014, which introduced for the first time an assessment of the wider impact of research as an element of assessment.

The REF is undertaken by the United Kingdom's four higher education funding bodies: Research England, the Higher Education Funding Council for Wales (HEFCW), the Scottish Funding Council (SFC) and the Department for the 
Economy of Northern Ireland. ${ }^{15}$ It has three main purposes:

1. Inform the selective allocation of research funding from the funding body to higher education institutions.

2. Provide accountability for public investment in research and produce evidence of the benefits of this investment.

3. Provide information that allows for cross$\mathrm{HEl}$ and cross-discipline benchmarking.

The next exercise will be in 2021 and, as with REF 2014, panels of experts from within and beyond the sector will assess the quality of outputs, the quality of impacts and the research environment.

\subsection{Overview of methodology}

This study considers the current system and possible changes to the research environment in the next 5 to 10 years in relation to the following questions:

- Why do we assess research and how might that change in the next 5 to 10 years?

- How do researchers expect the forms of output they are producing to change in the next 5 to 10 years?

- How do researchers expect the types of societal impact their research produces to change in the next 5 to 10 years?

- How do researchers expect the research environment they are in to change in the next 5 to 10 years?

- How could national research assessment exercises learn from developments in peer review?

Our methodological approach to this study is broadly summarised in Figure 1.1 and Table 1.1 below, with additional detailed methodology provided in Annex A.

\section{Figure 1.1: Methodology used in this study}

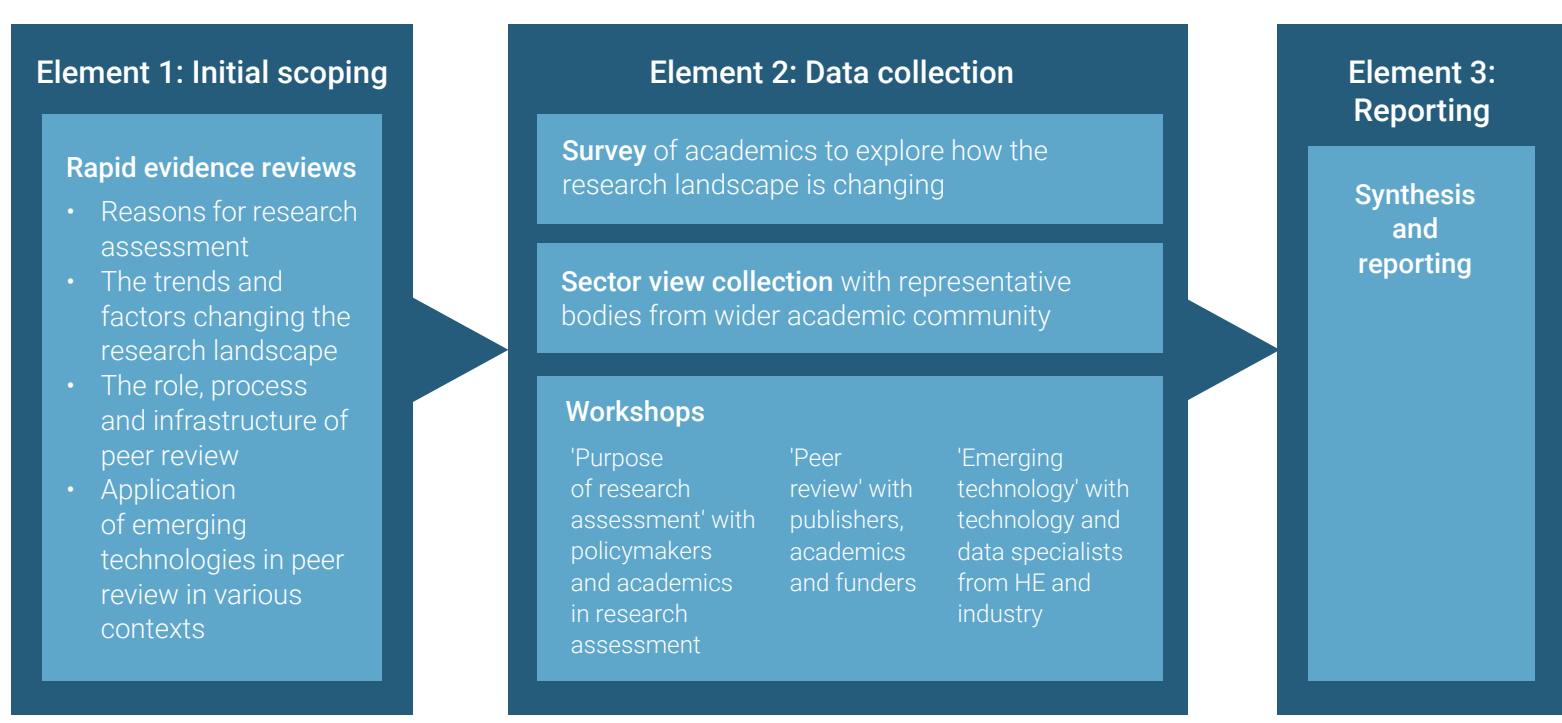

Project management and quality assurance

Ongoing engagement with Research England and the advisory group

15 Formerly the Department for Employment and Learning (DEL) 
Table 1.1: Methods used to address the key questions

\begin{tabular}{|c|c|c|c|c|c|c|}
\hline & \multicolumn{5}{|l|}{ Questions } \\
\hline & & $\begin{array}{l}\text { Why do } \\
\text { we assess } \\
\text { research and } \\
\text { how might } \\
\text { that change } \\
\text { in the next } 5 \\
\text { to } 10 \text { years? }\end{array}$ & $\begin{array}{l}\text { How do } \\
\text { researchers } \\
\text { expect the } \\
\text { forms of } \\
\text { output they } \\
\text { are producing } \\
\text { to change in } \\
\text { the next } 5 \text { to } \\
10 \text { years? }\end{array}$ & $\begin{array}{l}\text { How do } \\
\text { researchers } \\
\text { expect the } \\
\text { types of } \\
\text { societal impact } \\
\text { their research } \\
\text { produces to } \\
\text { change in the } \\
\text { next } 5 \text { to } 10 \\
\text { years? }\end{array}$ & $\begin{array}{l}\text { How do } \\
\text { researchers } \\
\text { expect the } \\
\text { research } \\
\text { environment } \\
\text { they are in to } \\
\text { change in the } \\
\text { next } 5 \text { to } 10 \\
\text { years? }\end{array}$ & $\begin{array}{l}\text { How could } \\
\text { national } \\
\text { research } \\
\text { assessment } \\
\text { exercises } \\
\text { learn from } \\
\text { developments } \\
\text { in peer review? }\end{array}$ \\
\hline \multirow{4}{*}{$\begin{array}{l}\text { Rapid } \\
\text { evidence } \\
\text { assessments }\end{array}$} & $\begin{array}{l}\text { Reasons for } \\
\text { research } \\
\text { assessment }\end{array}$ & $\checkmark$ & & & & \\
\hline & $\begin{array}{l}\text { The trends } \\
\text { and factors } \\
\text { changing } \\
\text { the research } \\
\text { landscape }\end{array}$ & & $\checkmark$ & $\checkmark$ & $\checkmark$ & \\
\hline & $\begin{array}{l}\text { The role, } \\
\text { process and } \\
\text { infrastructure } \\
\text { of peer review }\end{array}$ & & & & & $\checkmark$ \\
\hline & $\begin{array}{l}\text { Application } \\
\text { of emerging } \\
\text { technologies } \\
\text { in peer review } \\
\text { in various } \\
\text { contexts }\end{array}$ & & & & & $\checkmark$ \\
\hline \multicolumn{2}{|l|}{ Survey } & & $\checkmark$ & $\checkmark$ & $\checkmark$ & \\
\hline \multicolumn{2}{|c|}{ Sector view collection } & $\checkmark$ & $\checkmark$ & $\checkmark$ & $\checkmark$ & $\checkmark$ \\
\hline \multirow{3}{*}{ Workshops } & $\begin{array}{l}\text { 'Purpose } \\
\text { of research } \\
\text { assessment' } \\
\text { with } \\
\text { policymakers } \\
\text { and academics } \\
\text { in research } \\
\text { assessment }\end{array}$ & $\checkmark$ & & & & \\
\hline & $\begin{array}{l}\text { 'Peer review' } \\
\text { with publishers, } \\
\text { academics and } \\
\text { funders }\end{array}$ & & & & & $\checkmark$ \\
\hline & $\begin{array}{l}\text { 'Emerging } \\
\text { technology' } \\
\text { with technology } \\
\text { and data } \\
\text { specialists } \\
\text { from higher } \\
\text { education and } \\
\text { industry }\end{array}$ & & & & & $\checkmark$ \\
\hline
\end{tabular}




\subsubsection{Rapid evidence assessments}

Four rapid evidence assessments (REAs) of literature and commentary on national research assessment were performed as part of this study to understand the existing evidence, views and perspectives on (1) why different countries perform research assessment exercises; (2) the trends and factors changing the research landscape; (3) the role and purpose of peer review; and (4) how emerging technologies may affect the way research is assessed. Initial searches were performed using Web of Science and Google Scholar, with results limited to the past five years. Results were then screened by title and abstract for relevance, and data were extracted and analysed from relevant literature. This search was supplemented by a second, more targeted search based on the prior knowledge and expertise of the project team (and suggestions made by the advisory group ${ }^{16}$ and from attendees at the workshops) and involved a snowball methodology whereby appropriate references were pulled from reviewed documents.

\subsubsection{Workshops}

The results of the evidence reviews were used to inform three separate workshops on the purpose of research assessment, the use of peer review across the research system and the development of emerging technologies. During the workshops, stakeholders provided perspectives on developments in research assessment and the research environment. The first workshop (the purpose of research assessment) included representatives from the government and national funding bodies, organisations that fund research, and the higher education sector. The second workshop (the role and purpose of peer review) included representatives from academia, publishers and research funders. The third workshop (emerging technologies for research assessment) included participants from the higher education sector, publishers and experts in emerging technologies.

\subsubsection{Survey and sector view collection}

A large-scale survey of academic researchers in England was conducted to capture researchers' expectations of how research outputs, research impacts and the research environment more broadly would change over the next decade. Participants' field of study, career stage, institutional affiliation and gender were also captured as part of this survey. ${ }^{17}$ In order to have representation across disciplines, geography and type of university, 24 HEls were sampled and invited to participate. Nineteen universities agreed to participate, ${ }^{18}$ and the survey was distributed to their researchers over a four-week period. So as not to be restrictive, the survey was also publicised on social media to invite researchers from the wider community to participate (Figure 1.2).

The survey received 3,768 responses. $A$ response was defined as a respondent who

\footnotetext{
16 The advisory group was selected by Research England and included the following members: Dr Gemma Derrick. Professor Mark D'Inverno, Dr Emily Gale, Dr Daniel Hook, Professor Alis Oancea, Professor Mike Thelwall, Professor Jane Winters and Professor Sarah De Rijcke.

17 These characteristics were used to ensure the data were representative of the sector, rather than to analyse the data by these variables.

18 The 19 universities that agreed to participate were: the University of Bolton, the University of Chichester, the University of Liverpool, the University of Derby, the University of Nottingham, the University of Oxford, the University of Durham, Goldsmiths College, Keele University, Kingston University, Newcastle University, Queen Mary University of London, the Royal College of Music, the University of Brighton, the University of Bristol, the University of Cambridge, the University of East Anglia, the University of Hull and University College London.
} 
Figure 1.2: Locations of researchers responding to the study

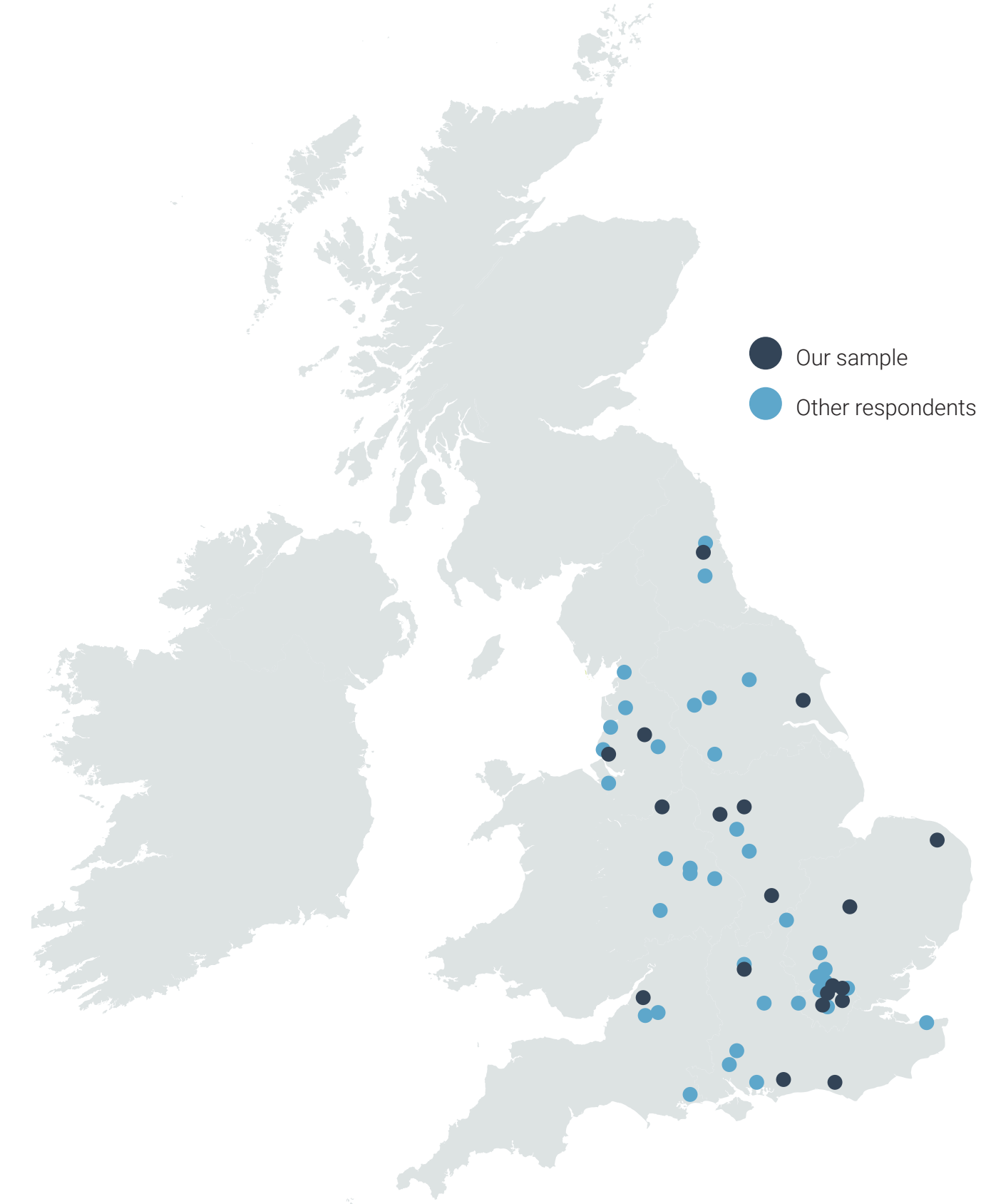

answered at least one question related to outputs, impacts or the research environment. Respondents were asked to assign themselves to REF 2021 units of assessment (UOA), and main panels were used as a proxy for disciplines by which to interrogate the analysis (Main Panel A: medicine, health and life sciences; Main Panel B: physical sciences, engineering and mathematics; Main Panel C: social sciences; and Main Panel D: arts and humanities). Responses were received from all UOAs, with at least 500 from each of the four main disciplinary categories (Table 1.2). Respondents were also asked to assign 
Table 1.2: Distribution of respondents to the survey by discipline and career stage

\begin{tabular}{|c|c|c|c|}
\hline Discipline ${ }^{1}$ & $\begin{array}{l}\text { Number of } \\
\text { respondents }\end{array}$ & Career stage & $\begin{array}{l}\text { Number of } \\
\text { respondents }\end{array}$ \\
\hline $\begin{array}{l}\text { Medicine, health and life } \\
\text { sciences }\end{array}$ & 1,409 & PhD Student & 896 \\
\hline $\begin{array}{l}\text { Physical sciences, engineering } \\
\text { and mathematics }\end{array}$ & 955 & Early-career researcher & 1,045 \\
\hline Social sciences & 664 & Mid-career researcher & 804 \\
\hline Arts and humanities & 582 & Established researcher & 955 \\
\hline Interdisciplinary & 126 & Retired or emeritus researcher & 47 \\
\hline Unknown & 32 & Unknown & 21 \\
\hline
\end{tabular}

${ }^{1}$ Respondents assigned themselves to REF 2021 units of assessment. REF main panels were used as a proxy for disciplines by which to interrogate the analysis. Main panel A: medicine, health and life sciences; Main Panel B: physical sciences, engineering and mathematics; Main Panel C: social sciences; and Main Panel D: arts and humanities.

themselves to a career stage, and over 800 responses from each of the four main career stages were received: PhD student, earlycareer researcher, mid-career researcher and established researcher (Table 1.2)

Quantitative analysis of the survey results was conducted in $\mathrm{R}$ and consisted of both descriptive statistics and statistical testing. ${ }^{19}$ Qualitative analysis was carried out in QRS NVivo 12 Plus and Excel software.

A further 12 representative bodies ${ }^{20}$ from the wider academic community were also surveyed to provide views of how they thought research outputs, impacts and the research environment would change over the next 5 to 10 years, and to comment on factors that may be driving these changes, how research assessment might adapt and how specific groups would be affected. Responses were received from four representative bodies. ${ }^{21}$

\subsubsection{Synthesis and analysis}

Following data collection, an internal team workshop was held to synthesise the data collected and identify key findings and themes across the three phases. Analysis focused on the changes to research produced as a result of changes emerging in the research environment across the United Kingdom, and how research assessment can be supported by technological and cultural developments. Key findings for each phase, as well as for the overall project, were identified, and a narrative was developed that was presented to the advisory group and Research England for their

\footnotetext{
19 R is a statistical programming language https://cran.r-project.org/

20 The 12 representative bodies invited to participate were the Higher Education Race Action Group; the Association of Research Managers and Administrators (ARMA); Universities UK; GuildHE; Advance HE; the Scottish Library and Information Council; Research Libraries UK; the UK Research Integrity Office (UKRIO); the Royal Society; the British Academy; the Society of College, National and University Libraries (SCONUL); and Jisc. 
input and feedback. This input and feedback was incorporated into the final report.

\subsubsection{Caveats and limitations}

All research methods have limitations. By using a mixed-methods approach the aim was to build on some of the strengths of each individual method, and limit the impact of the weaknesses on the study. Using a range of methods allowed for the gathering of wideranging evidence that could be triangulated to form robust conclusions. Despite this, it is still worth noting the limitations of the individual methods, particularly when considering a study that looks to anticipate the future. Within the three REAs, available literature is often more focused on the past than on the future. Workshops, although valuable for the depth of discussion they allow, provide only a snapshot of opinions and may not reflect the wider views of the sector. A range of representative bodies were approached for views to ensure a wide representation of stakeholders as part of the sector view collection, but only responses from one third were received. The survey, which had respondents from across career stages, types of $\mathrm{HEl}$, discipline and other attributes, is not necessarily representative of all views, and some views may be over or under-represented. The survey was also designed to be short and appealing to researchers to complete, and therefore was limited in the depth of data that could be collected. It is also important to note that the survey asked researchers what they were currently producing and what they expected to produce. Therefore, the results may include details of what they aspire or plan to achieve, rather than solely what they will. Research was focused on the changing landscape for research assessment in the broadest sense, i.e. assessing research at any stage, and it was not intended as an ex-post assessment of the REF. However, it was difficult for survey respondents (researchers) to make this distinction, which may be reflected in their answers. The upcoming REF in 2021, and the pressure it brings, may affect what people are currently doing vs. what they aspire to do.

\subsection{Outline of the report}

This report is structured around the three phases of the study. Chapter 2 discusses the reasons for conducting national research assessment, how these are likely to change in the next 5 to 10 years, and how these are viewed by the sector. Chapters 3, 4 and 5 consider how researchers expect the outputs from research, the impacts of research, and the research environment to change in the next 5 to 10 years. Chapter 6 reports on how national research assessment exercises learn from developments in peer review. Finally Chapter 7 concludes with how national research assessment may need to adapt to changes in the research landscape. 


\section{(2) Why do we assess research and how might that change in the next 5 to 10 years?}

This chapter describes the reasons for and purpose of conducting research assessment at a national level. It is primarily based on the results of desk research synthesised by the project team. It includes reflections from discussions at the first workshop with funders and researchers that focused on research assessment and aimed to explore how the purpose and process of research assessment may change in the future, the role of peer review in the process of research assessment, and how technology may impact the process of research assessment.

The key findings are:

- The reasons for doing research assessment can be summarised by six 'A's: analysis, advocacy, allocation, accountability, acclaim and adaptation.

- The reasons for assessing research are understood and interpreted differently by different stakeholders.

- The rationale for, and emphasis of, research assessment is likely to evolve in the future.

\subsection{The reasons for doing research assessment can be summarised by six 'A's}

National research assessment exercises have become common over the past couple of decades in many countries, including the United Kingdom, Italy, Australia and the Netherlands. The reasons for performing research assessment have previously been categorised into the four 'A's: accountability, advocacy, analysis and allocation (Guthrie et al. 2013; Morgan Jones \& Grant 2013). This chapter builds heavily on this work, from Morgan Jones \& Grant (2013) and Guthrie et al. 2013, which introduce the concept of the four 'A's for research assessment, draws on the work of the field, in particular Adam et al. (2018), and expands these to include an additional two 'A's: acclaim and adaptation. Definitions are provided in Box 1.1, with further detail in the sections below.

\subsubsection{Analysis}

Definition: To understand why, how and whether research is effective, and how it can be better supported.

Analysis is used to assess how research is performing in order to understand the research process, the research system and its outcomes, and propose ways of improvement, if needed. It is also used to stimulate continuous progress in research productivity (Abramo and D'Angelo 2015; Franceschini and Maisano 2017; Guthrie et al. 2013; Molas-Gallart 2015). For example, the National Institute for Health Research (NIHR) developed a research assessment framework consisting of a metrics dashboard to monitor the performance of research it 


\section{Box 1.1: Definitions of the proposed six 'A's as reasons for research assessment}

$\begin{array}{ll}\text { Analysis } & \text { To understand why, how and whether research is effective, and how it can be } \\ & \text { better supported. } \\ \text { Advocacy } & \text { To demonstrate the benefits of supporting research, and enhance the } \\ & \text { understanding of research and its processes among policymakers and the public. } \\ \text { Allocation } & \text { To determine how to distribute funding across the research system. } \\ \text { Accountability } & \text { To evidence that money and other resources have been used efficiently and } \\ \text { Acclaim } & \text { effectively, and to hold stakeholders to account. } \\ \text { Adaptation } & \text { To compare and recognise the value of higher education institutions and the } \\ & \text { Tosearch activities and priorities. }\end{array}$

Source: RAND Europe analysis.

funds (El Turabi et al. 2011). This framework allows frequent data collection on performance indicators designed to monitor the NIHR research administration process. It contributes to identifying efficiencies and increasing effectiveness, and the information can be used for strategic decision making and analysis (Guthrie et al. 2013; NIHR n.d.).

Some consider analysis to be the underpinning 'A' for all other 'A's (Adam et al. 2018) as it provides an understanding of how research works, including an understanding of the barriers and enablers to expanding knowledge and delivering impact. This allows for the identification of dysfunctions within a research programme, as well as opportunities to increase the value of research during its funding, planning and implementation (Adam et al. 2018). Analysis enables research assessment to be formative as well as summative. It plays a significant part in how institutions and funders understand the quality of research and how they enable the use of data to inform their approaches to developing their research capacity at an organisational and national level. For example, in Spain the Health
Research and Innovation Assessment System (SARIS) identified limitations of research funded under the Strategic Plan for Research and Innovation in Health (PERIS) programme, such as length of the grant and the grant's eligibility criteria. These identified limitations will be used for continuous improvements of the scheme (Adam et al. 2018). In another example, following REF 2014, the Higher Education Funding Council for England (now Research England) commissioned a study that looked at shared characteristics between research units whose submissions scored highly in the areas of research and impact in order to develop strategic approaches to delivering excellent research (Manville et al. 2015b). This has been replicated in a number of institutions and used to inform internal strategies.

RAND Europe has led a series of studies using payback case studies to trace research and its impact from the past (10 to 25 years ago) to understand the factors that support the outcomes and impacts of research (Wooding et al. 2005; 2011; 2013). Following studies in the fields of arthritis, cardiovascular and mental health, RAND Europe conducted a 
cross-cutting analysis highlighting factors that could help researchers and funders maximise opportunities for impact (Guthrie et al. 2016). These include skills beyond research, engagement with non-academic stakeholders, funding clinical over basic research, inclusion of impact on society as a criterion for funding decisions, understanding that larger studies do not necessarily deliver greater outcomes, the importance of international collaboration, variety across the portfolio, and an understanding that impact will not be delivered by all research funded.

Representatives from funding agencies that attended the workshop on the reasons for research assessment felt that analysis enabled funders to design more strategic research funding, and that research assessment exercises provide evidence and visibility of what funders are doing, as well as a long-term vision of the research landscape. In the United Kingdom, charitable and public funders, as well as institutions have used the impact case studies produced for assessment in REF 2014 to understand what factors lead to impact and hence to inform their strategies. A synthetic analysis of the 6,679 impact case studies submitted to the REF highlighted the range of pathways to impact as well as the different types of impact seen across the disciplines and presented by different types of HEI (Kings College London \& Digital Science 2015). This deeper understanding of how impact occurs aims to enable policymakers and institutions to better support research that may have a greater impact on society, and assist researchers to focus their time and effort on what works (Morgan Jones et al. 2017).

\subsubsection{Advocacy}

Definition: To demonstrate the benefits of supporting research, and enhance the understanding of research and its processes among policymakers and the public.
National research assessments provide evidence for advocacy by capturing the theoretical, economic and social value of research. This is valuable at a national level for government departments and funders to justify investment and support, and underpins the national case for research investment (Adam et al. 2018). Charitable organisations, among others, use this information to engage the public with the outcomes and wider impact of research. The advocacy function of research assessment is particularly important in supporting policymakers during times of change, such as budgetary cycles or wider economic challenges that require complex investment decisions to be made or wider policy engagement with the public to be undertaken (Adam et al. 2018). Other organisations that use the outcomes of research assessment for advocacy include charitable funders, who often need to appeal to the public to support their cause.

The database of impact case studies published from REF 2014 has been used to present the wider value of UK research, and therefore of research funding, to broader society. A number of analyses have been undertaken, which include:

- Highlighting research funded by a specific funding organisation, e.g. NIHR (Kamenetzky et al. 2016).

- Demonstrating the impact of research on a particular geography e.g. BRIC countries, (Brazil, Russia, India and China) (Kings College London \& Digital Science 2015).

- Demonstrating impact from a particular field of research, such as communitybased health sciences (Greenhalgh \& Fahy 2015) or international development (Hinrichs et al. 2015).

Some institutions have also reused the case study narratives to attract staff and students to their institutions by giving anecdotal examples 
of the relevance of their research and how it benefits society.

A recent review of research assessment frameworks worldwide found that 22 out of 25 frameworks provided evidence for advocacy (Deeming et al. 2017). In developing countries, research assessment was also used to identify high-quality research activities in order to inform policies that aimed to build sustainable national science systems and research structures, and contribute to enhancing scientific research (Glänzel \& Zhang 2018).

\subsubsection{Allocation}

\section{Definition: To determine how to distribute funding across the research system.}

Some national research assessment exercises are used to determine where to allocate future investment in order to make the best use possible of limited funds and improve or sustain returns from the public funding of research (Calver et al. 2013; Guthrie et al. 2013). ${ }^{22}$ An allocation approach to research assessment is considered to incentivise research excellence through economic rewards (Adam et al. 2018). The different ways in which countries use research assessment to allocate funding at a national level are presented in Table 2.1.

Table 2.1: Examples of research assessment exercises linked to funding allocation

\begin{tabular}{|c|c|c|}
\hline Country & National funding allocation mechanisms & References \\
\hline United Kingdom & $\begin{array}{l}\text { Quality of research is assessed in terms of output, impact and } \\
\text { environment, and funding is allocated taking into account the } \\
\text { volume of high-quality research and cost. The UK was the first } \\
\text { system to include an assessment of the non-academic impact } \\
\text { of research as one of the measures used to determine funding } \\
\text { allocation. Specifically, by assessing the reach and significance of } \\
\text { the impact of research on society beyond academia. }\end{array}$ & $\begin{array}{l}\text { (Atkinson 2014; } \\
\text { Johnston \& Reeves } \\
\text { 2017; Rebora \& Turri } \\
\text { 2013; Manville et al. } \\
\text { 2015a) }\end{array}$ \\
\hline Italy & $\begin{array}{l}\text { Resource allocation is based on a number of factors, including the } \\
\text { quality of research assessment, which is measured using both a } \\
\text { metrics and a peer review component. However, there is a limit on } \\
\text { the amount of state funding a university can receive determined } \\
\text { by the Ministry of Education, University and Research. }\end{array}$ & $\begin{array}{l}\text { (Rebora \& Turri } \\
\text { 2013; Franceschini } \\
\text { \& Maisano 2017; } \\
\text { Ancaiani et al. 2015) }\end{array}$ \\
\hline Norway & $\begin{array}{l}\text { The Performance Based Research Fund (PBRF) system in } \\
\text { Norway is used to allocate block funding to HEls and accounts } \\
\text { for } 70 \% \text { of an institution's funds. The PBRF uses the Norwegian } \\
\text { Publication Indicator, which consists of a system of weights that } \\
\text { makes field-specific publishing traditions comparable across } \\
\text { fields. }\end{array}$ & $\begin{array}{l}\text { (Aagaard et al. 2015; } \\
\text { Zacharewicz et al. } \\
\text { 2018) }\end{array}$ \\
\hline
\end{tabular}

\footnotetext{
22 Research assessment exercises are generally performed by researchers. Therefore, funding allocation as a result of research assessment exercises is in line with the Haldane principle which states that the research questions to be explored should be dictated by researchers and not politicians.
} 


\begin{tabular}{l|l|l}
\hline Country & National funding allocation mechanisms & References \\
\hline New Zealand & $\begin{array}{l}\text { Research assessment in New Zealand is done at an individual } \\
\text { level. Bibliometrics are used to assess every researcher working } \\
\text { in New Zealand's tertiary educational establishments on a six-year } \\
\text { cycle. Each researcher receives a ranking (A, B, C and R), which } \\
\text { is provided to the institutions. The outcomes are weighted by } \\
\text { quality and subject area, and aligned with the resources required } \\
\text { for each field. Results are then aggregated by institution and } \\
\text { used in combination with external income and research degree } \\
\text { completions to distribute research funding. }\end{array}$ & \\
\hline Hong Kong & $\begin{array}{l}\text { (Mong Kong uses the framework for research assessment } \\
\text { exercise to inform the distribution of part of the University Grants } \\
\text { Committee block funding. }\end{array}$ & $\begin{array}{l}\text { (Currie 2008; Parks } \\
\text { et al. 2017) }\end{array}$ \\
\hline
\end{tabular}

Research evaluation exercises can affect the allocation of research funds both between and within universities (Johnston \& Reeves 2017; Jonkers \& Zacharewicz, n.d.). For example, the REF assesses the quality of research in terms of outputs, impact and environment in different fields across all submitting institutions (REF 2019a). UK funding bodies ${ }^{23}$ use results from REF 2014, which detail the volume of highquality research and the relative costs of research, to allocate annual funding in the form of quality related (QR) funding ${ }^{24}$ or the Research Excellence Grant ${ }^{25}$ to institutions across the United Kingdom (HEFCE 2017; Scottish Funding Council n.d.). Institutions then decide how they distribute the funding internally (Johnston \& Reeves 2017). For example, following REF 2014 the University of Nottingham divided its annual QR funding between the different schools based on their performance in the REF, whereas Coventry University invested in future development and did not use REF results to inform its allocation of QR (Wellcome, n.d.).
Not all countries use research assessment exercises to allocate funding, for example Sweden and the Netherlands do not use this practice (Deeming et al. 2017; Sivertsen 2018). In Sweden, there was an attempt in 2009 to include a performance-based resource allocation system based on research production and citation rates, as well as on the ability to attract external funding (Karlsson 2017). However, the system was not implemented by the government due to cost and concerns from academics that it would interfere with institutional autonomy (Sivertsen 2018).

\subsubsection{Accountability}

\section{Definition: To evidence that money and other resources have been used efficiently and effectively, and to hold stakeholders to account.}

A common aim of research evaluation is to make research more accountable to taxpayers, donors, governments and society in general (Adam et al. 2018; Deeming et al. 2017; Penfield et al. 2014). The increased need for

\footnotetext{
23 These are Research England (previously HEFCE), the Higher Education Funding Council for Wales, the Scottish Funding Council, and the Department for the Economy in Northern Ireland

$24 \quad$ In the case of England, Wales and Northern Ireland.

$25 \quad$ In the case of Scotland.
} 
accountability comes from pressures to justify, or in some cases reduce public spending, which has led to a greater emphasis on transparency, efficiency, value and a return on investment to the public, private and charitable sectors in research. For example, the Australian government describes ERA as 'one of the primary mechanisms that government, public and private sectors have to account for their expenditure on the higher education research sector' (Australian Research Council 2018). An independent review of the ERA framework found that it contributed to increasing the social rate of return from research - i.e. the costs and benefits to society of investment in research, generated cost savings, increased university revenue and enhanced economic activity (ACIL Allen Consulting 2013).

Accountability in research is generally performance oriented (Deeming et al. 2017; Kwok 2013; Marques et al. 2017; Pajić 2015). There are a series of measures used in different settings to quantify research performance (e.g. number of publications, citation index, funding received and impact factor of publications) and inform an understanding of the value-for-money of funded research (Holland et al. 2016). ${ }^{26}$ Qualitative evidence can also be presented, for example case studies as part of the impact element of the REF and the pilot for ERA.

In recent years there has been an increase in the need for governments and researchers to show evidence of the economic and social value generated through research, which some have termed a 'new social contract for research' (Molas-Gallart 2015). This moves beyond the assumption that research is only valuable if it generates economic returns for industry to value the societal or public benefit, as well as knowledge creation (Bozeman \& Sarewitz 2011).

\subsubsection{Acclaim}

\section{Definition: To compare and recognise the value of HEls and the research conducted within them.}

Acclaim involves research assessment being undertaken to compare and recognise the value of research at an individual, departmental, institutional or national level. Acclaim can result in prestige, reputation or reward at these different levels. For an individual it could be recognition and promotion, and at an institutional or national level it could be through comparisons or rankings (Mingers, n.d.; Kwok 2013).

Ranking can be a factor in raising standards across institutions (Martin-Sardesai et al. 2017) or consolidating already high standards (Manville et al. 2015b; Rebora \& Turri 2013). Participants from the workshop on the reasons for research assessment felt that acclaim had become increasingly important given the role that league tables play in attracting students, researchers and funders to international research and the higher education system.

However, there are also some negative consequences to a focus on acclaim, and the use of research assessment exercises as a means for ranking is said to have led to the

26 The use of bibliometrics and peer review in national research assessment exercises vary per country and discipline. For example, the ERA in 2010 used a bibliometric approach for the hard sciences, using a citation index referring to world and Australian benchmarks to evaluate the outputs of researchers (Abramo \& D’Angelo 2015).

On the contrary, the Italian 2001-2003 exercise was entirely based on peer review. However, for the 2004-2010 Italian Research Quality Evaluation the system was changed to use a combination of peer review and bibliometrics, with universities required to submit the best three research outputs for each researcher (Abramo \& D'Angelo 2015). The UK REF makes use primarily of peer review, but metrics are supplied to some panels to help inform their judgement (Wilsdon et al. 2015). 
reconfiguration of some institutions in terms of mission and internal systems (Holland et al. 2016; Li 2016; Martin-Sardesai et al. 2017). For example, a study looking at organisational change in an Australian university found that the university had made significant changes in anticipation of the upcoming research assessment exercise, including appointing a new vice-chancellor with UK experience of government research assessment, and changes to mission and vision (Martin-Sardesai et al. 2017). This change and its implications are discussed under the final ' $A$ ', Adaptation.

The unit of assessment ${ }^{27}$ profiles for REF 2014 allowed institutions to show at a more granular level what they were 'best' at, and demonstrate success across the country (Wolff 2015). Participants from the workshop on the reasons for research assessment raised concerns that the search for acclaim may lead to improvements in the quality of research nationally to such a level that research assessment can no longer provide a distinction among excellent research, which participants felt would limit the value of the process. For example, over $70 \%$ of impact case studies submitted to REF 2014 were graded as three or four stars ${ }^{28}$ (Manville et al. 2015b). Another participant raised concerns that there is a risk that the drive for 'good' rankings could encourage perverse practices in the management of research institutions in order to deliver strong results. Participants agreed that in a world where acclaim is gaining importance, research assessment should ensure that it captures structures and processes that encourage research integrity and good practice.

In New Zealand, where the research assessment exercise is performed at an individual level, a researcher can apply to receive their own rating (McGilvray 2014). Although this was expected to stimulate higher quality research among researchers, there is evidence that it discourages universities from recruiting early-career researchers who will not have established research records. Additionally, individual-focused research assessment may result in 'citation clubs', where a group of researchers consistently cite each other's work to increase their citation index (Holland et al. 2016).

\subsubsection{Adaptation}

Definition: To steer change in organisational structures, behaviours and cultures, and research activities and priorities.

Research assessment exercises can provide a structure to incentivise change in individual and organisational performance (Marques et al. 2017; Kwok 2013). For example, analysis of research assessment exercises has been used for (1) guiding the research agenda; (2) increasing research productivity; (3) promoting impactful research; and (4) encouraging collaborative and interdisciplinary work. ${ }^{29}$

Research assessment exercises allow the identification of the strengths and weaknesses of different disciplines and geographic areas, with the aim of supporting the development of research policy and management strategies

\footnotetext{
27 In the REF, submissions are made in discipline-based 'units of assessments' (REF 2019a).

28 The level definitions used for assessing impact as part of REF 2014 were as follows: Four stars were awarded for outstanding impacts in terms of their reach and significance. Three stars were awarded for very considerable impacts in terms of their reach and significance. Two stars were awarded for considered impacts and one star for recognisable but modest impacts. Some were deemed as unclassified when the impact was of little or no reach and significance, or the impact was ineligible or not underpinned by excellent research produced by the submitted unit (REF 2019a). 
at both the governmental and institutional level (Franceschini \& Maisano 2017; Glänzel \& Zhang 2018; Rebora \& Turri 2013). An example of guiding the research agenda is the Dutch Standard Evaluation Protocol (SEP), which evaluates both the quality and relevance of research to society, and then assesses the research strategies of the different research groups to improve their performance (Association of Universities in the Netherlands et al. 2014).

Research assessment exercises can also be used to increase research productivity by measuring research outputs in terms of quality and quantity (Calver et al. 2013; Mingers, n.d.; Pajić 2015). For example, in Australia and New Zealand there is evidence to suggest that the overall quality of research has increased since the introduction of national assessments (McGilvray 2014). Additionally, a study looking at the evolution of research assessment methodologies in Lithuania found that the introduction of formal assessments of scientific publications encouraged researchers to communicate their results in international scientific journals, and stimulated Lithuanian scientific journals to seek inclusion in international databases, as well as improve their quality (Maskeliūnas et al. 2015).

As mentioned under accountability, in recent years there has been an increase in the need for government and researchers to measure and provide evidence on the value or benefit of research to society (Hill 2016). Methods to assess this include econometric approaches to quantify the relationship between investment in research and economic benefits; approaches focused on knowledge exchange interactions; and the use of qualitative methods, such as the case studies used in REF 2014 (Hill 2016). Submissions for the REF 2014 also included an 'impact template', which consisted of a narrative statement describing the unit's strategy to deliver impact.
An evaluation of impact assessment in REF 2014 found that the inclusion of impact as a criterion for assessment (using the case studies and the strategic template) has changed practice at an individual and institutional level (Manville et al. 2015c; Manville et al. 2015d). Changes observed in institutional practice include setting out an impact strategy for the institution or department, building impact plans into research projects, implementing systems to capture and store evidence of impact on an ongoing basis, including impact as a criterion for promotion, and creating positions such as impact officers (Manville et al. 2015c). In addition, the evaluation found evidence that the assessment of impact as part of REF 2014, along with other policies (such as the Research Councils UK 'Pathways to impact' - now part of UKRI) and the broader 'impact agenda', has led to perceived benefits at the level of individual researchers. For example, identifying and understanding impact, the value of reviewing and affirming relationships with research users, and the promotion or recognition of individuals (Manvilleet al. 2015c). Academics have also perceived a shift in the focus of research away from 'blue skies' and towards more applied research where impact is more easily demonstrated, for the purposes of assessment (Manville et al. 2015c). This is also reflected in an initial evaluation of the impact case studies, which found that the average time between conducting the research and achieving impact was 3 to 9 years, compared to an average of 15 to 20 years previously detailed in the literature (Kings College London \& Digital Science 2015). However, this shift may be an artefact of the assessment, rather than a shift in the research conducted.

Through incorporating the societal impact of research as a criterion for assessments, research collaborations have also increased. In Australia and New Zealand, the incorporation of societal impact as a criterion has contributed 
to collaborations between researchers from multiple disciplines, from the natural sciences to the humanities, with the aim of assessing societal problems holistically (McGilvray 2014). In the United Kingdom, research assessment has been found to encourage researchers to collaborate with researchers outside of their institution (Martin 2011). In Finland performance-related funding has been used to increase international collaboration (Geuna \& Martin 2003).

It is important to note that there may be unintended effects of adaptation that may create perverse incentives in the sector. For example, a shift from basic to applied research has been seen at an individual, institution and sector level in the United Kingdom, in part due to the inclusion of impact as an assessment criterion for the REF (Manville, et al. 2015c). It is not yet clear how far the research agenda in the United Kingdom should shift for the benefit of knowledge creation and society, or what would be 'too far'.

While adaptation as a result of research assessment exercises can happen at an organisational level, there is also the opportunity for adaptation at a local level within projects. For example, as a result of collecting data and evidence of impact, researchers can steer projects in a particular direction to ensure that they are having the desired outcomes and impacts; this has been termed as 'adjustment' (Hill 2017).

The six 'A's are interrelated rather than independent elements. For example, through analysis of 'what works', funders and other stakeholders develop their understanding of what behaviours they seek to promote to achieve the outcomes desired by their strategy.
They can influence this by adaptation and incentives, such as how funding is allocated.

\subsection{The reasons for assessing research are understood and interpreted differently by different audiences}

The purposes for research assessment are both implicit and explicit, and national systems across the world have different purposes. Research assessment can be used either to distribute institutional research funding based on performance, or to provide strategic information not linked to funding. An international landscape study of research and innovation systems found that 10 out of the 20 countries included in the study have at least a component of research assessment built into their national funding system (Kolarz et al. 2019). ${ }^{30}$ However, other countries did not have national research assessment exercises linked to funding. For example, in China, research assessment aims to achieve world class status (i.e. acclaim), and only a select group of high-performing universities are included in each assessment. Some countries use alternatives to national research assessment exercises to ensure high-quality research is being conducted within their institutions. For example, in the United States, the Carnegie Ranking of HEls assesses institutions to classify the country's HEls.

The primary purpose of the Research Assessment Exercise (RAE) in the United Kingdom was to produce quality profiles for each submission of research activity made by institutions in order to determine how the four UK funding bodies would allocate funding (Research Assessment Exercise 2009). 
Although allocation remains a key purpose of research assessment in the United Kingdom, the latest REF (REF 2014) had the following key purposes:

- To inform the selective allocation of funding for research.

- To provide accountability for public investment in research and produce evidence of the benefits of this investment.

- To provide benchmarking information and establish reputational yardsticks for use in the higher education sector and for public information (acclaim) (REF 2011).

Although these are the explicit purposes of the REF, the 2016 Stern review identified six purposes for the exercise (BEIS 2016), which have been aligned with the six 'A's for this study:

- Support the allocation of QR funding.

- Produce evidence for strategic decision making on national research priorities (advocacy).

- Provide an accountability mechanism for public investment in research.

- Create performance-based incentives for HEls and individual academics (adaptation).

- Contribute information to HEls to inform decisions on resource allocation (analysis).

- Provide a benchmark that may be especially important for less known universities (acclaim).

Reports, such as the Witty review, called for the inclusion of the impact element in national research assessment in order to encourage economic growth from the world leading research that occurs across the United Kingdom (Witty 2013). There could, therefore, be an argument that the explicit nature of the reasons behind assessment has changed over time as the legitimacy of the aims has developed. In a 2019 pilot study to examine the feasibility of evaluating perceptions and attitudes towards the REF, interviewees were asked about what they viewed as the main purpose of the REF (Weinstein et al. 2019). ${ }^{31}$ Respondents felt that the REF had broader purposes than the established three (allocation, accountability and benchmarking) (Weinstein et al. 2019). Most interviewees commented on how the REF impacts and influences HEI activity in the United Kingdom and globally in instrumental ways (adaptation), while also acting as a 'quality assurance' system. Many interviewees also acknowledged that the REF had evolved over time to include purposes beyond allocation and accountability. However, they did not provide a clear view on what the main purposes now were.

The view that national research assessment has evolved from its original purpose was shared by participants of the workshop on the purpose of research assessment, ${ }^{32}$ who felt that allocation used to be the dominant explicit reason for ex-post research assessment through the RAE. However, with the introduction of the impact element a decade ago (REF 2011), the focus has explicitly diversified to value accountability and advocacy, which are needed to underpin the case for public investment in research. Academics completing the survey ${ }^{33}$ for the

\footnotetext{
$31 \quad$ Interviewees for this study included research managers from Cardiff University, the University of Sheffield, the University of Sussex and the University of Lincoln

32 Participants from the workshop were representatives of the UK government funding bodies and academic experts in the topic of research assessment.

33 Survey participants were asked to rank the six purposes of the REF on a scale of 0 to 6 according to the extent to which the REF achieves the purposes identified in the Stern review. Participants were recruited from four universities: Cardiff University, the University of Sheffield, the University of Sussex and Lincoln University.
} 
2019 review on the REF, described above, agreed that although the three stated purposes of the REF remained (accountability, allocation and benchmarking), accountability had emerged as what should be the main purpose of the REF.

\subsection{The rationale for, and emphasis of, research assessment is likely to evolve in the future}

As the research landscape changes, the reasons for performing national research assessment are likely to develop. Given that the six 'A's are dynamic and interrelated elements for research assessment, they are likely to continue to evolve, and the weight and importance of each 'A' as a purpose for assessment may continue to shift over time.

In the United Kingdom, research assessment has always been about measuring and improving quality. In 2014, an impact assessment was included which expanded the meaning of quality, beyond academic outputs to include societal benefit beyond academia as an outcome (HEFCE 2009).

Participants of the workshop on the purposes of research assessment felt that the debate had now shifted more towards the use of research assessment to inform strategies (analysis) and focus on acclaim, with universities ranked according to the research they conduct, and using their REF results in the recruitment of staff and students (BEIS 2016; Manville et al. 2015a). The combination of scores for the outputs and impact elements allow HEls to demonstrate the value of research, as well as to demonstrate to students and their parents the type of environment that an institution creates for its students. The evaluation of the impact element of REF 2014 found that expanding the definition of quality to include the impact on wider society has enabled reward and recognition at an individual, departmental and institutional level for those already undertaking this breadth of activity, which may previously have been overlooked or undervalued (Manville et al. 2015c)

The rise in the role and prominence of analysis may be partly due to the availability of data and the technological capabilities to work with ever-growing datasets. A challenge that faces the sector today, therefore, is to ensure that decisions are data informed, rather than data driven, with sufficient interpretation of the results and an understanding of the data input and its limitations.

The diversification of purposes was previously noted by the 2016 Stern review, detailed above. The review found that although members of the academy still considered the main purpose of the exercise to be allocation of public funds for research, there were other relevant purposes, including informing institutional strategies (i.e. analysis) (BEIS 2016). This may affect the weighting or emphasis placed on different purposes over time. For example, one workshop participant argued that as the public are more engaged in research through public and patient involvement and engagement, their awareness and understanding would increase, which may reduce the drive for accountability to the public. 



\section{How do researchers expect the to change in the next 5 to 10 years?}

To understand what forms of outputs and impacts researchers' feel their research is currently leading to, how they expect this to evolve in the next 5 to 10 years, and how this is influenced by the research landscape a large- scale survey of academic researchers in England was conducted. This chapter focusses on the findings on the current and expected outputs of research. It draws on the findings from the large-scale survey of academic researchers in England, as well the rapid evidence assessments and responses to the sector view collection. Additional detail on the methods underpinning this are described in Annex A.

The key findings are:

- Researchers currently produce a diversity of output forms.

- Researchers expect that they will produce a greater diversity of outputs in the future.

- Researchers expect to continue to produce journal articles and conference contributions, and that they will remain the dominant forms in many disciplines in the future.

- Many researchers expect to start to produce more diverse forms of output aimed at a wider audience.
- Researchers' decisions on which forms of output to produce are influenced by factors such as career progression and personal preference, as well as institutional incentives and funder requirements.

- Researchers from different disciplines currently produce different output forms, and researchers' expectations suggest that these differences will continue in the future.

\subsection{Researchers currently produce a diversity of output forms}

Respondents to the survey were asked to select the forms of output they currently produce and those they plan to produce in the next 5 to 10 years. ${ }^{34}$ On average, respondents currently produce 4.7 different forms of output (Figure 3.1).

The most common output forms that respondents currently produce are journal articles and conference contributions, which were identified by $85 \%$ and $70 \%$ of respondents, respectively (Figure 3.2). No other forms of output are currently produced by more than $50 \%$ of respondents across disciplines. When looking at a discipline level in the field of arts 
Figure 3.1: Number of output forms currently produced

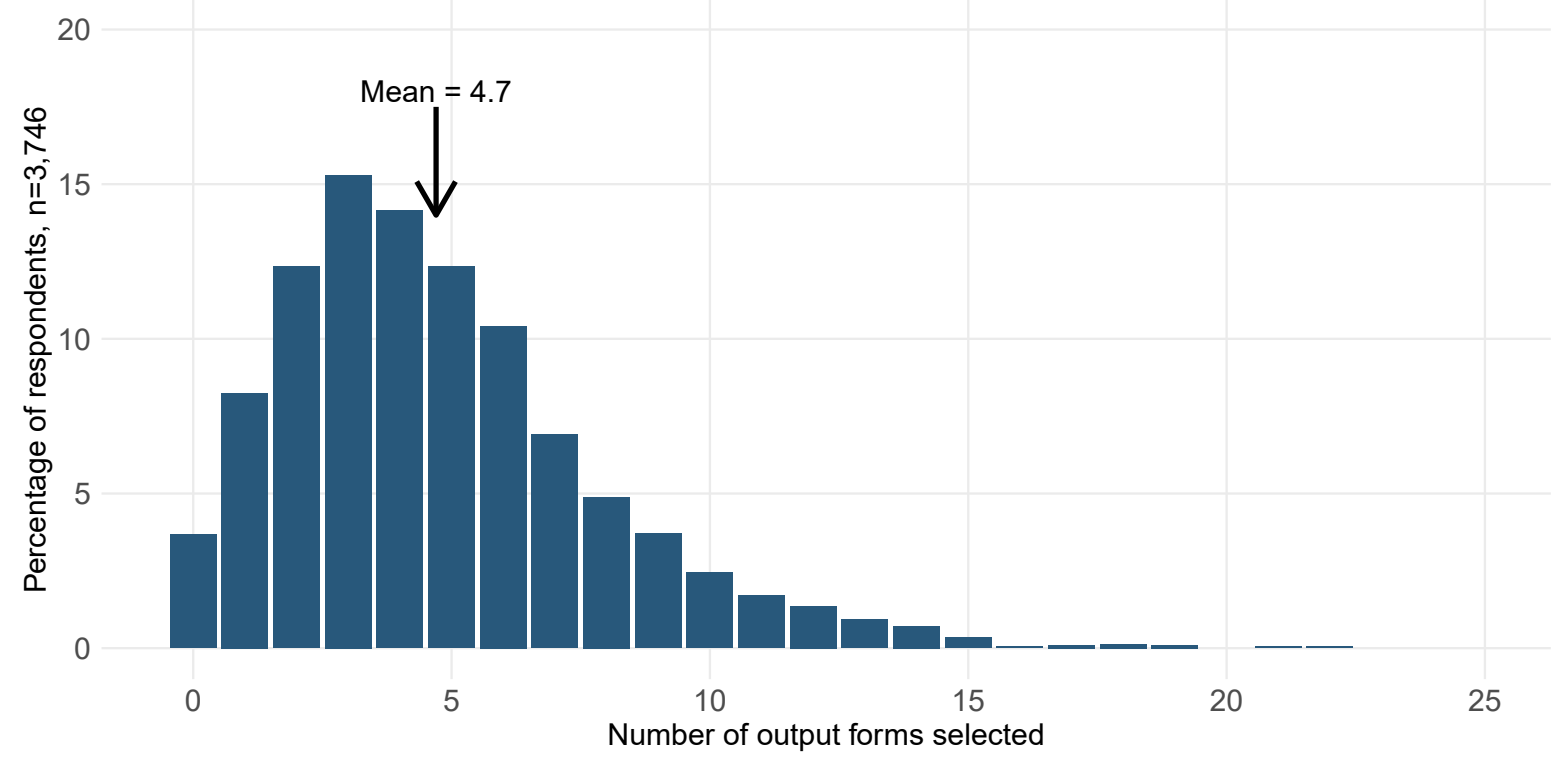

and humanities, $60 \%$ of respondents reported producing chapters in books, and $51 \%$ reported producing authored books (detailed below in Figure 3.5). More detail on the disciplinary differences is presented in Section 3.6.

\subsection{Researchers expect that they will produce a greater diversity of outputs in the future}

When asked to report the output forms respondents are planning to produce in the next 5 to 10 years, on average, respondents selected 6.5 forms of output (Figure 3.3), an average of 2.2 more different output forms than respondents reported currently producing. While there is generally a shift towards the production of more diversity of outputs per person ( $65 \%$ of respondents expect to produce more forms of output in the future), this is not uniform across all respondents. Some $18 \%$ of respondents expect to produce fewer forms of output than they currently produce.
The open text section of the survey asked respondents to comment on why they expect their research outputs to change or remain the same, and provides a possible explanation for why respondents reported a wider or narrower range of forms of output in the future. Nearly one quarter $(24.3 \%)$ of respondents who provided a free text answer (261 of 1,072 responses) cited career progression as the reason for their output forms changing in the future. Many felt that producing a greater range of outputs was associated with developing as a researcher - from being a PhD student or an early-career researcher to more senior research roles. These respondents reflected that they currently need to focus on journal articles until they are at a more advanced stage in their career, but that once they have progressed they will have the time and space to produce outputs besides journal articles. Those who reported a reduction in the range of outputs they expect to produce in the future were often respondents who were retiring or leaving academia. Some $61 \%$ of respondents reporting zero output forms were currently PhD students, but only $33 \%$ of 
Figure 3.2: The percentage of respondents currently producing each form of output

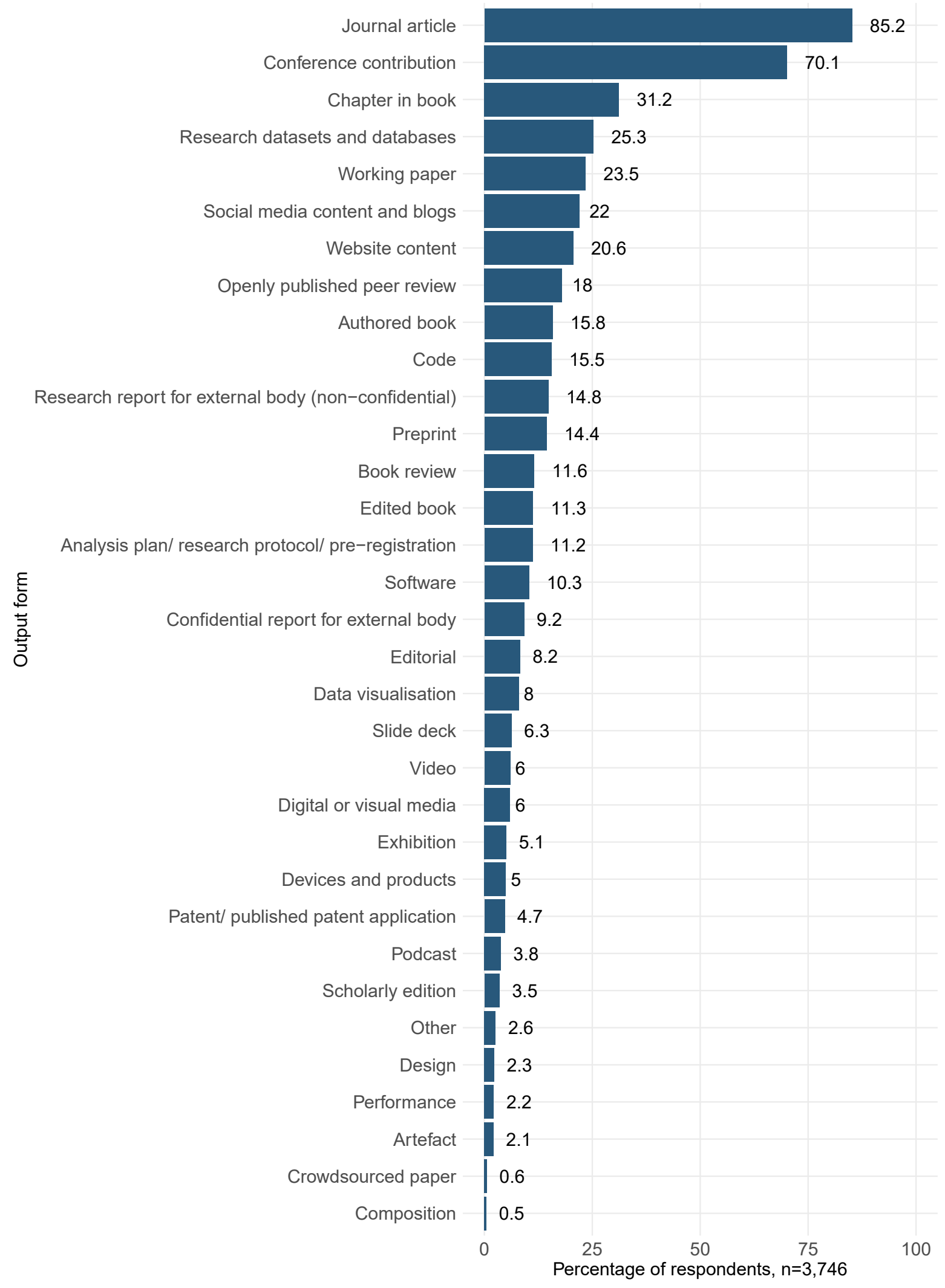


Figure 3.3: Number of output forms that researchers plan to produce in the next 5 to 10 years

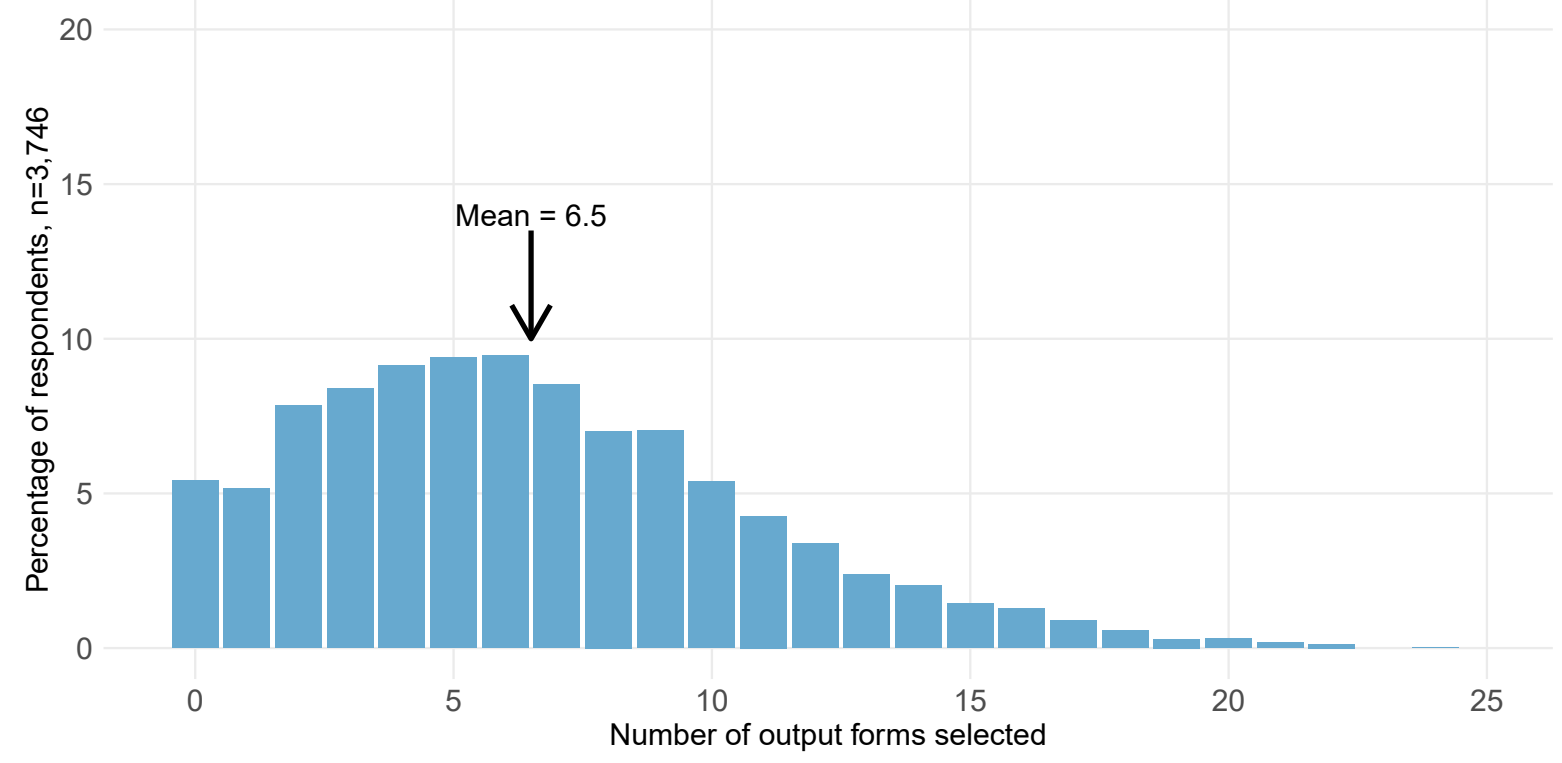

those expecting zero output forms in the future were PhD students. This supports the idea that some of the expected increase in outputs is likely driven by PhD students who will be starting to produce outputs, and some of the expected decrease in outputs is likely driven by those who will be leaving academia.

\subsection{Researchers expect to continue to produce journal articles and conference contributions, and that they will remain the dominant forms in many disciplines in the future}

The top three most frequent output forms, both now and in the future, were ranked as journal articles, conference contributions and chapters in a book (Table 3.1). Significantly ${ }^{35}$ more respondents expect to produce most output forms in the future than are currently producing them now (Figure 3.4), with authored books increasing the most from $15.8 \%$ to $36.7 \%$. Conference contributions, working papers, code and slide decks had no change between now and the future; journal articles had a slight but significant decrease; and the proportion reporting chapters in a book increased significantly by $18.6 \%$ (Figure 3.4 ).

Authored books, website content, openly published peer review, research report for external body (non-confidential) and edited books all move up the ranking, indicating that they are expected to become relatively more common in terms of the proportion of researchers that will produce them in the future. Working papers and code are some of the few output forms with no expected changes between now and the future. It is not clear why respondents did not expect these output forms to increase. However, in the open text responses about $4 \%$ of respondents mentioned that they expect to produce more software or code in the 
Table 3.1: Top 10 most frequently reported output forms being produced now and expected to be produced in 5 to 10 years' time

\begin{tabular}{|l|l|l|}
\hline Ranking & $\begin{array}{l}\text { Most frequently reported output } \\
\text { forms now }\end{array}$ & $\begin{array}{l}\text { Most frequently reported output forms in } \mathbf{5} \text { to } \mathbf{1 0} \\
\text { years' time }\end{array}$ \\
\hline 1 & Journal article & Journal article \\
\hline 2 & Conference contribution & Conference contribution \\
\hline 3 & Chapter in book & Chapter in book \\
\hline 4 & Research datasets and databases & Authored book \\
\hline 5 & Working paper & Research datasets and databases \\
\hline 6 & Social media content and blogs & Website content \\
\hline 7 & Website content & Openly published peer review \\
\hline 8 & Openly published peer review & Social media content and blogs \\
\hline 9 & Authored book & Research report for external body (non-confidential) \\
\hline 10 & Code & Edited book \\
\hline
\end{tabular}

Colour denotes consistency between the rankings for now and future.

next 5 to 10 years (38 out of 1,072), and about $3 \%$ mentioned that they would ideally produce more software or code (21 out of 640).

Respondents were also asked whether they expected a change in the form of outputs they are expecting to produce in the next 5 to 10 years, and the reasons behind their expectations. Although this question asked about output forms, researchers commented more about the quantity of different output forms (i.e. whether they would produce that output more or less), rather than whether they were producing them or not. In general, researchers reported increases in outputs that they will be producing rather than decreases, although there were divergent views as to whether the production of some common forms of output would increase or decrease in the future (Table 3.2).

\section{Table 3.2: Respondents who expect a change in the forms of output they produce in the next 5 to} 10 years $(n=1,072)$

\begin{tabular}{|l|l|l|}
\hline $\begin{array}{l}\text { Output forms commonly reported in } \\
\text { the quantitative element of the survey }\end{array}$ & $\begin{array}{l}\text { Respondents expecting } \\
\text { increase (\%) }\end{array}$ & $\begin{array}{l}\text { Respondents expecting } \\
\text { decrease (\%) }\end{array}$ \\
\hline Books for an academic audience & $70(6.5 \%)$ & $23(2.1 \%)$ \\
\hline Journal articles & $57(5.3 \%)$ & $47(4.4 \%)$ \\
\hline Book chapters & $19(1.8 \%)$ & $0(0 \%)$ \\
\hline Monographs & $14(1.3 \%)$ & $12(1.1 \%)$ \\
\hline Conference contributions & $8(0.7 \%)$ & $2(0.2 \%)$ \\
\hline Books for the public or for practitioners & $5(0.5 \%)$ & $0(0 \%)$ \\
\hline
\end{tabular}

Books for an academic audience: This category includes mentions of books, where the type of book was not specified. In these instances it was assumed that the respondent was referring to scholarly books rather than books aimed at a public or practitioner audience. 
Figure 3.4: The different forms of output respondents are producing now and expect to produce in the next 5 to 10 years

\author{
Journal article * \\ Conference contribution
}

Chapter in book *

Research datasets and databases *

Working paper

Social media content and blogs *

Website content *

Openly published peer review *

Authored book *

Code

Research report for external body (non-confidential) *

$$
\text { Preprint * }
$$

Book review *

Edited book *

Analysis plan/ research protocol/ pre-registration *

$$
\begin{aligned}
& \frac{E}{0} \\
& \frac{0}{2} \\
& \frac{7}{3} \\
& \frac{0}{7} \\
& \frac{7}{0}
\end{aligned}
$$

Software *

Confidential report for external body *

Editorial *

Data visualisation *

Slide deck

Video *

Digital or visual media *

Exhibition *

Devices and products *

Patent/ published patent application *

Podcast *

Scholarly edition *

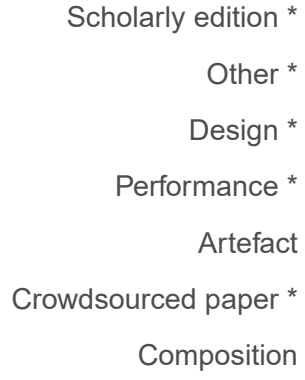

Composition

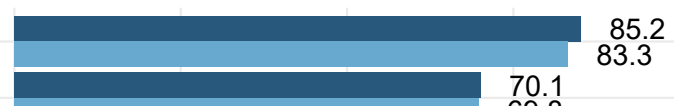

85.2

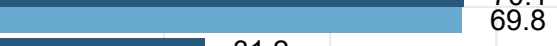

49.8

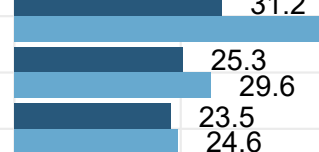

24.6
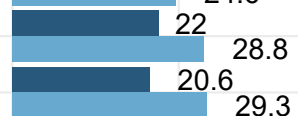

$\begin{array}{ll}18 & 29\end{array}$
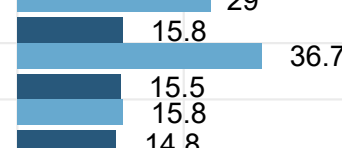

14.8

27.1

17.6

11.6

$11.3^{21.7}$

\begin{tabular}{l|l}
27 \\
11.2
\end{tabular}

14.1

10.3

9.216 .3

8.2

16.7

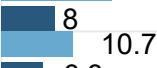

10.7

6.3
6.4

6

$6 \quad 11.9$

6

10.2

1

10.1

9.1

4.7

13.3

11.2

8.1

2.6
1.5

2.3

2.2

3.1

2.1
2.6

0.6
2.1

0.5
0.7

0

25

50

Percentage of respondents, $n=3,746$

100

future now

Researchers were provided with a list of 32 different output forms (labelled as types). This list was based on the output forms that can be submitted to REF 2021, supplemented with other output forms found within the literature or suggested by the advisory group.

The stars on the labels indicate a statistically significant difference $(p<0.05)$ between now and the future. 
Table 3.3 Respondents who would ideally like to produce more or fewer books, monographs and journal articles $(n=640)$

\begin{tabular}{|l|l|l|}
\hline Output form & $\begin{array}{l}\text { Respondents who would ideally } \\
\text { produce more of output form (\%) }\end{array}$ & $\begin{array}{l}\text { Respondents who would ideally } \\
\text { produce less of output form (\%) }\end{array}$ \\
\hline Books and monographs & $103(16.1 \%)$ & $10(1.6 \%)$ \\
\hline Journal articles & $18(2.8 \%)$ & $115(18 \%)$ \\
\hline
\end{tabular}

The expected increase in output forms reported may be due to respondents reflecting on their own career ambitions, rather than expected changes in the research landscape. Although career progression was identified as the reason for expecting to produce a particular form of output by about $24 \%$ of respondents overall (261 out of 1,072), it was identified as the reason for a third of those who expected increases in any of the common output forms listed in Table 3.2 (44 out of 139); and a third of those who expected increases in journal articles (19 out of 57 ); and $27 \%$ of those who expected increases in books and scholarly books (19 out of 70).

Respondents were also asked if, in an ideal world, they would produce different forms of outputs than they currently do. Nearly one quarter of respondents (712 out of 3,010 ) said that in an ideal world they would choose to produce different forms of output from what they are currently producing or expect to produce in the future. In the open text question that asked respondents to explain what their ideal outputs would be and why, the most frequently cited forms of output were books and monographs. The most frequently cited form of output that respondents would ideally produce fewer of were journal articles (Table 3.3).

Although respondents commonly mentioned that they expected to produce more journal articles in the future, they also commonly mentioned that they would ideally produce less of this type of output. The responses indicate that while many respondents expected to produce more journal articles as they advance in their careers because such outputs are valued by the academic system in terms of recruitment and career progression, they felt that ideally the system would value a more diverse set of outputs. Out of those who reported they would ideally like to produce fewer journal articles ( $n=115)$, more than $20 \%$ said that they are unable to produce fewer journal articles because it would hinder their career progression $(n=23)$ and because of the current publishing and peer review model $(n=25)$. Respondents noted that in an ideal world they would not want journal articles to be considered one of the most 'important' outputs, and that they would ideally like the time and space to write more books and monographs rather than focusing only on outputs they perceived were valued and rewarded through national research assessments such as the REF. Some responses perceived journal articles to be more valuable for research assessment $(n=16)$ because they can be produced quicker and in greater volume than other forms of research output. These comments also reflected that respondents felt that this was not always the most appropriate way to publish research. Respondents highlighted institutional pressures to produce more than one output per research project to provide a pool of outputs for assessment and demonstrate success measured in hiring and promotion decisions, which value productivity as well as quality. Many respondents also commented on the need for a wider range 
of outputs to be valued and evaluated within the research system, or to create a better measure of research quality than metrics that measure the quantity of journal outputs. Some respondents wanted to reduce the 'publish or perish' mentality in academia.

The expected increase in books may be due to the high proportion of respondents answering this question based on developments that they expect in their career, which was identified as the reason driving changes in future outputs by about $24 \%$ (261 out of 1,072) of respondents to the open text question on why respondents expected different forms of output. Of those who reported that they expected an increase in books and scholarly books $(n=70)$, career progression increases to over $25 \%(n=19)$, and was the only reason identified by more than $5 \%$ of respondents who expected to produce more books and scholarly books. A common argument was that as an individual's career advanced, so would the body of research they had developed, which would allow them to focus on writing books and monographs instead of outputs from individual grants. When asked about what outputs they would ideally produce, many respondents also mentioned institutional constraints in terms of having the time and resources to write books ( $n=17)$.

\subsection{Many researchers expect to start to produce more diverse forms of output aimed at a wider audience}

The top three forms of output with the greatest percentage increase in the next 5 to 10 years are different types of books (Table 3.4), which, as mentioned above, may be due to expected career progression.
Table 3.4: Top 10 output forms with greatest percentage increase in the number of respondents who plan to produce them in the next 5 to 10 years

\begin{tabular}{|l|l|}
\hline Ranking & Output forms \\
\hline 1 & Authored book \\
\hline 2 & Chapter in book \\
\hline 3 & Edited book \\
\hline 4 & $\begin{array}{l}\text { Research report for external body } \\
\text { (non-confidential) }\end{array}$ \\
\hline 5 & Openly published peer review \\
\hline 6 & Book review \\
\hline 7 & Website content \\
\hline 8 & Patent/ published patent application \\
\hline 9 & Editorial \\
\hline 10 & Podcast \\
\hline
\end{tabular}

Overall, based on researchers' expectations there is likely to be an increase in the diversity of output forms that each researcher plans to produce. There may be a slight decrease in the proportion of researchers producing journal articles, along with increases in the proportion of researchers producing other forms of output. The open text responses largely mirror these findings (Table 3.5 and Table 3.6). ${ }^{36}$

Table 3.5: Broad categories of less common output forms that respondents expect to increase producing

\begin{tabular}{|l|l|}
\hline Category of output & $\begin{array}{l}\text { Number of respondents } \\
(\mathbf{n = 1 , 0 7 2 )}(\mathbf{\%})\end{array}$ \\
\hline $\begin{array}{l}\text { Outputs with wider } \\
\text { audience }\end{array}$ & $286(26.7 \%)$ \\
\hline Open science outputs & $236(22 \%)$ \\
\hline $\begin{array}{l}\text { Outputs using non- } \\
\text { traditional mediums }\end{array}$ & $97(9 \%)$ \\
\hline
\end{tabular}


Table 3.6: Less common output forms that respondents expect to increase producing

\begin{tabular}{|c|c|}
\hline Output form & $\begin{array}{l}\text { Number of respondents } \\
(n=1,072)(\%)\end{array}$ \\
\hline More impactful or new forms of output (no specific form mentioned) & $65(6 \%)$ \\
\hline Online and digital outputs & $111(10.4 \%)$ \\
\hline Public-facing outputs & $111(10.4 \%)$ \\
\hline Social media posts & $60(5.6 \%)$ \\
\hline Blogs & $34(3.2 \%)$ \\
\hline Podcasts and radio & $25(2.3 \%)$ \\
\hline Website content & $22(2.1 \%)$ \\
\hline Open access publications & $111(10.4 \%)$ \\
\hline Open data or datasets & $57(5.3 \%)$ \\
\hline Open science outputs & $54(5 \%)$ \\
\hline Pre-prints & $53(4.9 \%)$ \\
\hline Open code or software & $38(3.5 \%)$ \\
\hline Open peer review & $21(2 \%)$ \\
\hline Open methodologies or pre-registrations & $18(1.7 \%)$ \\
\hline Open access books and monographs & $12(1.1 \%)$ \\
\hline Crowdsourced papers & $2(0.2 \%)$ \\
\hline Videos & $44(4.1 \%)$ \\
\hline Visual media & $25(2.3 \%)$ \\
\hline Interactive or multimedia outputs & $21(2 \%)$ \\
\hline Creative outputs & $16(1.5 \%)$ \\
\hline Data visualisations & $14(1.3 \%)$ \\
\hline Collaborative and interdisciplinary outputs & $28(2.6 \%)$ \\
\hline Patents and products & $26(2.4 \%)$ \\
\hline Reports & $18(1.7 \%)$ \\
\hline Outputs for industry & $18(1.7 \%)$ \\
\hline Shorter-format publications & $14(1.3 \%)$ \\
\hline Policy briefs & $12(1.1 \%)$ \\
\hline
\end{tabular}

This table includes all output forms that were mentioned by at least $1 \%$ of respondents to the free text question as forms they expect to increase in the future. 
Table 3.7: Respondents who would ideally like to produce more of different output forms

\begin{tabular}{|l|l|}
\hline Output form & $\begin{array}{l}\text { Number of respondents who would ideally } \\
\text { produce more of output form (n=640) (\%) }\end{array}$ \\
\hline Alternative outputs or more public facing outputs & $95(14.8 \%)$ \\
\hline Open access articles & $71(11.1 \%)$ \\
\hline $\begin{array}{l}\text { Popular media (including blogs, podcasts, magazines, } \\
\text { newspapers) }\end{array}$ & $70(10.9 \%)$ \\
\hline Video & $53(8.3 \%)$ \\
\hline Open science outputs & $39(6.1 \%)$ \\
\hline Interdisciplinary and collaborative outputs & $34(5.3 \%)$ \\
\hline
\end{tabular}

All other output forms were identified by less than $5 \%$ of the 640 respondents to the free text question as an output type they would ideally produce more of.

Some 640 respondents identified in the free text responses a number of less common outputs that they would ideally like to produce more of in the next 5 to 10 years (Table 3.7). Other than books and monographs (discussed above), the most common answers were more alternative outputs or more public facing outputs, which were identified by about $15 \%$ $(n=95)$ of respondents; open access articles, which were identified by over $10 \%(n=71)$; and more popular media (including blogs, podcasts, magazines and newspapers), which were identified by over $10 \%(n=70)$.

The expectation that researchers will produce more diverse outputs in the future was echoed in the four responses collected as sector views. When asked about how outputs are expected to change in the next 5 to 10 years, organisations mentioned the expectation that outputs will be more accessible in the future and more tailored to non-expert audiences. Organisations mentioned that this may take the form of more innovative formats or a wider range of outputs, such as blogs, videos, infographics, datasets and software. One organisation highlighted that this may reflect the transition to more granular outputs, or outputs with release versions rather than a final output.

Respondents also mentioned that diversification may mean that more outputs are produced per research project, including more granular outputs at different stages of the research (such as hypotheses, datasets, protocols and methods). Although organisations in the research sector expect more diverse outputs, they stressed that the level to which this is achieved is dependent on the importance of article prestige and metrics such as journal impact factor going forwards. If journal articles continue to dominate in terms of how research is evaluated both at an institutional level (e.g. recruitment and promotion decisions) and in the research system (e.g. grant decisions and publishing decisions), the diversity of outputs produced may be limited. This sentiment was largely reflected in the survey data, with respondents expecting to produce more outputs in the 
Table 3.8: Reasons provided for why researchers expect to produce new output forms in the future

\begin{tabular}{|l|l|}
\hline Reason why new output forms expected & Number of respondents (n=1,072) (\%) \\
\hline Career progression & $261(24.3 \%)$ \\
\hline Reaching new audiences & $93(8.7 \%)$ \\
\hline Creating impact & $32(3 \%)$ \\
\hline Funding opportunities & $30(2.8 \%)$ \\
\hline Promotion, reward and recognition systems & $29(2.7 \%)$ \\
\hline Rise of open access publications & $22(2.1 \%)$ \\
\hline The REF & $21(2 \%)$ \\
\hline Changes in academic publishing system & $20(1.9 \%)$ \\
\hline New technology & $19(1.8 \%)$ \\
\hline Improving communication & $13(1.2 \%)$ \\
\hline Improving research & $12(1.1 \%)$ \\
\hline Impact agenda & $11(1 \%)$ \\
\hline
\end{tabular}

future, while also identifying necessary changes in the research landscape that will facilitate the production of more diverse outputs.

\subsection{Researchers' decisions on which forms of output to produce are influenced by factors such as career progression and personal preference, as well as institutional incentives and funder requirements}

The open text responses in the survey provide some insight as to why researchers choose to produce certain output forms over others. Respondents were asked, 'Do you expect a change in the type of outputs you are producing in the next 5 to 10 years?'37 and then had the opportunity to answer in an open response, 'If yes, please explain below.' In total, 1,072 respondents provided an open text response to this question. There are a number of internal and external factors and motivations that they think will drive changes in the forms of output they expect to produce in the next 5 to 10 years. Table 3.8 shows the proportion of respondents who mentioned specific reasons for expecting different outputs in the future.

The top three reasons that respondents identified for expecting different outputs in the future were career progression, to reach new audiences and to create impact (Table 3.8). Similarly, when respondents were asked about why they would ideally produce different outputs ( $n=640$ ), the most common reason identified by nearly $20 \%$ was to reach new audiences $(n=120)$, followed by to create impact (identified by over $10 \%, n=67$ ).

Other factors and motivations that respondents identified as reasons why they expect different 
outputs in the future (or why they would ideally produce different outputs in the future) were improving communication and improving research and publishing systems, which includes the rise of open access publications and other changes in the academic publishing system (such as changes to peer review, fewer print publications and changes to subscription models). Respondents reported that longer format output forms such as books and monographs allowed them to explain more nuanced arguments or engage in deeper explorations of their research areas. Respondents also mentioned that producing output forms other than journal articles helps to improve the rigour, transparency and efficiency of the research system. For example, some respondents felt that publishing studies with null results and replication studies (which are less likely to be published as journal articles) allows researchers across the research system to build on one another's work rather than repeat work that has already been done but has not been published. Publishing pre-registrations and open datasets ensure that findings can be replicated by others.

When asked about the forms of output they would produce in an ideal world, ${ }^{38}$ over $15 \%$ of those who responded to this free text question (97 out of 640) reported that they are either unable to produce the outputs that they would ideally like to because they feel they are not valued at an institutional or research system level $(n=56)$ or that the national research assessment (i.e. the REF) impacts on the range of output forms produced ( $n=47)$. Many expressed that other output forms are desirable, but producing them takes time away from writing journal articles, which will be more significant in career progression and future funding opportunities

As discussed above, the publishing system is viewed as driving some respondents to change their outputs, and it was also seen as a constraint in terms of researchers producing the outputs they would like to publish $(n=640)$. About $8 \%$ of respondents said that they are not able to produce the outputs they would like to because of the current publishing and peer review model $(n=53)$. A small number of respondents (about $2 \%, n=19)$ also mentioned the role that they expected new technologies to play in the range of research outputs they produce in the future. Some of these respondents mentioned that digital media will allow them to produce more multimedia, video and interactive outputs, while others commented that new technologies such as artificial intelligence (AI) and machine learning would change how research is conducted, which would lead to new outputs in the future.

\subsection{Researchers from different disciplines currently produce different output forms, and researchers' expectations suggest that these differences will continue in the future}

When looking at the forms of output that researchers produce now and expect to in the future, similarities and differences across disciplines ${ }^{39}$ are expected to continue over the next 5 to 10 years (Figure 3.5). selected above?' and then had the opportunity to answer in an open text response 'If you answered yes to Question 8 , what would they be and why would you choose to produce them instead?' In total, 640 respondents provided an open response to this question. 
Figure 3.5: Percentage of respondents from each discipline who report producing each form of output now and who expect to do so in the future (in 5 to 10 years)

\begin{tabular}{|c|c|c|c|c|c|c|c|c|}
\hline \multirow[b]{2}{*}{ Output form } & \multicolumn{2}{|c|}{$\begin{array}{l}\text { Medicine, health } \\
\text { and life sciences } \\
n=1,404\end{array}$} & \multicolumn{2}{|c|}{$\begin{array}{c}\text { Physical sciences, } \\
\text { engineering and } \\
\text { mathematics } \\
n=954\end{array}$} & \multicolumn{2}{|c|}{$\begin{array}{c}\text { Social sciences } \\
n=664\end{array}$} & \multicolumn{2}{|c|}{$\begin{array}{c}\text { Arts and } \\
\text { humanities } \\
n=582\end{array}$} \\
\hline & Now & Future & Now & Future & Now & Future & Now & Future \\
\hline Journal article & 88 & 86 & 87 & 84 & 86 & 82 & 72 & 78 \\
\hline Conference contribution & 69 & 73 & 71 & 71 & 70 & 68 & 70 & 64 \\
\hline Chapter in book & 22 & 43 & 17 & 38 & 43 & 60 & 60 & 71 \\
\hline Research datasets and databases & 34 & 39 & 25 & 30 & 19 & 22 & 12 & 15 \\
\hline Working paper & 20 & 22 & 23 & 23 & 36 & 36 & 16 & 18 \\
\hline Social media content and blogs & 20 & 28 & 13 & 20 & 32 & 38 & 29 & 35 \\
\hline Website content & 18 & 26 & 20 & 30 & 24 & 28 & 23 & 35 \\
\hline Openly published peer review & 26 & 41 & 19 & 27 & 11 & 21 & 5 & 14 \\
\hline Authored book & 3 & 16 & 5 & 25 & 23 & 58 & 51 & 80 \\
\hline Code & 15 & 17 & 32 & 31 & 5 & 6 & 2 & 2 \\
\hline Research report for external body (non-confidential) & 16 & 30 & 13 & 25 & 21 & 36 & 6 & 12 \\
\hline Preprint & 17 & 23 & 25 & 27 & 5 & 7 & 3 & 5 \\
\hline Book review & 4 & 11 & 4 & 12 & 17 & 31 & 35 & 51 \\
\hline Edited book & 4 & 16 & 4 & 16 & 17 & 41 & 31 & 55 \\
\hline Analysis plan/ research protocol/ pre-registration & 23 & 28 & 4 & 6 & 5 & 6 & 2 & 2 \\
\hline Software & 7 & 10 & 26 & 31 & 3 & 3 & 1 & 2 \\
\hline Confidential report for external body & 9 & 18 & 13 & 20 & 9 & 15 & 4 & 7 \\
\hline Editorial & 10 & 21 & 5 & 11 & 10 & 18 & 8 & 14 \\
\hline Data visualisation & 8 & 11 & 12 & 15 & 5 & 8 & 2 & 6 \\
\hline Slide deck & 6 & 6 & 9 & 10 & 7 & 6 & 2 & 2 \\
\hline Video & 5 & 10 & 6 & 11 & 7 & 13 & 7 & 16 \\
\hline Digital or visual media & 4 & 9 & 4 & 7 & 8 & 12 & 10 & 16 \\
\hline Exhibition & 2 & 4 & 4 & 5 & 5 & 15 & 13 & 27 \\
\hline Devices and products & 4 & 10 & 10 & 16 & 2 & 2 & 2 & 3 \\
\hline Patent/ published patent application & 5 & 17 & 10 & 25 & 0 & 1 & 1 & 1 \\
\hline Podcast & 3 & 10 & 1 & 6 & 6 & 14 & 7 & 20 \\
\hline Scholarly edition & 2 & 5 & 1 & 3 & 4 & 9 & 11 & 23 \\
\hline Design & 1 & 1 & 5 & 6 & 2 & 3 & 1 & 1 \\
\hline Performance & 1 & 1 & 1 & 1 & 2 & 3 & 6 & 10 \\
\hline Artefact & 0 & 0 & 2 & 3 & 3 & 3 & 5 & 7 \\
\hline Crowdsourced paper & 1 & 2 & 1 & 3 & 0 & 2 & 0 & 1 \\
\hline Composition & 0 & 0 & 0 & 1 & 0 & 0 & 2 & 3 \\
\hline
\end{tabular}

Percentages are shown in bold where there is a significant difference between now and the future (significant differences between now and the future are also shown in Table 3.9). Output forms are shown shaded in grey if there is a significant difference across disciplines now, and in bold if there is a significant difference expected in the future. Each cell is shaded from white to dark red according to the percentage of respondents reporting producing or expecting to produce each type of output. The darker the red, the higher the percentage.

For a number of output forms across all disciplines, the percentage of respondents who expect to produce them in the future is significantly greater than the percentage who report producing them today. Across all disciplines, researchers expect that they will produce more authored books, edited books, chapters in a book, scholarly editions, research reports for external bodies (non-confidential), social media content and blogs, digital or visual media, openly published peer review, podcasts, videos, editorials, and book reviews in the future. The five output forms which do not have a significant difference between now and the future across the sample (code, working paper, slide deck, artefact and composition) also do not have a significant difference between now and the future within any of the disciplines. Design and performance also do not have significant differences between now 
and the future (likely due to small numbers of respondents who selected these options). Some output forms only present significant differences between now and the future for some disciplines (Table 3.9).

Table 3.9: Significant differences in outputs produced now and expected to be produced in the future, across disciplines

\begin{tabular}{|c|c|c|c|c|}
\hline Output type & $\begin{array}{l}\text { Medicine, } \\
\text { health and } \\
\text { life sciences }\end{array}$ & $\begin{array}{l}\text { Physical sciences, } \\
\text { engineering and } \\
\text { mathematics }\end{array}$ & $\begin{array}{l}\text { Social } \\
\text { sciences }\end{array}$ & $\begin{array}{l}\text { Arts and } \\
\text { humanities }\end{array}$ \\
\hline Journal article & & $\downarrow$ & & $\uparrow$ \\
\hline Conference contribution & $\uparrow$ & & & \\
\hline Chapter in book & $\uparrow$ & $\uparrow$ & $\uparrow$ & $\uparrow$ \\
\hline Research datasets and databases & $\uparrow$ & $\uparrow$ & & \\
\hline \multicolumn{5}{|l|}{ Working paper } \\
\hline Social media content and blogs & $\uparrow$ & $\uparrow$ & $\uparrow$ & $\uparrow$ \\
\hline Website content & $\uparrow$ & $\uparrow$ & & $\uparrow$ \\
\hline Openly published peer review & $\uparrow$ & $\uparrow$ & $\uparrow$ & $\uparrow$ \\
\hline Authored book & $\uparrow$ & $\uparrow$ & $\uparrow$ & $\uparrow$ \\
\hline \multicolumn{5}{|l|}{ Code } \\
\hline $\begin{array}{l}\text { Research report for external body (non- } \\
\text { confidential) }\end{array}$ & $\uparrow$ & $\uparrow$ & $\uparrow$ & $\uparrow$ \\
\hline Preprint & $\uparrow$ & & & \\
\hline Book review & $\uparrow$ & $\uparrow$ & $\uparrow$ & $\uparrow$ \\
\hline Edited book & $\uparrow$ & $\uparrow$ & $\uparrow$ & $\uparrow$ \\
\hline $\begin{array}{l}\text { Analysis plan/research protocol/pre- } \\
\text { registration }\end{array}$ & $\uparrow$ & & & \\
\hline Software & $\uparrow$ & & & \\
\hline Confidential report for external body & $\uparrow$ & $\uparrow$ & $\uparrow$ & \\
\hline Editorial & $\uparrow$ & $\uparrow$ & $\uparrow$ & $\uparrow$ \\
\hline Data visualisation & $\uparrow$ & & & \\
\hline \multicolumn{5}{|l|}{ Slide deck } \\
\hline Video & $\uparrow$ & $\uparrow$ & $\uparrow$ & $\uparrow$ \\
\hline Digital or visual media & $\uparrow$ & $\uparrow$ & $\uparrow$ & $\uparrow$ \\
\hline Exhibition & $\uparrow$ & & $\uparrow$ & $\uparrow$ \\
\hline Devices and products & $\uparrow$ & $\uparrow$ & & \\
\hline Patent/published patent application & $\uparrow$ & $\uparrow$ & & \\
\hline Podcast & $\uparrow$ & $\uparrow$ & $\uparrow$ & $\uparrow$ \\
\hline Scholarly edition & $\uparrow$ & $\uparrow$ & $\uparrow$ & $\uparrow$ \\
\hline \multicolumn{5}{|l|}{ Design } \\
\hline \multicolumn{5}{|l|}{ Performance } \\
\hline \multicolumn{5}{|l|}{ Artefact } \\
\hline Crowdsourced paper & $\uparrow$ & $\uparrow$ & $\uparrow$ & \\
\hline Composition & & & & \\
\hline
\end{tabular}

Key: upwards arrow= significant increase expected in the future; downward arrow =significant decrease expected in the future; no arrow = no significant change expected in the future. 
As outlined above, there are significant differences across disciplines in terms of what outputs they produce and expect to produce in the future. All but three output forms (conference contribution, website content and video) have a significant difference across disciplines now, and all but one (crowdsourced paper) have a significant difference for those expecting to produce them in the future. In particular, there are currently fewer arts and humanities researchers producing journal articles than researchers in other disciplines, while more social sciences and arts and humanities researchers produce book types (i.e. chapters in books, authored books, book reviews, and edited books), social media, blogs, podcasts and working papers. Openly published peer review, code, research datasets and databases and preprints are more common outputs for researchers in medicine, health and life sciences, as well as physical sciences, engineering and mathematics. Some outputs are also highly specific to certain disciplines, for example analysis plans are mainly produced in medicine, health and life sciences, and software is mainly produced in physical sciences, engineering and mathematics.

There are also some significant differences between career stages within disciplines.

Figure 3.6 shows the percentage of respondents from each discipline and career stage that report producing the top 10 forms of output now, and that expect to produce them in the future. Percentages are shown in bold where there is a significant difference within the discipline and time period (i.e. now or the future) across the career stage. There is a significant difference in the proportion of researchers who report producing journal articles and chapters in books across career stages within each discipline, with the exception of physical sciences, engineering and mathematics, and arts and humanities in relation to journal articles, and social sciences and arts and humanities in relation to chapters in books. There is a significant difference for research datasets and databases across career stages within medicine, health and life sciences, as well as physical sciences, engineering and mathematics, but this is not the case for social sciences and arts and humanities. Further differences can be seen in Figure 3.6.

Variation is also seen in some responses reported by career stage (Figure 3.7 and Table 3.10): eight output forms do not have a difference within each career stage in terms of the number of respondents reporting producing them now and in the future (Table 3.10). Eleven output forms have significant differences between now and the future for all career stages (website content, openly published peer review, research report for external body (non-confidential), book review, confidential report for external body, editorial, video, digital or visual media, exhibition, patent/ published patent application, and podcast) (Table 3.10). Some output forms only have significant differences for some career stages (Table 3.10). In general, fewer PhD students are producing each output type than respondents from other career stages, with the exception of working papers, code, data visualisations and design. In particular, code and data visualisations are mostly produced by $\mathrm{PhD}$ students and early-career researchers.

Overall, although there are significant differences across career stages for many output forms, there are more output forms with significant differences when looking across disciplines (see Figure 3.8), which suggests that disciplinary conventions have a greater bearing than career stage on the forms of output produced. 
Figure 3.6: Percentage of respondents reporting producing the top 10 overall forms of output now and expecting to produce them in the future: Differences across career stages within disciplines

\begin{tabular}{|c|c|c|c|c|c|c|c|c|c|c|c|c|c|c|c|c|}
\hline & \multicolumn{8}{|c|}{ Medicine, health and life sciences } & \multicolumn{8}{|c|}{ Physical sciences, engineering and mathematics } \\
\hline & \multicolumn{4}{|c|}{ Now } & \multicolumn{4}{|c|}{ Future } & \multicolumn{4}{|c|}{ Now } & \multicolumn{4}{|c|}{ Future } \\
\hline & $\mathrm{PhD}$ & ECR & MCR & ER & PhD & ECR & MCR & ER & $\mathrm{PhD}$ & ECR & MCR & ER & $\mathrm{PhD}$ & ECR & MCR & ER \\
\hline Journal article & 69.5 & 91.4 & 95.8 & 96.3 & 78.2 & 85.7 & 88.2 & 91.4 & 71.4 & 93.5 & 93.2 & 94.7 & 78.3 & 85.6 & 85.7 & 86.7 \\
\hline Conference contribution & 58.2 & 73.6 & 74.8 & 71.6 & 64.0 & 79.3 & 74.4 & 74.9 & 63.8 & 79.4 & 73.9 & 70.8 & 67.0 & 75.5 & 73.3 & 70.8 \\
\hline Chapter in book & 5.5 & 17.6 & 29.7 & 34.6 & 31.7 & 45.8 & 46.0 & 49.2 & 2.9 & 14.8 & 21.1 & 34.5 & 22.8 & 47.7 & 36.6 & 48.2 \\
\hline Research datasets and databases & 22.5 & 38.0 & 39.6 & 37.6 & 28.6 & 44.2 & 44.7 & 40.4 & 15.9 & 27.1 & 29.8 & 28.8 & 20.3 & 37.9 & 33.5 & 31.9 \\
\hline Working paper & 22.5 & 19.7 & 19.5 & 18.3 & 28.9 & 20.2 & 22.0 & 17.7 & 27.9 & 23.5 & 21.1 & 18.1 & 29.0 & 22.4 & 23.0 & 19.0 \\
\hline Social media content and blogs & 14.5 & 23.8 & 19.8 & 21.1 & 25.2 & 31.8 & 29.1 & 25.4 & 10.5 & 17.7 & 14.9 & 11.5 & 18.1 & 23.1 & 23.6 & 15.9 \\
\hline Website content & 9.8 & 16.9 & 21.7 & 26.0 & 16.6 & 26.1 & 32.9 & 31.2 & 9.8 & 26.7 & 24.2 & 23.5 & 19.6 & 38.3 & 32.9 & 31.9 \\
\hline Openly published peer review & 12.6 & 24.2 & 35.1 & 31.8 & 37.2 & 42.0 & 46.3 & 37.9 & 15.6 & 19.5 & 26.1 & 20.4 & 23.2 & 30.0 & 31.7 & 27.4 \\
\hline Authored book & 0.9 & 1.4 & 4.5 & 7.3 & 14.2 & 13.8 & 20.8 & 17.1 & 0.4 & 3.2 & 3.7 & 13.7 & 9.8 & 23.8 & 29.8 & 41.2 \\
\hline \multirow[t]{4}{*}{ Code } & 20.0 & 19.0 & 13.4 & 8.9 & 19.1 & 21.9 & 14.4 & 10.1 & 36.6 & 40.1 & 29.2 & 19.0 & 34.4 & 36.8 & 31.1 & 21.7 \\
\hline & \multicolumn{8}{|c|}{ Social sciences } & \multicolumn{8}{|c|}{ Arts and humanities } \\
\hline & \multicolumn{4}{|c|}{ Now } & \multicolumn{4}{|c|}{ Future } & \multicolumn{4}{|c|}{ Now } & \multicolumn{4}{|c|}{ Future } \\
\hline & $\mathrm{PhD}$ & ECR & MCR & ER & $\mathrm{PhD}$ & ECR & MCR & ER & $\mathrm{PhD}$ & ECR & MCR & ER & $\mathrm{PhD}$ & ECR & $M C R$ & ER \\
\hline Journal article & 68.3 & 88.6 & 91.3 & 95.2 & 73.4 & 79.5 & 85.7 & 88.2 & 55.7 & 87.3 & 73.4 & 71.8 & 81.1 & 70.4 & 78.4 & 81.8 \\
\hline Conference contribution & 68.3 & 73.5 & 68.3 & 69.9 & 59.7 & 71.1 & 65.8 & 73.1 & 74.6 & 73.2 & 69.1 & 67.1 & 59.0 & 62.7 & 62.6 & 70.6 \\
\hline Chapter in book & 19.4 & 36.7 & 54.0 & 57.0 & 66.2 & 50.6 & 62.1 & 63.4 & 21.3 & 65.5 & 70.5 & 74.7 & 72.1 & 70.4 & 71.2 & 72.4 \\
\hline Research datasets and databases & 15.8 & 24.1 & 15.5 & 18.8 & 18.7 & 22.3 & 18.0 & 26.3 & 12.3 & 13.4 & 10.1 & 11.8 & 11.5 & 15.5 & 15.1 & 16.5 \\
\hline Working paper & 36.7 & 38.6 & 31.1 & 34.4 & 43.2 & 39.2 & 27.3 & 35.5 & 26.2 & 17.6 & 10.1 & 11.8 & 25.4 & 19.7 & 12.2 & 17.1 \\
\hline Social media content and blogs & 30.9 & 37.3 & 31.1 & 29.6 & 36.7 & 43.4 & 41.0 & 33.9 & 34.4 & 32.4 & 28.1 & 24.1 & 36.9 & 43.0 & 38.8 & 26.5 \\
\hline Website content & 14.4 & 25.3 & 27.3 & 27.4 & 18.7 & 31.3 & 31.7 & 31.2 & 21.3 & 24.6 & 25.2 & 21.8 & 30.3 & 41.5 & 38.8 & 31.8 \\
\hline Openly published peer review & 4.3 & 13.9 & 11.2 & 12.4 & 25.2 & 24.1 & 16.8 & 18.8 & 4.1 & 5.6 & 7.9 & 4.7 & 15.6 & 18.3 & 12.2 & 11.2 \\
\hline Authored book & 5.8 & 19.9 & 27.3 & 36.0 & 54.7 & 48.2 & 63.4 & 64.5 & 9.0 & 55.6 & 61.9 & 67.6 & 82.8 & 79.6 & 81.3 & 77.6 \\
\hline Code & 6.5 & 8.4 & 3.7 & 2.7 & 4.3 & 11.4 & 4.3 & 3.8 & 1.6 & 4.2 & 2.2 & 1.8 & 2.5 & 2.8 & 2.2 & 1.2 \\
\hline
\end{tabular}

Percentages are shown in bold where there is a significant difference across career stages within disciplines and between now and in the future. Each cell is shaded from white to dark red according to the percentage of respondents reporting

producing or expecting to produce each type of output. The darker the red, the higher the percentage. 
Figure 3.7: Percentage of respondents from each career stage reporting producing forms of output now and expecting to produce them in the future

\begin{tabular}{|c|c|c|c|c|c|c|c|c|}
\hline \multirow[b]{2}{*}{ Output form } & \multicolumn{2}{|c|}{$\begin{array}{c}\text { PhD Student } \\
n=893\end{array}$} & \multicolumn{2}{|c|}{$\begin{array}{c}\text { Early-career } \\
\text { researcher } \\
n=1,043\end{array}$} & \multicolumn{2}{|c|}{$\begin{array}{c}\text { Mid-career } \\
\text { researcher } \\
n=803\end{array}$} & \multicolumn{2}{|c|}{$\begin{array}{c}\text { Established } \\
\text { researcher } \\
n=953\end{array}$} \\
\hline & Now & Future & Now & Future & Now & Future & Now & Future \\
\hline Journal article & 68 & 78 & 91 & 83 & 90 & 85 & 91 & 88 \\
\hline Conference contribution & 64 & 63 & 75 & 74 & 72 & 70 & 70 & 73 \\
\hline Chapter in book & 10 & 41 & 27 & 51 & 41 & 52 & 47 & 57 \\
\hline Research datasets and databases & 18 & 22 & 29 & 35 & 27 & 31 & 27 & 31 \\
\hline Working paper & 28 & 31 & 24 & 25 & 21 & 21 & 21 & 22 \\
\hline Social media content and blogs & 19 & 26 & 26 & 33 & 23 & 32 & 21 & 25 \\
\hline Website content & 12 & 20 & 22 & 33 & 24 & 33 & 25 & 32 \\
\hline Openly published peer review & 11 & 28 & 19 & 32 & 23 & 31 & 20 & 27 \\
\hline Authored book & 3 & 29 & 13 & 32 & 20 & 42 & 27 & 45 \\
\hline Code & 20 & 19 & 20 & 21 & 13 & 13 & 9 & 10 \\
\hline Research report for external body (non-confidential) & 7 & 21 & 14 & 29 & 19 & 30 & 20 & 30 \\
\hline Preprint & 9 & 14 & 16 & 20 & 17 & 19 & 15 & 18 \\
\hline Book review & 7 & 18 & 12 & 20 & 15 & 25 & 13 & 24 \\
\hline Edited book & 2 & 16 & 8 & 26 & 14 & 32 & 22 & 35 \\
\hline Analysis plan/ research protocol/ pre-registration & 10 & 13 & 13 & 17 & 12 & 16 & 10 & 12 \\
\hline Software & 9 & 12 & 13 & 16 & 10 & 13 & 10 & 11 \\
\hline Confidential report for external body & 3 & 10 & 8 & 16 & 11 & 18 & 15 & 22 \\
\hline Editorial & 2 & 7 & 6 & 16 & 10 & 21 & 16 & 24 \\
\hline Data visualisation & 11 & 13 & 9 & 13 & 8 & 11 & 5 & 7 \\
\hline Slide deck & 4 & 5 & 7 & 7 & 7 & 7 & 7 & 7 \\
\hline Video & 3 & 8 & 4 & 12 & 9 & 15 & 9 & 14 \\
\hline Digital or visual media & 4 & 7 & 6 & 11 & 8 & 13 & 7 & 11 \\
\hline Exhibition & 4 & 8 & 5 & 10 & 6 & 12 & 6 & 11 \\
\hline Devices and products & 2 & 8 & 4 & 9 & 5 & 10 & 8 & 10 \\
\hline Patent/ published patent application & 2 & 12 & 5 & 17 & 4 & 12 & 7 & 13 \\
\hline Podcast & 2 & 9 & 4 & 12 & 4 & 12 & 5 & 13 \\
\hline Scholarly edition & 1 & 8 & 3 & 8 & 4 & 8 & 6 & 9 \\
\hline Design & 3 & 5 & 2 & 3 & 2 & 3 & 2 & 2 \\
\hline Performance & 1 & 2 & 2 & 3 & 3 & 4 & 2 & 3 \\
\hline Artefact & 1 & 2 & 2 & 3 & 3 & 3 & 3 & 2 \\
\hline Crowdsourced paper & 1 & 2 & 1 & 3 & 0 & 1 & 1 & 2 \\
\hline Composition & 0 & 1 & 0 & 1 & 1 & 1 & 0 & 1 \\
\hline
\end{tabular}

Percentages are shown in bold where there is a significant difference between now and the future (significant differences between now and the future are also shown in Table 3.10). Output forms are shown shaded in grey if there is a significant difference across career stages now, and in bold if there is a significant difference across career stages expected in the future. Each cell is shaded from white to dark red according to the percentage of respondents reporting producing or expecting to produce each type of output. The darker the red, the higher the percentage. 
Table 3.10: Significant differences in outputs produced now and expected to be produced in the future, across career stages

\begin{tabular}{|c|c|c|c|c|}
\hline Output Type & PhD & ECR & MCR & ER \\
\hline Journal article & $\uparrow$ & $\downarrow$ & $\downarrow$ & \\
\hline \multicolumn{5}{|l|}{ Conference contribution } \\
\hline Chapter in book & $\uparrow$ & $\uparrow$ & $\uparrow$ & $\uparrow$ \\
\hline Research datasets and databases & & $\uparrow$ & & \\
\hline \multicolumn{5}{|l|}{ Working paper } \\
\hline Social media content and blogs & $\uparrow$ & $\uparrow$ & $\uparrow$ & \\
\hline Website content & $\uparrow$ & $\uparrow$ & $\uparrow$ & $\uparrow$ \\
\hline Openly published peer review & $\uparrow$ & $\uparrow$ & $\uparrow$ & $\uparrow$ \\
\hline Authored book & $\uparrow$ & $\uparrow$ & $\uparrow$ & $\uparrow$ \\
\hline \multicolumn{5}{|l|}{ Code } \\
\hline Research report for external body (non-confidential) & $\uparrow$ & $\uparrow$ & $\uparrow$ & $\uparrow$ \\
\hline Preprint & $\uparrow$ & $\uparrow$ & & \\
\hline Book review & $\uparrow$ & $\uparrow$ & $\uparrow$ & $\uparrow$ \\
\hline Edited book & $\uparrow$ & $\uparrow$ & $\uparrow$ & $\uparrow$ \\
\hline Analysis plan/ research protocol/ pre-registration & & $\uparrow$ & & \\
\hline Software & $\uparrow$ & $\uparrow$ & & \\
\hline Confidential report for external body & $\uparrow$ & $\uparrow$ & $\uparrow$ & $\uparrow$ \\
\hline Editorial & $\uparrow$ & $\uparrow$ & $\uparrow$ & $\uparrow$ \\
\hline Data visualisation & & $\uparrow$ & & \\
\hline \multicolumn{5}{|l|}{ Slide deck } \\
\hline Video & $\uparrow$ & $\uparrow$ & $\uparrow$ & $\uparrow$ \\
\hline Digital or visual media & $\uparrow$ & $\uparrow$ & $\uparrow$ & $\uparrow$ \\
\hline Exhibition & $\uparrow$ & $\uparrow$ & $\uparrow$ & $\uparrow$ \\
\hline Devices and products & $\uparrow$ & $\uparrow$ & $\uparrow$ & \\
\hline Patent/ published patent application & $\uparrow$ & $\uparrow$ & $\uparrow$ & $\uparrow$ \\
\hline Podcast & $\uparrow$ & $\uparrow$ & $\uparrow$ & $\uparrow$ \\
\hline Scholarly edition & $\uparrow$ & $\uparrow$ & $\uparrow$ & \\
\hline \multicolumn{5}{|l|}{ Design } \\
\hline \multicolumn{5}{|l|}{ Performance } \\
\hline \multicolumn{5}{|l|}{ Artefact } \\
\hline Crowdsourced paper & $\uparrow$ & $\uparrow$ & & \\
\hline Composition & & & & \\
\hline
\end{tabular}

Key: $E C R$ = early-career researcher; $M C R$ = mid-career researcher; $E R$ = established researcher; upwards arrow= significant increase expected in the future; downward arrow =significant decrease expected in the future; no arrow = no significant change expected in the future. 
Figure 3.8: Percentage of respondents reporting producing the top 10 forms of output now and expecting to produce them in the future: Differences across disciplines within career stages

\begin{tabular}{|c|c|c|c|c|c|c|c|c|c|c|c|c|c|c|c|c|}
\hline & \multicolumn{8}{|c|}{ PhD student } & \multicolumn{8}{|c|}{ Early-career researcher } \\
\hline & \multicolumn{4}{|c|}{ Now } & \multicolumn{4}{|c|}{ Future } & \multicolumn{4}{|c|}{ Now } & \multicolumn{4}{|c|}{ Future } \\
\hline & $A$ & $B$ & C & $\mathrm{D}$ & A & $B$ & C & D & A & $B$ & C & $D$ & $A$ & B & C & $D$ \\
\hline Journal article & 69.5 & 71.4 & 68.3 & 55.7 & 78.2 & 78.3 & 73.4 & 81.1 & 91.4 & 93.5 & 88.6 & 87.3 & 85.7 & 85.6 & 79.5 & 70.4 \\
\hline Conference contribution & 58.2 & 63.8 & 68.3 & 74.6 & 64.0 & 67.0 & 59.7 & 59.0 & 73.6 & 79.4 & 73.5 & 73.2 & 79.3 & 75.5 & 71.1 & 62.7 \\
\hline Chapter in book & 5.5 & 2.9 & 19.4 & 21.3 & 31.7 & 22.8 & 66.2 & 72.1 & 17.6 & 14.8 & 36.7 & 65.5 & 45.8 & 47.7 & 50.6 & 70.4 \\
\hline Research datasets and databases & 22.5 & 15.9 & 15.8 & 12.3 & 28.6 & 20.3 & 18.7 & 11.5 & 38.0 & 27.1 & 24.1 & 13.4 & 44.2 & 37.9 & 22.3 & 15.5 \\
\hline Working paper & 22.5 & 27.9 & 36.7 & 26.2 & 28.9 & 29.0 & 43.2 & 25.4 & 19.7 & 23.5 & 38.6 & 17.6 & 20.2 & 22.4 & 39.2 & 19.7 \\
\hline Social media content and blogs & 14.5 & 10.5 & 30.9 & 34.4 & 25.2 & 18.1 & 36.7 & 36.9 & 23.8 & 17.7 & 37.3 & 32.4 & 31.8 & 23.1 & 43.4 & 43.0 \\
\hline Website content & 9.8 & 9.8 & 14.4 & 21.3 & 16.6 & 19.6 & 18.7 & 30.3 & 16.9 & 26.7 & 25.3 & 24.6 & 26.1 & 38.3 & 31.3 & 41.5 \\
\hline Openly published peer review & 12.6 & 15.6 & 4.3 & 4.1 & 37.2 & 23.2 & 25.2 & 15.6 & 24.2 & 19.5 & 13.9 & 5.6 & 42.0 & 30.0 & 24.1 & 18.3 \\
\hline Authored book & 0.9 & 0.4 & 5.8 & 9.0 & 14.2 & 9.8 & \begin{tabular}{|l|l|}
54.7 \\
\end{tabular} & 82.8 & 1.4 & 3.2 & 19.9 & 55.6 & 13.8 & 23.8 & 48.2 & 79.6 \\
\hline \multirow[t]{4}{*}{ Code } & 20.0 & 36.6 & 6.5 & 1.6 & 19.1 & 34.4 & 4.3 & 2.5 & 19.0 & 40.1 & 8.4 & 4.2 & 21.9 & 36.8 & 11.4 & 2.8 \\
\hline & \multicolumn{8}{|c|}{ Mid-career researcher } & \multicolumn{8}{|c|}{ Established researcher } \\
\hline & \multicolumn{4}{|c|}{ Now } & \multicolumn{4}{|c|}{ Future } & \multicolumn{4}{|c|}{ Now } & \multicolumn{4}{|c|}{ Future } \\
\hline & A & B & C & D & A & $B$ & C & D & $A$ & B & C & D & A & B & C & D \\
\hline Journal article & 95.8 & 93.2 & 91.3 & 73.4 & 88.2 & 85.7 & 85.7 & 78.4 & 96.3 & 94.7 & 95.2 & 71.8 & 91.4 & 86.7 & 88.2 & 81.8 \\
\hline Conference contribution & 74.8 & 73.9 & 68.3 & 69.1 & 74.4 & 73.3 & 65.8 & 62.6 & 71.6 & 70.8 & 69.9 & 67.1 & 74.9 & 70.8 & 73.1 & 70.6 \\
\hline Chapter in book & 29.7 & 21.1 & 54.0 & 70.5 & 46.0 & 36.6 & 62.1 & 71.2 & 34.6 & 34.5 & 57.0 & 74.7 & 49.2 & 48.2 & 63.4 & 72.4 \\
\hline Research datasets and databases & 39.6 & 29.8 & 15.5 & 10.1 & 44.7 & 33.5 & 18.0 & 15.1 & 37.6 & 28.8 & 18.8 & 11.8 & 40.4 & 31.9 & 26.3 & 16.5 \\
\hline Working paper & 19.5 & 21.1 & 31.1 & 10.1 & 22.0 & 23.0 & 27.3 & 12.2 & 18.3 & 18.1 & 34.4 & 11.8 & 17.7 & 19.0 & 35.5 & 17.1 \\
\hline Social media content and blogs & 19.8 & 14.9 & 31.1 & 28.1 & 29.1 & 23.6 & 41.0 & 38.8 & 21.1 & 11.5 & 29.6 & 24.1 & 25.4 & 15.9 & 33.9 & 26.5 \\
\hline Website content & 21.7 & 24.2 & 27.3 & 25.2 & 32.9 & 32.9 & 31.7 & 38.8 & 26.0 & 23.5 & 27.4 & 21.8 & 31.2 & 31.9 & 31.2 & 31.8 \\
\hline Openly published peer review & 35.1 & 26.1 & 11.2 & 7.9 & 46.3 & 31.7 & 16.8 & 12.2 & 31.8 & 20.4 & 12.4 & 4.7 & 37.9 & 27.4 & 18.8 & 11.2 \\
\hline Authored book & 4.5 & 3.7 & 27.3 & 61.9 & 20.8 & 29.8 & 63.4 & 81.3 & 7.3 & 13.7 & 36.0 & 67.6 & 17.1 & 41.2 & 64.5 & 77.6 \\
\hline Code & 13.4 & 29.2 & 3.7 & 2.2 & 14.4 & 31.1 & 4.3 & 2.2 & 8.9 & 19.0 & 2.7 & 1.8 & 10.1 & 21.7 & 3.8 & 1.2 \\
\hline
\end{tabular}

Percentages are shown in bold where there is a significant difference between now and in the future. Each cell is shaded from white to dark red according to the percentage of respondents reporting producing or expecting to produce each type of output. The darker the red, the higher the percentage.

Key: Main panel $A$ = medicine, health and life sciences; $B$ = physical sciences, engineering and mathematics; $C=$ social sciences; and $D=$ arts and humanities. 



\section{How do researchers expect the types of societal impact their research produces to change in the next 5 to 10 years?}

To understand what forms of outputs and types of societal impacts researchers' feel their research is currently leading to, how they expect this to evolve in the next 5 to- 10 years, and how this is influenced by the research landscape a large- scale survey of academic researchers in England was conducted This chapter focusses on the findings related to the current and expected wider societal impacts of research and researchers' perceptions of the key drivers of expected changes in impact. It also draws on the rapid evidence assessments, responses to the sector view collection and evidence from the workshops. Additional detail on the methods underpinning this are described in Annex A.

The key findings are:

- More researchers expect that there will be societal impacts from their research in the future, although the balance of types of impact is expected to remain largely the same.

- Societal impact types differ across disciplines, and this is not expected to change.

- Researchers expect that they will continue to focus the majority of their efforts in the future on producing outputs.

- Respondents had differing views as to whether the importance placed on societal impact should increase or decrease in the future, and the reasons for this change.

\subsection{More researchers expect that there will be societal impacts from their research in the future, although the balance of types of impact is expected to remain largely the same}

Respondents were asked to select the types of impact their research currently produces and those they expect it to produce in the next 5 to 10 years. Some $77 \%$ of respondents currently expect their research to have societal impact, compared to $86 \%$ who expect their research to have societal impact in the future. Most respondents expect that their research will lead to more different types of impact in the future (Figure 4.1), with the mean number of types of impact per research increasing from 2.2 to 3.2.

The types of impact that researchers expect to produce remain constant, with the exception of the impact of research on culture and on the economy, which switch places in terms of how they are ranked: more respondents expect that research will have an impact on the economy than reported an impact on culture in the next 5 to 10 years. This was backed up in the sector views, where one response highlighted that the types of impact are unlikely to change. However this organisation felt that over time the sector was developing a deeper understanding of the process by which impact can occur and how to imbed it within academic 


\section{Figure 4.1: Types of impact that respondents are producing now and expecting to produce in the next 5 to 10 years}

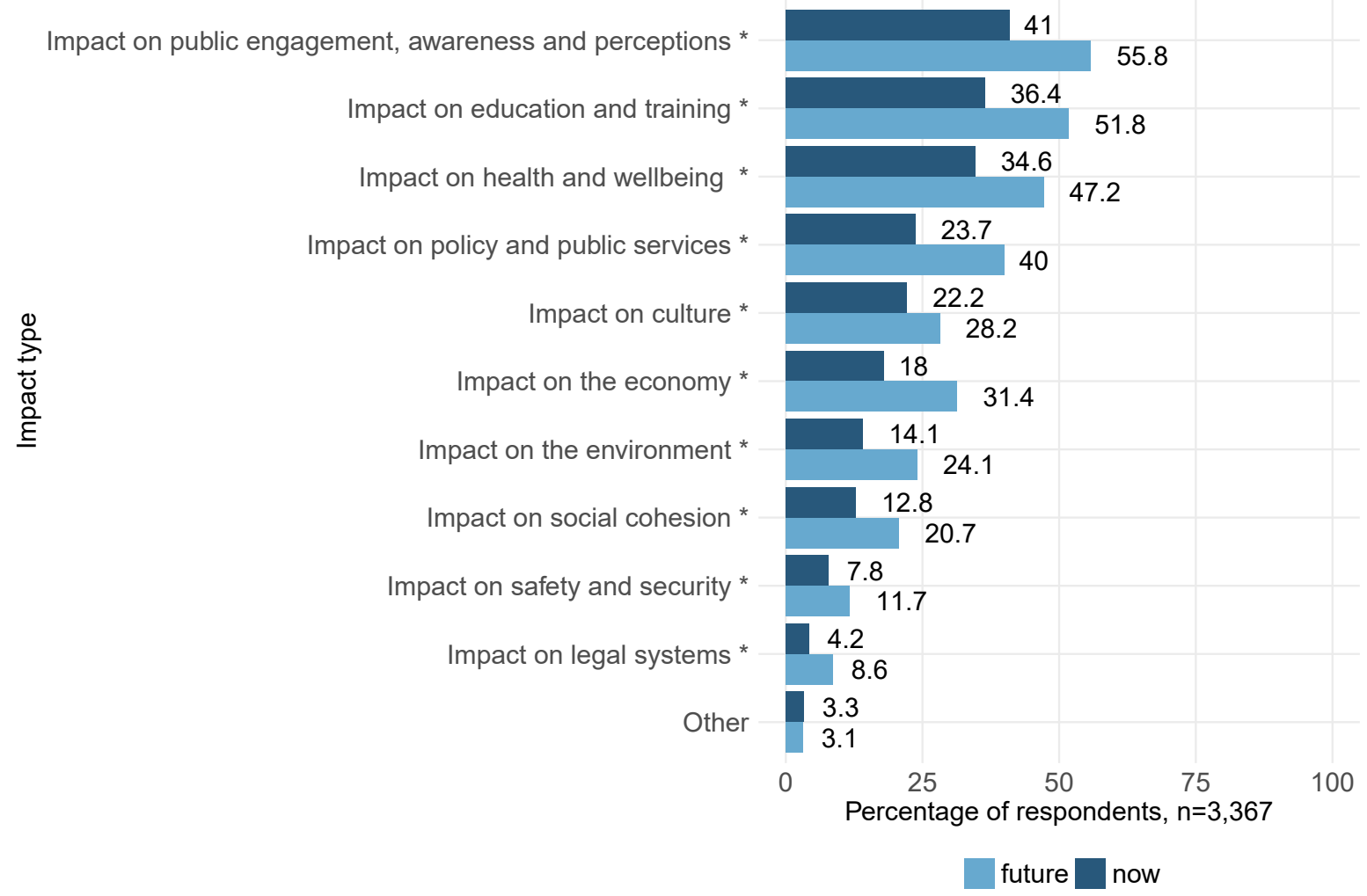

Researchers were provided with a list of 10 different impact types. This list was based on the definition of impact from REF 2021, supplemented with knowledge of research impact.

The stars on the labels indicate a statistically significant difference $(p<0.05)$ between now and the future.

research, which would enable a more nuanced practice and reporting of impact.

\subsection{Societal impact types differ across disciplines, and this is not expected to change}

The current and expected impacts that respondents reported by disciplines and career stage (Figure 4.2 and Figure 4.3, respectively) were also explored as part of this study. The biggest differences in terms of respondents' current and expected impact types are seen across disciplines, where there is a significant difference for all impact types (Figure 4.2). For example, impacts on health and wellbeing are reported most by researchers from medicine, health and life sciences; impacts on the economy are reported most by researchers in physical sciences, engineering and mathematics; impacts on policy and public services are reported most by researchers in social sciences; and impacts on culture are reported most by researchers in arts and humanities. Respondents from all disciplines expect to produce more of all impact types in the future, with the exception of those in the field of arts and humanities, where respondents do not expect a significant increase between now and the future in terms of impact on the 
Figure 4.2: Types of societal impact that respondents from each discipline are producing now and expecting to produce in the next 5 to 10 years (percentage)

\begin{tabular}{|c|c|c|c|c|c|c|c|c|}
\hline \multirow[b]{2}{*}{ Impact type } & \multicolumn{2}{|c|}{$\begin{array}{c}\text { Medicine, health and } \\
\text { life sciences } \\
n=1,252\end{array}$} & \multicolumn{2}{|c|}{$\begin{array}{c}\text { Physical sciences, } \\
\text { engineering and } \\
\text { mathematics } \\
n=812\end{array}$} & \multicolumn{2}{|c|}{$\begin{array}{c}\text { Social sciences } \\
\mathrm{n}=639\end{array}$} & \multicolumn{2}{|c|}{$\begin{array}{l}\text { Arts and humanities } \\
n=529\end{array}$} \\
\hline & Now & Future & Now & Future & Now & Future & Now & Future \\
\hline Impact on public engagement, awareness and perceptions & 38 & 54 & 29 & 44 & 51 & 66 & 52 & 65 \\
\hline Impact on education and training & 33 & 50 & 30 & 46 & 43 & 55 & 45 & 61 \\
\hline Impact on health and wellbeing & 63 & 79 & 19 & 33 & 18 & 28 & 10 & 16 \\
\hline Impact on policy and public services & 22 & 40 & 11 & 26 & 47 & 65 & 15 & 29 \\
\hline Impact on culture & 7 & 13 & 7 & 12 & 30 & 37 & 68 & 75 \\
\hline Impact on the economy & 11 & 27 & 30 & 50 & 21 & 31 & 10 & 15 \\
\hline Impact on the environment & 8 & 17 & 28 & 44 & 15 & 25 & 4 & 8 \\
\hline Impact on social cohesion & 6 & 13 & 2 & 6 & 31 & 43 & 21 & 33 \\
\hline Impact on safety and security & 5 & 7 & 16 & 24 & 8 & 11 & 2 & 3 \\
\hline Impact on legal systems & 2 & 6 & 2 & 6 & 12 & 20 & 3 & 6 \\
\hline
\end{tabular}

Percentages are shown in bold where there is a significant difference between now and in the future. Impact types are shown shaded in grey if there is a significant difference across disciplines now, and in bold if there is a significant difference expected in the future. Each cell is shaded from white to dark red according to the percentage of respondents reporting producing or expecting to produce each type of impact. The darker the red, the higher the percentage.

economy, on safety and security, and on legal systems.

There are notable differences in terms of what impacts respondents from different career stages produce now and expect to produce in the future (Figure 4.3). There is a significant increase in the number of respondents at all career stages expecting to produce impacts of all type between now and the future, with the exception of established researchers, where there is no significant increase between now and the future for impact on culture, impact on safety and security, and impact on legal systems (Figure 4.3). There are significant differences across career stages for the impact that research has currently on public engagement, awareness and perceptions; education and training; policy and public service; the economy; and legal systems. There are also significant differences across career stages for the expected impact that research will have on public engagement, awareness and perceptions; education and training; health and wellbeing; the economy; and the environment. Overall, although there are still differences between career stages in terms of the types of impact respondents produce or expect to produce, there are fewer differences across career stages than across disciplines. This indicates that there are differences between disciplines that exist outside of differences in career stage.

As discussed above, the predominant differences in impact types are between disciplines, rather than across career stages. This can be seen in particular when looking within career stages - there is a significant difference across disciplines, for all career stages and all impact types both now and in next 5 to 10 years, in terms of the number of established researchers who expect to have an impact on education and training in the future (Figure 4.4).

There are also some differences across career stages within disciplines (Figure 4.5), indicating there are differences across career stage that exist outside of disciplinary differences. For example, looking at the current types of impact achieved within medicine, health and 
Figure 4.3: Types of societal impact that respondents from each career stage are producing now and expecting to produce in the next 5 to 10 years (percentage)

\begin{tabular}{|c|c|c|c|c|c|c|c|c|}
\hline \multirow[b]{2}{*}{ Impact type } & \multicolumn{2}{|c|}{$\begin{array}{c}\text { PhD Student } \\
\mathrm{n}=754\end{array}$} & \multicolumn{2}{|c|}{$\begin{array}{c}\text { Early-career } \\
\text { researcher } \\
n=924\end{array}$} & \multicolumn{2}{|c|}{$\begin{array}{c}\text { Mid-career researcher } \\
\mathrm{n}=737\end{array}$} & \multicolumn{2}{|c|}{$\begin{array}{c}\text { Established } \\
\text { researcher } \\
n=904\end{array}$} \\
\hline & Now & Future & Now & Future & Now & Future & Now & Future \\
\hline Impact on public engagement, awareness and perceptions & 26 & 50 & 44 & 60 & 45 & 58 & 47 & 56 \\
\hline Impact on education and training & 21 & 46 & 34 & 52 & 41 & 55 & 48 & 53 \\
\hline Impact on health and wellbeing & 25 & 42 & 35 & 50 & 39 & 51 & 38 & 47 \\
\hline Impact on policy and public services & 14 & 37 & 23 & 42 & 23 & 41 & 33 & 40 \\
\hline Impact on culture & 17 & 29 & 21 & 27 & 24 & 29 & 26 & 28 \\
\hline Impact on the economy & 9 & 27 & 14 & 30 & 18 & 32 & 29 & 36 \\
\hline Impact on the environment & 12 & 27 & 15 & 26 & 12 & 20 & 16 & 22 \\
\hline Impact on social cohesion & 8 & 20 & 13 & 22 & 16 & 23 & 14 & 19 \\
\hline Impact on safety and security & 6 & 13 & 8 & 13 & 7 & 11 & 9 & 11 \\
\hline Impact on legal systems & 2 & 11 & 4 & 9 & 4 & 7 & 7 & 8 \\
\hline
\end{tabular}

Percentages are shown in bold where there is a significant difference between now and in the future. Impact types are shown shaded in grey if there is a significant difference across career stages now, and in bold if there is a significant difference expected in the future. Each cell is shaded from white to dark red according to the percentage of respondents reporting producing or expecting to produce each type of impact. The darker the red, the higher the percentage.

life sciences; physical sciences, engineering and mathematics; and social sciences, there is a significant difference across career stages for impact on the economy and impact on education and training. For physical sciences, engineering and mathematics and for social sciences, there is a significant difference across career stages for impact on policy and public services. For physical sciences, engineering and mathematics there is a significant difference across career stages for impact on public engagement, awareness and perceptions. For social sciences there is a significant difference across career stages for impact on social cohesion.

There are fewer significant differences across career stages within disciplines in terms of expected impact in 5 to 10 years (Figure 4.5). The differences observed were a significant difference across career stages in physical sciences, engineering and mathematics for expected impact on education and training; a significant difference across career stages in medicine, health and life sciences and arts and humanities for expected impact on culture; a significant difference across career stages in medicine, health and life sciences for expected impact on health and wellbeing; and a significant difference across career stages in physical sciences, engineering and mathematics for expected impact on public engagement, awareness and perceptions.

\subsection{Researchers expect that they will continue to focus the majority of their efforts in the future on producing outputs}

Respondents were asked about the balance of effort they currently spend on outputs versus impacts, and the balance of effort they expect to spend in 5 to 10 years' time. ${ }^{40} \mathrm{It}$ is worth 
Figure 4.4: Percentage of respondents reporting producing each type of impact now and expecting to produce each type of impact in the next 5 to 10 years: Differences across disciplines within career stages

\begin{tabular}{|c|c|c|c|c|c|c|c|c|c|c|c|c|c|c|c|c|}
\hline & \multicolumn{8}{|c|}{ PhD Student } & \multicolumn{8}{|c|}{ Early-career researcher } \\
\hline & \multicolumn{4}{|c|}{ Now } & \multicolumn{4}{|c|}{ Future } & \multicolumn{4}{|c|}{ Now } & \multicolumn{4}{|c|}{ Future } \\
\hline & A & $\mathrm{B}$ & $\mathrm{C}$ & $\mathrm{D}$ & A & $\mathrm{B}$ & C & $\mathrm{D}$ & A & $\mathrm{B}$ & C & $\mathrm{D}$ & A & $\mathrm{B}$ & $\mathrm{C}$ & $\mathrm{D}$ \\
\hline Impact on public engagement, awareness and perceptions & 28 & 15 & 34 & 36 & 49 & 33 & 66 & 71 & 40 & 36 & 54 & 55 & 59 & 50 & 68 & 65 \\
\hline Impact on education and training & 21 & 13 & 24 & 29 & 49 & 34 & 45 & 64 & 31 & 29 & 44 & 40 & 51 & 46 & 58 & 66 \\
\hline Impact on health and wellbeing & 49 & 13 & 9 & 7 & 71 & 29 & 25 & 16 & 62 & 19 & 18 & 9 & 82 & 34 & 27 & 17 \\
\hline Impact on policy and public services & 13 & 6 & 28 & 11 & 37 & 25 & 63 & 33 & 22 & 9 & 52 & 15 & 45 & 25 & 66 & 29 \\
\hline Impact on culture & 7 & 6 & 24 & 57 & 18 & 9 & 39 & 81 & 7 & 8 & 34 & 61 & 12 & 15 & 40 & 77 \\
\hline Impact on the economy & 5 & 16 & 12 & 5 & 21 & 44 & 26 & 10 & 7 & 29 & 16 & 6 & 25 & 51 & 25 & 18 \\
\hline Impact on the environment & 7 & 23 & 12 & 3 & 19 & 47 & 27 & 8 & 9 & 28 & 15 & 5 & 21 & 43 & 28 & 10 \\
\hline Impact on social cohesion & 5 & 2 & 18 & 15 & 13 & 6 & 43 & 32 & 6 & 2 & 40 & 18 & 13 & 5 & 53 & 39 \\
\hline Impact on safety and security & 4 & 12 & 5 & 1 & 9 & 22 & 16 & 2 & 5 & 16 & 8 & 3 & 8 & 24 & 8 & 1 \\
\hline \multirow[t]{4}{*}{ Impact on legal systems } & 2 & 0 & 6 & 2 & 7 & 6 & 27 & 6 & 1 & 2 & 13 & 3 & 6 & 7 & 22 & 6 \\
\hline & \multicolumn{8}{|c|}{ Mid-career researcher } & \multicolumn{8}{|c|}{ Established researcher } \\
\hline & \multicolumn{4}{|c|}{ Now } & \multicolumn{4}{|c|}{ Future } & \multicolumn{4}{|c|}{ Now } & \multicolumn{4}{|c|}{ Future } \\
\hline & $A$ & $\mathrm{~B}$ & $\mathrm{C}$ & $\mathrm{D}$ & A & B & C & $\mathrm{D}$ & A & $\mathrm{B}$ & $\mathrm{C}$ & $\mathrm{D}$ & A & $\mathrm{B}$ & $\mathrm{C}$ & $\mathrm{D}$ \\
\hline Impact on public engagement, awareness and perceptions & 42 & 31 & 54 & 56 & 57 & 48 & 64 & 65 & 41 & 35 & 58 & 60 & 53 & 46 & 66 & 60 \\
\hline Impact on education and training & 34 & 41 & 45 & 49 & 51 & 56 & 56 & 66 & 45 & 41 & 52 & 57 & 50 & 53 & 57 & 56 \\
\hline Impact on health and wellbeing & 67 & 29 & 20 & 13 & 83 & 39 & 29 & 17 & 71 & 21 & 25 & 10 & 80 & 33 & 32 & 15 \\
\hline Impact on policy and public services & 21 & 11 & 45 & 13 & 38 & 28 & 66 & 29 & 29 & 19 & 59 & 20 & 39 & 27 & 66 & 25 \\
\hline Impact on culture & 6 & 7 & 32 & 71 & 11 & 10 & 39 & 77 & 7 & 9 & 30 & 79 & 10 & 14 & 33 & 78 \\
\hline Impact on the economy & 11 & 34 & 21 & 13 & 29 & 56 & 31 & 18 & 20 & 46 & 32 & 16 & 31 & 54 & 38 & 19 \\
\hline Impact on the environment & 6 & 31 & 13 & 3 & 13 & 43 & 21 & 10 & 8 & 32 & 20 & 4 & 15 & 44 & 23 & 8 \\
\hline Impact on social cohesion & 8 & 1 & 34 & 25 & 13 & 5 & 43 & 39 & 6 & 3 & 29 & 25 & 12 & 6 & 36 & 28 \\
\hline Impact on safety and security & 4 & 18 & 8 & 0 & 7 & 26 & 10 & 1 & 5 & 19 & 10 & 4 & 6 & 24 & 11 & 4 \\
\hline Impact on legal systems & 2 & 1 & 12 & 1 & 4 & 4 & 15 & 6 & 5 & 3 & 15 & 5 & 5 & 6 & 18 & 6 \\
\hline
\end{tabular}

Percentages are shown in bold where there is a significant difference within career stage, between now and in the future. Each cell is shaded from white to dark red according to the percentage of respondents reporting producing or expecting to produce each type of impact. The darker the red, the higher the percentage.

Key: Main panel $A=$ medicine, health and life sciences; $B=$ physical sciences, engineering and mathematics; $C=$ social sciences; $D=$ arts and humanities. 
Figure 4.5: Percentage of respondents reporting producing each type of impact now and expecting to produce each type of impact in the next 5 to 10 years: Differences across career stages within disciplines

\begin{tabular}{|c|c|c|c|c|c|c|c|c|c|c|c|c|c|c|c|c|}
\hline & \multicolumn{8}{|c|}{ Medicine, health and life sciences } & \multicolumn{8}{|c|}{ Physical sciences, engineering and mathematics } \\
\hline & \multicolumn{4}{|c|}{ Now } & \multicolumn{4}{|c|}{ Future } & \multicolumn{4}{|c|}{ Now } & \multicolumn{4}{|c|}{ Future } \\
\hline & PhD & ECR & MCR & ER & PhD & ECR & MCR & ER & $\mathrm{PhD}$ & ECR & MCR & ER & $\mathrm{PhD}$ & ECR & MCR & ER \\
\hline Impact on public engagement, awareness and perceptions & 28 & 40 & 42 & 41 & 49 & 59 & 57 & 53 & 15 & 36 & 31 & 35 & 33 & 50 & 48 & 46 \\
\hline Impact on education and training & 21 & 31 & 34 & 45 & 49 & 51 & 51 & 50 & 13 & 29 & 41 & 41 & 34 & 46 & 56 & 53 \\
\hline Impact on health and wellbeing & 49 & 62 & 67 & 71 & 71 & 82 & 83 & 80 & 13 & 19 & 29 & 21 & 29 & 34 & 39 & 33 \\
\hline Impact on policy and public services & 13 & 22 & 21 & 29 & 37 & 45 & 38 & 39 & 6 & 9 & 11 & 19 & 25 & 25 & 28 & 27 \\
\hline Impact on culture & 7 & 7 & 6 & 7 & 18 & 12 & 11 & 10 & 6 & 8 & 7 & 9 & 9 & 15 & 10 & 14 \\
\hline Impact on the economy & 5 & 7 & 11 & 20 & 21 & 25 & 29 & 31 & 16 & 29 & 34 & 46 & 44 & 51 & 56 & 54 \\
\hline Impact on the environment & 7 & 9 & 6 & 8 & 19 & 21 & 13 & 15 & 23 & 28 & 31 & 32 & 47 & 43 & 43 & 44 \\
\hline Impact on social cohesion & 5 & 6 & 8 & 6 & 13 & 13 & 13 & 12 & 2 & 2 & 1 & 3 & 6 & 5 & 5 & 6 \\
\hline Impact on safety and security & 4 & 5 & 4 & 5 & 9 & 8 & 7 & 6 & 12 & 16 & 18 & 19 & 22 & 24 & 26 & 24 \\
\hline \multirow[t]{4}{*}{ Impact on legal systems } & 2 & 1 & 2 & 5 & 7 & 6 & 4 & 5 & 0 & 2 & 1 & 3 & 6 & 7 & 4 & 6 \\
\hline & \multicolumn{8}{|c|}{ Social sciences } & \multicolumn{8}{|c|}{ Arts and humanities } \\
\hline & \multicolumn{4}{|c|}{ Now } & \multicolumn{4}{|c|}{ Future } & \multicolumn{4}{|c|}{ Now } & \multicolumn{4}{|c|}{ Future } \\
\hline & PhD & ECR & MCR & ER & PhD & ECR & MCR & ER & $\mathrm{PhD}$ & ECR & MCR & ER & $\mathrm{PhD}$ & ECR & MCR & ER \\
\hline Impact on public engagement, awareness and perceptions & 34 & 54 & 54 & 58 & 66 & 68 & 64 & 66 & 36 & 55 & 56 & 60 & 71 & 67 & 65 & 60 \\
\hline Impact on education and training & 24 & 44 & 45 & 52 & 45 & 58 & 56 & 57 & 29 & 40 & 49 & 57 & 64 & 60 & 66 & 56 \\
\hline Impact on health and wellbeing & 9 & 18 & 20 & 25 & 25 & 27 & 29 & 32 & 7 & 9 & 13 & 10 & 16 & 18 & 17 & 15 \\
\hline Impact on policy and public services & 28 & 52 & 45 & 59 & 63 & 66 & 66 & 66 & 11 & 15 & 13 & 20 & 33 & 32 & 29 & 25 \\
\hline Impact on culture & 24 & 34 & 32 & 30 & 39 & 40 & 39 & 33 & 57 & 61 & 71 & 79 & 81 & 67 & 77 & 78 \\
\hline Impact on the economy & 12 & 16 & 21 & 32 & 26 & 25 & 31 & 38 & 5 & 6 & 13 & 16 & 10 & 11 & 18 & 19 \\
\hline Impact on the environment & 12 & 15 & 13 & 20 & 27 & 28 & 21 & 23 & 3 & 5 & 3 & 4 & 8 & 6 & 10 & 8 \\
\hline Impact on legal systems & 6 & 13 & 12 & 15 & 27 & 22 & 15 & 18 & 2 & 3 & 1 & 5 & 6 & 5 & 6 & 6 \\
\hline
\end{tabular}

Percentages are shown in bold where there is a significant difference between now and in the future. Each cell is shaded from white to dark red according to the percentage of respondents reporting producing or expecting to produce each type of impact. The darker the red, the higher the percentage.

Key: $E C R=$ early-career researcher; $M C R=$ mid-career researcher; $E R=$ established researcher. 
Figure 4.6: Change in the balance of efforts spent on producing outputs and impacts between now and 5 to 10 years' time

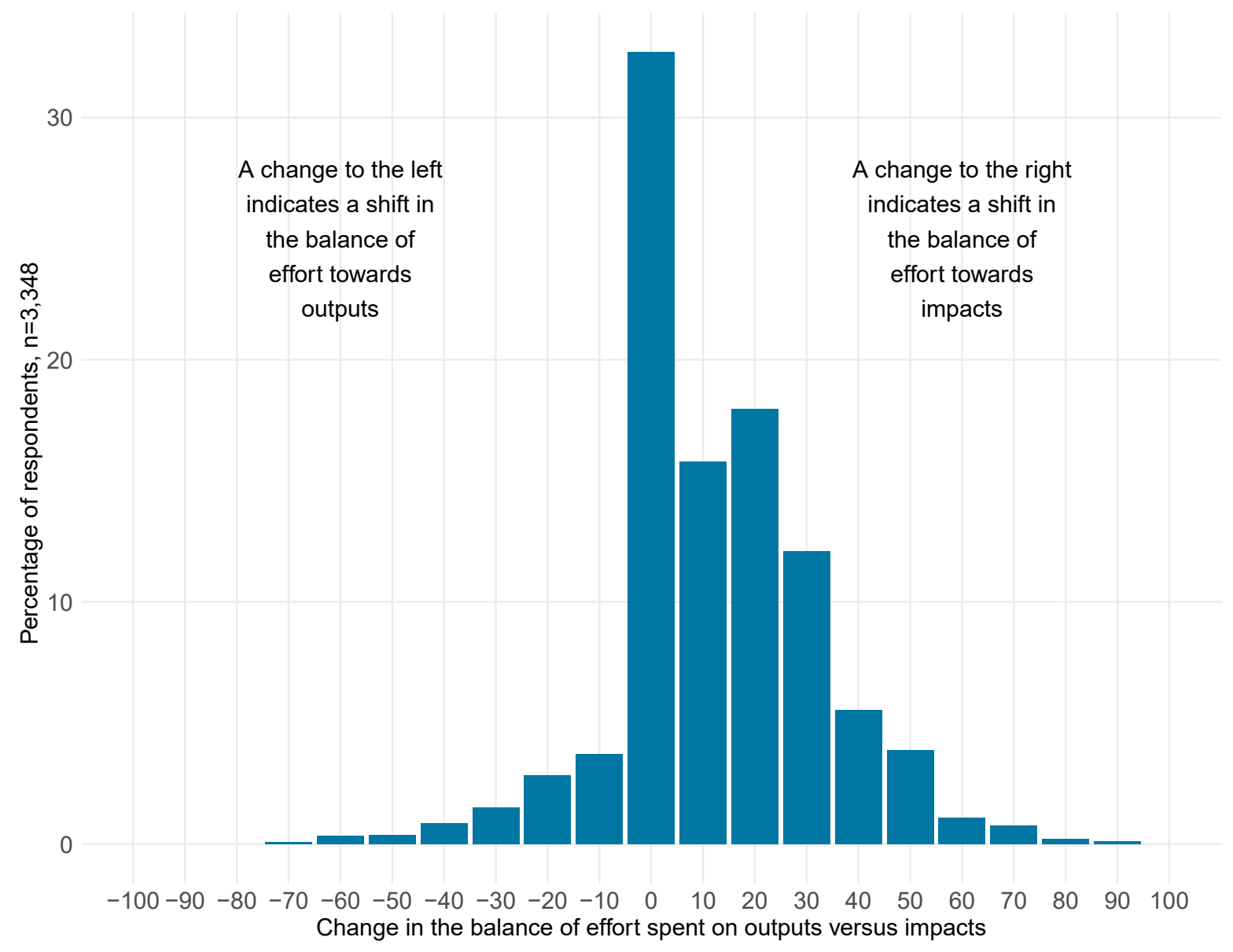

noting that although this question provides an insight into the changing focus on outputs and impacts, it does not necessarily capture how many respondents would think about the time they spend on outputs and impacts. For example, outputs and impacts are neither separate, linear nor direct, and researchers may not dedicate separate time and effort to each activity independently, or recognise a clear distinction.

On average, researchers indicated that the proportion of effort they currently devote to outputs is $74 \%$, and in 5 to 10 years they expect it to be $61 \%$, which indicates that despite a reduction, still over half of researchers' efforts will be spent on outputs. Figure 4.6 shows the change in balance that is expected between now and 5 to 10 years' time.

The majority of respondents expect a shift in effort towards impact in the future (Table 4.1). However, one third of respondents do not expect it to change, and nearly $10 \%$ predict a shift away from impacts and towards outputs.

Table 4.2 and Table 4.3 show the average balance of efforts spent on outputs and impacts across career stages and disciplines, respectively. In general, PhD students and early-career researchers report spending a 
Table 4.1: Expected shifts in effort between the production of outputs and impacts

\begin{tabular}{|l|l|}
\hline Expected shift in effort & Number of respondents $(\mathbf{n = 3 , 3 4 8 )} \mathbf{( \% )}$ \\
\hline Towards impact & $1,929(57.6 \%)$ \\
\hline Remain the same & $1,095(32.7 \%)$ \\
\hline Towards outputs & $324(9.7 \%)$ \\
\hline
\end{tabular}

Table 4.2: Average balance of efforts spent on outputs and impacts across career stages

\begin{tabular}{|l|l|l|l|}
\hline Career stage & $\begin{array}{l}\text { Balance of effort } \\
\text { currently spent } \\
\text { on outputs versus } \\
\text { impacts (\%) }\end{array}$ & $\begin{array}{l}\text { Balance of effort } \\
\text { expected to be spent } \\
\text { on outputs versus } \\
\text { impacts in } \mathbf{5} \text { to } \mathbf{1 0} \\
\text { years' time (\%) }\end{array}$ & $\begin{array}{l}\text { Change expected } \\
\text { between now and } \mathbf{5} \text { to } \\
\mathbf{1 0} \text { years' time (\%) }\end{array}$ \\
\hline PhD students & 71 & 55 & 16 \\
\hline Early-career researchers & 74 & 60 & 14 \\
\hline Mid-career researchers & 76 & 64 & 12 \\
\hline Established researchers & 75 & 65 & 10 \\
\hline
\end{tabular}

Table 4.3: Average balance of efforts spent on outputs and impacts across disciplines

\begin{tabular}{|l|l|l|l|}
\hline Discipline & $\begin{array}{l}\text { Balance of effort } \\
\text { currently spent } \\
\text { on outputs versus } \\
\text { impacts (\%) }\end{array}$ & $\begin{array}{l}\text { Balance of effort } \\
\text { expected to be spent } \\
\text { on outputs versus } \\
\text { impacts in } \mathbf{5} \text { to } \mathbf{1 0} \\
\text { years' time (\%) }\end{array}$ & $\begin{array}{l}\text { Change expected } \\
\text { between now and } \mathbf{5} \text { to } \\
\mathbf{1 0} \text { years' time (\%) }\end{array}$ \\
\hline $\begin{array}{l}\text { Medicine, health and life } \\
\text { sciences }\end{array}$ & 73 & 60 & 13 \\
\hline $\begin{array}{l}\text { Physical sciences, } \\
\text { engineering and } \\
\text { mathematics }\end{array}$ & 74 & 63 & 11 \\
\hline Social sciences & 73 & 60 & 13 \\
\hline Arts and humanities & 77 & 65 & 12 \\
\hline
\end{tabular}

lower proportion of effort on outputs versus impacts than mid-career and established researchers, and they expect this to be even lower in the future (Table 4.2). There is less difference between disciplines, with researchers from medicine, health and life sciences; physical sciences; engineering and mathematics; and social sciences being broadly similar in terms of the proportion of effort spent on outputs and impacts now and in the future. Arts and humanities were slightly higher (Table 4.3). 
Table 4.4: Reasons respondents gave for expecting different types of impact or an increase in impact in the future

\begin{tabular}{|l|l|}
\hline Reason & $\begin{array}{l}\text { Number of respondents } \\
(\mathbf{n = 4 9 9 )}(\%)\end{array}$ \\
\hline Change and developments in own research & $177(35.5 \%)$ \\
\hline Career progression & $87(17.4 \%)$ \\
\hline Research topic is becoming more relevant or impactful & $86(17.2 \%)$ \\
\hline Respondent is more actively focusing on impact or public engagement & $64(12.8 \%)$ \\
\hline Societal challenges & $62(12.4 \%)$ \\
\hline Respondents moving towards commercialisation or private sector & $38(7.6 \%)$ \\
\hline Changing outputs & $36(7.2 \%)$ \\
\hline New technology & $27(5.4 \%)$ \\
\hline Funding & $26(5.2 \%)$ \\
\hline Policy changes & $24(4.8 \%)$ \\
\hline Impact agenda & $16(3.2 \%)$ \\
\hline
\end{tabular}

\subsection{Respondents had differing views as to whether the importance placed on societal impact should increase or decrease in the future, and the reasons for this change}

Respondents were given the opportunity to provide an open text response about whether they thought the impacts of their research would change over the next 5 to 10 years, and their reasons for any change $(n=893)$. Of those who provided a reason, more than half $(n=499)$ said that they expected the impact arising from their research to change or increase, meaning that their research would either lead to new types of impact, different types of impact or a more substantial impact in the future. Over $25 \%(n=231)$ said that they expected their impacts to stay the same or decrease, and about $15 \%(n=159)$ were unsure as to whether or not their impacts would change. From some respondents who provided a reason it was unclear whether they expected their impacts to change or increase, stay the same or increase, or if they were unsure of their future impacts.
4.4.1. Reasons for expecting different or increased impacts in the future

Respondents who provided open text responses about why they expected their impacts to increase or change in future (499 out of 893) identified a number of factors and motivations that would drive changes to the type of impact or increases in the amount of impact achieved (Table 4.4).

The most common reason respondents cited for why they expected their impacts to increase or change in the future was changes or developments in the research that they were conducting $(n=177)$. This mostly consisted of respondents who said that over time their research will become more developed and closer to the end user, which creates the opportunity for greater or more diverse impacts. This included respondents conducting research they classified as 'fundamental' or 'basic', but that they envisaged would become more applied or would influence the work of other researchers over time. There were also respondents in this category who said that they were planning on moving into slightly different areas of research that had the potential for 
new types of impact or for more impact to be created. In some instances, this may reflect where the sector sees the availability of funding to be moving. One organisational response highlighted the alignment of research, and therefore impact, with sustainable development goals and other real world problems.

Another driver identified by respondents who expected their impacts to change or increase was career progression $(n=87)$, for example moving to more senior positions or leaving academia entirely over the next decade. Some of these respondents attributed their expectation for more impact as they progressed in their career to more esteem, expertise and opportunities to collaborate with industry and non-academic partners. Others, particularly those retiring or moving out of academia, focused on the fact that they would have more time and energy to create impact.

Over $15 \%$ of respondents who thought that their impact would change or increase in the future said that they expected the topic of their current or planned research to become more relevant in the future $(n=86)$. This was mostly due to big challenges in society that would drive impact $(n=62)$, such as the environment, climate change, reduced health resources, antimicrobial resistance, affordable housing, political systems and democracy.

\subsubsection{Reasons for expecting reduced or unchanged impacts in the future}

Not all respondents to the open text question thought that their research would have an impact or that their research would lead to new impacts in the future. About 25\% (231 out of 893) said that they think their research will lead to the same impacts in the future as it currently does, or that their research will lead to fewer impacts in the future. The most commonly reported reasons are given in Table 4.5.
The most common reason given for why impacts would not change or would decrease was that the research they conducted already had a particular impact, and that this was unlikely to develop further over the next decade $(n=64)$. Another frequent response was that respondents were undertaking 'basic' or 'fundamental' research $(n=34)$ where it was felt that the impact of the research would take longer than 10 years to materialise, that it would not lead to direct societal impacts, or that it has no societal impact and will therefore not lead to different impacts in the future $(n=10)$. Others in arts or humanities perceived that their discipline did not have wider societal impact, or that it only had a set number of types of impact that were already being achieved $(n=8)$. Other respondents said that their research would not have an impact or would not have new impacts because their career stage or the research they conduct was unlikely to change in the next 5 to 10 years to such a degree that it would create new impacts $(n=31)$. These respondents felt that the scope of their research was unlikely to change (either because of the researcher or because of constraints from the sector or their institutions), and that it only allowed for certain impacts. Other reasons that respondents provided for not creating new impacts included career progression $(n=12)$, including those who said that their work would not create impact because their career would still be at an early stage in the next 5 to 10 years, those who were moving to new roles with less potential for impact, and those who were moving out of academia entirely in the next decade.

Over $10 \%(n=26)$ of those who did not expect new impacts cited decreased funding. This was closely related to those who cited less 'risky' and basic research in the research landscape as the reason $(n=10)$. A number of respondents also felt that impact or engagement is not possible because there is a lack of interest 
Table 4.5: Reasons respondents gave for expecting the same or a reduction in the types of impact in the future

\begin{tabular}{|l|l|}
\hline Reason & Number of respondents (n=231) (\%) \\
\hline My research has always had impact & $64(27.7 \%)$ \\
\hline Research is fundamental or basic & $34(14.7 \%)$ \\
\hline Research and career is rigid & $31(13.4 \%)$ \\
\hline Funding & $26(11.3 \%)$ \\
\hline Impact is difficult or impossible because public is not interested & $23(10 \%)$ \\
\hline Impact agenda & $21(9.1 \%)$ \\
\hline Career progression & $12(5.2 \%)$ \\
\hline Societal change & $12(5.2 \%)$ \\
\hline Leaving the EU & $10(4.3 \%)$ \\
\hline Decreased 'risky' or basic research & $10(4.3 \%)$ \\
\hline My research does not have impact & $10(4.3 \%)$ \\
\hline The REF & $8(3.5 \%)$ \\
\hline Arts and humanities research & $8(3.5 \%)$ \\
\hline
\end{tabular}

This table details all reasons identified by at least 3\% $(n=23)$ of the respondents.

or understanding in the research conducted beyond academia $(n=23)$. Under $10 \%(n=21)$ of respondents who did not expect new impacts cited what some described as the 'artificial engineering' of impact, where research is conducted with a desired societal impact in a short timeframe, which may hinder more 'blue skies' or abstract research in favour of incremental improvements. This was linked to mentions of the importance of the European Research Council (ERC), which they perceived as funding 'riskier' research without a requirement for impact, and a concern over access to this type of funding following the United Kingdom's changing relationship with the EU. Some $5 \%(n=12)$ said that societal changes such as increasing levels of public distrust in science would make their research less impactful in the next 5 to 10 years, or that 'information overload' would make it difficult for scientific breakthroughs to be noticed. Some $(n=8)$ also said that they felt as though the REF exercise limits the investment in longer term, less demonstrable impacts that may be more meaningful to society in the long run by creating incentives to produce demonstrable and evidenced impacts from research. Some commented on the time to engage in institutional preparations for the REF exercise, such as mock exercises, which they felt could decrease the amount of time they had to conduct research and create impact.

\subsubsection{Reasons why respondents were unsure of whether their impacts would change in the future}

Under 20\% (159 out of 893) of respondents who provided at least one reason why they did or did not expect their impacts to change reported that they were unsure whether their 
Table 4.6: Reasons respondents gave for being unsure of how impacts would change in the future

\begin{tabular}{|l|l|}
\hline Reason & Number of respondents $\mathbf{( n = 1 5 9 ) ( \% )}$ \\
\hline Change or developments in research & $38(23.9 \%)$ \\
\hline Career progression & $24(15.1 \%)$ \\
\hline Funding & $20(12.6 \%)$ \\
\hline Policy changes & $18(11.3 \%)$ \\
\hline Societal change & $16(10.1 \%)$ \\
\hline The REF & $11(6.9 \%)$ \\
\hline Impact agenda & $11(6.9 \%)$ \\
\hline Changing outputs & $11(6.9 \%)$ \\
\hline Research is fundamental or basic & $11(6.9 \%)$ \\
\hline Topic becoming more relevant or impactful & $10(6.3 \%)$ \\
\hline Technology & $8(5 \%)$ \\
\hline
\end{tabular}

impacts would change in the next 5 to 10 years (Table 4.6). These factors reflect a level of uncertainty around some of the factors cited above.

The most common reasons for respondents being unsure of how impacts would change in the future were uncertainty in terms of how their research would develop or what the findings of their research would be over the next decade $(n=38)$, uncertainty of how their career would develop $(n=24)$, or uncertainty of how funding opportunities would affect impact $(n=20)$. Other areas of uncertainty included policy changes, such as changes in research and funding policy, policies around the REF and the impact agenda, as well as other measurements such as the Teaching Excellence Framework (TEF) and the Knowledge Exchange Framework (KEF), as well as societal changes. Respondents who mentioned societal changes tended to be unsure of how issues within society (such as housing prices, the environment and democracy) would develop or how they would be resolved, which had the potential to make their research either more relevant, or conversely, outdated $(n=16)$. 


\section{How do researchers expect the change in the next 5 to 10 years?}

To understand what types of outputs and impacts researchers' feel their research is currently leading to, how they expect this to evolve in the next 5 to 10 years, and how this is influenced by the research landscape a largescale survey of academic researchers in England was conducted. This chapter focusses on the findings related to how researchers expect the research environment to change over the next decade. It also draws on the rapid evidence assessments and responses to the sector view collection. Additional detail on the methods underpinning this are described in Annex A.

The key findings are:

- Researchers think that collaborating with other academics is the most important driver of change.

- There are significant differences across disciplines in the perceived importance of most of the drivers, although the three most important drivers are consistent.

- Overall, most drivers were seen as more important by PhD students and earlycareer researchers than by mid-career and established researchers, particularly open science.
- There are a range of views from researchers on how the research environment needs to adapt to change.

- Changes to support and drive developments need to happen at both an institutional and a sector level.

\subsection{Researchers think that collaborating with other academics is the most important driver of change}

When asked to rate a set of statements in terms of their importance for driving changes in the research environment, ${ }^{41}$ over $50 \%$ of respondents rated each statement as being important ('somewhat important' or 'very important') in driving changes in the research system (Figure 5.1). ${ }^{42}$ More than $75 \%$ of respondents considered 12 out of the 20 statements as important ('somewhat important' or 'very important') in driving the changes in the research system. The top five statements that were rated as the most important drivers of change in the research environment were the importance of were: not important, somewhat important, very important and unsure. It was not compulsory to answer the question. 
Figure 5.1: How respondents perceive the importance of potential drivers of change in the research environment

The value placed on research by society

The use of metrics (e.g. citation measures) in understanding research

Shift in global research balance

Open science

Increasing investment in some areas of research

Importance of collaborating with other academic researchers

Importance of collaborating with non-academic partners (excluding industry)

Importance of collaborating with industry

Importance of collaborating globally with other to academic researchers

$\stackrel{Z}{\mathrm{~L}}$ Importance of being mobile as a researcher

Focus on the non-academic impact of research

Focus on research into global challenges

Focus on research integrity

Focus on multidisciplinary research

Focus on inclusion and diversity

Focus on accountability (e.g. demonstrating that publicly funded research is valuable)

Emergence of new professional roles in academia

Decreasing investment in some areas of research

Citizen science

Changes in how research is assessed

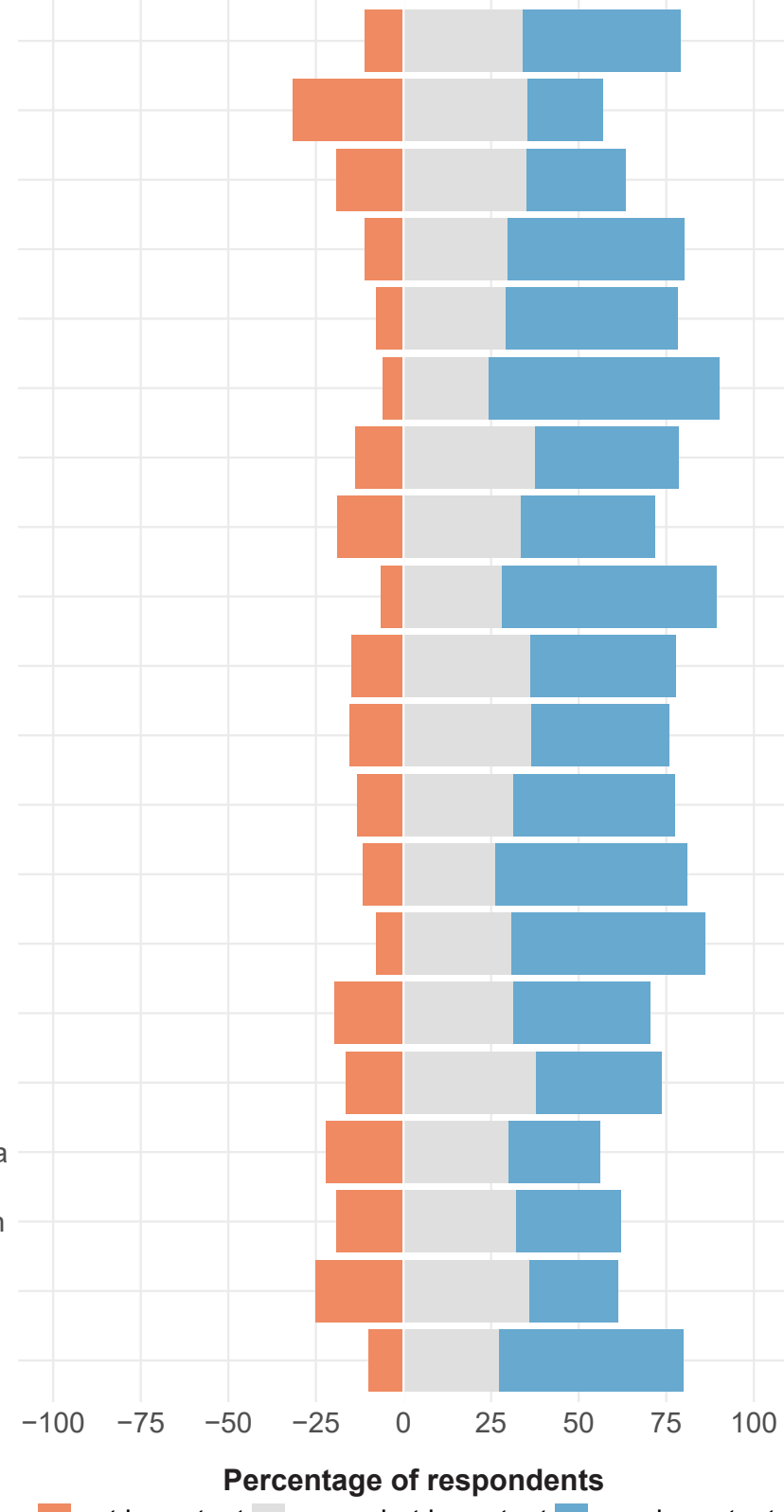

not important somewhat important very important collaborating with other academic researchers, the importance of collaborating globally with other academic researchers, the focus on multidisciplinary research, the focus on research integrity, and open science.

While collaborating and collaborating globally with other academic researchers came at the top of the list, collaborating with non-academic partners (except industry) and collaborating with industry came further down. This may indicate that academic collaborations are seen as a more important driver of change than the push toward non-academic impact.

No statements had more people select 'not important' than 'important', although three statements had more than $20 \%$ of respondents select 'not important' in driving the changes. These statements that were seen as the least 
important drivers of the research environment in our list of options, were the use of metrics (e.g. citation measures) in understanding research, citizen science, and the emergence of new professional roles in academia. However, when interpreting these data it is important to consider the level of certainty around each driver. Figure 5.2 shows the level of uncertainty, which is reflected by the percentage of respondents who answered each driver with

\section{Figure 5.2: Percentage of respondents who were unsure of importance of drivers of change (level of uncertainty)}

The value placed on research by society

The use of metrics (e.g. citation measures) in understanding research

Shift in global research balance

Open science

Increasing investment in some areas of research Importance of collaborating with other academic researchers

Importance of collaborating with non-academic partners (excluding industry)

Importance of collaborating with industry

Importance of collaborating globally with other academic researchers

$\bar{\Phi}$ Importance of being mobile as a researcher

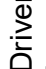

Focus on the non-academic impact of research

Focus on research into global challenges

Focus on research integrity

Focus on multidisciplinary research

Focus on inclusion and diversity

Focus on accountability (e.g. demonstrating that publicly funded research is valuable)

Emergence of new professional roles in academia

Decreasing investment in some areas of research

Citizen science

Changes in how research is assessed

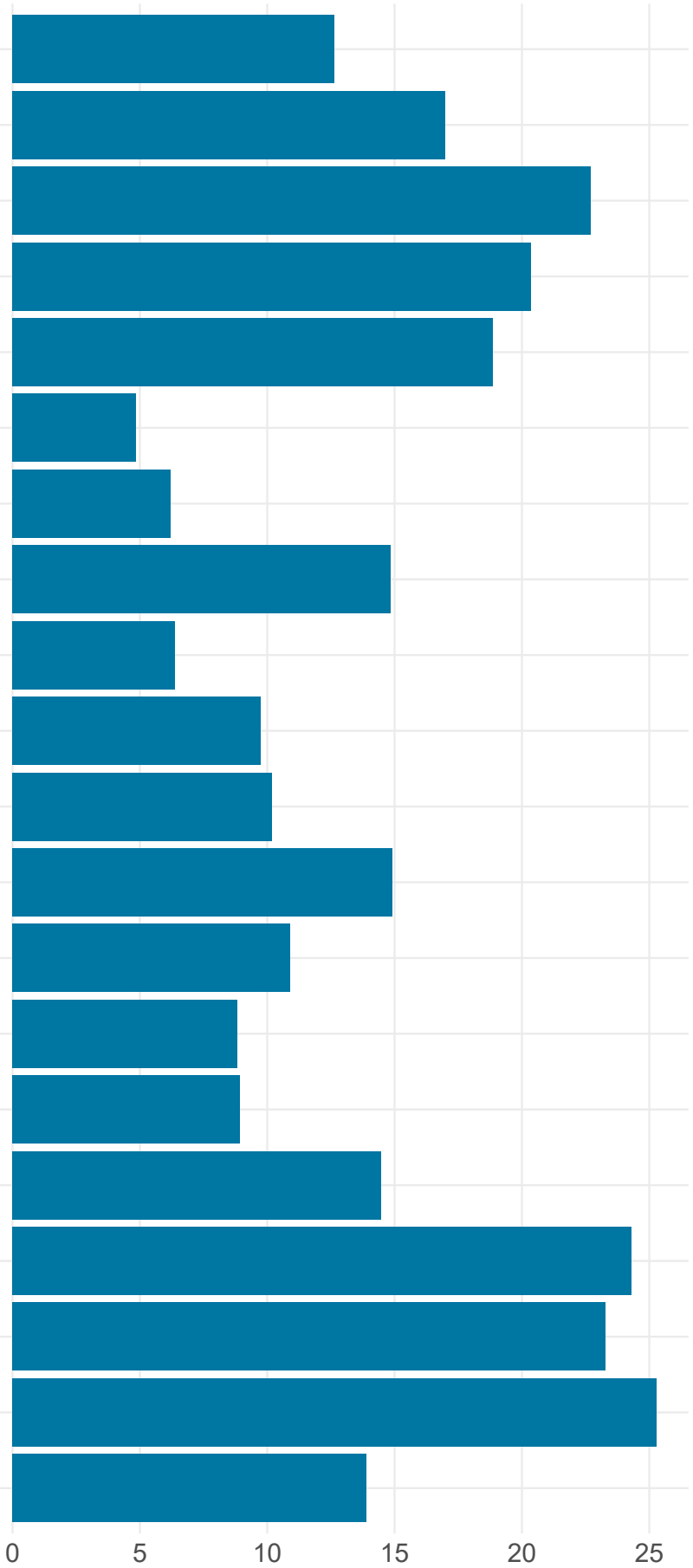

Percentage of respondents who selected 'unsure' 
'unsure'. The emergence of new professional roles in academia was the statement with the most uncertainty, with over $20 \%$ of respondents selecting that they were 'unsure' of how important this was in driving changes in the research system.

\subsection{There are significant differences across disciplines in the perceived importance of most of the drivers, although the three most important drivers are consistent}

Out of 18 drivers, 17 have a significant difference in the percentage of respondents who rated them as somewhat or very important across disciplines, with the exception being the importance of being mobile as a researcher, which was rated as somewhat/very important by $75-80 \%$ of respondents from each discipline (Figure 5.3).

Figure 5.4 shows the top five ranked drivers for each career stage, with each driver shaded a consistent colour. Looking across all disciplines, the importance of collaborating with other academic researchers is generally seen as the most important driver, followed by the importance of collaborating globally with other academic researchers and the focus on multidisciplinary research. For respondents in physical sciences, engineering and mathematics, the importance of collaborating globally with other academic researchers was seen as more important than collaborating with other academic researchers in general terms. This reflects the trends seen across the full dataset.

More notable differences in terms of how drivers of change are ranked are seen further down the list, for example, open science was ranked 4 th by respondents in medicine, health and life sciences, and 5th by respondents in physical sciences, engineering and mathematics; but 10th for respondents in social sciences and 14th by those in arts and humanities. The focus on research integrity was seen as one of the most important drivers of change only for respondents in medicine, health and life sciences, while the importance of being mobile as a researcher was seen as one of the most important drivers of change only for respondents in physical sciences, engineering and mathematics. Similarly, the importance of collaborating with non-academic partners (outside of industry) was ranked as the 4th most important driver of change for respondents in social sciences and arts and humanities, but comes 14th for respondents in physical sciences, engineering and mathematics. The focus on the non-academic impact of research was only seen as one of the most important drivers for researchers in social sciences, and the focus on inclusion and diversity was only seen as one of the most important drivers of change for researchers in arts and humanities.

There was no significant difference in terms of how respondents from different career stages within the same discipline rated the importance of different drivers of change (Figure 5.5), with some exceptions. There were significant differences in terms of how respondents from different career stages within medicine, health and life sciences, physical sciences, engineering and mathematics, and social sciences rated the importance of the emergence of new professional roles in academia. There was also a significant difference in how respondents from different career stages in physical sciences, engineering and mathematics, and social sciences rated the importance of citizen science, and how respondents from different career stages within physical sciences, engineering and mathematics rated the importance of open science, the focus on inclusion and diversity, 
Figure 5.3: How researchers perceive the importance of drivers of change, across disciplines

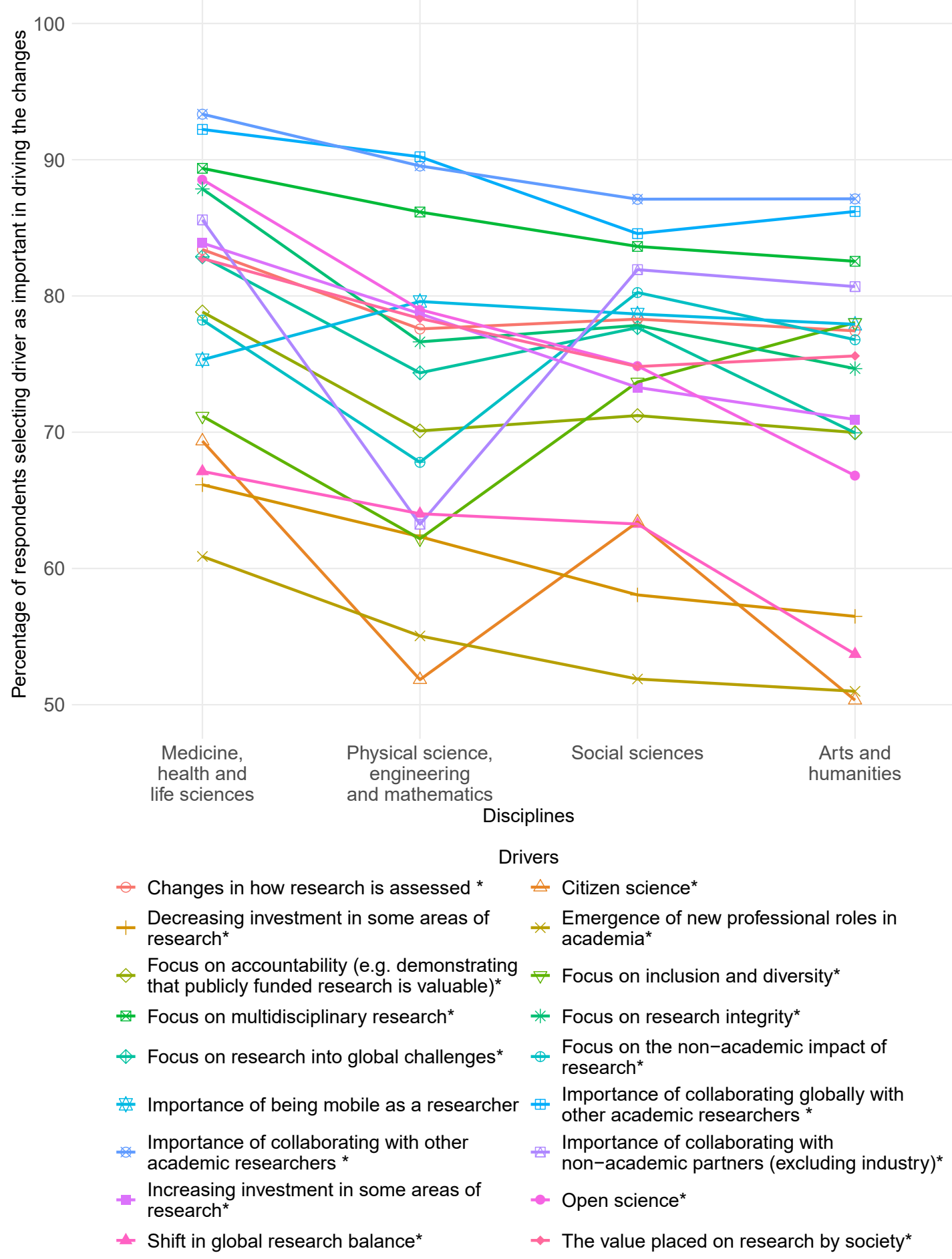

The * on labels represents a significant difference across disciplines.

Drivers are shown if they were selected as important by at least $50 \%$ of respondents from all disciplines. 
Figure 5.4: The top five ranked drivers of change in the research system, across disciplines

\section{Ranking Medicine, health and life sciences}

Physical science, engineering and mathematics
Social sciences

Importance of collaborating with other academic researchers

Importance of collaborating globally with other academic researchers
Arts and humanities

\begin{tabular}{|c|c|c|c|c|}
\hline 1 & $\begin{array}{l}\text { Importance of } \\
\text { collaborating with } \\
\text { other academic } \\
\text { researchers }\end{array}$ & $\begin{array}{l}\text { Importance of } \\
\text { collaborating globally } \\
\text { with other academic } \\
\text { researchers }\end{array}$ & $\begin{array}{l}\text { Importance of } \\
\text { collaborating with } \\
\text { other academic } \\
\text { researchers }\end{array}$ & $\begin{array}{l}\text { Importance of } \\
\text { collaborating with } \\
\text { other academic } \\
\text { researchers }\end{array}$ \\
\hline 2 & $\begin{array}{l}\text { Importance of } \\
\text { collaborating globally } \\
\text { with other academic } \\
\text { researchers }\end{array}$ & $\begin{array}{l}\text { Importance of } \\
\text { collaborating with } \\
\text { other academic } \\
\text { researchers }\end{array}$ & $\begin{array}{l}\text { Importance of } \\
\text { collaborating globally } \\
\text { with other academic } \\
\text { researchers }\end{array}$ & $\begin{array}{l}\text { Importance of } \\
\text { collaborating } \\
\text { globally with } \\
\text { other academic } \\
\text { researchers }\end{array}$ \\
\hline 3 & $\begin{array}{l}\text { Focus on } \\
\text { multidisciplinary } \\
\text { research }\end{array}$ & $\begin{array}{l}\text { Focus on } \\
\text { multidisciplinary } \\
\text { research }\end{array}$ & $\begin{array}{l}\text { Focus on } \\
\text { multidisciplinary } \\
\text { research }\end{array}$ & $\begin{array}{l}\text { Focus on } \\
\text { multidisciplinary } \\
\text { research }\end{array}$ \\
\hline 4 & Open science & $\begin{array}{l}\text { Importance of } \\
\text { being mobile as a } \\
\text { researcher }\end{array}$ & $\begin{array}{l}\text { Importance of } \\
\text { collaborating with } \\
\text { non-academic } \\
\text { partners (excluding } \\
\text { industry) }\end{array}$ & $\begin{array}{l}\text { Importance of } \\
\text { collaborating with } \\
\text { non-academic } \\
\text { partners (excluding } \\
\text { industry) }\end{array}$ \\
\hline 5 & $\begin{array}{l}\text { Focus on research } \\
\text { integrity }\end{array}$ & Open science & $\begin{array}{l}\text { Focus on the non- } \\
\text { academic impact of } \\
\text { research }\end{array}$ & $\begin{array}{l}\text { Focus on inclusion } \\
\text { and diversity }\end{array}$ \\
\hline
\end{tabular}

Colours denote different drivers to visualise the consistency or otherwise of responses across different disciplines.

changes in how research is assessed, and the focus on accountability. There were no significant differences in terms of how respondents from different career stages within arts and humanities rated the importance of any of the drivers of change.

\subsection{Overall, most drivers were seen as more important by PhD students and early-career researchers than by mid-career and established researchers, particularly open science}

The question that asked respondents to rate the importance of different drivers was also analysed by sub-group in order to draw out differences that exist between researchers at 
Figure 5.5: Percentage of respondents reporting a driver as important: Differences across career stages within disciplines

\begin{tabular}{|c|c|c|c|c|c|c|c|c|c|c|c|c|c|c|c|c|}
\hline & \multicolumn{4}{|c|}{$\begin{array}{l}\text { Medicine, health and life } \\
\text { sciences }\end{array}$} & \multicolumn{4}{|c|}{$\begin{array}{c}\text { Physical science, } \\
\text { engineering and } \\
\text { mathematics }\end{array}$} & \multicolumn{4}{|c|}{ Social sciences } & \multicolumn{4}{|c|}{ Arts and humanities } \\
\hline & PhD & $\mathrm{ECR}$ & MCR & ER & $\mathrm{PhD}$ & ECR & MCR & ER & $\mathrm{PhD}$ & ECR & MCR & $E R$ & $\mathrm{PhD}$ & ECR & MCR & ER \\
\hline Importance of collaborating with other academic researchers & 95 & 94 & 91 & 93 & 93 & 90 & 85 & 89 & 95 & 86 & 86 & 85 & 93 & 89 & 87 & 83 \\
\hline Importance of collaborating globally with other academic researchers & 94 & 92 & 92 & 91 & 93 & 90 & 89 & 90 & 92 & 84 & 83 & 82 & 91 & 85 & 87 & 84 \\
\hline Focus on multidisciplinary research & 93 & 91 & 86 & 88 & 88 & 88 & 82 & 84 & 88 & 81 & 82 & 83 & 87 & 81 & 84 & 80 \\
\hline Focus on research integrity & 91 & 88 & 86 & 86 & 81 & 79 & 73 & 72 & 83 & 76 & 75 & 77 & 86 & 70 & 72 & 74 \\
\hline Open science & 94 & 91 & 84 & 86 & 87 & 86 & 73 & 68 & 87 & 74 & 68 & 74 & 70 & 63 & 68 & 68 \\
\hline Changes in how research is assessed & 81 & 84 & 82 & 86 & 76 & 80 & 80 & 74 & 77 & 82 & 80 & 74 & 74 & 85 & 78 & 73 \\
\hline The value placed on research by society & 84 & 81 & 82 & 83 & 80 & 76 & 81 & 78 & 80 & 74 & 71 & 74 & 80 & 72 & 74 & 77 \\
\hline $\begin{array}{l}\text { Importance of collaborating with non-academic partners (excluding } \\
\text { industry) }\end{array}$ & 84 & 86 & 83 & 89 & 63 & 66 & 63 & 61 & 86 & 80 & 83 & 81 & 86 & 81 & 86 & 74 \\
\hline Increasing investment in some areas of research & 84 & 85 & 80 & 86 & 77 & 78 & 77 & 82 & 78 & 71 & 72 & 72 & 74 & 71 & 74 & 66 \\
\hline Importance of being mobile as a researcher & 76 & 74 & 75 & 76 & 79 & 82 & 76 & 82 & 89 & 77 & 79 & 74 & 83 & 80 & 72 & 78 \\
\hline Focus on research into global challenges & 87 & 82 & 78 & 84 & 80 & 75 & 66 & 75 & 80 & 78 & 78 & 76 & 78 & 62 & 77 & 66 \\
\hline Focus on the non-academic impact of research & 86 & 78 & 73 & 76 & 67 & 70 & 66 & 68 & 90 & 80 & 77 & 78 & 78 & 78 & 82 & 72 \\
\hline $\begin{array}{l}\text { Focus on accountability (e.g. demonstrating that publicly funded } \\
\text { research is valuable) }\end{array}$ & 81 & 82 & 75 & 78 & 71 & 72 & 72 & 66 & 80 & 71 & 71 & 66 & 71 & 67 & 75 & 67 \\
\hline Importance of collaborating with industry & 86 & 79 & 80 & 82 & 79 & 78 & 79 & 83 & 75 & 63 & 68 & 59 & 50 & 48 & 50 & 43 \\
\hline Focus on inclusion and diversity & 70 & 76 & 70 & 67 & 70 & 67 & 57 & 52 & 81 & 73 & 72 & 71 & 84 & 77 & 81 & 74 \\
\hline Shift in global research balance & 63 & 64 & 70 & 70 & 62 & 67 & 65 & 64 & 74 & 59 & 57 & 65 & 57 & 45 & 58 & 56 \\
\hline Decreasing investment in some areas of research & 61 & 63 & 61 & 78 & 55 & 58 & 66 & 73 & 58 & 57 & 55 & 61 & 43 & 59 & 56 & 63 \\
\hline Citizen science & 72 & 70 & 70 & 66 & 60 & 58 & 51 & 38 & 76 & 65 & 59 & 57 & 58 & 46 & 54 & 45 \\
\hline The use of metrics (e.g. citation measures) in understanding research & 59 & 61 & 62 & 70 & 57 & 55 & 52 & 56 & 65 & 51 & 56 & 49 & 43 & 47 & 41 & 57 \\
\hline Emergence of new professional roles in academia & 67 & 64 & 61 & 52 & 65 & 59 & 57 & 39 & 63 & 54 & 47 & 45 & 71 & 50 & 46 & 44 \\
\hline
\end{tabular}

Percentages are shown in bold if there is a significant difference across career stages within a discipline. Each cell is shaded from white to dark red according to the percentage of respondents reporting a driver as important. The darker the red, the higher the percentage.

Key: $E C R=$ early-career researcher; $M C R=$ mid-career researcher; $E R=$ established researcher. 
Figure 5.6: How researchers perceive the importance of drivers of change, across career stages

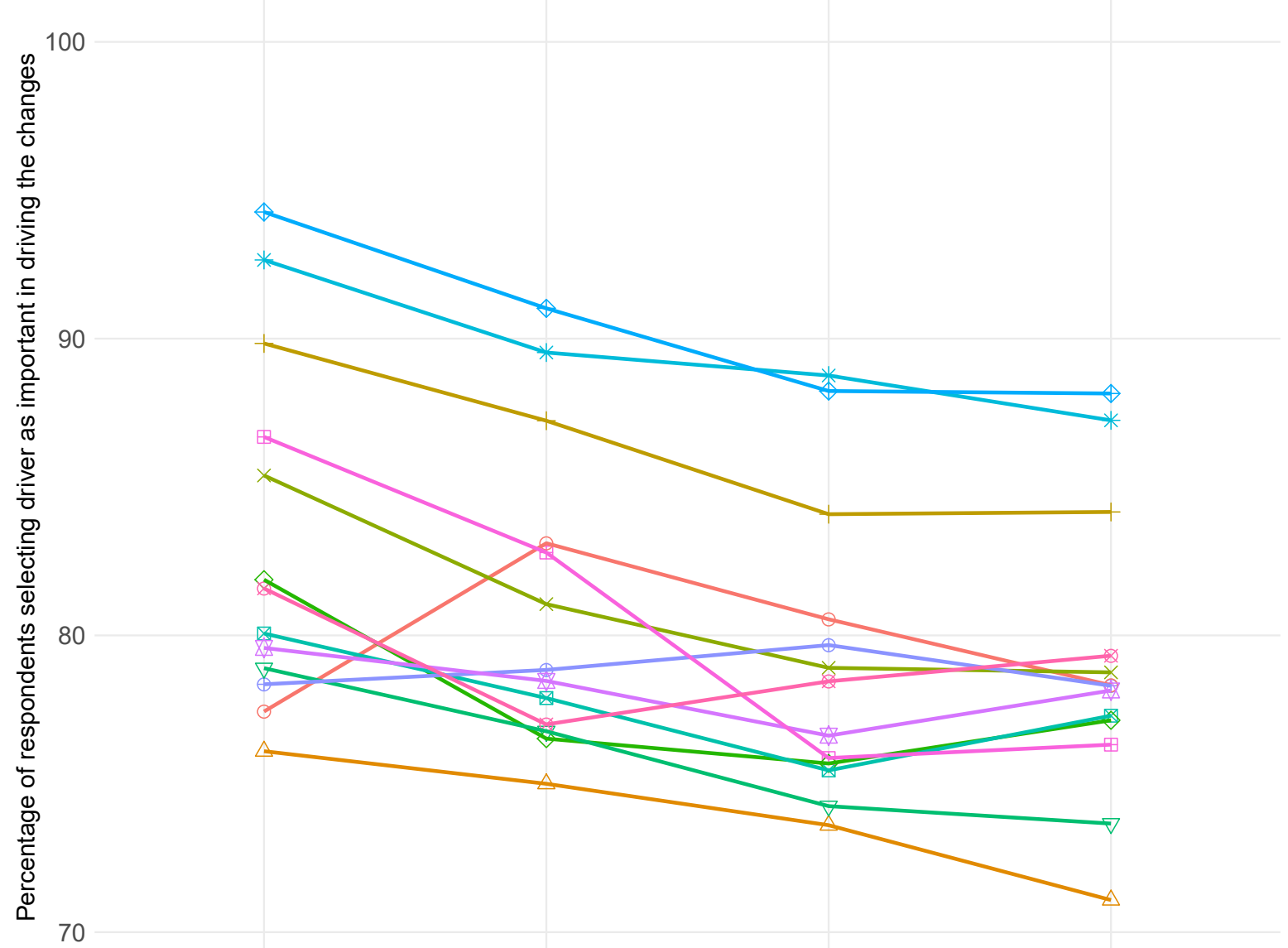

PhD Student Early-career researcher Mid-career researcher Established researcher Career stage

\section{Drivers}

\begin{tabular}{|c|c|}
\hline$\theta$ Changes in how research is assessed & $\begin{array}{l}\text { Focus on accountability (e.g. demonstrating } \\
\text { that publicly funded research is valuable) }\end{array}$ \\
\hline+ Focus on multidisciplinary research* & $*$ Focus on research integrity* \\
\hline$\ominus$ Focus on research into global challenges & $\forall$ Focus on the non-academic impact of research \\
\hline Importance of being mobile as a researcher & $\begin{array}{l}\text { Importance of collaborating globally with } \\
\text { other academic researchers * }\end{array}$ \\
\hline $\begin{array}{l}\text { Importance of collaborating with other } \\
\text { academic researchers * }\end{array}$ & $\begin{array}{l}\text { Importance of collaborating with } \\
\text { non-academic partners (excluding industry) }\end{array}$ \\
\hline $\begin{array}{l}\text { Increasing investment in some areas of } \\
\text { research }\end{array}$ & — Open science* \\
\hline
\end{tabular}


Figure 5.7: Top five ranked drivers of changes in the research system, by career stage

\begin{tabular}{|c|c|c|c|c|}
\hline Ranking & PhD Student & $\begin{array}{l}\text { Early-career } \\
\text { researcher }\end{array}$ & $\begin{array}{l}\text { Mid-career } \\
\text { researcher }\end{array}$ & $\begin{array}{l}\text { Established } \\
\text { researcher }\end{array}$ \\
\hline 1 & $\begin{array}{l}\text { Importance of } \\
\text { collaborating with } \\
\text { other academic } \\
\text { researchers }\end{array}$ & $\begin{array}{l}\text { Importance of } \\
\text { collaborating with } \\
\text { other academic } \\
\text { researchers }\end{array}$ & $\begin{array}{l}\text { Importance of } \\
\text { collaborating globally } \\
\text { with other academic } \\
\text { researchers }\end{array}$ & $\begin{array}{l}\text { Importance of } \\
\text { collaborating with } \\
\text { other academic } \\
\text { researchers }\end{array}$ \\
\hline 2 & $\begin{array}{l}\text { Importance of } \\
\text { collaborating } \\
\text { globally with } \\
\text { other academic } \\
\text { researchers }\end{array}$ & $\begin{array}{l}\text { Importance of } \\
\text { collaborating globally } \\
\text { with other academic } \\
\text { researchers }\end{array}$ & $\begin{array}{l}\text { Importance of } \\
\text { collaborating with } \\
\text { other academic } \\
\text { researchers }\end{array}$ & $\begin{array}{l}\text { Importance of } \\
\text { collaborating } \\
\text { globally with } \\
\text { other academic } \\
\text { researchers }\end{array}$ \\
\hline 3 & $\begin{array}{l}\text { Focus on } \\
\text { multidisciplinary } \\
\text { research }\end{array}$ & $\begin{array}{l}\text { Focus on } \\
\text { multidisciplinary } \\
\text { research }\end{array}$ & $\begin{array}{l}\text { Focus on } \\
\text { multidisciplinary } \\
\text { research }\end{array}$ & $\begin{array}{l}\text { Focus on } \\
\text { multidisciplinary } \\
\text { research }\end{array}$ \\
\hline 4 & Open science & $\begin{array}{l}\text { Changes in how } \\
\text { research is assessed }\end{array}$ & $\begin{array}{l}\text { Changes in how } \\
\text { research is assessed }\end{array}$ & $\begin{array}{l}\text { The value placed on } \\
\text { research by society }\end{array}$ \\
\hline 5 & $\begin{array}{l}\text { Focus on research } \\
\text { Integrity }\end{array}$ & Open science & $\begin{array}{l}\text { Importance of } \\
\text { collaborating with } \\
\text { non-academic } \\
\text { partners (excluding } \\
\text { industry) }\end{array}$ & $\begin{array}{l}\text { Focus on research } \\
\text { integrity }\end{array}$ \\
\hline
\end{tabular}

Shading denotes different drivers to visualise the consistency or otherwise of responses across career stages.

different stages of their careers (Figure 5.6). ${ }^{43}$ Figure 5.7 summarises the top five ranked drivers for each career stage, with each driver shaded a consistent colour. Looking across career stages the top three most important drivers of the changes in the system are the same: Importance of collaborating with other academic researchers, importance of collaborating globally with other academic researchers, and the focus on multidisciplinary research. For all of the top five drivers of change, PhD students and early-career researchers rated them as more important than mid-career researchers and established researchers, and there are significant differences in rating across the career stages.

Figure 5.8 shows the percentage of respondents from each career stage and discipline reporting a driver as being important. Within each career stage there is no significant 
difference across disciplines for the top three drivers of change (importance of collaborating with other academic researchers, importance of collaborating globally with other academic researchers, and focus on multidisciplinary research).

Within each career stage there is a significant difference between disciplines for the importance of collaborating with industry, the importance of collaborating with nonacademic partners (excluding industry), and citizen science (Figure 5.8). For PhD students there is a significant difference between disciplines for focus on inclusion and diversity and focus on the non-academic impact of research. For early-career researchers there is a significant difference between disciplines for open science, shift in global research balance and focus on the non-academic impact of research. For mid-career researchers there is a significant difference between disciplines for open science, focus on inclusion and diversity, and focus on research into global challenges.

For established researchers there is a significant difference between disciplines for open science, focus on inclusion and diversity, focus on research integrity, focus on research into global challenges, changes in how research is assessed, focus on accountability, focus on the non-academic impact of research, increasing investment in some areas of research, and the use of metrics.

\subsection{There are a range of views from researchers on how the research environment needs to adapt to change}

When asked to provide open text responses about how the research environment needs to adapt to the changes foreseen in the outputs and impacts researchers produce (if any), survey respondents $(n=1,930)$ revealed a range of views on the preferred direction of travel for the research environment. The main issues are summarised as follows: 44

- The drive for societal impact is generally seen as positive, although there are many divergent views and desires for change within the impact agenda.

- Dissemination and engagement are seen as important, and are closely tied to the current focus on societal impact.

- The pressure to publish in selective journals is seen as a concern of the current research landscape.

- New forms of output are seen as desirable, but adaptations in the research landscape are needed for them to become more accepted.

- Trends such as increased collaboration and open science will continue to shape the research landscape.

Each of these topics is discussed in the sections below.

\subsubsection{The drive for societal impact is} generally seen as positive, although there are many divergent views and desires for change within the impact agenda

Survey respondents had diverging views on whether the research environment should focus more on societal impact, or whether this is misguided. Of the responses that mentioned societal impact (606 out of 1,930 respondents), about one third ( $n=237$ ) said that the focus on societal impact in the research landscape should increase, while over $20 \%(n=148)$ said that it should decrease. About a third of all 
Figure 5.8: Percentage of respondents reporting a driver as important: Differences across disciplines within career stages

\begin{tabular}{|c|c|c|c|c|c|c|c|c|c|c|c|c|c|c|c|c|}
\hline & \multicolumn{4}{|c|}{ PhD student } & \multicolumn{4}{|c|}{ Early-career researcher } & \multicolumn{4}{|c|}{ Mid-career researcher } & \multicolumn{4}{|c|}{ Established researcher } \\
\hline & A & B & C & $\mathrm{D}$ & A & $\mathrm{B}$ & $\mathrm{C}$ & $\mathrm{D}$ & A & $\mathrm{B}$ & C & $\mathrm{D}$ & A & $\mathrm{B}$ & C & $\mathrm{D}$ \\
\hline Importance of collaborating with other academic researchers & 95 & 93 & 95 & 93 & 94 & 90 & 86 & 89 & 91 & 85 & 86 & 87 & 93 & 89 & 85 & 83 \\
\hline Importance of collaborating globally with other academic researchers & 94 & 93 & 92 & 91 & 92 & 90 & 84 & 85 & 92 & 89 & 83 & 87 & 91 & 90 & 82 & 84 \\
\hline Focus on multidisciplinary research & 93 & 88 & 88 & 87 & 91 & 88 & 81 & 81 & 86 & 82 & 82 & 84 & 88 & 84 & 83 & 80 \\
\hline Focus on research integrity & 91 & 81 & 83 & 86 & 88 & 79 & 76 & 70 & 86 & 73 & 75 & 72 & 86 & 72 & 77 & 74 \\
\hline Open science & 94 & 87 & 87 & 70 & 91 & 86 & 74 & 63 & 84 & 73 & 68 & 68 & 86 & 68 & 74 & 68 \\
\hline Changes in how research is assessed & 81 & 76 & 77 & 74 & 84 & 80 & 82 & 85 & 82 & 80 & 80 & 78 & 86 & 74 & 74 & 73 \\
\hline The value placed on research by society & 84 & 80 & 80 & 80 & 81 & 76 & 74 & 72 & 82 & 81 & 71 & 74 & 83 & 78 & 74 & 77 \\
\hline $\begin{array}{l}\text { Importance of collaborating with non-academic partners (excluding } \\
\text { industry) }\end{array}$ & 84 & 63 & 86 & 86 & 86 & 66 & 80 & 81 & 83 & 63 & 83 & 86 & 89 & 61 & 81 & 74 \\
\hline Increasing investment in some areas of research & 84 & 77 & 78 & 74 & 85 & 78 & 71 & 71 & 80 & 77 & 72 & 74 & 86 & 82 & 72 & 66 \\
\hline Importance of being mobile as a researcher & 76 & 79 & 89 & 83 & 74 & 82 & 77 & 80 & 75 & 76 & 79 & 72 & 76 & 82 & 74 & 78 \\
\hline Focus on research into global challenges & 87 & 80 & 80 & 78 & 82 & 75 & 78 & 62 & 78 & 66 & 78 & 77 & 84 & 75 & 76 & 66 \\
\hline Focus on the non-academic impact of research & 86 & 67 & 90 & 78 & 78 & 70 & 80 & 78 & 73 & 66 & 77 & 82 & 76 & 68 & 78 & 72 \\
\hline $\begin{array}{l}\text { Focus on accountability (e.g. demonstrating that publicly funded research is } \\
\text { valuable) }\end{array}$ & 81 & 71 & 80 & 71 & 82 & 72 & 71 & 67 & 75 & 72 & 71 & 75 & 78 & 66 & 66 & 67 \\
\hline Importance of collaborating with industry & 86 & 79 & 75 & 50 & 79 & 78 & 63 & 48 & 80 & 79 & 68 & 50 & 82 & 83 & 59 & 43 \\
\hline Focus on inclusion and diversity & 70 & 70 & 81 & 84 & 76 & 67 & 73 & 77 & 70 & 57 & 72 & 81 & 67 & 52 & 71 & 74 \\
\hline Shift in global research balance & 63 & 62 & 74 & 57 & 64 & 67 & 59 & 45 & 70 & 65 & 57 & 58 & 70 & 64 & 65 & 56 \\
\hline Decreasing investment in some areas of research & 61 & 55 & 58 & 43 & 63 & 58 & 57 & 59 & 61 & 66 & 55 & 56 & 78 & 73 & 61 & 63 \\
\hline Citizen science & 72 & 60 & 76 & 58 & 70 & 58 & 65 & 46 & 70 & 51 & 59 & 54 & 66 & 38 & 57 & 45 \\
\hline The use of metrics (e.g. citation measures) in understanding research & 59 & 57 & 65 & 43 & 61 & 55 & 51 & 47 & 62 & 52 & 56 & 41 & 70 & 56 & 49 & 57 \\
\hline Emergence of new professional roles in academia & 67 & 65 & 63 & 71 & 64 & 59 & 54 & 50 & 61 & 57 & 47 & 46 & 52 & 39 & 45 & 44 \\
\hline
\end{tabular}

Percentages are in bold if there is a significant difference across disciplines within a career stage. Each cell is shaded from white to dark red according to the percentage of respondents reporting a driver as important. The darker the red, the higher the percentage.

Key: $A$ = medicine, health and life sciences; $B=$ physical sciences, engineering and mathematics; $C=$ social sciences; $D=$ arts and humanities. 
responses that mentioned societal impact $(n=221)$ tended to critique at least some aspects of the current impact agenda. The most common issue discussed by respondents was a concern that the current focus on societal impact leads to more shallow or short-term impacts $(n=90)$, followed by a desire for a clearer definition of societal impact $(n=63)$. Those who wanted a clearer definition of societal impact referred to both the consistency of what constitutes societal impact in general and in specific disciplines, such as in the arts and humanities, which many respondents felt had less clear definitions of social impact. Many respondents also mentioned that societal impact takes time and resources to develop ( $n=62$ ), and that this is not always recognised in how funding is allotted and in how researchers are required to demonstrate impact. Respondents also commented that societal impact is appropriate for some research and researchers, but not for all $(n=51)$, and that the concept of societal impact should be adapted to accommodate differences between researchers and disciplines.

Many respondents said that there is a need for more institutional and sectoral support to achieve societal impact through research $(n=245)$. Those who indicated that the research landscape should focus more on societal impacts ( $n=237)$ in the future tended to also cite a need for increased funding $(n=52)$, with most of these responses highlighting the need to adequately fund impact activities. Respondents who indicated that they would like more focus on societal impact also tended to cite that although societal impacts are now included in processes at the sector level, such as grant applications and research assessments, they are not sufficiently incentivised at an institutional level through mechanisms such as reward and recognition systems (e.g. recruitment and promotion) $(n=49)$. These respondents tended to express that there needs to be a more systematic and deeper focus on societal impact, rather than just 'ticking boxes' in engagement and societal impact activities.

Respondents who said that the focus on societal impact should decrease expressed concerns about the direction that the impact agenda has taken within the research environment. Limitations of assessment included the relevance of measuring impact in some research fields where research does not have a direct application, and the serendipitous nature of impact meaning that it cannot be predicted when the research is commenced. Respondents also felt that by focusing on societal impact as a goal in and of itself, the research agenda and funding may shift away from fundamental or 'blue skies' research, which although has no pre-specified societal objective and involves uncertain impacts, is potentially more meaningful. It was felt that this may increase the perceived loss of academic independence. Others were concerned that the current focus on societal impact underappreciates the intrinsic value of knowledge produced through academic research as it quantifies impacts and focuses on impacts to the economy and the private sector.

of the respondents who thought that the focus on societal impact should decrease $(n=148)$, many also said that funding should change $(n=21)$, with most of these responses expressing that funding should not be granted based on the potential for societal impact. Many also thought that policy should change $(n=13)$, with many commenting on the recent focus of the UK Research Councils on impact, as well as the desire to decrease the weight of the impact portion of the REF exercise $(n=16)$.

\subsubsection{Dissemination and engagement are seen as important, and are closely tied to the current focus on societal impact}

The vast majority of respondents who mentioned wider engagement (187 out of $1,930)$ expressed that an increased focus on 
the dissemination of research findings and engagement with interested stakeholders would be beneficial to the wider societal impact of research $(n=184)$. This was closely tied to the desire for an increased focus on societal impact and the desire for more nontraditional outputs that are accessible to a wider audience. Some respondents expressed that although dissemination and engagement already occur, there should be a deeper or more meaningful engagement of stakeholders, rather than 'tokenistic' engagement to tick boxes in grant requirements.

Many respondents cited the need for more institutional and sectoral support for engagement activities ( $n=190)$, such as more delegated resources for dissemination and engagement $(n=31)$, particularly after producing grant outputs. These respondents tended to cite the need for recognition that dissemination and engagement takes more time and resources than are currently allotted, and that the time spent on dissemination and engagement is time that cannot be spent elsewhere. Respondents who wanted the focus on dissemination and engagement to increase $(n=184)$ also tended to mention the need for more training $(n=13)$ and more integration of engagement activities into institutional reward and recognition systems $(n=12)$ (described further below).

\subsubsection{The pressure to publish in selective journals is seen as a concern of the current research landscape}

Many respondents (244 out of 1,930) mentioned the pressure to publish in selective journals, with over $90 \%$ of these respondents $(n=227)$ expressing that the pressure to publish a large number of outputs in selective journals should decrease. Respondents said that this pressure comes from both their institutions and the wider system. For example, citationbased metrics and individual publishing records are used by some institutions in hiring, promotion and tenure decisions.

Respondents felt that the quality of outputs should be more valued than the quantity of publications in selective high-profile journals, and that there should be more holistic ways of measuring a researcher's or institution's productivity. Respondents in this category tended to also mention the need for different institutional reward and recognition systems $(n=51)$ that take into account more holistic factors besides the quantity of publications in peer reviewed journals. The need for different funding mechanisms was also identified $(n=36)$, with most responses focusing on the need to reduce the pressure to publish a large number of grant outputs. Many respondents who commented on the need to reduce the pressure to publish in selective journals also mentioned the need for different metrics to measure research quality and productivity $(n=20)$.

Some respondents in these categories expressed that the pressure to publish in selective journals disadvantages researchers conducting interdisciplinary and applied research, and makes it risky for researchers to conduct replication studies or studies that may find null results as these are rarely published in selective journals. This type of research can be highly impactful and is important in terms of assuring that research is replicable and robust, and therefore respondents felt that it should not be disincentivised, particularly in light of the reproducibility issues in the sector. ${ }^{45}$ Respondents also commented on the need for

45 In 2005, loannidis published an essay to assess the validity of concerns on the fact that most published research findings are false. Simulations showed that for most study designs and settings it was more likely for a research finding to be false than true. To improve the situation he suggested striving for better powered evidence, introducing enhanced research standards to diminish bias between research conducted by different teams, and improve the understanding of statistics (Ioannidis 2005). 
increased research that is more focused on the research itself rather than quickly publishing outputs, which can only happen when there is less pressure to produce a high number of publications in selective journals. Respondents coined this 'slow science'. Respondents also expressed concerns that the 'publish or perish' mindset in academia prevents researchers from producing alternative outputs that may reach a wider audience than print publications; however, reaching a wider audience is desirable if impact and engagement are to be prioritised.

\subsubsection{New forms of output are seen as desirable, but adaptations in the research landscape are needed for them to become more accepted}

Over $10 \%$ of survey respondents cited the need to improve the quality of research outputs in the future or to publish more diverse outputs (220 out of 1,930), of these, nearly 50\% ( $n=101)$ commented on the need for new forms of output in the future. Many respondents who commented on the need for better and new forms of output in the future also commented on the need for new output forms to be recognised in national research assessment $(n=31)$, the need for them to be valued in institutional reward and recognition systems $(n=30)$, and the need for funding and resources for outputs that are not journal articles $(n=23)$.

When thinking about new forms of output, respondents commented that shorter and more plain-language publications may be more accessible to a wider public audience, as well as to important stakeholders such as policymakers and businesses, who are often key audiences to access for research uptake and impact. However, the counter argument from some survey respondents was that targeting outputs to make research findings and outputs more accessible to the public would lead to over-simplifying complex research topics, which they felt would have negative consequences for research in terms of the quality of outputs produced.

\subsubsection{Trends such as increased collaboration and open science will continue to shape the research landscape}

Respondents cited a number of other developments that they would like to see in the research environment. Under $10 \%$ of respondents (148 out of 1,930) commented on collaboration in some way, and all but five of these responses expressed a desire for collaboration to increase rather than decrease. The responses focused on collaboration with other academics $(n=72)$, collaboration with non-academics $(n=57)$ and international collaborations $(n=18)$. Respondents saw the benefits of collaborative research and 'team science' as including bringing diverse perspectives into research, creating higher quality research and ensuring that research is useful in society. Collaboration was seen by some respondents as a challenge because of the competitive nature of academia and traditional authorship norms that make it risky for researchers to contribute to research in which they will be listed as middle authors. Of the respondents who wanted collaborations with other academics to increase $(n=72)$, many commented on the need for funding $(n=14)$, with many of these commenting on the need for funding for collaborative projects, as well as funding for travel. A small minority of respondents $(n=4)$ in the arts and humanities cited the need to decrease the pressure to collaborate with other academics, arguing that lone researchers produce high-quality work in many research fields.

Under $5 \%$ of respondents (73 out of 1,930) mentioned the open science agenda, with the majority of these responses ( $n=64)$ arguing for a need to focus more on open science and 
open access, including following through on Plan $\mathrm{S} .{ }^{46}$ They argued that making research publications and datasets more accessible would not only increase public engagement with research and help create societal impact, but also help support reproducible science, as replication studies and studies with null results would be available and datasets would be reused more. Of those respondents who wanted the focus on openness to increase, many also mentioned the need for an overhaul of the academic publishing system $(n=20)$ and the need for new funding or funding mechanisms ( $n=15)$, with many of these commenting on open access requirements for funders. A small minority of respondents $(n=6)$ expressed concerns about open science, particularly in the arts and humanities, and commented on the need to protect intellectual knowledge and early-career researchers without permanent posts. These researchers were seen as most at risk, as traditional publication records in selective journals are still seen as important for recruitment and career progression.

Many respondents (57 out of 1,930) also mentioned interdisciplinary research, with all but three of these responses citing the need for more interdisciplinary research, which is often well suited to addressing complex societal issues. Respondents expressed that interdisciplinary research is sometimes seen as challenging because of the nature of research funding in the United Kingdom ( $n=21)$, which they perceived to be siloed, as well as the decreased potential to publish in selective journal, as described above.

\subsection{Changes to support and drive developments need to happen at both an institutional and a sector level}

Respondents who provided open text responses $(n=1,930)$ identified a number of institutional and sectoral mechanisms that may support the changes identified above. These mechanisms can be roughly grouped into three broad categories: a strong need for institutions and the wider research sector to support engagement $(n=190)$, a need to support impact activities ( $\mathrm{n}=245)$, and a need to support the growing workload of academic researchers $(n=224)$. The specific forms of support suggested are provided in Table 5.1.

\subsubsection{Increased funding and new ways to allocate funding are needed to encourage impactful research}

Nearly $20 \%$ of respondents (368 out 1,930 ) to the open text question mentioned funding as a mechanism that may support changes in the research environment. Respondents cited a number of ways that increased funding, changes in funding allocations and changes in funding policy can improve the research environment, or help guide it in the direction that researchers would like to see.

Among the respondents who mentioned funding ( $n=368)$, some cited the need to provide designated funding for impact $(n=52)$ and engagement activities $(n=31)$. They felt many of these activities are currently undertaken by researchers without additional resources, and that specific funding for impact and engagement would incentivise researchers to spend adequate time and

$46 \quad$ Plan S is a mandate that all cOAlition S (an international consortium of research funders) members require that research they fund be published in compliant open access journals and platforms by 2020 (coAlition S 2018). This deadline has now been shifted to 2021 (www.coalition-s.org/revised-implementation-guidance/). 
Table 5.1: Main forms of institutional and sectoral mechanisms to support changes in the research landscape, as suggested by respondents

\begin{tabular}{|c|c|}
\hline Type of support & Number of respondents $(n=1,930)(\%)$ \\
\hline Funding to develop research that has societal impact & $368(19.1 \%)$ \\
\hline $\begin{array}{l}\text { Valuing societal impact and engagement within HEI reward } \\
\text { and recognition systems }\end{array}$ & $180(9.3 \%)$ \\
\hline $\begin{array}{l}\text { Adjusting workload models to take account of work that } \\
\text { develops societal impact }\end{array}$ & $139(7.2 \%)$ \\
\hline $\begin{array}{l}\text { Changes to policy to address concerns about a culture of audit } \\
\text { and the impact of the UK's changing relationship with the EU }\end{array}$ & $93(4.8 \%)$ \\
\hline $\begin{array}{l}\text { Training to develop expertise in engagement, societal impact } \\
\text { and new digital methodologies }\end{array}$ & $91(4.7 \%)$ \\
\hline $\begin{array}{l}\text { Changes to the academic publishing system to increase } \\
\text { openness and improve peer review }\end{array}$ & $52(2.7 \%)$ \\
\hline $\begin{array}{l}\text { Infrastructure to support openness and collaboration on a } \\
\text { global scale }\end{array}$ & $45(2.3 \%)$ \\
\hline $\begin{array}{l}\text { Creation of new roles to take account of work that develops } \\
\text { societal impact }\end{array}$ & $37(1.9 \%)$ \\
\hline IT to support openness and collaboration on a global scale & $17(0.9 \%)$ \\
\hline
\end{tabular}

resources at the end of a project to create impact and to publish non-traditional outputs that are more accessible to key stakeholders $(\mathrm{n}=23)$. Respondents reported that they felt that these activities are not effectively incentivised and sufficiently supported where they were contributing to their institutions' REF submission, as an impact case study. Similarly, some respondents felt that changes to funding schemes could support interdisciplinary research $(n=21)$, which they perceived as currently disadvantaged by funding schemes they viewed as siloed by disciplines.

Conversely, over $5 \%$ of respondents who mentioned that changes to funding are needed cited the desire for a decreased focus on societal impact $(n=21)$, mostly because they felt that funding should not be tied to the potential for research to achieve impact. Some respondents felt that researchers are not the most suited actors to carry out these activities, as most academics are not skilled in engagement and impact, and it is expensive for them to try to create impact.

Similarly, many respondents who mentioned funding cited a need for the United Kingdom to develop a longer term research strategy in terms of what research is funded. They felt that the current approach was focused on the short term and encouraged researchers to create 
'quick' demonstrable impacts rather than longer term impacts that take time to achieve and evidence and that address major societal issues. Some thought that a UK research strategy should prioritise societal impact and major societal challenges, while others thought that it should be aimed at 'blue skies' research $(n=26)$ or 'riskier' projects $(n=16)$ without set objectives. Many of these respondents identified this as a requirement to maintain the United Kingdom's place in terms of cutting edge research and innovation $(n=11)$. Some mentioned that this shift in funding strategy will be especially important as the United Kingdom leaves the European Union ( $n=18)$, with a perception that the ERC currently funds this type of research more frequently than funders within the United Kingdom.

One option identified by respondents was to have a funding stream for engagement and impact that is separate to the funding for conducting the research. ${ }^{47}$ This would allow researchers to bring together separate strands of research that all contribute to a larger impact, and to facilitate impacts that are not tied to a single research output. It would also ensure that funding for impact and engagement does not compete with funding for 'blue skies' research, which would continue to be funded.

Other options mentioned by respondents included allocation policies, such as a desire to expand the diversity of who receives funding in the future beyond the 'usual suspects' of HEls and previous grant holders. To support this, some respondents felt that grant applications should be assessed holistically. There was a perception that the quantity of publications and selectivity of the journals in which they were published was a factor in decision making, even though a number of funders have actively indicated that this is not the case. Similarly, respondents suggested that diverse sources of funding, such as jointly funded projects between public and private sources, and greater diversity in the length of grants would be helpful. Short-term grants with a quick turnaround could allow researchers to take advantage of fleeting opportunities for engagement and impact activities, ${ }^{48}$ while long-term grants could allow researchers to more fully develop research ideas with possibly unpredictable but potentially significant societal impacts. Some respondents also called for more opportunities for researchers to join research projects, for example in research centres or centres of excellence, rather than compete for small pots of money. This would allow larger research projects with the same themes, questions and goals to be collaborative, rather than competitive.

Many respondents commented on the need to streamline the grant application process, citing the amount of time it takes researchers to apply for highly competitive grants. ${ }^{49}$ By making

This is already present through some funders. For example, the Wellcome Trust has developed the Public Engagement Fund for researchers and organisations to use creative approaches to engage the public with health research ('Public Engagement Fund' Wellcome n.d.). Additionally, the Economic and Social Research Council's Festival of Social Science Impact Acceleration Accounts consist of block funding made to research organisations to accelerate impact and allow organisations to respond to impact opportunities ('Impact Acceleration Accounts', Economic and Social Research Council 2019).

48 Previous research by RAND Europe found that focus groups of researchers from Hong Kong were concerned that short-term funding, together with the requirement to publish in order to secure subsequent funding, impacted the type of research questions that could be addressed successfully (Parks et al. 2017).

49 The burden on researchers of grant applications has been previously assessed. For example, an Australian study found that academic researchers spent an average of 38 days preparing a new grant application for the National Health and Medical Research Council (Herbert et al. 2013). Additionally, from an economic perspective it has been estimated that application preparation can account for up to 35\% of the application budget (Guthrie et al. 2018). 
the application process less cumbersome, many researchers expressed that they would have more time to conduct high-quality research and produce outputs. ${ }^{50}$

\subsubsection{New institutional mechanisms for reward and recognition are seen by some as necessary to incentivise high-quality research}

Nearly $10 \%$ of respondents (180 out of 1,930$)$ commented on what institutions could do to incentivise the behaviour that they wanted to promote through reward and recognition systems. For example, respondents said that if institutions would like their researchers to concentrate more on impact $(n=49)$ and engagement $(n=12)$, these need to be valued within the institution and demonstrated through appropriate incentives in terms of recruitment, promotion and tenure. Some respondents felt that there was a disconnect between the proimpact rhetoric of institutions and the incentives that prioritise a high quantity of publications in selective journals or first author publications for career progression $(n=51)$.

Other comments discussed the need for longer term contracts and increased job security, especially for early-career researchers. Respondents felt that greater job security would allow early-career researchers to spend more time conducting research rather than applying for future positions, and would allow researchers to engage in longer term projects without the pressure to publish quickly. Some respondents also expressed a desire for more diverse posts, including more jointly funded posts with industry, more part-time research contracts, and more posts that are focused on engagement and impact.

\subsubsection{Some researchers are concerned with growing academic workloads}

More than $10 \%$ of respondents (224 out of $1,930)$ expressed concern that researchers' workloads are growing, ${ }^{51}$ and that time spent in activities such as teaching $(n=37)$, administration ( $n=39$ ), impact and engagement $(n=85)$, and internal and external audits takes away from time spent on research. To address this, many respondents $(n=139)$ identified the need for revised workload models that consider the non-research activities that researchers are responsible for, or dedicated time to support research workloads. There should also be clearer guidelines on what is expected at an institutional level, for example, respondents expressed that institutions should communicate better with researchers in terms of the amount of time that they should spend on research activities, producing outputs, teaching and creating impact, and engagement, as they felt that it is not possible to dedicate effort to all of these activities at once.

Outside of adjusting workload models, one potential solution to growing workloads identified in the responses was to allocate or outsource different activities (beyond research) to other individuals within the higher education

50 Previous research by RAND Europe found that focus groups of researchers from Hong Kong considered the grant application process to be burdensome and could be streamlined. Researchers felt that increasing the number of applications per year, reducing the length of time it takes to learn the outcome of an application, and reducing the level of declaration currently required could contribute to reducing the burden on applicants (Parks et al. 2017). Time Directive (European Commission 2019b). For example, a study from 2010 found that academics in the UK have worked an average of 50 hours per week since the 1960s, when the figure increased from approximately 40 hours (Tight 2010). There is evidence that this increased workload impacts the wellbeing of researchers, who have a lower wellbeing in this respect than workers in other industries (Kinman \& Wray 2013). A 2013 survey showed that $79 \%$ of $\mathrm{HEl}$ workers reported 'always' or 'often' having to work very intensively, and $50 \%$ reported feeling pressured to work long hours (always or often) (Kinman \& Wray 2013) 
setting (mentioned by 16 of those who expressed concern about workloads, and by 37 respondents in total). Some suggested that this would allow specialisation so that individuals could focus on the areas in which they excel (mentioned by 13 of those who expressed concern about workloads, and 31 respondents in total). It was also suggested that universities may consider hiring impact and engagement officers with specific training in this area. These officers would be allocated a certain amount of time to each department or researcher to help create and monitor societal impact, for example the collection of evidence of impact. However, one concern from an organisational response was that these positions are time-bounded and may vanish post-REF, which would lose the knowledge from the sector and result in a transient workforce if short-term strategies are adopted. Some respondents felt that impact should be integrated into regular research activities so that it was not seen as an add-on, but as an integral part of the research process.

Respondents commented that an individual's focus on the range of activities conducted as an academic may vary depending on the researcher's specific discipline, over the course of a researcher's career, and with differences in natural aptitude.

\subsubsection{Some researchers feel that national policy changes are needed in order to address concerns about the culture of audit and the United Kingdom's changing relationship with the EU}

About $5 \%$ (93 out of 1,930) of respondents made suggestions around national policy in the open text responses. Many were critical of the 'audit culture' in the United Kingdom ( $n=20)$, particularly regarding the time and resources it takes to conduct national research assessment exercises and the knock on implications for internal audits. For example, respondents reported that many institutions conduct mock REF exercises that take time and resources to conduct, and that limit the available time that researchers have to conduct research.

Some respondents also made suggestions for how national policy could address concerns around the United Kingdom's changing relationship with the EU (37 out of 1,930). Respondents particularly identified the need to support and retain researcher mobility, and the importance of maintaining funding for 'blue skies' research and early-career researchers.

\subsubsection{Additional training could fill gaps in researchers' expertise in engagement, impact and new digital methodologies}

Approximately $5 \%$ of respondents (91 out of 1,930 ) identified training as a mechanism that can support changes in the research environment. Some respondents highlighted the need for more training in impact $(n=38)$ and engagement $(n=23)$, as this is an area where researchers, and early-career researchers in particular, lack expertise. In particular they commented that training should include more clarity on what constitutes a societal impact in different fields, social media use, publications for a lay audience, and event management, as well as softer skills such as communication and collaboration with non-academics, especially policymakers and industry. ${ }^{52}$ Some respondents also identified a need to receive training in new digital methodologies such as data visualisation, artificial intelligence and coding. This aligns with responses from sectoral organisations, where respondents suggested that new roles within academia 
may be developed, both to respond to shortterm impact and engagement strategies and to support researchers in incorporating new technology-enabled methods in their research. Roles mentioned included software engineers and statistical support roles.

Some respondents also cited a need for a review of how PhD students are trained in the changing research landscape, particularly in areas such as collaboration, impact and engagement, and transferable skills, due to the limited number of more senior academic positions. Some also cited a perception that there are currently too many PhD students competing for too few roles, and that the number of PhD students trained should take account of the volume of academic opportunities.

\subsubsection{The academic publishing system may need to adapt to changes in how research is conducted and made available}

Less than $5 \%$ of respondents ( 52 out of 1,930 ) identified changes to the academic publishing system that would support changes in the research landscape. One of the most frequent changes discussed was the need for more open access publishing $(n=20)$ and less reliance on traditional selective journals within the research landscape $(n=9)$. Respondents felt that this would help make science more reproducible and rigorous through the open publication of pre-registrations, datasets, replication studies and studies with null results. They also identified that more open access publishing would help save resources by preventing datasets from being duplicated or unused, and would facilitate the publication of non-traditional outputs that are more accessible to a wider audience.
Some respondents to the survey also commented on changes that they would like to see in the peer review system used in publishing, ${ }^{53}$ such as the need for a faster, more efficient process, and the need to avoid publishing decisions perceived as arbitrary and biased. Some commented on the need to ensure that peer reviewers have equal or greater expertise in the research topic than the author of the paper to ensure that a high standard in peer review is met. An option identified in the responses that may increase the quality and efficiency of peer review is to recognise peer reviewers for their contributions by open acknowledgement or reward.

\subsubsection{IT and infrastructural improvements may support changes within the research landscape}

Respondents identified infrastructure (47 out of 1,930) and IT improvements (17 out of 1,930) as being able to support changes in the research landscape, such as the growing number and size of collaborations, interdisciplinary research and open science. Respondents identified the need for open data repositories and open collaboration platforms, along with more interdisciplinary infrastructure at an institutional level, rather than investing in departments that can silo funding, activities and collaboration. To facilitate impact and engagement activities, respondents cited the need for more networks between HEls, policymakers, media contacts and other non-academic stakeholders.

To support high-quality research in response to new technologies and methodologies, respondents suggested computational support and support with statistical modelling and infrastructure to support Al, large datasets and integrated data.

53 Previous research on peer review in the grant application process identified potential improvements to peer review These include asking reviewers both for their rating of the proposal and a measure of their confidence in this rating, introducing an element of randomness into the allocation system in order to acknowledge the difficulty of predicting the future (e.g. a lottery system or a two-stage system), making the application process more valuable for unsuccessfu applicants, and publishing results from evaluations of alternative approaches (Guthrie et al. 2018). 


\section{- How could national research (2) assessment exercises learn from developments in peer review?}

Peer review is defined as 'the process of subjecting an author's scholarly work, research or ideas to the scrutiny of others who are experts in the same field' (International Journal of Computer Applications n.d.). Peer review plays an important role in the research system. It is commonly used to assess research in a number of settings, such as funding allocation, through grant applications and ex-post assessments; journal publications; and selecting oral and poster presentations for conferences (Deveugele \& Silverman 2017; Shergill et al. 2017). It can be (and is being) used to consider all elements of research, from the proposed methodology, manuscripts and finalised outputs themselves, to the environment that research takes place in, and the impact that it has beyond the academy. Peer review activities for researchers have also been developed, such as workshops on group peer review (Dumenco et al. 2017) and collaborative manuscript writing activities (Corcelles et al. 2017).

Within national research assessment in the United Kingdom, peer review is the central method used to evaluate and grade the quality of research outputs, impact and environment. Developments in automated or semiautomated data processing and analysis are likely to change the way research is assessed, and may become more integrated into the research assessment process.
This chapter describes the role and purpose of peer review, and how technology could be used to complement peer review and contribute to the process. It is primarily based on the results of desk research synthesised by the project team, and includes reflections from discussions at the three workshops that aimed to explore how the purpose and process of research assessment may change in the future, the role of peer review in the process of research assessment, and how technology may impact the process of research assessment.

The key findings are:

- Peer review is the predominant method for research assessment in the United Kingdom, and there is no expectation that this will change.

- Technological approaches are expected to further support peer review in the future.

- Cultural shifts, as well as technological shifts, are both needed and happening.

\subsection{Peer review is the predominant method for research assessment in the United Kingdom, and there is no expectation that this will change}

As described above, peer review is used for research assessment across many contexts, such as grant applications, journal 
Figure 6.1: Settings in which peer review occurs
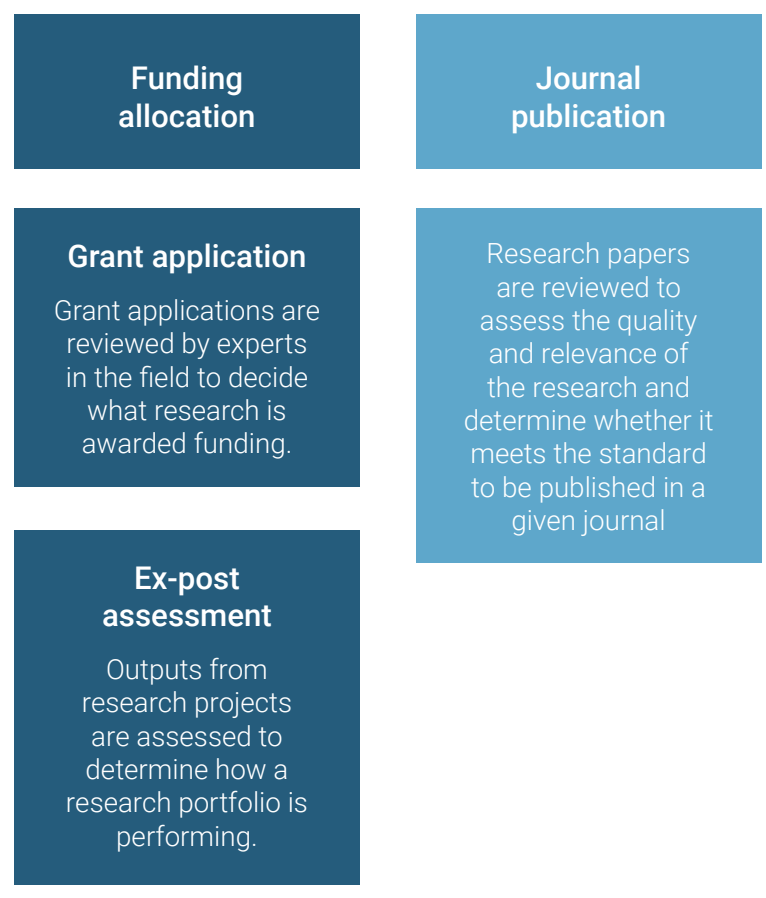

publications, ex-post assessments and conference contributions. Peer review can also be supplemented by metrics, which is the dominant approach in some international contexts (e.g. Norway) (Kolarz et al. 2019). Peer review is currently the predominant method for research assessment in the United Kingdom, and there was no expectation from workshop participants, across all three workshops, that this will change in the next 5 to 10 years.

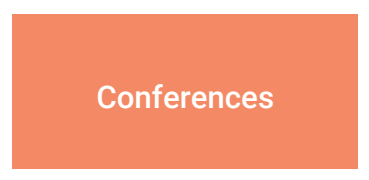

Oral presentations

Abstracts from a research project are reviewed to assess whether the research should be presented orally at a conference.

Poster

presentations

Abstracts from a research project are reviewed to assess whether the research should be presented in the form of a poster at a conference.
National research assessment

Evaluate and grade the quality of research outputs, impact and environment in a given country.
The process of research assessment through peer review involves a number of stages, which may or may not be present in the different settings of research assessment (Figure 6.2).

Typically, the peer review process consists of three stages: a triage stage where items that clearly do not meet the eligibility requirements are rejected, a review stage in which items are reviewed and assessed for quality, and a decision phase where the final outcome

\section{Figure 6.2: The stages of peer review}

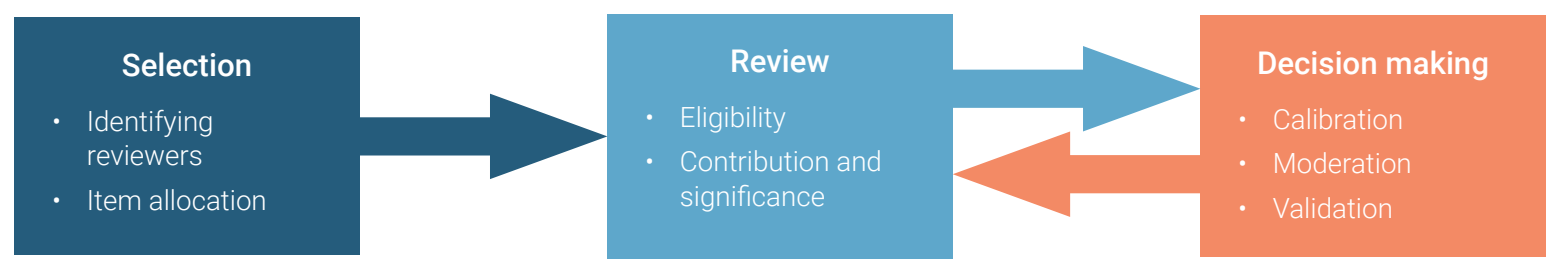


of the review process is determined and communicated (Guthrie et al. 2018). The main role of peer review is in the review stage, which generally involves selecting reviewers, allocating research outputs to reviewers, and assessing and scoring the quality of research. ${ }^{54}$ These different steps are not always present in the different settings for research assessment, and the order in which they are conducted can vary. Further details on each step, and the specific process of peer review in UK national research assessment, are described in Section 6.2.

\subsubsection{Strengths and weaknesses of peer review}

The process of peer review has been widely studied, and a number of strengths and weaknesses have been identified. This section provides a brief overview of some of these strengths and weaknesses in order to set the context within which technological developments may operate, and how they may support or enhance the process currently undertaken.

\section{Strengths}

Peer review 'sets academia apart from all other professions by construing value through peer judgement, not market dynamics' (Biagioli 2002). Participants from the workshops agreed that the peer review process is a highly valued mechanism for research assessment. In the context of academic publishing, peer review is intended to serve two primary purposes (Ware 2008). First, it ensures that only high-quality research is published by determining the validity, significance and originality of research (Kelly et al. 2014). Participants from the peer review workshop, which considered peer review in all contexts, agreed that peer review serves as a quality assurance mechanism. Second, peer review is intended to improve the quality of research and its outputs through suggestions on how to improve the quality of a manuscript or a research proposal. ${ }^{55}$ Participants from the workshops on both peer review and technology also commented that many academics participate in peer review as it provides them with the opportunity to learn and helps them become better scholars.

Peer review also supports and ensures integrity and authenticity in the progress of science. This view was shared by participants from the peer review workshop, who agreed that it serves as a way of providing accountability and enhancing international development. Some believe that 'a scientific statement is generally not accepted by the academic community unless it has been published in a peer reviewed journal' (Mulligan 2005).

Participants from the workshop on peer review commented on the role of peer review in bringing experts into research. Peer review generally relies on the views of more than one expert, which, in the context of publishing, ensures that editors are supported in their decisions by the views of experts (Ware 2008). The evaluation of the impact element of REF 2014 found that there was value in diversifying those classified as experts for the purpose of assessment. For example, it was felt to be successful and valuable to bring together the different perspectives of academics and research users to assess impact case studies and strategies (Manville et al. 2015c). It was widely agreed that the two perspectives moderated each other and added to panellists' confidence in the process.

\footnotetext{
$54 \quad$ These stages have been identified based on the project team's understanding of assessment systems, such as the Research Excellence Framework (REF) (Manville et al. 2015a)

55 There are a number of studies that support this (Ware 2008; Ballantyne et al. 2017; Mulligan et al. 2013)
} 
Some studies of peer review have found a high level of agreement between reviewers on between $80 \%$ and $90 \%$ of manuscripts (Bornmann et al. 2008; Clarke et al. 2016). However, there is also a body of literature that claims inter-reviewer reliability is low (Jirschitzka et al. 2017; Pier et al. 2018), and that peer review is not able to accurately stratify research proposals to identify the most meritorious (Fang \& Casadevall 2016).

There is mixed evidence on the role of collaborative discussion such as panel meetings to improve reviewer agreement, with an argument that they can be subject to collective anchoring effects (the cognitive bias that describes the common human tendency to rely too heavily on the first piece of information offered) (Roumbanis 2017; Derrick \& Samuel 2017). Pina et al. (2015) found that consensus meetings improved agreement where there were high levels of disagreement. However, across all proposals this improvement was not detected. Conversely, when evaluating the process of National Institutes of Health $(\mathrm{NIH})$ research grant applications, Martin et al. (2010) found that meeting discussions had an important effect in more than $13 \%$ of applications (Guthrie et al. 2018).

\section{Weaknesses}

Peer review is often cited as the 'gold standard' for the evaluation of scholarly activities; however, as with any system it has challenges (Biagioli 2002; Enslin \& Hedge 2018; Mayden 2012; Sayer 2014; Wilsdon et al. 2015), such as managing bias effectively, ensuring transparency, minimising burden, and providing incentives through reward and recognition.

Peer review is a human process, and therefore subjective. For example, there are reports in the literature of an advantage or disadvantage to a subset of applicants (e.g. early-career researchers with a limited publication record, or women) (Malikireddy et al. 2017; Risnes 2018; Tamblyn et al. 2018; Wennerås \& Wold 1997) or types of research (e.g. null findings) (Nosek et al. 2015). Peer review seeks to manage subjectivity through the specification of clear criteria and review procedures, including, in some cases, relevant training such as unconscious bias training that seeks to minimise and provide space to challenge conscious or unconscious bias.

Transparency regarding the rules and processes of research assessment is considered by researchers to be an important characteristic of the assessment of research. In many settings, peer review is anonymous. ${ }^{56}$ Anonymity promotes the creation of full and frank review that is not limited by concerns of unreasonable challenge, and reduces the risk of 'status' playing a strong role (Samorodnitsky n.d.; Enago Academy 2018; DeCoursey 2006). Although the principles of the process may be clear, the anonymity of reviewers has contributed to concerns around potential bias in decision making and misuse of reviewer power (Lipworth et al. 2011). There are also concerns that it can contribute to slow peer review and extended publishing times (Jan 2018).

Peer review is time consuming (Huisman \& Smits 2017; Riley \& Jones 2016), and it has been noted that the pool of known peer reviewers does not appear to be expanding at a rate sufficient to accommodate the growth in outputs (Björk 2015; Spearpoint 2017; Van Noorden 2014). The demands of peer review are not necessarily evenly distributed across the sector or aligned with wider incentives, as although there are benefits of participating in peer review, reviewers are not typically 
Figure 6.3: The peer review process and examples of technologies that can support the different stages

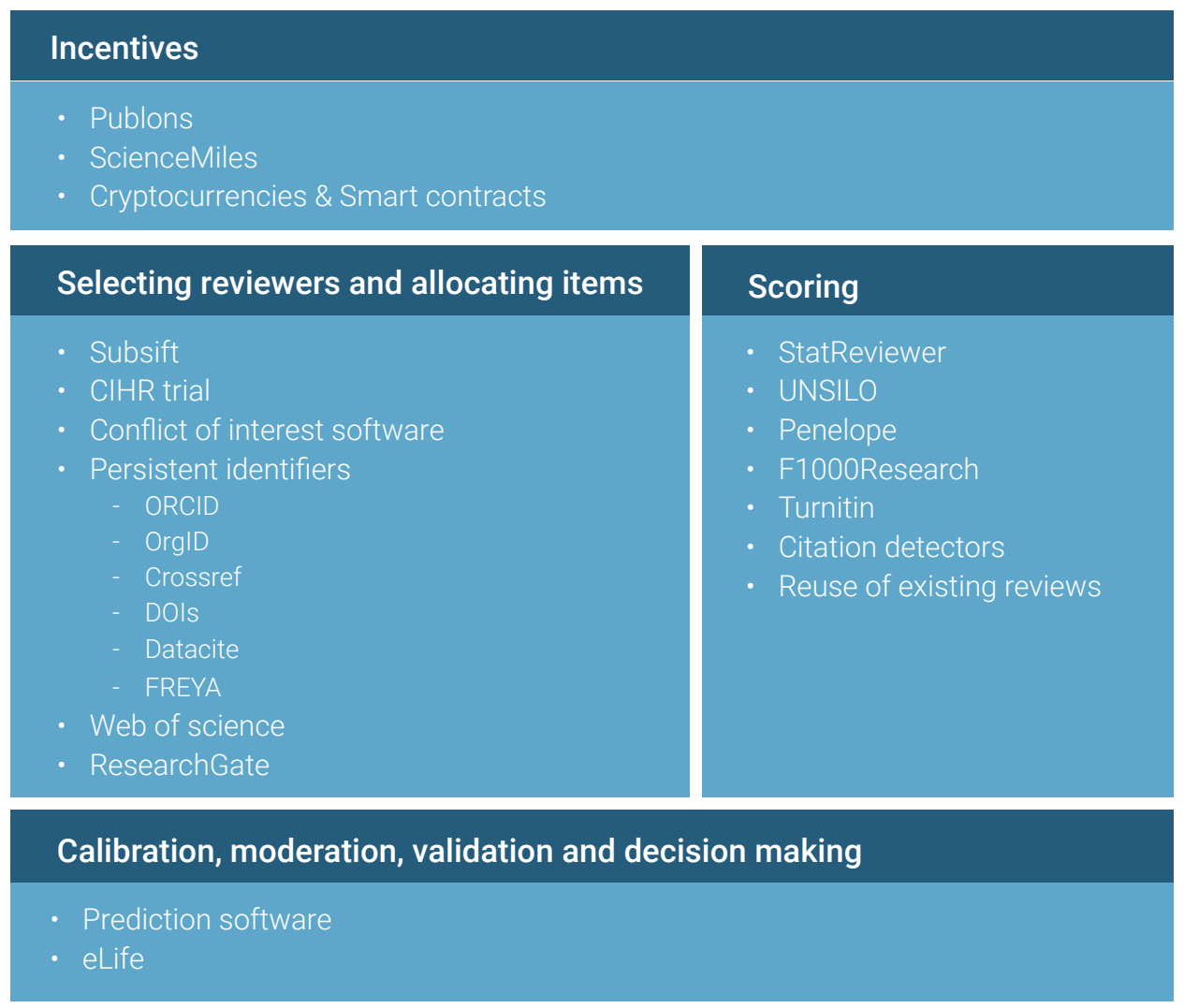

Parts of the process

Examples recognised or rewarded directly for their efforts (Ballantyne et al. 2017).

Participants from workshops on both peer review and technology felt that although the concept of peer review was part of scholarly endeavour, and that it was important and valuable to contribute to peer review, there was concern regarding a lack of recognition and reward, which made it difficult to prioritise. Participants commented that this was less observed in the REF, where panel membership is often associated with some relief of other duties by an employer in recognition of the value of the reviewer's experience of the process more generally. There is also scope for researchers to contribute to the development of the REF process nationally and locally.

\subsection{Technological approaches are expected to further support peer review in the future}

Keeping these strengths and weaknesses in mind, workshop participants across the two workshops focusing on peer review and technology identified a number of areas where technological developments could support or complement the peer review process (Figure 6.3). Workshop participants felt that this was a timely discussion as advances in technology meant that it was possible to do things now which were previously undeliverable due to the scale of data. It was felt that this could enhance the process going forwards. 


\subsubsection{Selecting reviewers and allocating items}

The first step in research assessment by peer review is the selection and recruitment of reviewers. Editorial peer review is generally conducted by two independent reviewers, who are mostly unpaid volunteers viewed as knowledgeable and capable in the subject matter (Ballantyne et al. 2017). Grant application and ex-post assessment peer reviews are generally conducted using a panel of reviewers comprised of two or more reviewers (Manville, Guthrie, Henham, et al. 2015; Parks et al. 2017). Often in these circumstances, two reviewers will review the submission, which is calibrated or moderated with the views of others through discussion.

Peer review holds a central place in national ex-post research assessment as it is the sole method for assessing the quality of research at a national level across all disciplines within the United Kingdom. In other countries, such as Belgium, Italy and Portugal, it is used together with metrics (Kolarz et al. 2019). In the case of the UK REF, main panel and sub-panel members are nominated by members of the academic community and wider stakeholders, and appointed by the four UK funding bodies..$^{57}$ Reviewers are selected to be on panels because of their expertise in the subject area covered by that unit of assessment (Manville, Guthrie, Henham, et al. 2015). The funding councils use the intention to submit process to verify that different research fields within a unit are sufficiently represented by experts. This process, conducted one year before submission, allows HEls to provide an indication of what their submission will look like (REF 2012a). Individual items are then manually allocated by the panel chair to individual reviewers on the panel to review, in line with their knowledge of the subject area.

There can be challenges in identifying reviewers and assigning outputs within the limits of known networks; an increase in demand for review is seen as placing increased burden on a limited pool of reviewers. Participants at the peer review workshop reported that in their experience, it is increasingly necessary to reach out to a larger number of people in order to get positive responses to review requests.

\section{The use of persistent identifiers and text mining can facilitate reviewer selection}

A persistent identifier (PID) is an enduring reference to a resource that is often associated with a set of metadata describing the object. In the context of research, PIDS can be used for items such as publications or researchers (THOR 2019). PIDS could be used to expand the pool of relevant reviewers by serving as a database of active researchers in the different fields and topic areas. A number of persistent identifiers have been developed for research, mainly in a digital format, which has led to the name of digital object identifier (DOI). Such identifiers include ORCiD, Crossref, and Datacite (Box 6.1).

The European Commission has funded a three-year project, FREYA, that aims to 'build the infrastructure for persistent identifiers as a core component of open science'. Goals of the project include (1) improving data discovery by extending and cross-linking PID services, building on existing infrastructure; (2) designing and delivering services for data discovery, resource identification and provenance tracking; (3) integrating the PID Graph (which connects and integrates PID systems) in 


\section{Box 6.1: Description of some current persistent identifiers}

ORCiD: web-based service that provides a non-proprietary alphanumeric code to uniquely identify academic authors. This allows researchers to track contributions and affiliations (ORCiD 2019). Crossref: membership-based organisation that aims to make research outputs easy to find, cite, link and assess. It offers and enables access to a registry of metadata and DOIs for millions of sources, including books, articles, conference proceedings and datasets (Crossref 2016).

the European Open Science Cloud (EOSC); (4) building and promoting a community of practice; and (5) sustaining an open PID e-infrastructure for the broader research community (FREYA 2019).

Online research platforms, such as Web of Science and ResearchGate that catalogue publications, may also facilitate identifying appropriate reviewers. Web of Science enables the simultaneous cross-searching of a range of citation indexes and databases, and offers access to research tools such as citation reports and cited reference searching. The platform also provides personalised features such as saved searches and alerts (University of Sheffield 2019). ResearchGate is a global professional network for scientists and researchers that provides an online platform for members to share and discuss research. It provides members with access to statistics on who is reading and citing their work, as well as the opportunity to connect with peers and specialists, and search for jobs (ResearchGate 2019).

Artificial intelligence and machine learning have been used to profile researchers and match submitted papers to appropriate reviewers based on a full text analysis of the reviewer's previous work in specific contexts. For example, new technologies allow expert reviewers to be taken from an 'open world setting' or from the whole pool of researchers within a certain field, language or geographical area, which reduces reliance on the possibly incomplete knowledge of the known network of a particular journal or funder (Price \& Flach 2017). This process has already been implemented through a web service called SubSift, which was used to profile and match papers and reviewers for a data mining conference where 537 papers were matched to reviewers with high rates of success (Flach et al. 2010). It has also been used in several other major conferences, where a full text analysis of publications available on bibliographic databases has been conducted (Price et al. 2013).

Technologies that make use of text mining can help assign appropriate reviewers. Frameworks have been specified for the use of ontological text mining to cluster papers for review based on full-text analysis. The papers can then be assigned to appropriate reviewers based on their full body of work (Arunachalam et al. 2013; Patil \& Uddin 2015; Srivastava \& Bagwan 2015). Text mining can also be incorporated into conflict of interest software that manages and automates conflict of interest disclosure, attestations, certifications, policies and compliance surveys to help organisations remain compliant.

The use of new technologies is not always well received. In an attempt to reform the former Open Operating Grants Program, the Canadian Institutes of Health Research 
(CIHR) made the decision to replace faceto-face peer review meetings with an online system (Gluckman et al. 2017), which was not well received by the research community. Researchers found the reforms to be poorly designed and rolled out hastily, and stated that this decision had led to unpredictability and a lack of confidence in the review process (Payne 2016a). Following the controversy, CIHR reverted back to face-to-face peer review (Payne 2016b). A participant from the workshop on the purposes of research assessment used the CIHR case as an example of why the use of technology should be implemented carefully and in a progressive manner.

\section{Crowdsourcing and public involvement can contribute to increasing the pool of reviewers}

Crowdsourced peer review shifts the concept of 'peer' in peer review from academic experts to a broader involvement of the public. With this approach, any reviewer or qualified reviewer would be able to openly comment on the paper and suggest revisions, which, with careful moderation, would have the potential to improve the quality of research outputs (Cohen 2017).

The result of crowdsourced peer review would be paper-level metrics that may more accurately reflect the heterogeneous quality of research outputs, compared to journal-level scores, such as impact factors, that do not fully illustrate the quality of each article published within a given publication (Sabater-Mir et al. n.d.). Metrics in which credible researchers are able to award reputational points based on their assessment of the research may increase the speed at which the quality of research is assessed and captured in metrics, and could capture a wider range of views than is currently captured (SabaterMir et al. n.d.; van Rossum 2017). However, these metrics would be susceptible to gaming, for example if those awarding reputational points were closely associated with the author, or if they awarded points transactionally. Crowdsourced peer review has already been implemented in open access publishers such as F1000Prime, where a crowd of relative experts are invited to rate, recommend and comment on published articles, which leads to an evaluation that leverages the wisdom of the crowds (Fresco-Santalla \& Hernández-Pérez 2014; Kovanis et al. 2017).

As mentioned previously, the changing definition of 'peer' in peer review is broadening from disciplinary experts to include those beyond the sector, such as the wider public, which could contribute to increasing the pool of reviewers and diversify the views considered when assessing research quality. This has the potential to decrease bias in panel discussions. For example, panels could be chaired by nonacademics to encourage debate and actively challenge the consensus (Derrick 2018). In 2014, the UK REF included a greater proportion of non-academics in the review panel than in the previous assessment (Derrick 2018; Manville, Guthrie, Henham, et al. 2015). As the public is brought more into research through initiatives to encourage patient and public involvement and engagement (INVOLVE n.d.), the role of nonacademics in research assessment is likely to grow.

\subsubsection{Scoring}

The scoring phase of peer review generally includes two slightly different tasks: an objective measure that the research meets basic requirements of scientific rigour, and a more subjective measure of how much the research contributes to the wider field, and its significance. First, research needs to be scrutinised to ensure that it meets basic eligibility requirements for submission, for example validating the author's identity and institutional associations, and assessing the scientific accuracy of the output. Second, reviewers assess the value of the contribution 
against the scoring criteria. For example, with journal articles this often includes the contribution and significance of the research. Although many factors may come into play when making decisions about contribution and significance, there are some limitations in accurately assessing this aspect of research.

There are two main challenges to the scoring stage of the peer review process: the relevance and ability of the reviewer to review the output; and the context they bring into the process, consciously or unconsciously, that informs their decision. Workshop participants were concerned that as outputs and applications become increasingly interdisciplinary in nature, it is very difficult for a single reviewer to confidently review all aspects of an output.

Specific to national research assessment, participants from the workshops noted that the review and scoring stage of the assessment process could be considered a repetition of work that may already have been carried out (e.g. publications are peer reviewed prior to their publication), although it is important to note that the criteria may vary. More broadly this could also be seen to be the case when journal articles are reviewed following the success of a funding application. However, this may reinforce biases and unfairly prejudice against research that pushes the boundaries or contradicts accepted dogma, where research which is unimaginable is continually assessed in light of these initial views around which subsequent reviews anchor.

\section{Limiting peer review criteria}

New and emerging technologies can automate or partially automate some parts of the peer review process, which may reduce burden by focusing the peer reviewer's efforts on other elements of review, or reduce the risk of bias by removing individual subjectivity from some elements of the process. Tools that can support ensuring an output is eligible include plagiarism software, which validates the author's identity and institutional associations and confirms the scientific accuracy of specific elements, such as statistics. Examples of software to deliver this are listed in Box 6.2.

These kinds of automated or semi-automated artificial intelligence checks can be used to support the traditional peer review system or to assist in the publication of pre-prints in the absence of comprehensive peer review (Tennant et al. 2017). There have also been instances of supervised machine learning completing an automated risk of bias assessments on a set of 1,467 full-text articles, with reasonable success compared to human researchers (Millard et al. 2015). This was used in a systematic review context, but may be possible to use it to support research assessment processes in a wider context.

\section{Box 6.2: Examples of software to support eligibility checks}

Plagiarism detection: e.g. Turnitin highlights similarities between the content of submitted papers and the content of academic papers, webpages and student papers available online (Turnitin 2019).

Review of statistical reporting integrity: e.g. StatReviewer scans manuscripts and assessed standard format statistics from multiple scientific fields, verifying that information such as sample sizes are correctly included (Stat Reviewer 2019). The software generates a report based on the guidelines specified by a given journal, which could be adapted for national research assessment. 


\section{Publish-then-filter model}

In addition to technological developments, the 'peer review light' idea has been gaining popularity as a way of addressing limitations with the current peer review system (Tennant et al. 2017), or of reviewing outputs to ensure that the research was conducted through a scientific process and that conclusions are based on results rather than reviewing to evaluate contribution or significance. With this approach, humans or machines would assess outputs for scientific accuracy, and filter out research that was not conducted according to the scientific process. Crowdsourced peer review would then assess the research for contribution and significance over time. In this scenario, the role of peer review would move from selective gatekeeper to more of an objective filter (Tennant et al. 2017), which may lead to more favourable assessments for studies with null results, studies whose results contradict the current status quo and replication studies (Nosek et al. 2015; Risnes 2018).

\section{Distributed ledger technologies may maximise the knowledge gained through peer review}

Workshop participants agreed that there was a considerable amount of knowledge and information that could be reused across the research process. Participants suggested that reusing information from existing reviews at other stages in the research process, such as grant applications and journal article submissions, could reduce the burden of assessment, facilitate the review process and allow the transfer of knowledge.

Distributed ledger technologies such as blockchain could support this through an immutable file management system accessible to all actors in the research system (Janowicz et al. 2018). This would mean that tamper-proof and permanently linked data, pre-analysis plans and pre-prints could be assessed alongside the final output to ensure that data and protocols are consistent throughout the research process. Others have echoed this use for distributed ledger technologies in making data and research protocols permanent and linking all outputs throughout the research process as a way of helping mitigate reproducibility concerns in science (Kochalko et al. 2018), which may come to play a larger role in the research assessment process as they are integrated into the larger research system. Smart contracts in particular may radically change how research is conducted and assessed as they make it possible for protocols that were previously set in 'blockchain stone' before data was collected to be automatically carried out (van Rossum 2017).

\subsubsection{Calibration, moderation, validation and decision making}

Once an individual reviewer has reviewed an output and provided comments and/or a score, there is usually a level of moderation. This can be conducted through discussion or through independent arbitration, such as by an editor for a journal. In many cases of grant applications and ex-post assessments, such as for the REF, at least two panellists review and score the output prior to the panel discussion. The number of outputs discussed and the depth of discussion on each one will depend on the size and breadth of the panel, the number of submissions, the degree of variation in view, and the length of the meeting. Options include discussing all those that meet the minimum score by both reviewers, those where there is disagreement between the reviewers or those that are borderline. Within the impact element of REF 2014, the review process was decided at a sub-panel level. For example, in some cases the submission was discussed by the reviewers, and if consensus not achieved it 
was escalated to the sub-panel level (Manville, Guthrie, Henham, et al. 2015).

Moderating discussion generally follows the scoring stage. However, in REF 2014 there was a calibration stage for both output and impact assessments at a main panel and sub-panel level, which took place prior to the scoring of all assigned case studies (Manville, Guthrie, Henham, et al. 2015; REF 2012b). Each main panel calibrated a sample of items from their respective sub-panels and shared their views on what constituted impact in each of the sub-panels, as well as across the main panels. This calibration stage ensured consistency of understanding and approach to assessing and evaluating impact (Manville, Guthrie, Henham, et al. 2015).

The peer review process leads to a decision on the quality of the research. The outcome is often linked to a rating or judgement, which has implications for publication or funding. Participants from the workshops commented that the decision-making process was different for editorial publishing and grant applications, and national research assessment.

\section{Using technology to moderate reviews}

In cases where a research output has been assigned to more than one reviewer for assessment, new and emerging technologies can help to reconcile score differences. For example, machine learning can be used to automatically calibrate the scores of individual reviewers based on their previous history of reviews. This technology is enabled by open access for peer review (Price \& Flach 2017).

One digital example of collaborative review is eLife, which is an open access, peer reviewed biomedical journal that uses open internal consultation between reviewers when deciding whether to accept a journal article. Once a decision has been made, eLife makes reviewer decisions and author responses publicly available. Although workshop participants agreed that collaborative review facilitates discussion and increases transparency, they also felt that the process was likely to further increase the burden and expense of peer review.

\subsection{Cultural shifts, as well as technological shifts, are both needed and happening}

When thinking about the future, it is important to consider how peer review and emerging technology fits in with the other trends influencing change. For example, the rise of open science has led to significant changes in how research is conducted (Neylon 2013), and may lead to more significant changes in the future, possibly disrupting the traditional publishing model (Van Noorden 2013; Risnes 2018).

During the workshops on peer review and technology, participants were asked their perspectives on the ongoing developments they envisage in the field of peer review, and to prioritise the topics they thought were most likely to change and that were most beneficial to change (Table 6.1 and Table 6.2). ${ }^{58}$ Participants from the peer review workshop provided insight into the cultural developments around peer review, which have been aligned with the new technologies described in the workshop on technology for this report.

Within both workshops there was misalignment between what participants viewed as developments likely to change within the next 5 to 10 years and the developments participants viewed to be most beneficial to peer review. 
For example, in the peer review workshop, nearly $60 \%$ of votes were allocated to rewarding reviewers and initiatives on equality, diversity and inclusion as changes that would be the most beneficial to peer review. These were also the areas that participants felt were not likely to change in the next 5 to 10 years, which were instead identified as increasing the pool of reviewers, allocating articles, and checking requirements through platforms and automation (nearly $50 \%$ of votes).

Within the technology workshop, participants felt that the most beneficial advances to peer review would be the use of ORCiD, digital preservation and distributed ledger technology, although ORCiD was seen as likely to change in the next 5 to 10 years. Other realistic developments were in areas of reward, such as publons, Al and machine learning techniques.

The responses from organisations identified that caution was needed regarding the potential of technology to be abused, such as the use of machine learning to produce deep fakes or to compromise datasets and codebases, which could lead to a reduction in trust of academic research. It was also noted that although technology could support increased diversity in the types of output and impact possible, it could further disadvantage those taking a career break, for example to look after dependants, due to the speed at which the digital environment and the associated culture changes.

Table 6.1: Views from the workshop on peer review on the areas most likely to change, and those that would be most beneficial to change, in the next 5 to 10 years

\begin{tabular}{|c|c|c|c|}
\hline Developments & $\begin{array}{l}\text { Description and role of the development in peer } \\
\text { review }\end{array}$ & $\begin{array}{l}\text { Likely to } \\
\text { change in } \\
\text { the next } 5-10 \\
\text { years }(\%)\end{array}$ & $\begin{array}{l}\text { Most } \\
\text { beneficial to } \\
\text { peer review } \\
(\%)\end{array}$ \\
\hline $\begin{array}{l}\text { Increasing pool } \\
\text { of reviewers }\end{array}$ & $\begin{array}{l}\text { The development of platforms such as Web of } \\
\text { Science or ResearchGate enable research activities } \\
\text { to be more visible, and therefore contribute to } \\
\text { broadening the pool of reviewers for a given discipline } \\
\text { or topic area. }\end{array}$ & 23.5 & 5.8 \\
\hline Output visibility & $\begin{array}{l}\text { One of the issues raised by participants was regarding } \\
\text { whether the research community was assessing the } \\
\text { most appropriate research outputs or the most visible } \\
\text { research outputs. Increasing the visibility of non- } \\
\text { traditional research outputs (e.g. genome sequences } \\
\text { or databases) could impact how research is assessed. }\end{array}$ & 5.8 & 8.8 \\
\hline $\begin{array}{l}\text { Rewarding } \\
\text { reviewers }\end{array}$ & $\begin{array}{l}\text { Peer reviewing is a time-consuming process. } \\
\text { Compensating researchers for the time spent } \\
\text { reviewing a research output may contribute to more } \\
\text { researchers agreeing to participate in the peer review } \\
\text { process, as well as encourage researchers to provide } \\
\text { reviews in a timely manner. }\end{array}$ & 11.7 & 29.4 \\
\hline
\end{tabular}




\begin{tabular}{|c|c|c|c|}
\hline Developments & $\begin{array}{l}\text { Description and role of the development in peer } \\
\text { review }\end{array}$ & $\begin{array}{l}\text { Likely to } \\
\text { change in } \\
\text { the next } 5-10 \\
\text { years }(\%)\end{array}$ & $\begin{array}{l}\text { Most } \\
\text { beneficial to } \\
\text { peer review } \\
\text { (\%) }\end{array}$ \\
\hline Automation & $\begin{array}{l}\text { Automation refers to the use of technology such as } \\
\text { text mining, artificial intelligence or machine learning } \\
\text { to streamline certain aspects of peer review (e.g. } \\
\text { identifying reviewers and allocating research outputs). }\end{array}$ & 23.5 & 2.9 \\
\hline New metrics & $\begin{array}{l}\text { Participants felt that with an increase in the variety of } \\
\text { research outputs (e.g. databases), new metrics should } \\
\text { be developed to more accurately assess the quality } \\
\text { and impact of research. }\end{array}$ & 14.7 & 0 \\
\hline $\begin{array}{l}\text { Review of } \\
\text { reviews }\end{array}$ & $\begin{array}{l}\text { One of the main issues highlighted by participants } \\
\text { was that knowledge gained through peer review was } \\
\text { usually lost. Participants felt that peer review would } \\
\text { be less burdensome if reviewers could rely on reviews } \\
\text { already carried out. }\end{array}$ & 0 & 2.9 \\
\hline Training & $\begin{array}{l}\text { Providing training to researchers undertaking peer } \\
\text { review could contribute to improving the quality of } \\
\text { reviews. Training could be provided in the form of a } \\
\text { buddy system or through learned societies. }\end{array}$ & 14.7 & 8.8 \\
\hline $\begin{array}{l}\text { Collaborative } \\
\text { review }\end{array}$ & $\begin{array}{l}\text { Collaborative review refers to reviews being conducted } \\
\text { collaboratively between reviewers, rather than having } \\
\text { independent reviews. }\end{array}$ & 0 & 8.8 \\
\hline $\begin{array}{l}\text { Self- } \\
\text { assessment of } \\
\text { confidence }\end{array}$ & $\begin{array}{l}\text { This refers to providing reviewers with a self- } \\
\text { assessment opportunity on whether they have the } \\
\text { desired knowledge to review the entire journal article, } \\
\text { sections of the article, or neither. Experts can be both } \\
\text { topical and methodological, and participants felt that } \\
\text { reviewers should be assessed on both counts. }\end{array}$ & 2.9 & 2.9 \\
\hline $\begin{array}{l}\text { Understanding } \\
\text { of metrics }\end{array}$ & $\begin{array}{l}\text { In addition to the development of new metrics, } \\
\text { participants felt that a better understanding of the } \\
\text { different metrics in place could be beneficial to } \\
\text { research assessment. }\end{array}$ & 0 & 11.7 \\
\hline $\begin{array}{l}\text { Quality } \\
\text { threshold }\end{array}$ & $\begin{array}{l}\text { The scoring stage has a subjective component to it. It } \\
\text { has been suggested that peer review cannot properly } \\
\text { distinguish between two excellent research proposals, } \\
\text { and that it would be better to instate a lottery to } \\
\text { randomly allocate funding among the top applications. } \\
\text { Participants felt that in order to do this a standardised } \\
\text { quality threshold should be developed, and reviewers } \\
\text { should be thoroughly trained on these standards. }\end{array}$ & 2.9 & 0 \\
\hline $\begin{array}{l}\text { Equality, } \\
\text { diversity and } \\
\text { inclusion }\end{array}$ & $\begin{array}{l}\text { Equality, diversity and inclusion initiatives are working } \\
\text { towards removing the biases of traditional publishing. }\end{array}$ & 0 & 29.4 \\
\hline
\end{tabular}


Table 6.2: Views from the workshop on technology on the areas most likely to change, and those that would be most beneficial to change, in the next 5 to 10 years

\begin{tabular}{|l|l|l|}
\hline Technology & $\begin{array}{l}\text { Likely to change in the } \\
\text { next } \mathbf{5} \text { to } \mathbf{1 0} \text { years } \mathbf{( \% )}\end{array}$ & $\begin{array}{l}\text { Most beneficial to peer } \\
\text { review (\%) }\end{array}$ \\
\hline ORCID & 18.2 & 18 \\
\hline $\begin{array}{l}\text { Technology to increase discoverability of research } \\
\text { outputs }\end{array}$ & 9.1 & 6.5 \\
\hline Publons & 20.5 & 9.8 \\
\hline Distributed ledger technology & 2.3 & 13.1 \\
\hline Artificial intelligence & 18.2 & 3.3 \\
\hline Machine learning & 13.6 & 4.9 \\
\hline Sentiment analysis & 2.3 & 1.6 \\
\hline $\begin{array}{l}\text { Automation of the assignment of outputs to peer } \\
\text { review }\end{array}$ & 2.3 & 3.3 \\
\hline Conflict of interest software & 2.3 & 0 \\
\hline Plagiarism software & 0 & 0 \\
\hline Citation detector & 4.5 & 4.9 \\
\hline REF predictors & 2.3 & 0 \\
\hline Preservation (digital) & 2.3 & 14.7 \\
\hline Distributed ledger technology & 2.3 & 13.1 \\
\hline Continuous project reporting & 0 & 6.5 \\
\hline
\end{tabular}




\section{Reflections on how national research assessment may need to adapt to changes in the research landscape}

This chapter provides a summary of the key findings of the report, and reflections across the questions asked in this study. It considers in particular how UK national research assessment may need to adapt to the changing research landscape in terms of adaptations that may be needed to ensure that it continues to assess the key elements of the research landscape, and those that may allow it to incentivise, and potentially drive, desired research cultures.

\subsection{Why assess research, and how might that change in the next 5 to 10 years?}

There are many reasons for assessing research. This study summarises the six 'A's, which expand on the existing four 'A's previously described in the literature (Morgan Jones \& Grant 2013). The six 'A's, accountability, acclaim, advocacy, analysis, allocation and adaptability, are dynamic and interrelated. The purposes for research assessment are both implicit and explicit, which results in a varied understanding and interpretation of purpose by different stakeholders. Over time there has been a shift in the focus of the rationale behind assessment, possibly due to the legitimacy of the aims developing and the different aims gaining popularity or importance within the research system and wider society. Given that the six 'A's are dynamic and interrelated elements for research assessment, they are likely to continue to evolve, and the weight and importance of each ' $A$ ' as a reason for assessment may continue to shift over time. This is particularly visible through the additional emphasis now placed on analysis in terms of the use of research assessment to inform higher education and funding strategies, and acclaim in terms of the ranking of universities and departments according to the research conducted within them at an institutional and national level.

\subsection{How do researchers expect the forms of output they are producing to change in the next 5 to 10 years?}

Researchers expect that the different forms of output they will each produce in the next 5 to 10 years will increase from a mean of 4.7 to a mean of 6.5. Researchers will continue to produce common output forms such as journal articles and conference contributions (currently produced by $85 \%$ and $70 \%$ of respondents, respectively), while also starting to produce less common outputs and outputs aimed at a wider audience. The forms of output with the greatest percentage increase in the number of researchers producing them between now and 5 to 10 years' time are books (authored book, chapter in a book, and edited book), 
non-confidential research reports for external bodies and openly published peer review.

The changes are particularly driven by an expectation of career progression, which brings with it the opportunity or requirement to produce different output forms (e.g. books). Other factors influencing the changes in output forms cited within the survey include the desire to reach new audiences and create impact, as well as wider changes controlled by external bodies (e.g. funding, open access requirements, the REF) or other changes influencing the research landscape (e.g. societal changes and new technology).

There are significant differences in the forms of output being produced by researchers from different disciplines, and some outputs are highly specific to certain disciplines. There are also some significant differences between career stages, although there are fewer differences between career stages than between disciplines.

\subsection{How do researchers expect the types of societal impact their research produces to change in the next 5 to 10 years?}

Researchers expect their research to lead to more types of impact in the future, with the mean number of types of impact increasing from 2.2 to 3.2. The number of respondents who expect that their research will have an impact on society also increases between now and the future, with the percentage of those expecting their research to lead to impact increasing from $77 \%$ to $86 \%$ of respondents. Impact type differs by disciplines, and this is expected to continue.

When asked about the distribution of balance of effort between producing research outputs and impacts, researchers expect the majority of effort to remain on outputs in the future, but with a slight increase of effort spent producing impacts, mainly due to the continued emphasis on the impact agenda and its implications for funding at an individual and institutional level.

The focus on impact may change throughout a researcher's career. Some argue that as research takes time to have an impact it is more common in more established researchers. Others argue that early-career researchers are less likely to be able to invest time and resource on creating impact, as short-term contracts mean that they must prioritise publications. More research could be conducted to understand what can be done to support researchers across career stages deliver impact from their research.

\subsection{How do researchers expect the research environment they are in to change in the next 5 to 10 years?}

Researchers identified a large number of drivers as being important in influencing the changes happening in the research system. Across disciplines the three most important drivers were consistently collaborating with other academic researchers, collaborating globally with other academic researchers, and the focus on multidisciplinary research. However, there were significant differences by discipline in the importance of most of the drivers further down the list.

There were also changes across career stages. Overall, most drivers, particularly open science, were seen as more important by PhD students and early-career researchers than mid-career and established researchers.

Researchers were asked about how the research environment needs to adapt to the changes they foresee in the outputs and impacts they produce. These are important considerations to ensure that new forms of 
output are acceptable in research assessment and other aspects of the sector. Many researchers discussed how they would like the environment to change, and their preferred direction of travel.

The range of topics discussed is presented in Box 7.1. Changes to support and drive developments need to happen at an institutional and a sector level. The specific forms of support suggested by respondents are provided in Box 7.2.

\subsection{How could UK national} research assessment learn from advances in other applications of peer review?

Peer review is currently the predominant method for research assessment in the United Kingdom. It is used across many contexts such as grant applications, journal publications, ex-post assessments and conference contributions. Although it has both strengths

Box 7.1: Factors identified by participants that will shape the research landscape over the next 5 to 10 years

- Societal impact: both to increase and decrease the emphasis on this factor

- Reducing pressure and incentives to produce a large number of research outputs in selective journals.

- Incentivising researchers to produce higher quality and new forms of output to engage a more diverse audience.

- Focusing on dissemination and engagement as routes to societal impact.

- Increasing collaborative research.

- Balancing basic and applied research.

- Making research accessible through open science and open access.

- Increasing support for interdisciplinary research.

\section{Box 7.2: Types of support suggested by survey respondents}

- Funding to develop research that has societal impact.

- Valuing societal impact and engagement within HEl reward and recognition systems.

- Adjusting workload models and the creation of new roles to take into account work to develop societal impact.

- Changes to policy to address concerns about a culture of audit and the impact of the United Kingdom's changing relationship with the EU.

- Training to develop expertise in engagement, societal impact and new digital methodologies.

- Changes to the academic publishing system to increase openness and improve peer review.

- IT and infrastructure to support openness and collaboration on a global scale. 
and weaknesses, there was no expectation from workshop participants, across all three workshops, that its predominance in research assessment will change in the future.

There is, however, an expectation that technological approaches, which already underpin many aspects of peer review, may further support peer review in the future. There are a number of technologies and approaches being developed which span the entire pathway of peer review, from selecting reviewers and allocating items, to scoring, to calibration moderation, validation and decision making, and incentives

However, current technologies are not able to address all the limitations of peer review alone. For example, some areas that participants in the workshop on peer review felt most needed to be addressed, such as equality and diversity issues, may in fact be exacerbated by automation and technological developments if not carefully thought through and adapted when implemented. Additionally, improvements to peer review are likely to require cultural changes, as well as technological changes, and may require additional approaches such as training and incentives

\subsection{Considerations for the future}

As described above, this study has considered three main questions: why is national research assessment carried out and how might that change in the next 5 to 10 years; how might the research landscape, and in particular the forms of output and the types of impact being produced, change in the next 5 to 10 years; and how might the practicalities of national research assessment change, including what can be learnt from developments in technology being applied to other research assessment processes. Across these questions no disruptive changes that would indicate a large or immediate shift in the research landscape have been identified. Instead there are likely to continue to be gradual changes as current drivers within the system develop alongside developments in the external environments (e.g. technological developments). UK national research assessment is therefore likely to need to continue to remain engaged with the sector and respond to changes as they arise or can be anticipated.

\subsubsection{Research assessment needs to continue to consider the diversity of outputs produced by academic research}

It is important that national research assessment can shift with the research landscape. The survey indicated an expected increase in diversity of output forms, with the possibility that research projects may produce a 'basket' of outputs that complement each other, rather than one key output (such as a journal article). The vast majority of outputs that have been submitted to research assessment exercises in the United Kingdom (and considered as important and hence used within promotion and hiring decisions) represent a small number of output forms; they are largely journal articles and books, depending on discipline (Table 7.1). Overall, over $80 \%$ of output submissions to REF 2014 were journal articles, 8\% were chapters in books, $5 \%$ were authored books, and all other output forms made up just $6 \%$ of the submissions. If the increased diversity of output forms is considered valuable to the system and need assessment, then it may be necessary to consider suitable ways to encourage the submission of these forms of output and ensure appropriate capacity to both assess and ensure confidence in the assessment of these outputs. This is because, as shown in this study, national research assessment and funder requirements and policies are drivers of the forms of output researchers produce. 
Table 7.1: The percentage of different output forms submitted to REF 2014 overall and by discipline

\begin{tabular}{|c|c|c|c|c|c|}
\hline \multirow[b]{2}{*}{ Output type } & \multicolumn{5}{|c|}{ Percentage of different output forms submitted (\%) } \\
\hline & $\begin{array}{l}\text { Medicine, } \\
\text { health } \\
\text { and life } \\
\text { sciences }\end{array}$ & $\begin{array}{l}\text { Physical } \\
\text { sciences, } \\
\text { engineering } \\
\text { and } \\
\text { mathematics }\end{array}$ & $\begin{array}{l}\text { Social } \\
\text { sciences }\end{array}$ & $\begin{array}{l}\text { Arts and } \\
\text { humanities }\end{array}$ & $\begin{array}{l}\text { All } \\
\text { disciplines }\end{array}$ \\
\hline Authored book & 0.08 & 0.21 & 7.19 & 16.52 & 5.43 \\
\hline Edited book & 0.01 & 0.02 & 0.82 & 4.30 & 1.12 \\
\hline Chapter in book & 0.11 & 0.43 & 7.91 & 25.51 & 7.54 \\
\hline Journal article & 99.51 & 94.41 & 81.52 & 40.16 & 81.09 \\
\hline Conference contribution & 0.08 & 4.26 & 0.45 & 0.97 & 1.44 \\
\hline $\begin{array}{l}\text { Patent/published patent } \\
\text { application }\end{array}$ & 0.06 & 0.11 & 0.00 & 0.06 & 0.06 \\
\hline Software & 0.00 & 0.03 & 0.02 & 0.03 & 0.02 \\
\hline Website content & 0.01 & 0.02 & 0.05 & 0.31 & 0.08 \\
\hline Performance & 0.00 & 0.00 & 0.00 & 1.24 & 0.26 \\
\hline Composition & 0.00 & 0.00 & 0.00 & 1.70 & 0.35 \\
\hline Design & 0.00 & 0.00 & 0.22 & 0.18 & 0.10 \\
\hline Artefact & 0.00 & 0.01 & 0.03 & 1.80 & 0.38 \\
\hline Exhibition & 0.00 & 0.02 & 0.04 & 3.09 & 0.65 \\
\hline $\begin{array}{l}\text { Research report for external } \\
\text { body }\end{array}$ & 0.11 & 0.06 & 0.96 & 0.24 & 0.36 \\
\hline Devices and products & 0.00 & 0.00 & 0.00 & 0.06 & 0.01 \\
\hline Digital or visual media & 0.00 & 0.00 & 0.01 & 1.21 & 0.25 \\
\hline Scholarly edition & 0.00 & 0.00 & 0.02 & 0.89 & 0.19 \\
\hline $\begin{array}{l}\text { Research datasets and } \\
\text { databases }\end{array}$ & 0.00 & 0.00 & 0.03 & 0.14 & 0.04 \\
\hline Other & 0.02 & 0.04 & 0.09 & 1.21 & 0.29 \\
\hline Working paper & 0.01 & 0.36 & 0.65 & 0.39 & 0.35 \\
\hline
\end{tabular}

Source: REF 2019b

Books are the second most common outputs submitted to REF 2014 (Table 7.1). The survey results indicate that books (or book chapters) are still seen by researchers as aspirational outputs that they wish to produce in the future. This sits alongside a smaller number of comments indicating that books are becoming less important and less relevant. The strong desire to produce books (or book chapters) is seen across disciplines and career stages, and assessment will need to continue to consider 
how wider assessment policy relates to books/ monographs.

\subsubsection{It is important to consider the needs of different disciplines when undertaking a nationwide assessment}

Across outputs, impacts and drivers, there were more significant differences in the survey between disciplines than between career stages. This was particularly strong for impacts, but also very noticeable for outputs and slightly less noticeable for the drivers of change. This reinforces the importance of considering the needs of different disciplines when making decisions about national research assessment, particularly if that assessment will be applied across all disciplines. It is worth noting that disciplinary differences are not expected to increase, rather that disciplinary differences currently exist, and it is not expected that disciplines will become more similar over time.

\subsubsection{Drivers that researchers perceive to be important are generally within the academic system}

While the majority of drivers participants were asked about were considered to be important in driving changes in the system, those that were seen as the most important were more inwardly facing academic drivers rather than drivers related to societal impact. For example, emphasis was placed on the need to collaborate, in general and internationally, the need to focus on multidisciplinary research, the need to focus on research integrity, and a drive towards open science. The questions on impact revealed that a high percentage of researchers expect their research to have greater impact in the future, and that they expect to spend some more of their time on impact in the future, although the majority of time will still be spent on outputs. These results show the increased value being placed on societal impact, although this increased value did not emerge as a primary driver of the system as a whole.

While this research shows how researchers think the outputs and impacts of research will change going forwards, and the trends that are driving them, it did not explicitly address whether the direction of change of the research sector is the 'right' direction, and if the changes are desirable. Further research should try to understand the specific impacts of the drivers identified as being of particular importance, which of these impacts and changes are seen as beneficial, and which are seen as less beneficial. This research could also consider the contributions of different stakeholders (e.g. academics, HEIs, funders and charities) to the drivers. This would allow stakeholders within the system to consider how they can encourage beneficial changes, while considering interventions to guard against the effect of changes seen as less beneficial.

\subsubsection{National research assessment is an important driver of behaviour for the sector}

UK national research assessment needs to continue to consider its own role in the system and how it may drive changes. As the reasons for research assessment shift over time, and more focus is placed on analysis (even if in part due to increased technological capacity to carry out analysis) and adaptation, it is important to acknowledge that research assessment is itself a driver of the research system. While this is exemplified by the behavioural changes that have taken place throughout the research system in the United Kingdom as a result of the introduction of the impact element of the REF, smaller changes to the rules and process of research assessment also influence the system. The existence of the national research assessment also drives the system at an institution and individual 
academic level, as can be seen by how universities deploy scores as a measure of acclaim and the inclusion by some institutions of societal impact as a criterion for reward and recognition. Continued research is needed to understand the incentives and effects and ensure that they encourage a positive research environment.

Initially national research assessment will need to choose whether to reduce burden or provide additional data when considering the role of technology in supporting the peer review process. The research has highlighted a number of technologies which could be implemented to support peer review in the context of national research assessment. When considering which of these should be explored it is important to consider the aim of changing systems. A common discussion in the context of national research assessment is burden, and technological developments bring the opportunity to reduce burden on those organising peer review systems, as well as potentially on those undertaking peer review by improving the supporting systems and architecture. However, across the workshops there were concerns regarding whether national research assessment data were fully utilised. In light of the growing emphasis on data use and analysis to help inform future strategies and learn from experiences, it is worth considering whether technological developments could bring opportunities to improve the utility of the system itself and provide more outputs that could be used for analysis and learning. However, there is a risk that this additional information may, in the short term at least, increase the burden of the process. From a practical point of view, it may be necessary to initially prioritise these aims and select only some types of technology to explore. Regardless of the purpose of technology, it should be noted that potential developments highlighted in this work have not been tested for utility within a national research assessment system - pilots and more research would be needed to test the effectiveness of these tools, how much of a difference they would make to the process, and at what cost. 



\section{References}

Aagaard, Kaare, Carter Bloch \& Jesper W. Schneider. 2015. 'Impacts of PerformanceBased Research Funding Systems: The Case of the Norwegian Publication Indicator.' Research Evaluation 24 (2): 106-17. As of 20 August 2019: https://doi.org/10.1093/reseval/rvv003

Abramo, Giovanni, and Ciriaco Andrea D’Angelo. 2015. 'The VQR, Italy's Second National Research Assessment: Methodological Failures and Ranking Distortions.' Journal of the Association for Information Science and Technology 66 (11): 2202-14. As of 20 August 2019:

https://doi.org/10.1002/asi.23323

Abreu, Maria \& Vadim Grinevich. 2013. 'The Nature of Academic Entrepreneurship in the UK: Widening the Focus on Entrepreneurial Activities.' Research Policy 42 (2): 408-22.

ACIL Allen Consulting. 2013. 'Benefits Realisation Review of Excellence in Research for Australia.' Melbourne: ACIL Allen Consulting.

Adam, Paula, Pavel V. Ovseiko, Jonathan Grant, Kathryn E.A. Graham, Omar F. Boukhris, Anne-Maree Dowd, Gert V. Balling, et al. 2018. 'ISRIA Statement: Ten-Point Guidelines for an Effective Process of Research Impact Assessment.' Health Research Policy and Systems 16 (1): 8. https://doi.org/10.1186/s12961-018-0281-5 Adams, Jonathan. 2013. 'Collaborations: The Fourth Age of Research.' Nature 497 (7451): 557.
---. 2017. 'International Research Collaboration after the UK Leaves the European Union.'

Ancaiani, Alessio, Alberto F. Anfossi, Anna Barbara, Sergio Benedetto, Brigida Blasi, Valentina Carletti, Tindaro Cicero, et al. 2015. 'Evaluating Scientific Research in Italy: The 2004-10 Research Evaluation Exercise.' Research Evaluation 24 (3): 242-55. As of 20 August 2019: https://doi.org/10.1093/reseval/rvv008

Arunachalam, N., E. Sathya, S. Hismath Begum \& M. Uma Makeswari. 2013. 'An Ontology Based Text Mining Framework for R\&D Project Selection.' International Journal of Computer Science \& Information Technology 5 (1): 161.

Assante, Massimiliano, Leonardo Candela, Donatella Castelli, Paolo Manghi, Pasquale Pagano \& C. Nazionale. 2015. 'Science 2.0 Repositories: Time for a Change in Scholarly Communication.' D-Lib Magazine 21 (1/2): 1-14. Association of Universities in the Netherlands, Netherlands Organisation for Scientific Research, and Royal Netherlands Academy of Arts and Sciences. 2014. 'Standard Evaluation Protocol 2015-2021. Protocol for Research Assessments in the Netherlands.'

Atkinson, Peter. 2014. 'Assess the Real Cost of Research Assessment: Nature News \& Comment.' 2014. As of 20 August 2019: https://www.nature.com/news/assess-the-realcost-of-research-assessment-1.16526 
Australian Research Council. 2018. 'Excellence in Research for Australia.' May 24, 2018. As of 20 August 2019:

https://www.arc.gov.au/

excellence-research-australia

Ballantyne, Kaye N., Gary Edmond \& Bryan Found. 2017. 'Peer Review in Forensic Science.' Forensic Science International 277 (August): $66-76$. As of 20 August 2019:

https://doi.org/10.1016/j.forsciint.2017.05.020

Barbaro, Annarita, Donatella Gentili \& Chiara Rebuffi. 2014. 'Altmetrics as New Indicators of Scientific Impact.' Journal of the European Association for Health Information and Libraries 10 (1): 3-6.

BEIS. 2016. 'Building on Success and Learning from Experience - An Independent Review of the Research Excellence Framework.' London: Department for Business, Energy and Industrial Strategy (BEIS). As of 20 August 2019: https://assets.publishing.service.gov.uk/ government/uploads/system/uploads/ attachment_data/file/541338/ind-16-9-refstern-review.pdf

Bhattacharya, Sujit \& Arshia Kaul. 2015. 'Emerging Countries Assertion in the Global Publication Landscape of Science: A Case Study of India.' Scientometrics 103 (2): 387-411.

Biagioli, Mario. 2002. 'From Book Censorship to Academic Peer Review.' Emergences: Journal for the Study of Media \& Composite Cultures 12 (1): 11-45. As of 20 August 2019: https://doi. org/10.1080/1045722022000003435

Björk, Bo-Christer. 2015. 'Have the 'MegaJournals' Reached the Limits to Growth?' PeerJ 3: e981. As of 20 August 2019: https://doi.org/10.7717/peerj.981

Bonney, Rick, Jennifer L. Shirk, Tina B. Phillips, Andrea Wiggins, Heidi L. Ballard, Abraham J. Miller-Rushing \& Julia K. Parrish. 2014. 'Next Steps for Citizen Science.' Science $343(6,178)$ : 1,436-37.
Bornmann, Lutz, Rüdiger Mutz \& Hans-Dieter Daniel. 2008. 'Latent Markov Modeling Applied to Grant Peer Review.' Journal of Informetrics 2 (3): 217-28.

Bozeman, Barry \& Daniel Sarewitz. 2011. 'Public Value Mapping and Science Policy Evaluation.' Minerva 49 (1): 1-23. As of 20 August 2019: https://doi.org/10.1007/s11024-011-9161-7

Brechelmacher, Angelika, Elke Park, Gülay Ates \& David F.J. Campbell. 2015. 'The Rocky Road to Tenure - Career Paths in Academia.' In Academic Work and Careers in Europe: Trends, Challenges, Perspectives. The Changing Academy - The Changing Academic Profession in International Comparative Perspective, edited by Tatiana Fumasoli, Gaële Goastellec \& Barbara M. Kehm, 13-40. Cham: Springer. As of 20 August 2019: https://doi.org/10.1007/978-3-319-10720-2_2

Brown, Sheridan, Rachel Bruce \& David Kernohan. 2015. 'Directions for Research Data Management in UK Universities.' Bristol: Jisc. As of 20 August 2019: http://repository.jisc.ac.uk/5951/4/JR0034 RDM report_200315 v5.pdf

Calver, Michael C., Maggie Lilith \& Christopher R. Dickman. 2013. 'A "Perverse Incentive" from Bibliometrics: Could National Research Assessment Exercises (NRAEs) Restrict Literature Availability for Nature Conservation?' Scientometrics 95 (1): 243-55. As of 20 August 2019: https://doi.org/10.1007/s11192-012-0908-1

Cervantes, Mario \& Dirk Meissner. 2014. 'Commercialising Public Research under the Open Innovation Model: New Trends.' Foresight and STI Governance 8 (3): 70-81.

Clarke, Philip, Danielle Herbert, Nick Graves \& Adrian G. Barnett. 2016. 'A Randomized Trial of Fellowships for Early Career Researchers Finds a High Reliability in Funding Decisions.' Journal of Clinical Epidemiology 69 (January): 147-51. As of 20 August 2019: https://doi.org/10.1016/j.jclinepi.2015.04.010 
cOAlition S. 2018. 'About Plan S.' As of 20 August 2019: https://www.coalition-s.org/

Cohen, Philip. 2017. 'The next Stage of SocArXiv's Development: Bringing Greater Transparency and Efficiency to the Peer Review Process.' LSE Impact Blog. London School of Economics and Political Science.

Corcelles, Mariona, Maribel Cano, Paula Mayoral \& Montserrat Castelló. 2017. 'Enseñar a Escribir Un Artículo de Investigación Mediante La Revisión Colaborativa: Percepciones de Los Estudiantes.' Revista Signos. Estudios De Lingüística. ISSN 0718093450 (95). As of 20 August 2019: https://doi.org/10.4067/ $\underline{\text { S0718-09342017000300337 }}$

Crossref. 2016. 'Our Truths.' 16 November 2016. As of 20 August 2019:

https://www.crossref.org/truths/

Currie, Jan. 2008. 'The Research Assessment Exercise in Hong Kong: Positive and Negative Consequences.' International Education Journal: Comparative Perspectives 9 (1): 47-58.

DataCite. n.d. 'DataCite - Mission.' As of 20 August 2019: https://datacite.org/mission.html DeCoursey, Thomas. 2006. "The Pros and Cons of Open Peer Review." Nature.

https://doi.org/10.1038/nature04991.

Deeming, Simon, Andrew Searles, Penny Reeves \& Michael Nilsson. 2017. 'Measuring Research Impact in Australia's Medical Research Institutes: A Scoping Literature Review of the Objectives for and an Assessment of the Capabilities of Research Impact Assessment Frameworks.' Health Research Policy and Systems 15 (1): 22. As of 20 August 2019: https://doi.org/10.1186/s12961-017-0180-1

Derrick, Gemma. 2018. 'Take Peer Pressure out of Peer Review.' Nature 554 (January): 7. As of 20 August 2019:

https://doi.org/10.1038/d41586-018-01381-y
Derrick, Gemma \& Samuel, Gabrielle. 2017 'The future of societal impact assessment using peer review: Pre-evaluation training, consensus building and inter-reviewer reliability' Palgrave Communications 3: 17040, As of 20 August 2019:

https://www.nature.com/articles/ palcomms 201740

Deveugele, Myriam \& Jonathan Silverman. 2017. 'Peer-Review for Selection of Oral Presentations for Conferences: Are We Reliable?' Patient Education and Counseling 100 (11): 2147-50. As of 20 August 2019 : https://doi.org/10.1016/j.pec.2017.06.007

Dumenco, Luba, D. Engle, K. Goodell, A. Nagler, R. Ovitsh \& S. Whicker. 2017. 'Expanding Group Peer Review: A Proposal for Medical Education Scholarship.' Academic Medicine 92 (2): 147-49. As of 20 August 2019:

https://doi.org/10.1097/

ACM.0000000000001384

Economic and Social Research Council. 2019. 'Impact Acceleration Accounts.' As of 20 August 2019:

https://esrc.ukri.org/collaboration/ collaboration-oportunities/ impact-acceleration-accounts/

El Turabi, Anas, Michael Hallsworth, Tom Ling \& Jonathan Grant. 2011. 'A Novel Performance Monitoring Framework for Health Research Systems: Experiences of the National Institute for Health Research in England.' Health Research Policy and Systems 9 (1): 13. As of 20 August 2019: https://doi.org/10.1186/1478-4505-9-13

Elsevier. n.d. 'International Comparative Performance of the UK Research Base 2016.' As of 20 August 2019: https://www.elsevier.com/ research-intelligence?a=507321 
Elsevier \& Ipsos MORI. 2019. 'Research Futures

- Drivers and Scenarios for the next Decade.'

As of 20 August 2019:

https://www.elsevier.com/connect/

elsevier-research-futures-report

Enago Academy. 2018. 'Open or Blind

Peer Review: Which Is Better?' Enago

Academy (blog). As of 20 August 2019:

https://www.enago.com/academy/

open-vs-blind-peer-review/

Enslin, Penny \& Nicki Hedge. 2018. 'On Peer

Review as the 'Gold Standard' in Measuring

Research Excellence: From Secrecy to

Openness?' Journal of Philosophy of Education

52 (3): 379-396. As of 20 August 2019:

https://doi.org/10.1111/1467-9752.12312

European Commission. 2019a. 'Open Science

Policy Platform.' As of 20 August 2019:

https://ec.europa.eu/research/openscience/

index.cfm?pg=open-science-policy-platform

---. 2019b. 'Working Conditions -

Employment, Social Affairs \& Inclusion.' As of

20 August 2019:

https://ec.europa.eu/social/main.

jsp?catld=706\&langld=en\&intPageld $=205$

Fang, Ferric C. \& Arturo Casadevall. 2016.

'Research Funding: The Case for a Modified Lottery.' MBio 7 (2): e00422-16. As of 20 August 2019: https://doi.org/10.1128/mBio.00422-16

Fecher, Benedikt \& Sascha Friesike. 2014.

'Open Science: One Term, Five Schools of Thought.' In Opening Science, edited by S.

Bartling and Saskia Friesike, 17-47. Cham:

Springer.

Flach, Peter A., Sebastian Spiegler \& Bruno Gol. 2010. 'Novel Tools to Streamline the Conference Review Process: Experiences from SIGKDD'09.' ACM SIGKDD Explorations Newsletter 11 (2): 63-67.

Franceschini, Fiorenzo, and Domenico Maisano. 2017. 'Critical Remarks on the Italian Research Assessment Exercise VQR
2011-2014.' Journal of Informetrics 11 (2):

337-57. As of 20 August 2019:

https://doi.org/10.1016/j.joi.2017.02.005

Fresco-Santalla, Ana \& Tony Hernández-Pérez.

2014. 'Current and Evolving Models of Peer

Review.' The Serials Librarian 67 (4): 373-98. As

of 20 August 2019:

https://doi.org/10.1080/0361526X.2014.985415

FREYA. 2019. 'The FREYA Project.' As of 20

August 2019:

https://www.project-freya.eu/en/about/mission

Geuna, Aldo \& Ben R. Martin. 2003. 'University

Research Evaluation and Funding: An

International Comparison.' Minerva 41 (4): 277-

304. As of 20 August 2019:

https://doi.org/10.1023/

B:MINE.0000005155.70870.bd

Glänzel, Wolfgang \& Lin Zhang. 2018.

'Scientometric Research Assessment in the Developing World: A Tribute to Michael J.

Moravcsik from the Perspective of the Twenty-

First Century.' Scientometrics 115 (3): 1,517-

32. As of 20 August 2019:

https://doi.org/10.1007/s11192-018-2647-4

Gluckman, Sir Peter, Professor Mark Ferguson, Dame Anne Glover, Professor Jonathan Grant, Dr Trish Groves, Dr Michael Lauer \& Professor Mats Ulfendahl. 2017. 'International Peer Review Expert Panel Report: A Report to the Governing Council of the Canadian Institutes of Health Research.'

Greenhalgh, Trisha \& Nick Fahy. 2015.

'Research Impact in the Community-Based Health Sciences: An Analysis of 162 Case Studies from the 2014 UK Research Excellence Framework.' BMC Medicine 13 (1): 232. As of 20 August 2019: https://doi.org/10.1186/s12916-015-0467-4

Guthrie, Susan, Ioana Ghiga \& Steven Wooding. 2018. 'What Do We Know about Grant Peer Review in the Health Sciences?' Santa Monica, CA: RAND Corporation. 
Guthrie, Susan, Anne Kirtley, Bryn Garrod, Alexandra Pollitt, Jonathan Grant, and Steven Wooding. 2016. 'A "DECISIVE" Approach to Research Funding.' Santa Monica, Calif: RAND Corporation. As of 20 August 2019:

https://www.rand.org/pubs/research_reports/ RR1132.html

Guthrie, Susan, Watu Wamae, Stephanie Diepeveen, Steven Wooding \& Jonathan Grant. 2013. 'Measuring Research - A Guide to Research Evaluation Frameworks and Tools.' Santa Monica, Calif.: RAND Corporation, As of 20 August 2019:

https://www.rand.org/pubs/monographs/ MG1217.html

Haustein, Stefanie. 2016. 'Grand Challenges in Altmetrics: Heterogeneity, Data Quality and Dependencies.' Scientometrics 108 (1): 413-23.

HEFCE. 2009. 'Research Excellence Framework: Second Consultation on the Assessment and Funding of Research.' Policy development. Bristol: Higher Education Funding Council for England (HEFCE). As of 20 August 2019: https://dera.ioe.ac.uk/9288/1/09_38.pdf ---. 2017. 'How We Fund Research.' Higher Education Funding Council for England (HEFCE). As of 20 August 2019: https://webarchive.nationalarchives.gov. uk/20180319121626/http://www.hefce.ac.uk/ rsrch/funding/

Herbert, Danielle L., Adrian G. Barnett, Philip Clarke \& Nicholas Graves. 2013. 'On the Time Spent Preparing Grant Proposals: An Observational Study of Australian Researchers.' BMJ Open 3 (5): e002800. As of 20 August 2019: https://doi.org/10.1136/bmjopen-2013-002800

Hesse-Biber, Sharlene \& R. Burke Johnson. 2013. 'Coming at Things Differently: Future Directions of Possible Engagement with Mixed Methods Research.' Journal of Mixed Methods Research 7 (2): 103-109. As of 20 August 2019: https://doi.org/10.1177/1558689813483987
Hill, Steven. 2016. 'Assessing (for) Impact: Future Assessment of the Societal Impact of Research.' Palgrave Communications, As of 20 August 2019: https://doi.org/10.1057/palcomms.2016.73 ---. 2017. 'The Fifth A of Assessing Impact.' 4 December 2017. As of 20 August 2019: http://stevenhill.org.uk/ the-fifth-A-of-assessing-impact/

Hinrichs, Saba, Adam Kamenetzky, Louise Borjes \& Jonathan Grant. 2015. 'The NonAcademic Impact of International Development Research in UK Higher Education.' Policy Research Paper. London: UK Collaborative on Development Sciences (UKCDS).

Hodonu-Wusu \& James Oluwaseyi. 2018. 'Open Science: A Review on Open Peer Review Literature.' Library Philosophy \& Practice.

Holland, Charlotte, Francesca Lorenzi \& Tony Hall. 2016. 'Performance Anxiety in Academia: Tensions within Research Assessment Exercises in an Age of Austerity.' Policy Futures in Education 14 (8): 1,101-16. As of 20 August 2019: https://doi.org/10.1177/1478210316664263

Huisman, Janine \& Jeroen Smits. 2017. 'Duration and Quality of the Peer Review Process: The Author's Perspective.'

Scientometrics 113 (1): 633-50. As of 20 August 2019:

https://doi.org/10.1007/s11192-017-2310-5

International Journal of Computer Applications. 2019. 'Peer Review.' As of 20 August 2019: https://www.ijcaonline.org/peer-review-

INVOLVE. 2019. 'What Is Public Involvement in Research?' As of 20 August 2019:

https://www.invo.org.uk/find-out-more/ what-is-public-involvement-in-research-2/

Ioannidis, John P.A. 2005. 'Why Most Published Research Findings Are False.' PLOS Medicine 2 (8): e124. As of 20 August 2019: https://doi.org/10.1371/journal.pmed.0020124 
Jan, Zeeshan. 2018. 'Recognition and Reward System for Peer-Reviewers.' In CEUR Workshop Proceedings, CEUR-WS.org, 2181 pp. 46-54, 2181:46-54. CEUR-WS. org.

Janowicz, Krzysztof, Blake Regalia, Pascal Hitzler, Gengchen Mai, Stephanie Delbecque, Maarten Fröhlich, Patrick Martinent \& Trevor Lazarus. 2018. 'On the Prospects of Blockchain and Distributed Ledger Technologies for Open Science and Academic Publishing.' Semantic Web, no. Preprint: 1-11.

Jirschitzka, Jens, Aileen Oeberst, Richard Göllner \& Ulrike Cress. 2017. 'Inter-Rater Reliability and Validity of Peer Reviews in an Interdisciplinary Field.' Scientometrics 113 (2): 1,059-92. As of 20 August 2019: https://doi.org/10.1007/s11192-017-2516-6

Johnes, Jill \& Jim Taylor. 1992. 'The 1989 Research Selectivity Exercise: A Statistical Analysis of Differences in Research Rating between Universities at the Cost Centre Level.' Higher Education Quarterly 46 (1): 67-87. As of 20 August 2019:

https://doi.org/10.1111/j.1468-2273.1992. tb01585.x

Johnston, James \& Alan Reeves. 2017.

'Assessing Research Performance in UK Universities Using the Case of the Economics and Econometrics Unit of Assessment in the 1992-2014 Research Evaluation Exercises.' Research Evaluation 26 (1): 28-40. As of 20 August 2019:

https://doi.org/10.1093/reseval/rvw021

Jonkers, Koen \& Thomas Zacharewicz. n.d. 'Research Performance Based Funding Systems: A Comparative Assessment,' Publications Office of the European Union 108.

Kamenetzky, Adam, Saba Hinrichs-Krapels, Steven Wooding \& Jonathan Grant. 2016. 'An Analysis of the Impact of Research Supported by the UK National Institute of Health
Research.' Conference proceedings. Kings

College London.

Karlsson, Sara. 2017. 'Evaluation as a Travelling Idea: Assessing the Consequences of Research Assessment Exercises.' Research Evaluation 26 (2): 55-65. As of 20 August 2019: https://doi.org/10.1093/reseval/rvx001

Kehm, Barbara M. 2015. 'Academics and New Higher Education Professionals:

Tensions, Reciprocal Influences and Forms of Professionalization.' In Academic Work and Careers in Europe: Trends, Challenges, Perspectives. The Changing Academy - The Changing Academic Profession in International Comparative Perspective, edited by Tatiana Fumasoli, Gaële Goastellec \& Barbara M. Kehm, 177-200. Cham: Springer. As of 20 August 2019: https://doi.org/10.1007/978-3-319-10720-2_9

Kelly, Jacalyn, Tara Sadeghieh \& Khosrow Adeli. 2014. 'Peer Review in Scientific Publications: Benefits, Critiques, \& A Survival Guide.' EJIFCC 25 (3): 227-43.

Kings College London \& Digital Science. 2015. 'The Nature, Scale and Beneficiaries of Research Impact - An Initial Analysis of Research Excellence Framework (REF) 2014 Impact Case Studies.'

Kinman, Gail \& S Wray. 2013. 'Higher Stress: A Survey of Stress and Well-Being among Staff in Higher Education.' University and College Union.

Kochalko, David, Courtney Morris \& Jason Rollins. 2018. 'Applying Blockchain Solutions to Address Research Reproducibility and Enable Scientometric Analysis.' Leiden: Centre for Science and Technology Studies (CWTS).

Kolarz, Peter, Erik Arnold, Felix Dijkstal, Kalle Nielsen \& Kristine Farla. 2019. 'International Landscape Study of Research and Innovation Systems.' Technopolis. 
Kovanis, Michail, Ludovic Trinquart, Philippe Ravaud \& Raphaël Porcher. 2017. 'Evaluating Alternative Systems of Peer Review: A LargeScale Agent-Based Modelling Approach to Scientific Publication.' Scientometrics 113 (1): $651-71$

Kwiek, Marek. 2015. 'The Internationalization of Research in Europe: A Quantitative Study of 11 National Systems from a Micro-Level Perspective.' Journal of Studies in International Education 19 (4): 341-59.

Kwok, Jen Tsen. 2013. 'Impact of ERA Research Assessment on University Behaviour and Their Staff.' NTEU National Policy and Research Unit.

Li, Jun. 2016. 'The Global Ranking Regime and the Reconfiguration of Higher Education: Comparative Case Studies on Research Assessment Exercises in China, Hong Kong, and Japan.' Higher Education Policy 29 (4): 473-93. As of 20 August 2019: https://doi.org/10.1057/s41307-016-0015-7

Lightowler, Claire \& Christine Knight. 2013. 'Sustaining Knowledge Exchange and Research Impact in the Social Sciences and Humanities: Investing in Knowledge Broker Roles in UK Universities.' Evidence \& Policy: A Journal of Research, Debate and Practice 9 (3): 317-34.

Lipworth, Wendy, Ian H. Kerridge, Stacy M. Carter \& Miles Little. 2011. 'Should Biomedical Publishing Be 'Opened Up'? Toward a ValuesBased Peer-Review Process.' Journal of Bioethical Inquiry 8 (3): 267-80. As of 20 August 2019:

https://doi.org/10.1007/s11673-011-9312-4

Lupton, Deborah. 2014. "'Feeling Better Connected": Academics' Use of Social Media.' Canberra: News \& Media Research Centre, University of Canberra.

Malikireddy, Dastagiri Reddy, Madeline Jens, Amarette Filut, Anupama Bhattacharya, Elizabeth L. Pier, You Geon Lee, Molly Carnes
\& Anna Kaatz. 2017. 'Network Analysis of NIH Grant Critiques.' Proceedings of the 2017 IEEE/ ACM International Conference on Advances in Social Networks Analysis and Mining 2017 ASONAM '17, 240-43. Sydney: ACM Press. As of 20 August 2019:

https://doi.org/10.1145/3110025.3116212

Manville, Catriona, Susan Guthrie, MarieLouise Henham, Bryn Garrod, Sonia Sousa, Anne Kirtley, Sophie Castle-Clarke \& Tom Ling. 2015a. 'Assessing Impact Submissions for REF2014: An Evaluation,' 109. HEFCE (Higher Education Funding Council for England). As of 20 August 2019:

https://www.rand.org/pubs/research_reports/ RR1032.htm

Manville, Catriona, Saba Hinrichs, Sarah Parks, Adam Kamenetzky, Salil Gunashekar, Benedict Wilkinson \& Jonathan Grant. 2015b. 'Characteristics of High-Performing Research Units - A Preliminary Analysis.'

https://www.kcl.ac.uk/sspp/policy-institute/ publications/Characteristics-of-highperforming-research-units-FINAL.pdf Manville, Catriona, Molly Morgan Jones, Michael Frearson, Sophie Castle-Clarke, MarieLouise Henham, Salil Gunashekar \& Jonathan Grant. 2015c. 'Preparing Impact Submissions for REF 2014: An Evaluation - Findings and Observations.' HEFCE (Higher Education Funding Council for England). As of 20 August 2019:

https://www.rand.org/pubs/research_reports/ RR727.html

Manville, Catriona, Molly Morgan Jones, MarieLouise Henham, Sophie Castle-Clarke, Michael Frearson, Salil Gunashekar \& Jonathan Grant. 2015d. 'Preparing Impact Submissions for REF 2014: An Evaluation - Approach and Evidence.' HEFCE (Higher Education Funding Council for England). As of 20 August 2019:

https://www.rand.org/pubs/research_reports/ $\underline{\text { RR726.html }}$ 
Marques, Marcelo, Justin J.W. Powell, Mike Zapp \& Gert Biesta. 2017. 'How Does Research Evaluation Impact Educational Research? Exploring Intended and Unintended Consequences of Research Assessment in the United Kingdom, 1986-2014.' European Educational Research Journal 16 (6): 820-42. As of 20 August 2019 : https://doi.org/10.1177/1474904117730159

Martin, Ben R. 2011. 'The Research Excellence Framework and the 'Impact Agenda': Are We Creating a Frankenstein Monster?' Research Evaluation 20 (3): 247-54. As of 20 August 2019: https://doi.org/10.3152/0958202 11X13118583635693

Martin, Michael R., Andrea Kopstein \& Joy M. Janice. 2010. 'An Analysis of Preliminary and Post-Discussion Priority Scores for Grant Applications Peer Reviewed by the Center for Scientific Review at the NIH.' PLOS ONE 5 (11). As of 20 August 2019: https://doi.org/10.1371/journal.pone.0013526

Martin-Sardesai, Ann, Helen Irvine, Stuart Tooley \& James Guthrie. 2017. 'Organizational Change in an Australian University: Responses to a Research Assessment Exercise.' The British Accounting Review 49 (4): 399-412. As of 20 August 2019:

https://doi.org/10.1016/j.bar.2017.05.002

Maskeliūnas, Saulius, Ulf Sandström \& Eleonora Dagienè. 2015. 'Evolution of Research Assessment in Lithuania 20052015.' Proceedings of Issi 2015 Istanbul: 15th International Society of Scientometrics and Informetrics Conference.

Mayden, Kelley D. 2012. 'Peer Review: Publication's Gold Standard.' Journal of the Advanced Practitioner in Oncology 3 (2): 117-22.

McGilvray, Annabel. 2014. 'Research Assessment: The Limits of Excellence.' Nature 511 (July): S64-66. As of 20 August 2019: https://doi.org/10.1038/511S64a
Millard, Louise A.C., Peter A. Flach \& Julian P.T. Higgins. 2015. 'Machine Learning to Assist Risk-of-Bias Assessments in Systematic Reviews.' International Journal of Epidemiology 45 (1): 266-77.

Mingers, John. n.d. 'Throwing Out the Baby with the Bathwater: The Undesirable Effects of National Research Assessment Exercises on Research.' Canterbury: Kent Business School, University of Kent. As of 20 August 2019:

https://arxiv.org/ftp/arxiv/ papers/1502/1502.00658.pdf

Molas-Gallart, Jordi. 2015. 'Research Evaluation and the Assessment of Public Value.' Arts and Humanities in Higher Education 14 (1): 111-26. As of 20 August 2019: https://doi.org/10.1177/1474022214534381

Morgan Jones, Molly \& Jonathan Grant. 2013. 'Making the Grade: Methodologies for Assessing and Evidencing Research Impact.' In 7 essays on impact. DESCRIBE Project Report for Jisc. Exeter: University of Exeter.

Morgan Jones, Molly, Catriona Manville \& Joanna Chataway. 2017. 'Learning from the UK's Research Impact Assessment Exercise: A Case Study of a Retrospective Impact Assessment Exercise and Questions for the Future.' The Journal of Technology Transfer, As of 20 August 2019:

https://doi.org/10.1007/s10961-017-9608-6

Mulligan, A. 2005. 'Is Peer Review in Crisis?' Oral Oncology 41 (2): 135-41. As of 20 August 2019:

https://doi.org/10.1016/j. oraloncology.2004.11.001

Mulligan, Adrian, Louise Hall \& Ellen Raphael. 2013. 'Peer Review in a Changing World: An International Study Measuring the Attitudes of Researchers.' Journal of the American Society for Information Science and Technology 64 (1): 132-61. As of 20 August 2019: https://doi.org/10.1002/asi.22798 
Nature Index. 2018. 'A Guide to the Nature Index.' As of 20 August 2019:

https://www.nature.com/magazine-assets/ d41586-018-02904-3/d41586-018-02904-3.pdf

Neylon, Cameron. 2013. 'Architecting the Future of Research Communication: Building the Models and Analytics for an Open Access Future.' PLoS Biology 11 (10): e1001691.

NIHR. n.d. 'Metrics Dashboard.' As of 20 of August 2019:

https://www.nihr.ac.uk/about-us/how-we-aremanaged/our-structure/systems/researchinformation/metrics-dashboard.html

Nosek, B.A, G. Alter, G.C. Banks, D. Borsboom, S.D. Bowman, S.J. Breckler, S. Buck, et al. 2015. 'Promoting an Open Research Culture.' Science 348 (6,242): 1,422-25.

ORCiD. 2019. 'Our Mission.' As of 20 August 2019 . https://orcid.org/about/what-is-orcid/mission

Pajić, Dejan. 2015. 'Globalization of the Social Sciences in Eastern Europe: Genuine Breakthrough or a Slippery Slope of the Research Evaluation Practice?' Scientometrics 102 (3): 2,131-50. As of 20 August 2019: https://doi.org/10.1007/s11192-014-1510-5

Parks, Sarah, Catriona Manville, Katherine Stewart, Louise Lepetit, Marie-Louise Henham, Miaoqing Yang \& Joanna Chataway. 2017. 'A Review of the Hong Kong Research Grants Council.' University Grants Committee of Hong Kong (UGC), As of 20 August 2019: https://www.rand.org/pubs/research_reports/ RR2289.html

Patil, Snehal Shivaji \& S.A. Uddin. 2015.

'Research Paper Selection Based on an Ontology and Text Mining Technique Using Clustering.' J Comput Eng 17 (1): 65-71.

Payne, Elizabeth. 2016a. 'CIHR Backs down from Research Financing Reform.' Ottawa Citizen. As of 20 August 2019:

https://ottawacitizen.com/news/local-news/ cihr-backs-down-from-research-financing-reform
---. 2016b. 'Scientists Urge Health Minister to Stop "Failed Experiment" at ClHR.' Ottawa Citizen. As of 20 August 2019:

https://ottawacitizen.com/news/local-news/ scientists-urge-health-minister-to-stop-failedexperiment-at-cihr

Penfield, Teresa, Matthew J. Baker, Rosa Scoble, and Michael C. Wykes. 2014.

"Assessment, Evaluations, and Definitions of Research Impact: A Review." Research Evaluation 23 (1): 21-32. https://doi.org/10.1093/reseval/rvt021

Pier, Elizabeth L., Markus Brauer, Amarette Filut, Anna Kaatz, Joshua Raclaw, Mitchell J. Nathan, Cecilia E. Ford \& Molly Carnes. 2018. 'Low Agreement among Reviewers Evaluating the Same NIH Grant Applications.' Proceedings of the National Academy of Sciences 115 (12): 2,952-57. As of 20 August 2019: https://doi.org/10.1073/pnas.1714379115 Pina, David G., Darko Hren \& Ana Marušić. 2015. 'Peer Review Evaluation Process of Marie Curie Actions under EU's Seventh Framework Programme for Research.' PLOS ONE 10 (6): e0130753. As of 20 August 2019: https://doi.org/10.1371/journal.pone.0130753

Piwowar, Heather A. \& Todd J. Vision. 2013. 'Data Reuse and the Open Data Citation Advantage.' PeerJ PrePrints 1:e1v1. As of 20 August 2019:

https://doi.org/10.7287/peerj.preprints.1v1

PLOS ONE. 2019. 'PLOS ONE: Journal Information.' As of 20 August 2019: https://journals.plos.org/plosone/s/ journal-information

Price, Simon \& Peter A. Flach. 2017. 'Computational Support for Academic Peer Review: A Perspective from Artificial Intelligence.' Communications of the ACM 60 (3): $70-79$. 
Price, Simon, Peter A. Flach, Sebastian Spiegler, Christopher Bailey \& Nikki Rogers. 2013.

'SubSift Web Services and Workflows for Profiling and Comparing Scientists and Their Published Works.' Future Generation Computer Systems 29 (2): 569-81.

Rebora, Gianfranco \& Matteo Turri. 2013. 'The UK and Italian Research Assessment Exercises Face to Face.' Research Policy 42 (9): 1,657-66.

REF. 2011. 'Assessment Framework and Guidance on Submissions.' Bristol: Research Excellence Framework.

---. 2012a. 'Invitation to Complete the Research Excellence Framework (REF) Survey of Submission Intentions: REF 2014.' Bristol: Research Excellence Framework. https://www.ref.ac.uk/2014/pubs/ surveysubmit/

---. 2012b. 'Panel Criteria and Working Methods: REF 2014.' Bristol: Research Excellence Framework. As of 20 August 2019: https://www.ref.ac.uk/2014/media/ref/content/ pub/panelcriteriaandworkingmethods/01_12. pdf

---. 2019a. 'Guidance on Submissions REF 2021.' Bristol: Research Excellence Framework. ---. 2019b. 'Download submission data' webpage. As of 22 August 2019:

https://results.ref.ac.uk/ (S(41wezbilcaxf3dcoiveaq3zo))/ DownloadSubmissions/ByForm/REF2 --- n.d. 'REF 2021: Nominating Bodies.'

Bristol: Research Excellence Framework. As of 20 August 2019:

https://www.ref.ac.uk/media/1129/ref-2021nominating-bodies.pdf

Research Assessment Exercise. 2009. 'RAE 2008.' As of 20 August 2019:

https://www.rae.ac.uk/
ResearchGate. 2019. 'ResearchGate - Press

Page.' As of 20 August 2019:

https://www.researchgate.net/press

Rhoods, Samira \& Anca Babor. 2018. 'The Future of Global Research: A Case Study on the Use of Scenario Planning in the Publishing Industry.' Learned Publishing 31 (3): 254-60. As of 20 August 2019:

https://doi.org/10.1002/leap.1152

Ribeiro, Leonardo Costa, Márcia Siqueira Rapini, Leandro Alves Silva \& Eduardo Motta Albuquerque. 2018. 'Growth Patterns of the Network of International Collaboration in Science.' Scientometrics 114 (1): 159-79. As of 20 August 2019:

https://doi.org/10.1007/s11192-017-2573-x

Riley, Benjamin Joshua \& Roger Jones. 2016. 'Peer Review: Acknowledging Its Value and Recognising the Reviewers.' The British Journal of General Practice: The Journal of the Royal College of General Practitioners 66 (653): 629-30. As of 20 August 2019: https://doi.org/10.3399/bjgp16X688285

Risnes, Steinar. 2018. 'Need for a Change in Scientific Publishing.' Nordic Perspectives on Open Science 0 (1): 13-29. As of 20 August 2019:

https://doi.org/10.7557/11.4509

Roumbanis, Lambros. 2017. 'Academic Judgments under Uncertainty: A Study of Collective Anchoring Effects in Swedish Research Council Panel Groups.' Social Studies of Science 47 (1): 95-116. As of 20 August 2019:

https://doi.org/10.1177/0306312716659789

Rousidis, Dimitris, Emmanouel Garoufallou, Panos Balatsoukas \& Miguel-Angel Sicilia. 2014. 'Metadata for Big Data: A Preliminary Investigation of Metadata Quality Issues in Research Data Repositories.' Information Services \& Use 34 (3-4): 279-86. 
Sabater-Mir, Jordi, Francisco Grimaldo \& Mario Paolucci. n.d. 'Peer Review as a Reputation System.'

Samorodnitsky, Dan. 2019. 'Should Peer Review Stop Being Anonymous?' Massive Science. As of 20 August 2019: https://massivesci.com/articles/ peer-review-anonymous-signed/

San Francisco Declaration on Research Assessment. 2012. 'San Francisco Declaration on Research Assessment.' As of 20 August 2019: https://sfdora.org/read/

Sayer, Derek. 2014. 'Time to Abandon the Gold Standard? Peer Review for the REF Falls Far Short of Internationally Accepted Standards.' LSE Impact Blog. 19 November 2014. London School of Economics and Political Science. As of 20 August 2019:

https://blogs.Ise.ac.uk/ impactofsocialsciences/2014/11/19/ peer-review-metrics-ref-rank-hypocrisies-sayer/ Scanlon, Eileen. 2014. 'Scholarship in the Digital Age: Open Educational Resources, Publication and Public Engagement.' British Journal of Educational Technology 45 (1): 12-23.

Schiltz, Marc. 2018. 'Science without Publication Paywalls: COAlition S for the Realisation of Full and Immediate Open Access.' PLoS Medicine 15 (9): e1002663.

Scottish Funding Council. 2019. 'Research Excellence Framework.' As of 20 August 2019: http://www.sfc.ac.uk/research/researchexcellence/research-excellence.aspx

Shergill, Ravi, Hussam Kaka, Sean A. Kennedy \& Mark O. Baerlocher. 2017. 'Publication Rates of Abstracts Presented at Major Interventional Radiology Conferences.' Diagnostic and Interventional Radiology 23 (6): 435-40. As of 20 August 2019:

https://doi.org/10.5152/dir.2017.16499

Siebert, Sabina, Laura M. Machesky, and Robert H. Insall. 2015. 'Point of View: Overflow in Science and Its Implications for Trust.' Elife 4: e10825.

Sigl, Lisa. 2016. 'On the Tacit Governance of Research by Uncertainty: How Early Stage Researchers Contribute to the Governance of Life Science Research.' Science, Technology, \& Human Values 41 (3): 347-74.

Sivertsen, Gunnar. 2018. 'Why Has No Other European Country Adopted the Research Excellence Framework?' LSE Impact Blog. 3 February 2018. London School of Economics and Political Science. As of 20 August 2019: http://blogs.Ise.ac.uk/politicsandpolicy/whyhas-no-other-european-country-adopted-theresearch-excellence-framework/

Smart, Warren. 2009. 'The Impact of the Performance-Based Research Fund on the Research Productivity of New Zealand Universties.' Wellington: Ministry of Education. As of 20 August 2019:

https://www.educationcounts.govt. nz/publications/tertiary_education/ education-research/49897

Spearpoint, Michael. 2017. 'A Proposed Currency System for Academic Peer Review Payments Using the Blockchain Technology.' Publications 5 (3): 19.

Spezi, Valerie, Simon Wakeling, Stephen Pinfield, Claire Creaser, Jenny Fry \& Peter Willett. 2017. 'Open-Access Mega-Journals: The Future of Scholarly Communication or Academic Dumping Ground? A Review.' Journal of Documentation 73 (2): 263-83.

Srivastava, Ratish \& A.B. Bagwan. 2015. 'Classification and Assignment of Research Papers Using Ontology Based Hybrid Approach.'

Stat Reviewer. 2019. 'Stat Reviewer: Automated Statistical Support for Journals and Authors.'

As of 20 August 2019: http://www.statreviewer.com/ 
Symplectic. 2019. 'A Brief Timeline of Open Access.' As of 20 August 2019: https://symplectic.co.uk/open-access-timeline/

Tamblyn, Robyn, Nadyne Girard, Christina J. Qian \& James Hanley. 2018. 'Assessment of Potential Bias in Research Grant Peer Review in Canada.' CMAJ 190 (16): E489-99. As of 20 August 2019: https://doi.org/10.1503/cmaj.170901

Tennant, Jonathan P., Jonathan M. Dugan, Daniel Graziotin, Damien C. Jacques, François Waldner, Daniel Mietchen, Yehia Elkhatib, Lauren B. Collister, Christina K. Pikas \& Tom Crick. 2017. 'A Multi-Disciplinary Perspective on Emergent and Future Innovations in Peer Review.' F1000Research 6.

THOR. 2019. 'What Are Persistent Identifiers? Overview.' As of 20 August 2019: https://project-thor.readme.io/docs/ introduction-to-persistent-identifiers

Tight, Malcolm. 2010. 'Are Academic Workloads Increasing? The Post-War Survey Evidence in the UK.' Higher Education Quarterly 64 (2). As of 20 August 2019:

https://doi. org/10.1111/j.1468-2273.2009.00433.x

Tijssen, Robert, Wout Lamers \& Alfredo Yegros. 2017. 'UK Universities Interacting with Industry: Patterns of Research Collaboration and InterSectoral Mobility of Academic Researchers.' Centre for Global Higher Education Working Paper Series N, 14.

Turnitin. 2019. 'Turnitin: Education with Integrity.' As of 20 August 2019: https://www.turnitin.com/

Universities UK. 2019. 'The UK Forum for Responsible Research Metrics.' As of 20 August 2019: https://www.universitiesuk.ac.uk/policy-andanalysis/research-policy/open-science/Pages/ forum-for-responsible-research-metrics.aspx
University of Sheffield. 2019. 'The University Library - Web of Science.' As of 20 August 2019:

https://www.sheffield.ac.uk/library/cdfiles/wos

Van Noorden, Richard. 2013. 'Open Access: The True Cost of Science Publishing.' Nature News $495(7,442): 426$.

---. 2014. 'Online Collaboration: Scientists and the Social Network.' Nature News 512 (7,513): 126.

van Rossum, Joris 2017. 'Blockchain for Research - Perspectives on a New Paradigm for Scholarly Communication.' Digital Science. As of 20 August 2019: https://doi.org/10.6084/m9.figshare.5607778

Ware, Mark. 2008. 'Peer Review: Benefits, Perception and Alternatives.' Publishing Research Consortium.

Watermeyer, Richard. 2015. 'Lost in the 'Third Space': The Impact of Public Engagement in Higher Education on Academic Identity, Research Practice and Career Progression.' European Journal of Higher Education 5 (3): 331-47.

Webb, Jeremy. 2016. 'The Hell of Uncertainty.' New Scientist $231(3,086): 44-45$.

Weingart, Peter. 2013. 'The Loss of Trust and How to Regain It: Performance Measures and Entrepreneurial Universities.' In Trust in Universities. Vol. 86.

Weinstein, Netta, James Wilsdon, Jennifer Chubb \& Geoffrey Haddock. 2019. 'A Pilot Study to Examine the Feasibility of a Longitudinal Evaluation of Perceptions and Attitudes Towards REF 2021: Working Paper on Key Findings.' Cardiff University \& The University of Sheffield. As of 20 August 2019: https://osf.io/preprints/socarxiv/78aqu 
Wellcome. n.d. 'Empowering UK Universities: How Strategic Institutional Support Helps Research Thrive.' London: Wellcome Trust. As of 20 August 2019:

https://wellcome.ac.uk/sites/default/files/ empowering-uk-universities-how-strategicinstitutional-support-helps-research-thrive.pdf

Wellcome. 2019. 'Public Engagement Fund.' As of 20 August 2019:

https://wellcome.ac.uk/funding/schemes/ public-engagement-fund

Wennerås, Christine \& Agnes Wold. 1997. 'Nepotism and Sexism in Peer-Review.' Nature 387 (6631): 341-43. As of 20 August 2019: https://doi.org/10.1038/387341a0

"What Is Disruptive Technology? - Definition from Whatls.Com." n.d. Whatls.Com. Accessed August 23, 2019.

https://whatis.techtarget.com/definition/ disruptive-technology

Witty, Andrew. 2013. 'Encouraging a British Invention Revolution: Sir Andrew Witty's Review of Universities and Growth.'

Wolff, Jonathan. 2015. 'Has the Research Excellence Framework Been Drowned out by Its Own Noise?' The Guardian. 27 January 2015. As of 20 August 2019:

https://www.theguardian. com/education/2015/jan/27/ research-excellence-framework-university

Wooding, Steven, S. Hanney, M. Buxton, and J. Grant. 2005. 'Payback Arising from Research Funding: Evaluation of the Arthritis Research Campaign.' Rheumatology (Oxford, England) 44 (9): 1,145-56. As of 20 August 2019: https://doi.org/10.1093/rheumatology/keh708
Wooding, Steven, Stephen Hanney, Alexandra Pollitt, Martin Buxton \& Jonathan Grant. 2011. 'Project Retrosight: Understanding the Returns from Cardiovascular and Stroke Research:

The Policy Report.' Santa Monica, Calif.: RAND Corporation. As of 20 August 2019:

https://www.rand.org/pubs/monographs/ MG1079.html

Wooding, Steven, Alexandra Pollitt, Sophie Castle-Clarke, Gavin Cochrane, Stephanie Diepeveen, Susan Guthrie, Marcela HorvitzLennon, et al. 2013. 'Mental Health Retrosight. Understanding the Returns from Research (Lessons from Schizophrenia): Policy Report.' Product Page. Santa Monica, Calif.: RAND Corporation. As of 20 August 2019: https://www.rand.org/pubs/research_reports/ RR325.html

Zacharewicz, Thomas, Benedetto Lepori, Emanuela Reale \& Koen Jonkers. 2018. 'Performance-Based Research Funding in EU Member States: A Comparative Assessment.' Science and Public Policy 46 (1): 105-115. As of 20 August 2019:

https://doi.org/10.1093/scipol/scy041

Zhou, Yingying. 2015. 'The Rapid Rise of a Research Nation.' Nature 528 (7,582): S170-73. 



\section{Annex A. Methodology}

\section{A.1. Methodology overview}

This study considers the following questions in relation to the current research system and possible changes to the research environment in the next 5 to 10 years:

- Why do we assess research and how might that change in the next 5 to 10 years?

- How do researchers expect the forms of output they are producing to change in the next 5 to 10 years?
- How do researchers expect the types of societal impact their research produces to change in the next 5 to 10 years?

- How do researchers expect the research environment they are in to change in the next 5 to 10 years?

- How could national research assessment exercises learn from developments in peer review?

The methodological approach to this study is broadly summarised in Figure A.1 and Table A. 1 below.

\section{Figure A.1: Methodology used in this study}

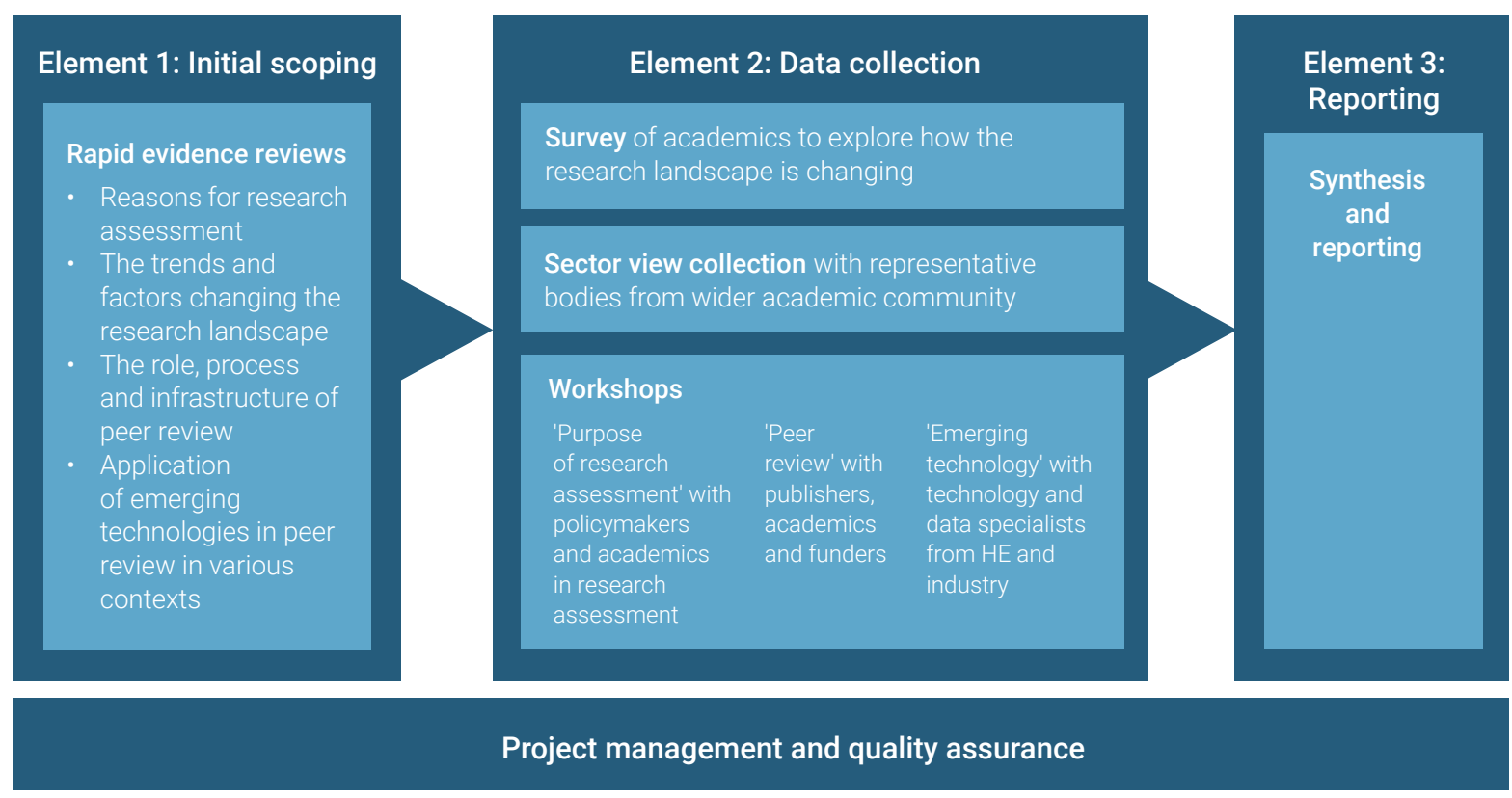

Ongoing engagement with Research England and the advisory group 
Table A.1: Methods used to address the key questions

\begin{tabular}{|c|c|c|c|c|c|c|}
\hline & \multicolumn{5}{|l|}{ Questions } \\
\hline & & $\begin{array}{l}\text { Why do } \\
\text { we assess } \\
\text { research and } \\
\text { how might } \\
\text { that change } \\
\text { in the next } 5 \\
\text { to } 10 \text { years? }\end{array}$ & $\begin{array}{l}\text { How do } \\
\text { researchers } \\
\text { expect the } \\
\text { forms of } \\
\text { output they } \\
\text { are producing } \\
\text { to change in } \\
\text { the next } 5 \text { to } \\
10 \text { years? }\end{array}$ & $\begin{array}{l}\text { How do } \\
\text { researchers } \\
\text { expect the } \\
\text { types of } \\
\text { societal impact } \\
\text { their research } \\
\text { produces to } \\
\text { change in the } \\
\text { next } 5 \text { to } 10 \\
\text { years? }\end{array}$ & $\begin{array}{l}\text { How do } \\
\text { researchers } \\
\text { expect the } \\
\text { research } \\
\text { environment } \\
\text { they are in to } \\
\text { change in the } \\
\text { next } 5 \text { to } 10 \\
\text { years? }\end{array}$ & $\begin{array}{l}\text { How could } \\
\text { national } \\
\text { research } \\
\text { assessment } \\
\text { exercises } \\
\text { learn from } \\
\text { developments } \\
\text { in peer review? }\end{array}$ \\
\hline \multirow{4}{*}{$\begin{array}{l}\text { Rapid } \\
\text { evidence } \\
\text { assessments }\end{array}$} & $\begin{array}{l}\text { Reasons for } \\
\text { research } \\
\text { assessment }\end{array}$ & $\checkmark$ & & & & \\
\hline & $\begin{array}{l}\text { The trends } \\
\text { and factors } \\
\text { changing } \\
\text { the research } \\
\text { landscape }\end{array}$ & & $\checkmark$ & $\checkmark$ & $\checkmark$ & \\
\hline & $\begin{array}{l}\text { The role, } \\
\text { process and } \\
\text { infrastructure } \\
\text { of peer review }\end{array}$ & & & & & $\checkmark$ \\
\hline & $\begin{array}{l}\text { Application } \\
\text { of emerging } \\
\text { technologies } \\
\text { in peer review } \\
\text { in various } \\
\text { contexts }\end{array}$ & & & & & $\checkmark$ \\
\hline \multicolumn{2}{|l|}{ Survey } & & $\checkmark$ & $\checkmark$ & $\checkmark$ & \\
\hline \multicolumn{2}{|c|}{ Sector view collection } & $\checkmark$ & $\checkmark$ & $\checkmark$ & $\checkmark$ & $\checkmark$ \\
\hline \multirow{3}{*}{ Workshops } & $\begin{array}{l}\text { 'Purpose } \\
\text { of research } \\
\text { assessment' } \\
\text { with } \\
\text { policymakers } \\
\text { and academics } \\
\text { in research } \\
\text { assessment }\end{array}$ & $\checkmark$ & & & & \\
\hline & $\begin{array}{l}\text { 'Peer review' } \\
\text { with publishers, } \\
\text { academics and } \\
\text { funders }\end{array}$ & & & & & $\checkmark$ \\
\hline & $\begin{array}{l}\text { 'Emerging } \\
\text { technology' } \\
\text { with technology } \\
\text { and data } \\
\text { specialists } \\
\text { from higher } \\
\text { education and } \\
\text { industry }\end{array}$ & & & & & $\checkmark$ \\
\hline
\end{tabular}




\section{A.2. Rapid evidence assessments}

This study was informed by four rapid evidence assessments (REAs) that looked at the published and grey literature. These REAs were conducted concurrently at the beginning of the study, and later supplemented with additional publications suggested by workshop participants and key stakeholders. Rapid evidence assessments aim to be rigorous and explicit in method, and thus systematic, however they limit particular aspects of the full systematic review process which provide value for money.

A search strategy for each of the four REAs was developed using key words through an iterative process to ensure that searches would produce informative results to answer the key research question of the REA. Details about the research question and key word search strings for each REA are provided in Box A.1. Each search string was run in Google Scholar and Web of Science, with results limited to the past five years to ensure that they were up-to-date with current trends. For each search string detailed below, the first 100 results in Google Scholar were screened, and those that were relevant were read completely. This initial search was supplemented with targeted searches based on prior knowledge and expertise within the project team, as well as a snowball methodology in which appropriate references were pulled from relevant articles identified in the original searches conducted in Google Scholar and Web of Science. Along with the results of the initial searches, targeted searches and articles retrieved through the snowball technique, the literature review was supplemented with articles suggested by workshop participants (described in Section A.3 below) and other key stakeholders.

Relevant information from each article read completely was extracted into a matrix, which was organised into sub-themes to aid in analysis (sub-themes provided in Box A.1). After information from all articles was extracted in this way, the matrix was read in its entirety and analysed to provide information on the research question for each REA.

\section{A.3. Workshops}

The results of the literature review were used to inform three separate workshops, which addressed the topics of the study. During the workshops, stakeholders provided perspectives on developments in research assessment and the research environment. This helped ensure that a wide range of views from across the research system in England were included in the study, and that the findings captured emerging trends not yet published in the literature, which tends to be less future focused. The names of those who attended the workshops is listed in Annex G.

\section{A.3.1. Workshop 1 - Why is research assessed?}

The first workshop focused on why research is currently assessed at a national level, and how this may change in the future. It took place in London on 1 February 2019 and was delivered primarily by Research England, with RAND Europe developing the material, the agenda for the workshop and providing secretariat. The workshop included representatives from the government and national funding bodies, organisations that fund research and the higher education sector. There were eight participants (including two who attended via teleconference), along with two representatives from RAND Europe and two representatives from Research England. During the workshop, participants considered findings from the rapid evidence assessment (REA 1, described above) and had the chance to discuss, as a group, why research is assessed. 


\section{Box A.1: Search sequence for the rapid evidence assessments}

REA 1: Why do we assess research and how is this changing? Initial search strings:

'Research assessment' OR 'research evaluation' AND '2013-2018'

'Research assessment' AND 'national' AND 'consequence' OR 'purpose

Total articles read: 36

REA 2: How is the research landscape changing?

Initial search strings:

'international collaboration' AND 'academic research'

'research nation' AND ('future' OR 'change' OR 'trend' OR 'shift' OR 'growth' OR 'rise')

'researcher mobility' AND 'future'

"impact of ('global challenges' OR 'grand challenges') research"

'impact' AND ('open science' OR 'open data' OR 'open access' OR 'citizen science' OR 'altmetrics' OR 'open research' OR 'open research data' OR 'open scientific code' OR 'open scholarly communication')

('research products' OR 'publication format' OR 'altmetrics') AND ('change' OR 'future')

('big data' OR 'artificial intelligence') AND ('research assessment' OR 'measuring research' OR 'quality of research')

('technology' OR 'technological') AND 'change' AND 'research method'

('future' OR 'change') AND ('public funding' OR 'public spending' OR 'public expenditure') AND 'research' AND ('UK' OR 'United Kingdom' OR 'England')

future impact 'trust in science' assessment

('future' OR 'change' OR 'trend' OR 'shift') AND 'academic research' AND ('UK' or 'United Kingdom')

('change' OR 'growth' OR 'trend' OR 'shift' OR 'rise' OR 'future') AND ('open science' OR 'open data' OR 'open access' OR 'citizen science' OR 'open research' OR 'open research data' OR 'open scientific code' OR 'open scholarly communication')

'replication crisis' OR 'reproducibility crisis'

('change' OR 'growth' OR 'trend' OR 'shift' OR 'rise' OR 'future') AND ('open science' OR 'open data' OR 'open access' OR 'citizen science' OR 'open research' OR 'open research data' OR 'open scientific code' OR 'open scholarly communication')

Sub-themes: Global balance, international collaboration, Brexit, open science, role of science, public funding, emerging technology, altmetrics, interdisciplinary research, impact, outputs, commercialisation

Total articles read: 52 


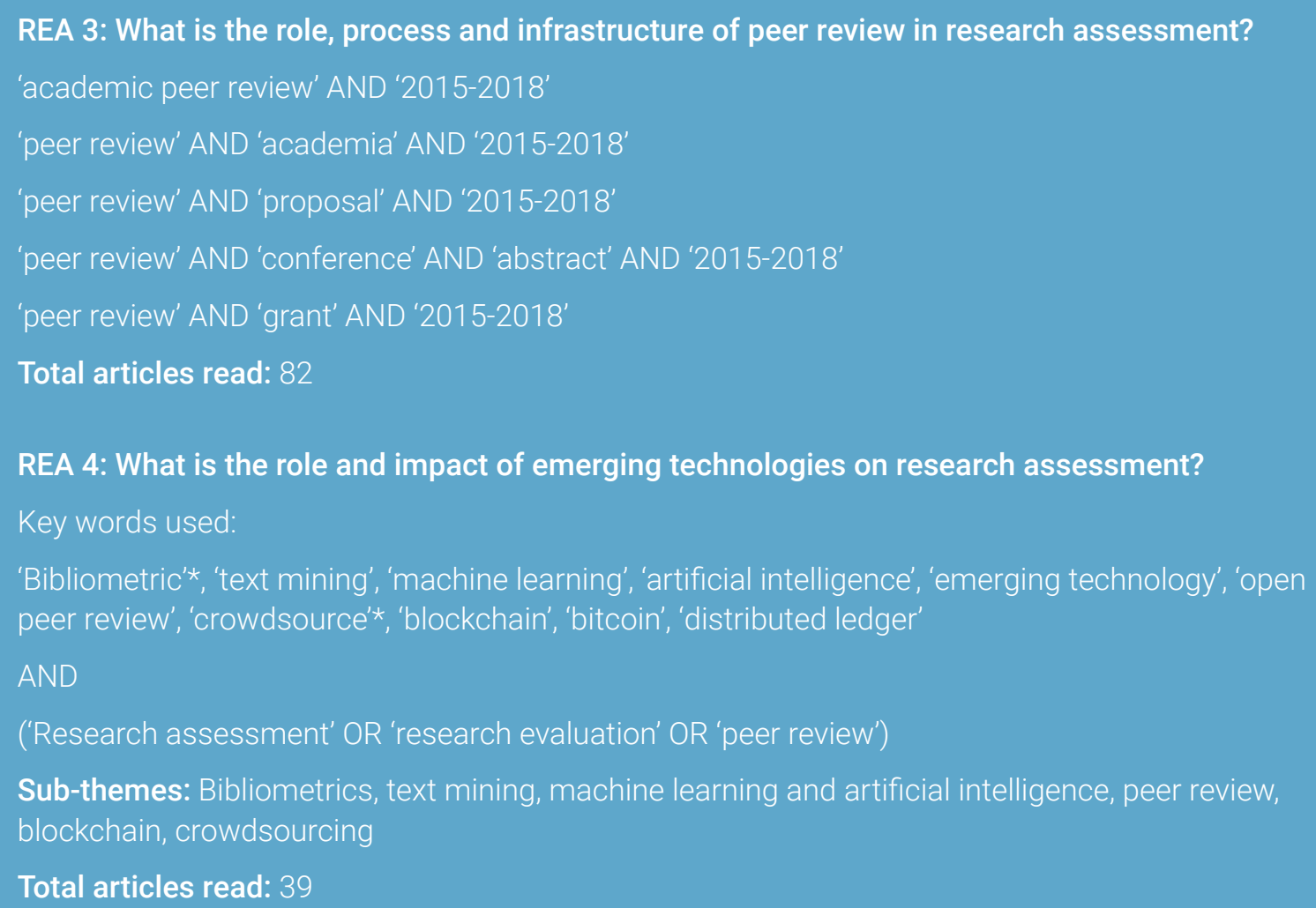

\section{A.3.2. Workshop 2 - Peer review}

The second workshop focused on how peer review is used in research assessment, developments and trends in peer review, and how these may shift in the future. It took place in London on 13 March 2019, and was jointly delivered by Research England and RAND Europe. There were 12 participants along with two representatives from RAND Europe and three representatives from Research England. Attendees included representatives from academia, academic publishing houses and research funders.

Discussions in the workshop focused around the following topics:

- What are the strengths and weaknesses of peer review as a method for research assessment?
- How can developments in the system, including technological developments, seek to address the limitations of traditional peer review?

- What are the opportunities and challenges associated with changes to the peer review process?

- What level of technology do you think would be appropriate for use in peer review as part of national research assessment?

- How might trends, both internal and external to the research system, influence the development of peer review, particularly within national research assessment?

Following the plenary discussion, participants were divided into three groups, each of which was assigned a stage of the peer review process (selecting reviewers and allocating items; scoring; and calibration, moderation, 
validation and decision making). Participants were asked to fill in a table to provide information on new developments they were aware of in peer review, as well as their benefits and drawbacks. The tables from the three groups were combined into one table and participants were asked to distribute six voting dots across the different developments they considered most likely to change in the next 5 to 10 years, and those most beneficial to peer review.

\section{A.3.3. Workshop 3 - Emerging technology}

The third workshop focused on how emerging technologies may be incorporated into research assessment in the future. It took place in London on 14 March 2019 and was jointly delivered by Research England and RAND Europe. There were 16 participants, including two participants that overlapped with workshop 2 from the previous day. ${ }^{59}$ Attendees included participants from the higher education sector, publishing services and experts in emerging technologies.

Discussions in the workshop focused around the following topics:

- What are the strengths and weaknesses of current research assessment processes?

- What are the up-and-coming technologies that will change how research is assessed?

- What are the opportunities and challenges regarding the use of technology in the research assessment processes?

- What level of integration of technology do you think would be appropriate for use in peer review as part of national research assessment?

- How might trends, both internal and external to the research system, influence the development and use of technology in research assessment processes?

As with workshop 2, participants were divided into three groups following the plenary discussion, each of which was assigned a stage of the peer review process (selecting reviewers and allocating items; scoring; and calibration, moderation, validation and decision making). Participants were asked to fill in a table to provide information on any new technologies they were aware of being developed for research assessment, as well as their benefits and drawbacks. The tables from the three groups were combined into one table and participants were asked to distribute six voting dots across the different developments they considered most likely to change in the next 5 to 10 years, and those most beneficial to peer review.

\section{A.4. Survey}

\section{A.4.1. Designing and sending the survey}

In order to get a broad range of perspectives of how the research environment may shift over the next 5 to 10 years, an online survey of academic researchers in England was conducted. This survey was designed to capture expected changes in research outputs, research impacts and the research environment more broadly, as well as information such as the participant's field of study, career stage, institutional affiliation and gender. The survey protocol is attached in Annex C. It was uploaded to SmartSurvey and consisted mainly of multiple choice questions, with several opportunities for participants to provide open text responses.

The strategy for sending out the survey was to invite HEls to participate in the study, and 
then send the survey to all researchers at those institutions, including PhD students and postdoctoral researchers. Academic researchers in England were also invited to participate via RAND Europe's Facebook and Twitter pages.

The sample of HEls invited to participate was obtained by splitting all universities that had made submissions as part of the REF 2014 exercise into groups based on number of staff; eight universities per group were then randomly selected. The sample was checked and redrawn if necessary to ensure that it met the following criteria: one HEl from each of the nine regions in England; no more than one $\mathrm{HEI}$ within each group from the same region outside London; no more than two HEls within the same group from the region of London; at least one mono-technic HEI (submitting to only one unit of assessment (UOA) in REF 2014); at least one HEl that submitted to all UOAs in REF 2014; and a proportionate spread across disciplines (determined using REF2021 UOAs and main panels as a proxy for discipline). Using this strategy, 24 institutions were invited to participate. ${ }^{60}$

Research England sent each institution an email inviting them to participate and requesting a point of contact at the HEI who would liaise with the project team for the study. Of the $24 \mathrm{HEls}$ invited to participate, 19 accepted the invitation and participated in the study. The point of contact at the HEI was given the option of either sending out the survey link to all researchers at the HEI themselves using an institution-specific link, or providing the project team with a list of contact information for all researchers to send the link directly. All but one institution that participated in the study chose to send out the survey link to their researchers themselves rather than have the project team reach out to researchers, although one institution included the link in their routine newsletter rather than sending the link via email.

The project team provided the point of contact at each $\mathrm{HEI}$ with a document that suggested text for the initial invitation to send to researchers at their institution, as well as two reminder messages to be sent out at set intervals while the survey was open. The survey was open for a period of four weeks. So as not to be restrictive, it was also publicised on social media so that researchers from the wider community could participate. Through this route responses from researchers at an additional $44 \mathrm{HEls}$ across England were received. ${ }^{61}$

60 The HEls selected within the sample were: The University of Oxford, Queen Mary University of London, University College London, The University of Bristol, The University of Liverpool, The University of Cambridge, University of Nottingham, Newcastle University, The University of Brighton, The University of Derby, Liverpool John Moores University, University of Durham, Leeds Beckett University, Birmingham City University, Kingston University, The University of East Anglia, Goldsmiths College, The Royal College of Music, The University of Bolton, Keele University, Norwich University of the Arts, The University of Chichester, The University of Hull and The University of Northampton

These were Aston University, Bath Spa University, Birkbeck College, Birmingham City University, Bournemouth University, Coventry University, Cranfield University, Edge Hill University, King's College London, Leeds Arts University, Liverpool John Moores University, London School of Hygiene and Tropical Medicine, Loughborough University, Middlesex University, Oxford Brookes University, Royal Holloway and Bedford New College, St George's, University of London, The Institute of Cancer Research, The Open University, The University of Bath, The University of Birmingham The University of Bradford, The University of Central Lancashire, The University of Exeter, The University of Greenwich, The University of Kent, The University of Lancaster, The University of Leicester, The University of Manchester, The University of Portsmouth, The University of Reading, The University of Sheffield, The University of Southampton, The University of Westminster, The University of Winchester, The University of Wolverhampton, The University of Chester, The University of Cumbria, The University of Durham, The University of Hertfordshire, The University of London (Institutes and activities), The University of Northumbria at Newcastle, The University of Worcester, The University of York 
Table A.2: Open response question coding

\begin{tabular}{|l|l|l|l|l|}
\hline Question text & $\begin{array}{l}\text { Number of } \\
\text { responses }\end{array}$ & $\begin{array}{l}\text { Number of } \\
\text { references } \\
\text { coded }\end{array}$ & $\begin{array}{l}\text { Number of } \\
\text { categories }\end{array}$ & $\begin{array}{l}\text { Method for } \\
\text { coding }\end{array}$ \\
\hline $\begin{array}{l}\text { Do you expect a change in the type of outputs } \\
\text { you are producing in the next } 5 \text { to } 10 \text { years? If } \\
\text { yes, please explain below. }\end{array}$ & 1,072 & 2,068 & 87 & Excel \\
\hline $\begin{array}{l}\text { In an ideal world, would you choose to produce } \\
\text { different types of outputs from those you } \\
\text { have selected above? If you answered yes to } \\
\text { Question 8, what would they be and why would } \\
\text { you choose to produce them instead? }\end{array}$ & 640 & 1,574 & 87 & Excel \\
$\begin{array}{l}\text { Do you anticipate that the type of impacts that } \\
\text { your work might contribute to will change in } \\
\text { the next } 5 \text { to 10 years and why? }\end{array}$ & 1,863 & 3,146 & 40 & Excel \\
$\begin{array}{l}\text { Given the changes you foresee in the outputs } \\
\text { and impacts you produce (if any), how do you } \\
\text { think the research environment needs to adapt } \\
\text { to support these changes? }\end{array}$ & 1,930 & 5,491 & 244 & NVivo \\
\hline
\end{tabular}

\section{A.4.2. Survey analysis}

In total, 3,768 responses ${ }^{62}$ were received and included in the survey analysis. Quantitative analysis of the survey results was conducted in R. Results were analysed to test if there were significant differences in current and expected future research outputs and impacts, and to look at drivers of change that researchers identified as important within the research landscape. Sub-group analyses were conducted to look at how responses differed between disciplines (determined by REF 2021 main panels) and career stage using chisquared tests.

Four open response questions were analysed qualitatively using NVivo and Excel. The codebooks for the qualitative analysis are provided in Annex E. There were 1,930 free text responses to the question 'Given the changes you foresee in the outputs and impacts you produce (if any), how do you think the research environment needs to adapt to support these changes?' This resulted in 5,491 references being coded into 244 codes in NVivo. However, many of these codes were at a high level, and did not have any references coded to them. NVivo was chosen to analyse this question based on the broad range of ideas that respondents expressed through their open text responses, although Excel was used for the other questions to make analysis more efficient. An overview of coding processes is provided in Table A. 2 above, which provides information on the number of responses, number of references and number of categories used for coding, as well as the coding method used. 
Once the open text responses were coded, all references within codes with a large number of coded references were reread to understand the body of responses as a whole. Codes identified as often being coded into the same category were read together.

\section{A.5. Collection of sector views}

Representative bodies from the wider academic community were invited to respond to a collection of views, which asked representatives to provide their views on how they thought research outputs, impacts and the research environment would change over the next 5 to 10 years, and to comment on factors that may be driving these changes. ${ }^{63}$ They were also asked how research assessment might adapt and how specific groups would be affected by changes in the research landscape. These questions were uploaded to SmartSurvey, although responses were also accepted via email.
The collection of views was originally going to be left open for eight working days, however, to allow further participation following a low response, the deadline was extended a further ten days. In this time, three responses to the collection of views were received. One late response was received via email and is included in the analysis.

\section{A.6. Analysis and reporting}

An internal team workshop was held to identify cross-cutting themes across the three phases.

Analysis focused on the changes to the research produced as a result of changes emerging in the research environment across the United Kingdom, and how research assessment can be supported by technological and cultural developments. Key findings for each phase, as well as for the overall project, were identified, and a narrative was developed and presented to the advisory group and Research England on 1 May 2019 for input and feedback. 



\section{Annex B. Survey respondent demographics}

This annex presents a description of the types of respondent who responded to the survey based on demographic data collected at the beginning and end of the survey (See Annex $C$ for survey protocol). The survey was not specifically designed to collect a fully representative sample of researchers from across the United Kingdom, but rather to collect a diverse range of views.

In total there were 3,768 respondents to the survey. Respondents have been defined as those researchers who answered at least one question related to outputs, impacts or the research environment. Demographic questions specifically required for the analysis were asked at the beginning of the survey, while additional demographic questions were asked at the end of the survey. Due to a drop off in respondents across the survey, which is to be expected, there are fewer respondents who answered demographic questions at the end of the survey than at the beginning.

\section{B.1. Career stage}

At the beginning of the survey, respondents were asked how they would define their career stage. The options were: PhD student, early-career research, mid-career researcher, established researcher and retired or emeritus researcher. Figure B.1 shows the distribution of respondents across career stages. In general, there were similar numbers of respondents from each career stage, with the exception of retired or emeritus researchers, for which a lower number of respondents was expected.

\section{B.2. Universities}

Respondents were asked to select the institution that represented their primary affiliation from a drop-down list of institutions that submitted to REF 2014, or by selecting 'other' and writing their primary affiliation in an open text response. Some $89 \%$ of responses came from HEls within the sample of $19 \mathrm{HEls}$, and $11 \%$ from outside the sample. Table B. 1 shows the number of respondents from each HEI within the sample, and Table B. 2 shows the number of respondents from HEls outside the sample. In addition, 43 respondents did not provide an affiliation, and 26 classified themselves as 'other'.

There was representation from all regions of England, with a skew towards some areas (particularly in the East of England). This is likely due to a high response rate from the University of Cambridge and a very low response from University College London. The smallest number of responses from any particular region was 94 from Yorkshire and the Humber. There were at least 100 respondents from each region, with many regions greatly exceeding this number. 
Figure B.1: Career stage of respondents

PhD Student

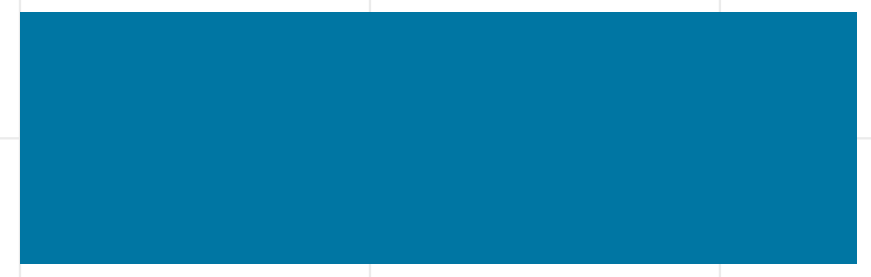

Early-career researcher

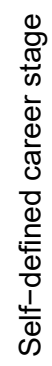

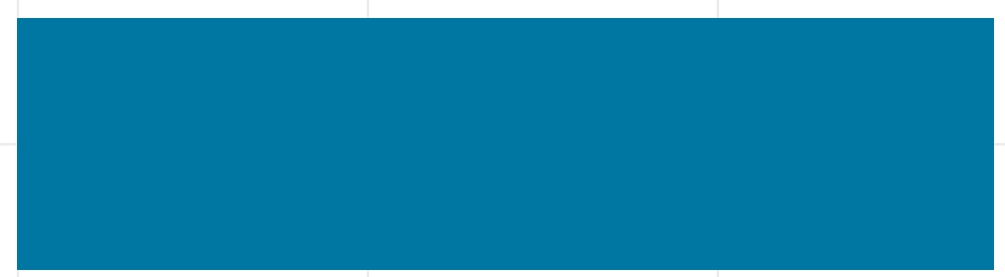

Mid-career researcher

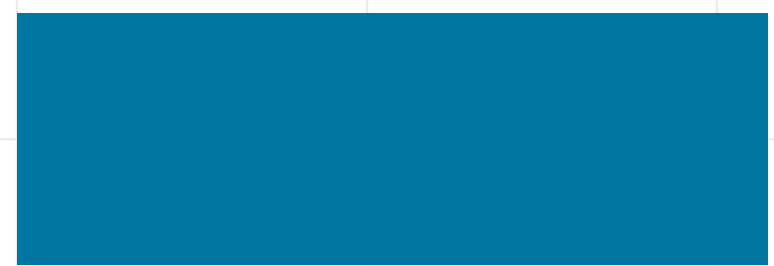

Established researcher

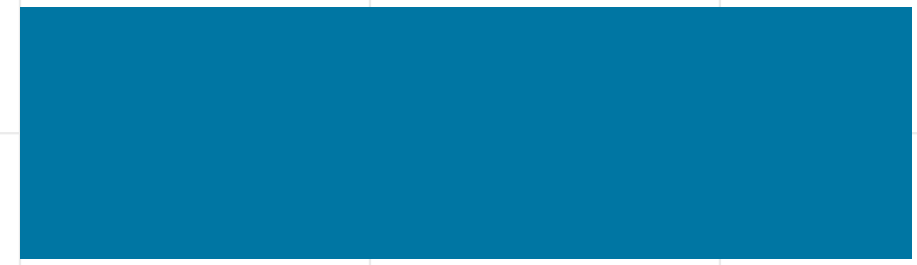

Retired or emeritus researcher

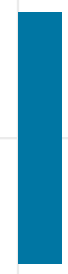

0
10

20

Percentage of respondents, $n=3,747$ 
Table B.1: Number of respondents from each HEI within the sample

\begin{tabular}{|c|c|}
\hline Higher education institution & Number of respondents \\
\hline Goldsmiths College & 56 \\
\hline Keele University & 96 \\
\hline Kingston University & 130 \\
\hline Newcastle University & 67 \\
\hline Queen Mary University of London & 202 \\
\hline Royal College of Music & 9 \\
\hline The University of Bolton & 34 \\
\hline The University of Brighton & 133 \\
\hline The University of Bristol & 270 \\
\hline The University of Cambridge & 925 \\
\hline The University of Chichester & 24 \\
\hline The University of East Anglia & 113 \\
\hline The University of Hull & 74 \\
\hline The University of Liverpool & 294 \\
\hline The University of Northampton & 2 \\
\hline The University of Oxford & 385 \\
\hline University College London & 10 \\
\hline University of Derby & 21 \\
\hline University of Nottingham & 513 \\
\hline
\end{tabular}

Table B.2: Number of respondents from HEls outside of the sample

\section{Higher education institution}

Aston University

Bath Spa University

Birkbeck College

Birmingham City University

Bournemouth University

Coventry University

Cranfield University

Edge Hill University

King's College London

Leeds Arts University

Liverpool John Moores University

\section{Number of respondents}

1

41

2

1

7

2

8

1

3

1

1 


\section{Higher education institution}

\section{Number of respondents}

London School of Hygiene and Tropical Medicine 1

Loughborough University

3

Middlesex University

Oxford Brookes University

Royal Holloway and Bedford New College

6

St George's, University of London

The Institute of Cancer Research

5

The Open University 20

The University of Bath 1

The University of Birmingham

24

The University of Bradford 5

\begin{tabular}{|l|l|}
\hline The University of Central Lancashire & 27 \\
\hline
\end{tabular}

\begin{tabular}{|l|l|}
\hline The University of Exeter & 2 \\
\hline
\end{tabular}

\begin{tabular}{|l|l|}
\hline The University of Greenwich & 18 \\
\hline
\end{tabular}

\begin{tabular}{|l|l|}
\hline The University of Kent & 1
\end{tabular}

\begin{tabular}{|l|l|}
\hline The University of Lancaster & 10 \\
\hline
\end{tabular}

\begin{tabular}{l|l} 
The University of Leicester & 1
\end{tabular}

\begin{tabular}{|l|l|}
\hline The University of Manchester & 11 \\
\hline
\end{tabular}

\begin{tabular}{|l|l|} 
The University of Portsmouth & 2
\end{tabular}

The University of Reading $\quad 5$

\begin{tabular}{|l|l|}
\hline The University of Sheffield & 2 \\
\hline
\end{tabular}

\begin{tabular}{|l|l|}
\hline The University of Southampton & 1
\end{tabular}

\begin{tabular}{l|l}
\hline The University of Westminster & 7
\end{tabular}

\begin{tabular}{|l|l}
\hline The University of Winchester & 2 \\
\hline
\end{tabular}

\begin{tabular}{|l|l|}
\hline The University of Wolverhampton & 1
\end{tabular}

\begin{tabular}{|l|l|}
\hline The University of York & 1 \\
\hline
\end{tabular}

\begin{tabular}{|l|l|}
\hline University of Chester & 3 \\
\hline
\end{tabular}

\begin{tabular}{|l|l|}
\hline University of Cumbria & 1 \\
\hline
\end{tabular}

\begin{tabular}{|l|l|}
\hline University of Durham & 66
\end{tabular}

\begin{tabular}{|l|l}
\hline University of Hertfordshire & 14
\end{tabular}

\begin{tabular}{|l|l|}
\hline University of London (Institutes and activities) & 5
\end{tabular}

\begin{tabular}{|l|l}
\hline University of Northumbria at Newcastle & 6
\end{tabular}

\begin{tabular}{|l|l|}
\hline University of Worcester & 2 \\
\hline
\end{tabular} 
Figure B.2: Geography of respondents

East of England

South East

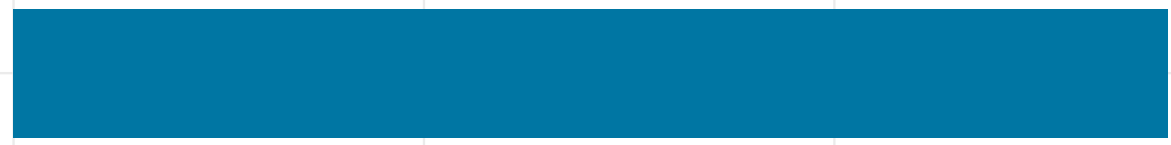

East Midlands

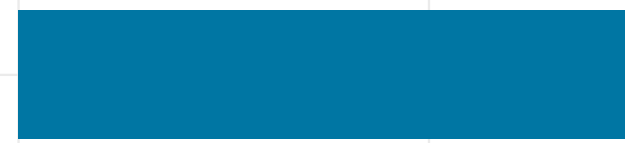

$\begin{array}{ll} & \text { London } \\ \frac{\pi}{0} & \\ \frac{0}{0} & \text { North West } \\ \frac{0}{0} & \\ \frac{0}{0} & \\ \frac{\pi}{0} & \\ \frac{0}{0} & \text { South West }\end{array}$

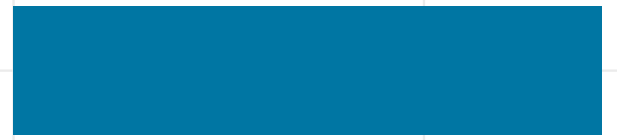

North East
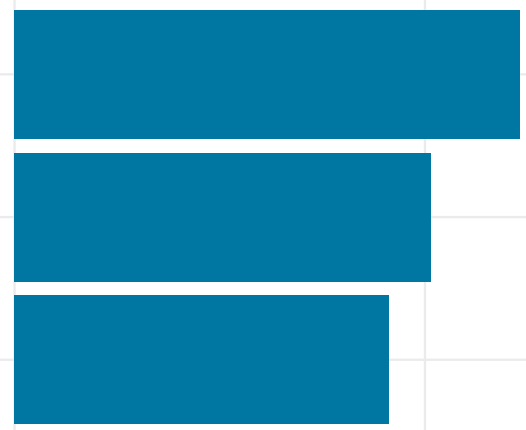

West Midlands
Yorkshire and
The Humber

Unknown
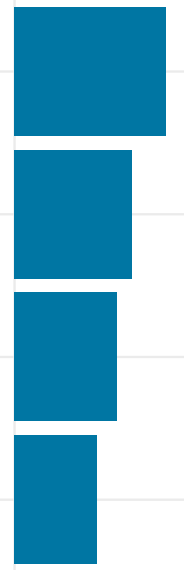

0

10

Percentage of respondents, $n=3,768$

\section{B.3. Disciplines}

Respondents were asked to select the main research area that best describes their work, along with a selection of all research areas in which they work. Respondents were able to select research areas that represented the 34 REF 2021 units of assessment (described in Annex F, Table F.1), which were then grouped into Main Panels A, B, C and D according to REF 2021 main panels. ${ }^{64}$ Respondents were classified to a UOA and main panel based on 
the main research area they provided. They were classified as interdisciplinary if they provided multiple main research areas.

Table B. 3 shows the percentage of respondents from each UOA. There were respondents from all REF2021 UOAs, although the proportion varied. A particularly strong response was received from researchers from UOA 5 (579 respondents, $15 \%$ of all responses) and UOA 4 (291 respondents, 8\% of all responses), which correspond with biological sciences and psychology, and psychiatry and neuroscience, respectively. At the main panel level, $37 \%$ of respondents came from Main Panel A, 25\% from Main Panel B, 18\% from Main Panel $C$ and 15\% from Main Panel D.
In terms of subject area, more responses were received from main panels $A$ and $B$ compared to $C$ and $D$, although all main panels had more than 500 respondents.

Main Panel A and Main Panel B have a higher percentage of responses from PhD students and early-career researchers (53\% and 58\%, respectively), and Main Panel $\mathrm{C}$ and Main Panel $D$ have a higher percentage of respondents from mid-career and established researchers (52\% and 53\%, respectively) (Table B.4). Main Panel B also has a much higher percentage of respondents who are male than other main panels (Table B.5).

Table B.3: Respondents from each UOA

\begin{tabular}{|l|l|l|}
\hline Main Panel & UOA & $\begin{array}{l}\text { Percentage of } \\
\text { responses }\end{array}$ \\
\hline & 1 & $3.8 \%$ \\
\hline Main Panel & 2 & $4.8 \%$ \\
\hline & 4 & $2.4 \%$ \\
\hline & 5 & $7.7 \%$ \\
\hline & 6 & $15.4 \%$ \\
\hline Main Panel & 13 & $1.8 \%$ \\
\hline C & 14 & $1.2 \%$ \\
\hline & 15 & $1.5 \%$ \\
\hline & 16 & $1.3 \%$ \\
\hline & 17 & $1.5 \%$ \\
\hline & 20 & $2.7 \%$ \\
\hline & 21 & $1.3 \%$ \\
\hline & 22 & $1.6 \%$ \\
\hline & 23 & $0.5 \%$ \\
\hline & 24 & $0.5 \%$ \\
\hline
\end{tabular}

\begin{tabular}{|c|c|c|}
\hline Main Panel & UOA & $\begin{array}{l}\text { Percentage of } \\
\text { responses }\end{array}$ \\
\hline \multirow{6}{*}{$\begin{array}{l}\text { Main Panel } \\
\text { B }\end{array}$} & 7 & $2.8 \%$ \\
\hline & 8 & $3.4 \%$ \\
\hline & 9 & $5.8 \%$ \\
\hline & 10 & $3.2 \%$ \\
\hline & 11 & $3.3 \%$ \\
\hline & 12 & $5.6 \%$ \\
\hline \multirow{10}{*}{$\begin{array}{l}\text { Main Panel } \\
\text { D }\end{array}$} & 25 & $0.4 \%$ \\
\hline & 26 & $1.8 \%$ \\
\hline & 27 & $2.9 \%$ \\
\hline & 28 & $3.3 \%$ \\
\hline & 29 & $0.7 \%$ \\
\hline & 30 & $0.9 \%$ \\
\hline & 31 & $0.6 \%$ \\
\hline & 32 & $1.6 \%$ \\
\hline & 33 & $1.6 \%$ \\
\hline & 34 & $0.8 \%$ \\
\hline \multicolumn{2}{|l|}{ Other } & $2.8 \%$ \\
\hline \multicolumn{2}{|c|}{ Interdisciplinary } & $5.5 \%$ \\
\hline
\end{tabular}

Units of Assessment (UOA) are listed in Annex F, Table F.1. 
Table B.4: Percentage of respondents across career stages for each main panel

\begin{tabular}{|l|l|l|l|l|l|}
\hline Discipline & $\begin{array}{l}\text { PhD } \\
\text { Student }\end{array}$ & $\begin{array}{l}\text { Early-career } \\
\text { researcher }\end{array}$ & $\begin{array}{l}\text { Mid-career } \\
\text { researcher }\end{array}$ & $\begin{array}{l}\text { Established } \\
\text { researcher }\end{array}$ & $\begin{array}{l}\text { Retired or } \\
\text { emeritus } \\
\text { researcher }\end{array}$ \\
\hline Main Panel A & $23 \%$ & $30 \%$ & $22 \%$ & $23 \%$ & $1 \%$ \\
\hline Main Panel B & $29 \%$ & $29 \%$ & $17 \%$ & $24 \%$ & $1 \%$ \\
\hline Main Panel C & $21 \%$ & $25 \%$ & $24 \%$ & $28 \%$ & $2 \%$ \\
\hline Main Panel D & $21 \%$ & $24 \%$ & $24 \%$ & $29 \%$ & $1 \%$ \\
\hline Interdisciplinary & $22 \%$ & $27 \%$ & $20 \%$ & $30 \%$ & $1 \%$ \\
\hline Total & $\mathbf{2 4 \%}$ & $\mathbf{2 8} \%$ & $\mathbf{2 1} \%$ & $\mathbf{2 5} \%$ & $\mathbf{1} \%$ \\
\hline
\end{tabular}

Due to rounding the total does not add to $100 \%$

Table B.5: Gender distribution of respondents for each main panel

\begin{tabular}{|l|l|l|l|}
\hline Discipline & Female & Male & Other or unknown \\
\hline Main Panel A & $42 \%$ & $36 \%$ & $22 \%$ \\
\hline Main Panel B & $19 \%$ & $55 \%$ & $26 \%$ \\
\hline Main Panel C & $42 \%$ & $40 \%$ & $18 \%$ \\
\hline Main Panel D & $44 \%$ & $34 \%$ & $22 \%$ \\
\hline Interdisciplinary & $42 \%$ & $29 \%$ & $29 \%$ \\
\hline Total & $\mathbf{3 6 \%}$ & $\mathbf{4 1} \%$ & $\mathbf{2 3} \%$ \\
\hline
\end{tabular}



Annex C. Survey protocol

See overleaf. 


\title{
National Research Landscape Survey
}

\section{Introduction}

Research

England

RAND EUROPE

\begin{abstract}
Research England is interested in understanding how researchers think the research landscape (i.e. research outputs, impacts and the research environment) might change over the next 5 to 10 years, in order to inform their planning for future research assessment (post 2021). This survey is intended to collect information on these issues and is part of a wider study being conducted by RAND Europe (https://www.rand.org/randeurope.html) on behalf of Research England.

This survey is for researchers within English Higher Education Institutions (HEls).

It should take 8-12 minutes to complete. We are very grateful for your participation.

If you have any questions about the survey please contact the RAND Europe project team at research_landscape_survey@rand.org (mailto:research_landscape_survey@rand.org).
\end{abstract}

\section{Privacy Notice}

\section{About the project}

RAND Europe has been commissioned by Research England to conduct a study of how the research landscape in the UK will change in the next 5-10 years in order to inform how research assessment may need to adapt. This document describes a survey of academic researchers being carried out as part of the study.

\section{Who is conducting this research?}

RAND Europe is a not-for profit research Institute based in Cambridge. They have been commissioned by Research England (UK Research and Innovation) to carry out this study, who are the data controller for any data you submit. The research team is led by Dr Catriona Manville.

What data are we collecting?

RAND Europe is collecting information on the research landscape now, as well as how you think 
it will develop over the next 5-10 years. It will also collect demographic information including: the number of years you have been conducting research, your research area, your institution, your career stage, your age, your gender, your ethnicity and whether you have a disability. We are not collecting email addresses or names. RAND Europe and Research England will not use the information you submit to identify you.

\section{How are we collecting the data?}

The data will be collected through a survey hosted on SmartSurvey. The data will be stored on SmartSurvey and then downloaded to RAND Europe servers where it will be stored in password protected folders. Only SmartSurvey and the research team at RAND Europe carrying out the study will have access to your data.

\section{Why are we collecting it?}

The purpose of the study is to better understand how research, the research environment and its outputs are developing and may change over time. This study is part of a programme of work that Research England have commissioned to explore the research assessment landscape. The study involves a survey of the academic population focusing on how they feel the research landscape may change, and what is driving these changes.

\section{What is the legal basis for processing your data?}

Your data will be processed in accordance with the General Data Protection Regulation 2016 (GDPR). All information collected will be treated as sensitive. Personal data and sensitive data including demographic information such as gender, ethnicity, disability and age inform the research. We are required by law to ensure that we protect this information, the use of the data is considered a task in the public interest. In doing so RAND Europe and Research England (UKRI) recognise the need to ensure your privacy and in doing so will not include any personal identifiers. No attempt will be made to combine the information you have provided in order to identify you and in doing so your data is pseudoanonymised. In doing so RAND Europe and Research England recognise the need to ensure your privacy and in doing so will not include any personal identifiers. No attempt will be made to combine the information you have provided in order to identify you and in doing so your data is pseudoanonymised.

\section{What are we using the data for?}

Responses will be analysed and aggregated to inform a report to be presented to Research England and published.

\section{How will we be sharing the data?}

Data will be aggregated and reported to Research England in a report which will also be published. Within the report, some quotes may be used from free text responses. These will be presented anonymously. Research England has instructed that access to the survey data be limited to the research team based at RAND Europe and destroyed on completion of the research.

\section{How do we keep your data secure?}

RAND Europe has implemented a company wide Information Security Management System (ISMS). RAND Europe is accredited for ISO 27001 certification and Cyber Essentials Plus. We have a senior management team that supports the continuous review and improvement of the company ISMS. 
Page 3 of 16

\section{Key controls RAND Europe has implemented include:}

An Information Security Risk Assessment Process that assesses the business harm likely to result from a security failure and the realistic likelihood of such a failure occurring in the light of prevailing threats and vulnerabilities, and controls currently implemented.

An Information Classification and Handling Policy including compliance with regulations under the Data Protection Act to protect client, partner, supplier, our own and personal employee information which is not in the public domain.

A Business Continuity Plan to counteract interruptions to business activities and to protect critical business processes from the effects of major failures or disasters.

Defined security-controlled perimeters and access to controlled offices and facilities to prevent unauthorised access, damage and interference to business premises and information and data that might be held there.

Mandatory Information security awareness guidance for all company employees.

Background screening of all company employees

Data will be held on a server located in RAND Europe's Cambridge, UK office. Only the research team will have access to the data. Backups taken for disaster recovery purposes will be encrypted and stored in a secure offline site.

\section{How long do we keep your data?}

Your data will be destroyed after the research is completed and the project published.

\section{What choices do you have in our use of your data?}

You are able to request deletion of any data supplied although identification is only possible through reprovision of all your data.

\section{What are your rights?}

RAND Europe operates in accordance with the Data Protection Act 2018 and GDPR. You are provided with certain rights that you may have the right to exercise through us. Your data is pseudoanonymised at the point of receipt and thereafter shall not be made identifiable as instructed by Research England. You are entitled to request your data's deletion through contacting Research England at researchpolicy@re.ukri.org (mailto:researchpolicy@re.ukri.org)whilst the study is underway. We note that to exercise this right you will need to provide all data originally provided to facilitate identification of your records as no personal identifiers are retained in this project.

\section{How do you contact us?}

If you have any questions about the survey or the study please contact RAND Europe (research_landscape_survey@rand.org (mailto:research_landscape_survey@rand.org)) or Research England (Charlotte.Lester@re.ukri.org (mailto:Charlotte.Lester@re.ukri.org)).

If you wish to raise concerns independently of the study team please contact RAND Europe (REdpo@rand.org (mailto:REdpo@rand.org)) or Research England (researchpolicy@re.ukri.org (mailto:researchpolicy@re.ukri.org)). 


\section{Demographics}

1. Do you conduct academic research as part of your current job? *

\section{Thank you}

Thank you for your interest in this survey. However, the questions are intended for those undertaking research as part of their current role as we are trying to gather data and information to inform understanding of potential changes in UK research.

\section{Demographics (cont.)}

2. How many years have you been conducting research, including postgraduate/PhD study?
$0-5$ years
6-10 years
$11-15$ years
16-20 years
21-25 years
26-30 years
31-35 years
36-40 years
41-45 years
45-50 years
$51+$ years

3. Which of the following best describes your research area? Please select all those that apply and then the research area that you mainly associate yourself with.

All research areas you work in

Clinical Medicine

Public Health, Health

Services and Primary Care
Main research area (Please select only 1 area) 
Page 5 of 16

All research areas you work in

Allied Health Professions,

Dentistry, Nursing and

Pharmacy

Psychology, Psychiatry and

Neuroscience

Biological Sciences

Agriculture, Veterinary and

Food Science

Earth Systems and

Environmental Sciences

Chemistry

Physics

Mathematical Sciences

Computer Science and

Informatics

Engineering

Architecture, Built

Environment and Planning

Geography and

Environmental Studies

Archaeology

Economics and

Econometrics

Business and Management

Studies

Law

Politics and International

Studies

Social Work and Social

Policy

Sociology

Anthropology and

Development Studies

Education

Sport and Exercise

Sciences, Leisure and

Tourism

Area Studies

Modern Languages and

Linguistics

English Language and

Literature

History

Classics
Main research area (Please select only 1 area) 
All research areas you work in

Philosophy

Theology and Religious

Studies

Art and Design: History,

Practice and Theory

Music, Drama, Dance,

Performing Arts, Film and

Screen Studies

Communication, Cultural

and Media Studies, Library

and Information

Management

Other (Please explain

below)
Main research area (Please select only 1 area)

If you selected other, please provide an explanation

4. Which of these institutions is your primary affiliation?

If you selected none, please provide information below

5. How would you define your career stage?

PhD Student

Early-career researcher

Mid-career researcher

Established researcher

Retired or emeritus researcher

\section{Research Outputs}

6. What type of outputs are you currently producing and what type of outputs are you planning to produce in the next 5 to 10 years? 
Page 7 of 16

Authored book

Edited book

Chapter in book

Scholarly edition

Journal article

Conference contribution

Working paper

Artefact

Devices and products

Exhibition

Performance

Patent/ published patent

application

Composition

Design

Research report for external body (non-confidential)

Confidential report for external body

Software

Website content

Social media content and

blogs

Digital or visual media

Research datasets and databases

Preprint

Analysis plan/ research protocol/ pre-registration

Code

Slide deck

Openly published peer

review

Crowdsourced paper

Podcast

Video

Editorial

Book review

Data visualisation

Please select all those you are producing now

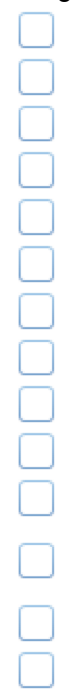

Please select all the types you may produce in the next 5 to 10 years 
Please select all those you are producing now

Other (provide details below)
Please select all the types you may produce in the next 5 to 10 years

If you selected other, please provide details below:

7. Do you expect a change in the type of outputs you are producing in the next 5-10 years?
Yes
No

If yes, please explain below:

8. In an ideal world, would you choose to produce different types of outputs from those you have selected above?
Yes
No

9. If you answered yes to Question 8, what would they be and why would you choose to produce them instead?

\section{Research outcomes/impacts}


Page 9 of 16

10. What types of impacts might you reasonably expect your research to lead to now and what type of impacts do you think your research might lead to in the next 5 to 10 years?

Please select all those you might reasonably expect your research to lead to now
Please select all those you might reasonably expect your research to lead to in the next 5 to

10 years

Impact on the economy

Examples (including, but not limited to): Generating revenue; improving processes; opening up new markets; creating employment in industry; generating revenue through books, materials or events; attracting capital investment to the region; contributing to the digital economy; enabling companies to access new markets; creating new products which are now sold. Impact on social cohesion Examples (including, but not limited to): Conflict reduction, improving equity, alleviating inequalities, strengthening civic participation

Impact on education and training

Examples (including, but not limited to): Changing curricula; improving training materials, text books or other teaching resources; creating materials for specialised teaching contexts; changing the structure of a course; increasing access to education; improving educational outcomes 
Please select all those you might reasonably expect your research to lead to now
Please select all those you might reasonably expect your research to lead to in the next 5 to

\section{Impact on the}

environment

Examples (including, but not limited to): Reducing pollution levels; improving measures of environmental conditions; contributing to conservation; improving waste management environmental efficiency or environmental management; reducing the depletion of a natural resource; developing adaptations to environmental conditions/changes Impact on legal systems Examples (including, but not limited to): Improving the efficiency of the legal process, setting a legal precedent, improved access to legal counsel, improving the quality of evidence underpinning a legal decision Impact on safety and security

Examples (including, but not limited to): Improving infrastructure security/resilience; improving policing/security practices; creating new tools for police, safety and security services; improving safety in workplace, at home or in other settings 
Please select all those you might reasonably expect your research to lead to now
Please select all those you might reasonably expect your research to lead to in the next 5 to

\section{Impact on health and}

\section{wellbeing}

Examples (including, but not limited to): Improving health outcomes; changing healthcare practice; improving health equity; increasing patient/user choice; increasing access to health services; improving the management of healthcare performance; improving patient/user satisfaction

Impact on policy and public services

Examples (including, but not limited to): Informing policy debate with the general public, in a government body, or at a non-governmental organisation; increasing public engagement with the policy process; improving efficiency of or access to public services; improving the equity of public service provision

Impact on public engagement, awareness and perceptions

Examples (including, but not limited to): Shaping the nature of public debate; increasing public engagement with research findings; increasing public awareness; creating publicly available tools or resources

10 years 
Please select all those you might reasonably expect your research to lead to now
Please select all those you might reasonably expect your research to lead to in the next 5 to

10 years

Impact on culture

Examples (including, but not limited to): Improving the quality of cultural events/activities or the evidence underpinning it; contributing to or improving public debate; improving attendance at cultural events; preserving cultural heritage; increasing engagement of cultural activities; improving understanding of cultural heritage; enriching cultural experiences.

Other (provide details below)

If you selected other, please provide details below:

11. Do you anticipate that the type of impacts that your work might contribute to will change in the next 5-10 years and why?

\section{Balance of outputs and impact}

12. What is the balance of effort you currently spend on outputs versus impacts?

$0 \%$ is all effort is on impacts and $100 \%$ is all effort is on outputs 
13. In the next 5 to 10 years, what is the balance of effort you plan to spend on outputs versus impacts?

$0 \%$ is all effort is on impacts and $100 \%$ is all effort is on outputs

\section{Research and the environment}

14. Given the changes you foresee in the outputs and impacts you produce (if any), how do you think the research environment needs to adapt to support these changes?

\section{Drivers of change}

15. How important are the following factors in driving the changes you foresee in the next 5 to 10 years?

This factor is not $\quad$ This factor is
somewhat This factor is very

Importance of collaborating with other academic researchers (e.g. collaborating rather than working alone) Importance of collaborating globally with other academic researchers (e.g collaborating with researchers in other countries) 
Importance of

\begin{tabular}{|c|c|c|}
\hline $\begin{array}{c}\text { This factor is not } \\
\text { important in driving } \\
\text { the changes }\end{array}$ & $\begin{array}{c}\text { This factor is } \\
\text { somewhat } \\
\text { important in driving } \\
\text { the changes }\end{array}$ & $\begin{array}{c}\text { This factor is very } \\
\text { important in driving } \\
\text { the changes }\end{array}$ \\
\hline
\end{tabular}

collaborating with

industry

Importance of

collaborating with non-

academic partners

(excluding industry)

(e.g. charities, non-

governmental

organisations,

museums, etc.)

Importance of being

mobile as a researcher

(e.g. travelling to other

countries for short or

long term visits)

Shift in global

research balance (e.g.

change in which

countries produce the

most or best research)

Emergence of new

professional roles in

academia

Open science (e.g.

open access, open data,

open code, etc.)

Citizen science (e.g.

the involvement of the

public in research)

Focus on inclusion

and diversity

Focus on research

integrity

Focus on research into global challenges (e.g.

ageing society, food

security, etc.)

Focus on

multidisciplinary

research 


$\begin{array}{ccc}\text { This factor is not } & \text { This factor is } & \text { This factor is very } \\ \text { important in driving } & \text { somewhat important in driving } \begin{array}{c}\text { important in driving } \\ \text { the changes }\end{array} \text { Unsure } \\ \text { the changes } & \text { the changes }\end{array}$

Changes in how

research is assessed

(e.g. assessment of

research excellence)

Focus on

accountability(e.g.

demonstrating that

publicly funded research

is valuable)

Focus on the non-

academic impact of

research

Increasing investment

in some areas of

research

Decreasing investment

in some areas of

research

The value placed on

research by society

The use of metrics

(e.g. citation

measures) in

understanding

research

Other (Please describe

below)

If you provided another driver of change, please describe below

\section{Additional demographic questions}

16. How old are you?
Under 21
21- 30
$31-40$
$41-50$ 

$51-60$
$61-70$
Over 70

17. How would you describe your gender?
Male
Female
Other
Prefer not to say

18. What is your ethnicity?

If you selected other, please specify:

19. The Equality Act 2010 considers a person disabled if: You have a physical or menta impairment or disability that has lasted or is likely to last at least $\mathbf{1 2}$ months, and this condition or disability has a substantial long-term effect on your ability to carry out day to day activities. Do you consider yourself disabled?
Yes
No
Prefer not to say

\section{Final comments}

If there are any other comments you think should be considered within this study please provide them below. 



\section{Annex D. Sectoral views questions}

See overleaf. 
Page 1 of 4

\section{National Research Landscape - Organisational Views}

\section{Introduction}

Research England is interested in understanding how the research landscape (i.e. research outputs, impacts and the research environment) might change over the next 5 to 10 years, in order to inform their planning for future research assessment (post 2021). This evidence gathering is intended to collect information on these issues and is part of a wider study being conducted by RAND Europe (https://www.rand.org/randeurope.html) on behalf of Research England.

We are very grateful for your participation.

If you have any questions please contact the RAND Europe project team at research_landscape_survey@rand.org (mailto:research_landscape_survey@rand.org) or Research England at Charlotte.Lester@re.ukri.org (mailto:Charlotte.Lester@re.ukri.org).

\section{Privacy Notice}

\section{About the project}

RAND Europe has been commissioned by Research England (one of the councils within UK Research and Innovation) to conduct a study of how the research landscape in the UK will change in the next 5-10 years in order to inform how research assessment may need to adapt. This document describes a request for views on the developing research landscape being carried out as part of the study.

\section{Who is conducting this research?}

RAND Europe is a not-for profit research Institute based in Cambridge. They have been commissioned by Research England (UK Research and Innovation) to carry out this study, who are the data controller for any data you submit. The research team is led by Dr Catriona Manville. 
Research England is responsible for funding, engaging with and understanding English higher education institutions (HEls). Research England is formed of the Research and Knowledge Exchange functions of the former HEFCE. This includes oversight of the Research Excellence Framework (REF) and the UK Research Partnership Investment Fund (UKRPIF).

\section{What data are we collecting?}

RAND Europe is collecting information on how organisations supporting the academic community think the research landscape will develop over the next 5-10 years. It will collect your organisational affiliation, IP addresses and email address for the purpose of this study.

\section{How are we collecting the data?}

The data will be collected through a survey hosted on SmartSurvey. The data will be stored on SmartSurvey and then downloaded to RAND Europe servers where it will be stored in password protected folders. Only SmartSurvey and the research team at RAND Europe carrying out the study will have access to your personal data.

\section{Why are we collecting it?}

This survey involves an opportunity for input from organisations, such as yourselves to provide views on how you feel the research landscape may change, and what is driving these changes. We will collect two pieces of personal data: your email address in order to be able to contact you for any clarifications and to send you a copy of the final report, and your IP address (which is collected automatically in the process of accessing the online survey and may be used to verify the response is unique).

\section{What is the legal basis for processing your data?}

Your data will be processed in accordance with the Data Protection Act 2018 and the General Data Protection Regulation. We are required by law to ensure that we protect this information, the use of the data is considered a task in the public interest. RAND Europe and Research England recognise the need to ensure your privacy and will minimise the use of personal identifiers.

\section{What are we using the data for?}

The organisational affiliation will allow us to compare and contrast responses with similar organisations. Your email address will be collected in order to allow the research team be able to contact you for any clarifications and to send you a copy of the final report, and your IP address (which is collected automatically in the process of accessing the online survey) may be used to verify the response is unique. Responses will be analysed and aggregated to inform a report to be presented to Research England and published.

\section{How will we be sharing the data?}

Research England (UKRI) has instructed that access to personal data be limited to SmartSurvey and RAND Europe.

\section{How do we keep your data secure?}

RAND Europe has implemented a company wide Information Security Management System (ISMS). RAND Europe is accredited for ISO 27001 certification and Cyber Essentials Plus. We have a senior management team that supports the continuous review and improvement of the company ISMS. 
Key controls RAND Europe has implemented include:

An Information Security Risk Assessment Process that assesses the business harm likely to result from a security failure and the realistic likelihood of such a failure occurring in the light of prevailing threats and vulnerabilities, and controls currently implemented.

An Information Classification and Handling Policy including compliance with regulations under the Data Protection Act to protect client, partner, supplier, our own and personal employee information which is not in the public domain.

A Business Continuity Plan to counteract interruptions to business activities and to protect critical business processes from the effects of major failures or disasters.

Defined security-controlled perimeters and access to controlled offices and facilities to prevent unauthorised access, damage and interference to business premises and information and data that might be held there.

Mandatory Information security awareness guidance for all company employees.

Background screening of all company employees

Data will be held on a server located in RAND Europe's Cambridge, UK office. Only the research team will have access to the data. Backups taken for disaster recovery purposes will be encrypted and stored in a secure offline site.

How long do we keep your data?

Your data will be destroyed after the research is completed and the project published.

What choices do you have in our use of your data?

You are able to request deletion of any data supplied whilst the study is underway.

What are your rights?

RAND Europe operates in accordance with the Data Protection Act 2018 and GDPR. You are provided with certain rights that you may have the right to exercise through us. You are entitled to request your data's deletion through contacting Research England at

researchpolicy@re.ukri.org (mailto:researchpolicy@re.ukri.org) whilst the study is underway.

\section{How do you contact us?}

If you have any questions about the use of your personal data in this study please contact Research England (researchpolicy@re.ukri.org (mailto:researchpolicy@re.ukri.org)) or RAND Europe (REdpo@rand.org (mailto:REdpo@rand.org)).

\section{Demographics}

\section{What organisation are you responding on behalf of? *}


2. What is your email address?

3. How do you expect the types of outputs and impacts of research to change over the next 5-10 years? (i.e. what different types of outputs or impacts might be produced and how might the balance of outputs and impacts change from what we have now)

4. How do you think the research environment might evolve in response to these changes?

5. What are the key drivers you foresee causing these changes?

6. Do you foresee that these changes would have a particular effect on specific groups of researchers? 



\section{Annex E. Codebooks for open-ended questions in the survey}

This annex provides the codebooks used to qualitatively analyse responses to four free text questions in the survey of academic researchers in England. The thematic categories were produced based on the responses, which is why the categories between similar questions may vary, and why some categories are very specific. When a response did not fit into an existing category, a new one was made.

\section{E.1. Codebook for expected outputs question}

Table E. 1 provides the codebook used in Excel to analyse the 1,072 responses to the open text question asking respondents to explain their responses to the question 'Do you expect a change in the type of outputs you are producing in the next 5 to 10 years?'

\section{Table E.1: Codebook used in Excel for expected outputs question}

\begin{tabular}{|l|l|l|}
\hline & Book chapters \\
\hline & Textbooks \\
\hline Patents and products \\
\hline Pre-prints \\
\hline Books and scholarly books \\
\hline Books for the public or practitioners \\
\hline Respondent expects & Textbooks \\
\hline to produce more & Reok reviews \\
\hline Edited volumes \\
\hline Online-only or digital outputs \\
\hline eBooks \\
\hline Journal articles \\
\hline Conference contributions \\
\hline Public-facing outputs \\
\hline Interactive and multimedia outputs \\
\hline
\end{tabular}




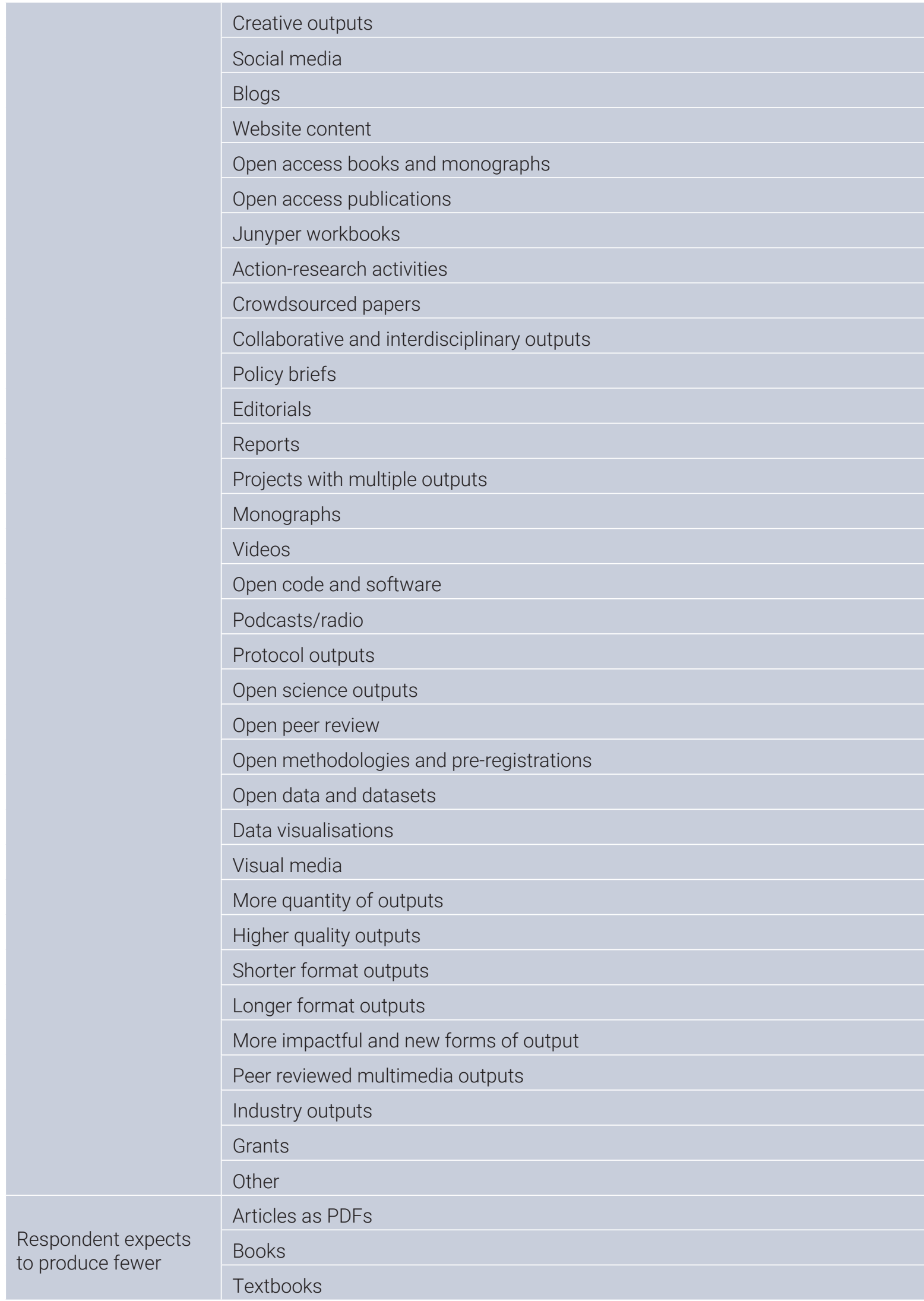




\begin{tabular}{|c|c|}
\hline & Journal articles \\
\hline & Reviews \\
\hline & Conference contributions \\
\hline & Monographs \\
\hline & Randomised Control Trials \\
\hline & Reports \\
\hline & Edited volumes \\
\hline & Lower quantity of outputs \\
\hline & Lower quality outputs \\
\hline & Blogs \\
\hline & Social media \\
\hline & Collaborative outputs \\
\hline & Practitioner-focused research \\
\hline \multirow{19}{*}{$\begin{array}{l}\text { Reason respondent } \\
\text { provided for expecting } \\
\text { different outputs in } \\
\text { the future }\end{array}$} & Career development \\
\hline & Promotion, recognition and reward system \\
\hline & Funding \\
\hline & Time \\
\hline & The REF \\
\hline & Impact agenda \\
\hline & Machine readable science \\
\hline & Reaching new audiences \\
\hline & Creating impact \\
\hline & Improving research \\
\hline & Improving communication \\
\hline & Changes in open access \\
\hline & Changes in academic publishing system \\
\hline & Reproducibility project \\
\hline & Saving resources \\
\hline & New technology \\
\hline & Brexit \\
\hline & Marketisation of research \\
\hline & Better teaching tools \\
\hline \multicolumn{2}{|l|}{ Non-response } \\
\hline \multicolumn{2}{|l|}{ Unsure } \\
\hline
\end{tabular}




\section{E.2. Codebook for ideal outputs question}

Table E.2 provides the codebook used in Excel to analyse the 640 responses to the question 'If you answered yes to Question 8, what would they be and why would you choose to produce them instead?' This question immediately followed the closed-ended question 'In an ideal world, would you choose to produce different outputs from those you have selected above?'

\section{Table E.2: Codebook used in Excel for ideal outputs question}

\begin{tabular}{|l|l|l|l|l}
\hline & Alternative outputs and public-facing outputs \\
\hline Books and monographs & \multicolumn{1}{|c|}{ Scholarly books and monographs } \\
\hline Conference contributions & Book the public or practitioners \\
\hline Creative outputs & Critical editions \\
\hline Crowdsourced papers & Open data and datasets \\
\hline Data visualisations \\
\hline Design \\
\hline Digital articles and digital dissemination \\
\hline Editorials \\
\hline Engagement with industry \\
\hline Evaluations \\
\hline Foreign language outputs \\
\hline Grey literature \\
\hline Guidelines and recommendations \\
\hline Implementation and interventions \\
\hline Interactive outputs \\
\hline Interdisciplinary and collaborative outputs \\
\hline Journal articles \\
\hline Lab books \\
\hline Longer format publications \\
\hline Open access articles \\
\hline Open science outputs \\
\hline Open access books and monographs \\
\hline Pamphlets \\
\hline Papers \\
\hline Patents and products \\
\hline Peer reviews \\
\hline
\end{tabular}




\begin{tabular}{|c|c|}
\hline & Popular media (blogs, podcasts, magazines, newspapers) \\
\hline & Policy briefs \\
\hline & Practice- or practitioner-based outputs \\
\hline & Pre-registrations \\
\hline & Pre-prints \\
\hline & Protocols and workflows \\
\hline & Shorter format publications \\
\hline & Social media \\
\hline & Open code and software \\
\hline & Teaching tools \\
\hline & Technical reports \\
\hline & Talks and lectures \\
\hline & Textbooks \\
\hline & Translations \\
\hline & Reports \\
\hline & Resources \\
\hline & Videos \\
\hline & Virtual reality outputs \\
\hline & Visual artefacts and exhibitions \\
\hline & Website and online content \\
\hline & Workshops and events \\
\hline & New ways of communicating with different audiences \\
\hline & Other \\
\hline & Journal articles \\
\hline & Workshops \\
\hline & Conference contributions \\
\hline & Books and monographs \\
\hline Respondents would ideally & Book chapters \\
\hline like to produce fewer & Book reviews \\
\hline & Quantity of outputs \\
\hline & Alternative outputs \\
\hline & Proprietary or confidential research outputs \\
\hline & Open access outputs \\
\hline Reasons why respondents & No time in role \\
\hline would like to produce & Lack of know-how or tools \\
\hline cannot produce the outputs & Lack of remuneration or resources \\
\hline they would ideally like to & The REF prevents respondent from producing ideal outputs \\
\hline
\end{tabular}




\begin{tabular}{|l|l|}
\hline Creating impact \\
\hline Reaching new audiences \\
\hline Producing certain outputs in research system or in career progression \\
\hline Funding for research \\
\hline Funding model of academic journals \\
\hline Publishing and peer review model \\
\hline Improving communication \\
\hline Improving research \\
\hline Salesmanship \\
\hline Avoiding information overload \\
\hline Getting immediate feedback \\
\hline Better teaching tools \\
\hline Non-response
\end{tabular}

\section{E.3. Codebook for expected impacts question}

Table E.3 provides the codebook used in Excel to analyse the 893 responses to the question
'Do you anticipate that the type of impacts that your work might contribute to will change in the next 5 to 10 years and why?'

\section{Table E.3: Codebook used in Excel for expected impacts question}

\begin{tabular}{|c|c|}
\hline \multirow{3}{*}{$\begin{array}{l}\text { Expected changes in } \\
\text { impact }\end{array}$} & Unsure of future impact \\
\hline & No change or decrease in impact \\
\hline & More impact \\
\hline \multirow{12}{*}{$\begin{array}{l}\text { Reason provided for } \\
\text { expected changes in } \\
\text { impact }\end{array}$} & Changes or developments in research \\
\hline & More collaborations with other researchers \\
\hline & More collaborations with non-academics \\
\hline & Career progression \\
\hline & Networking/meeting new people \\
\hline & Technology \\
\hline & More data \\
\hline & The REF \\
\hline & Impact agenda \\
\hline & Funding \\
\hline & Changes to academic publishing system \\
\hline & Institutional pressure (incentives, promotion) \\
\hline
\end{tabular}


Moving towards commercialisation or private sector

Topic becoming more relevant or impactful

Societal change

Information overload

More actively focusing on impact and engagement

Impact is difficult or impossible because public is not interested

Science or career is rigid

Brexit

Policy changes

Decreased 'risky' or basic research

Research is fundamental or basic

Arts and humanities research

My research already has an impact

My research does not have impact

Open science and open access

More training

Teaching

\section{E.4. Codebook for the research environment question}

Table E.4 provides the codebook used in NVivo to analyse the 1,930 responses to the question 'Given the changes you foresee in the outputs and impacts you produce (if any), how do you think the research environment needs to adapt to support these changes?' The table also shows the respondent attributes that were coded automatically using respondents' answers to the demographic questions at the beginning and end of the survey.

\section{Table E.4: Codebook used in NVivo for the research environment question}

\section{Value/focus}

01.01 Dissemination and engagement

01.02 Societal impact

\begin{tabular}{|c|c|}
\hline \multirow{2}{*}{$\begin{array}{l}\text { 01.01.01 Suggested } \\
\text { direction }\end{array}$} & 01.01.01.01 Should increase \\
\hline & 01.01.01.02 Should decrease \\
\hline \multicolumn{2}{|l|}{ 01.01.02 Other } \\
\hline \multirow{2}{*}{$\begin{array}{l}\text { 01.02.01 Suggested } \\
\text { direction }\end{array}$} & 01.02.01.01 Should increase \\
\hline & 01.02.01.02 Should decrease \\
\hline \multirow{3}{*}{ 01.02.02 Other } & 01.02.02.01 Clarifying definition of impact \\
\hline & 01.02.02.02 Creating impact takes resources and time \\
\hline & 01.02.02.03 Geographic range of impact \\
\hline
\end{tabular}




\begin{tabular}{|c|c|c|c|}
\hline & & \multicolumn{2}{|c|}{$\begin{array}{l}01.02 .02 .04 \text { Impact needs to be considered at beginning } \\
\text { of project }\end{array}$} \\
\hline & & \multicolumn{2}{|c|}{$\begin{array}{l}\text { 01.02.02.05 Measuring impact leads to more shallow } \\
\text { impacts }\end{array}$} \\
\hline & & \multicolumn{2}{|c|}{$\begin{array}{l}\text { 01.02.02.06 Some disciplines and researchers will have } \\
\text { impact and some won't }\end{array}$} \\
\hline & & \multicolumn{2}{|c|}{$\begin{array}{l}\text { 01.02.02.07 Impact activities should be done by non- } \\
\text { academics }\end{array}$} \\
\hline & & \multicolumn{2}{|c|}{ 01.02.02.08 Focusing on impact jeopardises career } \\
\hline & & \multicolumn{2}{|c|}{ 01.02.02.09 Other } \\
\hline \multirow{6}{*}{01.03 Outputs } & \multirow{3}{*}{$\begin{array}{l}\text { 01.03.01 Quantity of } \\
\text { outputs }\end{array}$} & \multirow{2}{*}{$\begin{array}{l}01.03 .01 .01 \\
\text { Suggested } \\
\text { direction }\end{array}$} & 01.03.01.01.01 Should increase \\
\hline & & & 01.03.01.01.02 Should decrease \\
\hline & & \multicolumn{2}{|c|}{ 01.03.01.02 Other } \\
\hline & \multirow{3}{*}{$\begin{array}{l}01.03 .02 \text { Quality of } \\
\text { outputs }\end{array}$} & \multirow{2}{*}{$\begin{array}{l}\text { 01.03.02.01 } \\
\text { Suggested } \\
\text { direction }\end{array}$} & 01.03.02.01.01 Should increase \\
\hline & & & 01.03.02.01.02 Should decrease \\
\hline & & \multicolumn{2}{|c|}{ 01.03.02.02 Other } \\
\hline \multirow{10}{*}{ 01.04 Collaboration } & \multirow{3}{*}{ 01.04.01 Academics } & \multirow{2}{*}{$\begin{array}{l}01.04 .01 .01 \\
\text { Suggested } \\
\text { direction }\end{array}$} & 01.04.01.01.01 Should increase \\
\hline & & & 01.04.01.01.02 Should decrease \\
\hline & & \multicolumn{2}{|c|}{ 01.04.01.02 Other } \\
\hline & & \multirow{2}{*}{$\begin{array}{l}01.04 .02 .01 \\
\text { Suggested } \\
\text { direction }\end{array}$} & 01.04.02.01.01 Should increase \\
\hline & $\begin{array}{l}01.04 .02 \\
\text { International }\end{array}$ & & 01.04.02.01.02 Should decrease \\
\hline & & \multicolumn{2}{|c|}{ 01.04.02.02 Other } \\
\hline & & \multirow{2}{*}{$\begin{array}{l}\text { 01.04.03.01 } \\
\text { Suggested } \\
\text { direction }\end{array}$} & 01.04.03.01.01 Should increase \\
\hline & Academics & & 01.04.03.01.02 Should decrease \\
\hline & & \multicolumn{2}{|c|}{ 01.04.03.02 Other } \\
\hline & 01.04.04 Other & & \\
\hline \multirow{12}{*}{$\begin{array}{l}01.05 \text { Type of } \\
\text { research }\end{array}$} & \multirow{3}{*}{$\begin{array}{l}01.05 .01 \\
\text { Interdisciplinary } \\
\text { research }\end{array}$} & \multirow{2}{*}{$\begin{array}{l}\text { 01.05.01.01 } \\
\text { Suggested } \\
\text { direction }\end{array}$} & 01.05.01.01.01 Should increase \\
\hline & & & 01.05.01.01.02 Should decrease \\
\hline & & \multicolumn{2}{|c|}{ 01.05.01.02 Other } \\
\hline & \multirow{3}{*}{$\begin{array}{l}01.05 .02 \text { Basic } \\
\text { research }\end{array}$} & \multirow{2}{*}{$\begin{array}{l}\text { 01.05.02.01 } \\
\text { Suggested } \\
\text { direction }\end{array}$} & 01.05.02.01.01 Should increase \\
\hline & & & 01.05.02.01.02 Should decrease \\
\hline & & \multicolumn{2}{|c|}{ 01.05.02.02 Other } \\
\hline & \multirow{3}{*}{$\begin{array}{l}01.05 .03 \text { Applied } \\
\text { research }\end{array}$} & \multirow{2}{*}{$\begin{array}{l}01.05 .03 .01 \\
\text { Suggested } \\
\text { direction }\end{array}$} & 01.05.03.01.01 Should increase \\
\hline & & & 01.05.03.01.02 Should decrease \\
\hline & & 01.05.03.02 & \\
\hline & & 01.05 .04 .01 & 01.05.04.01.01 Should increase \\
\hline & $\begin{array}{l}01.05 .04 \text { Global } \\
\text { challenges research }\end{array}$ & $\begin{array}{l}\text { suggested } \\
\text { direction }\end{array}$ & 01.05.04.01.02 Should decrease \\
\hline & & 01.05 .04 .02 & \\
\hline
\end{tabular}




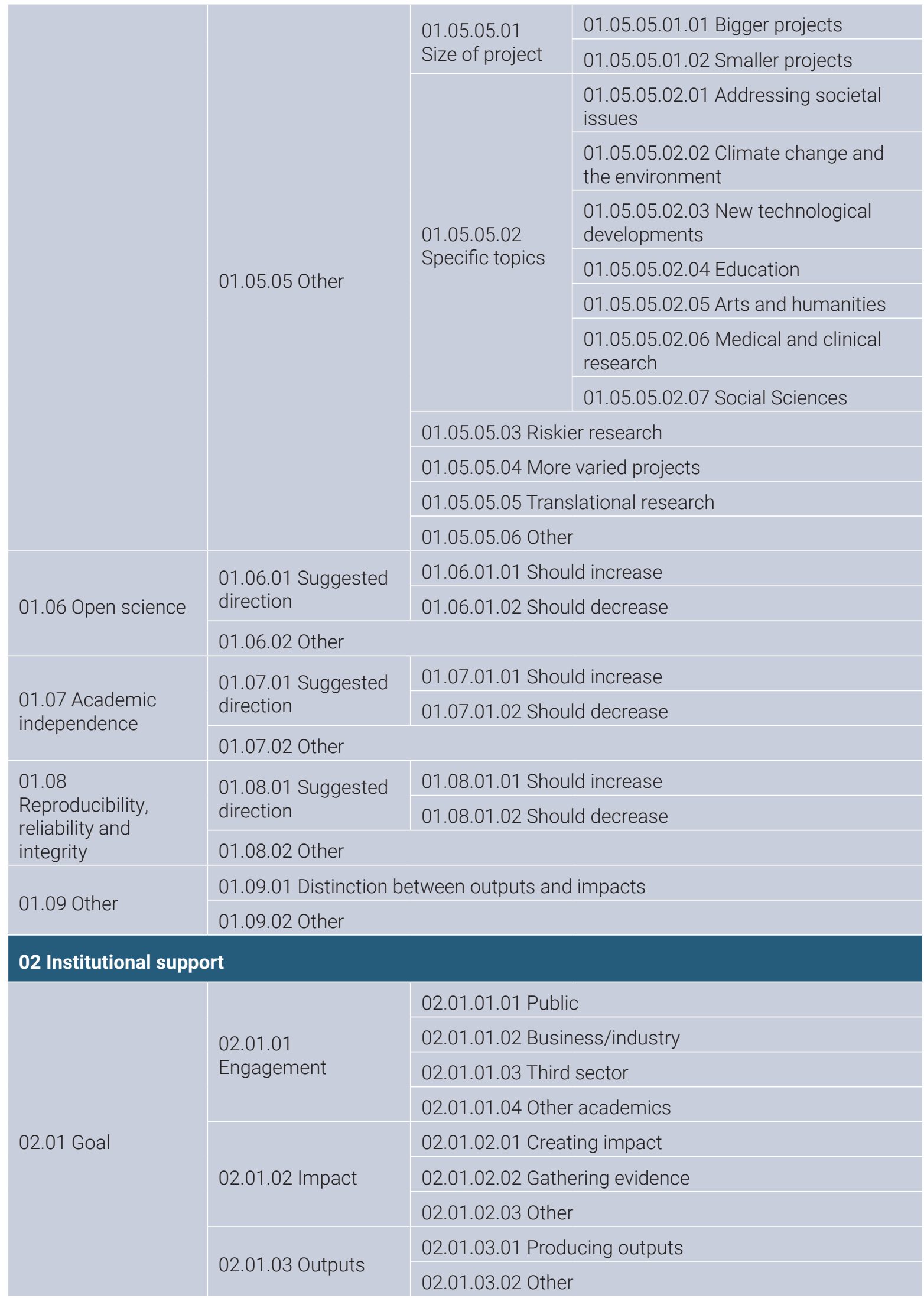




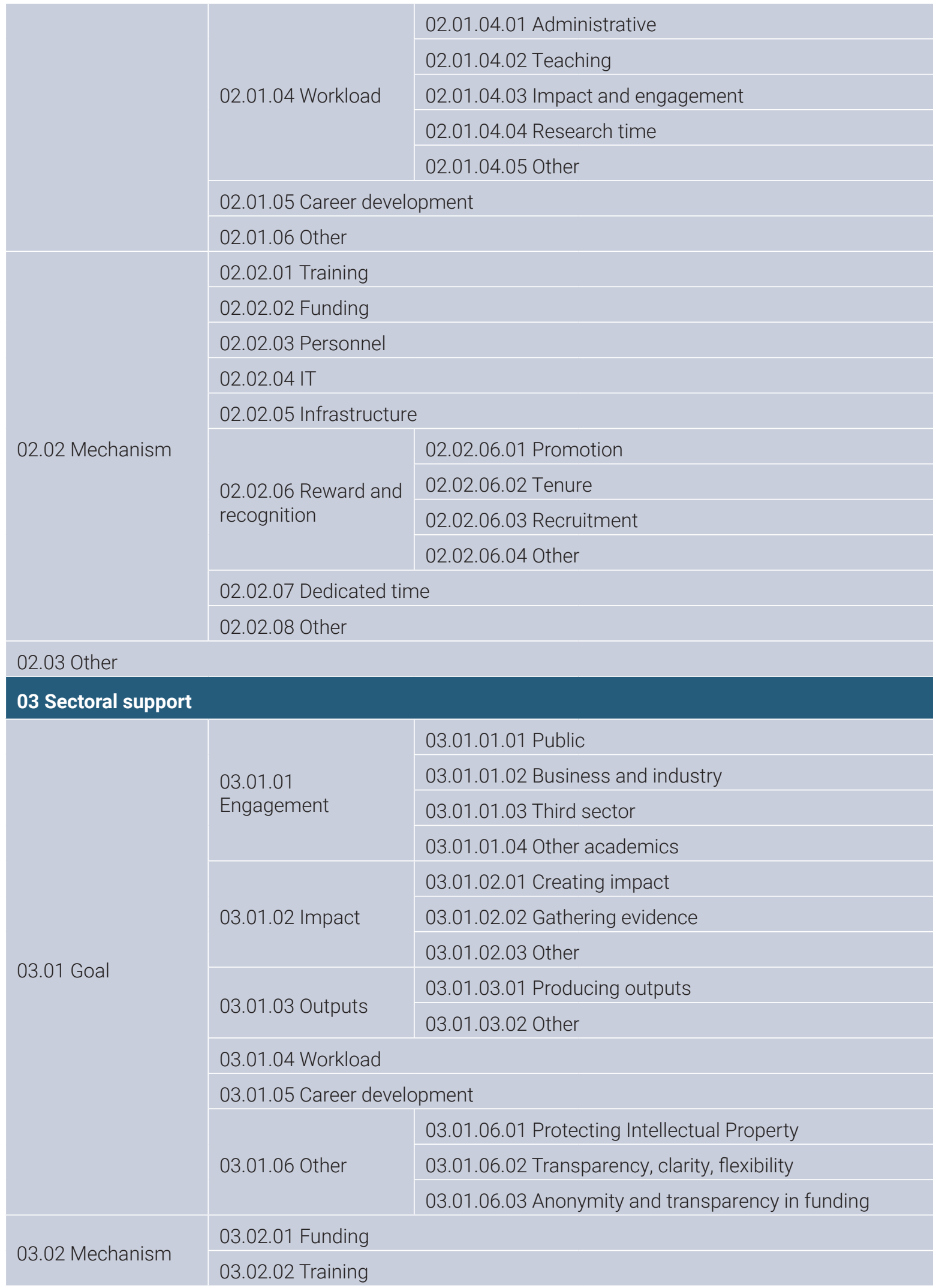




\begin{tabular}{|c|c|c|}
\hline & \multicolumn{2}{|l|}{ 03.02.03 Infrastructure } \\
\hline & \multicolumn{2}{|l|}{ 03.02.04 Policy } \\
\hline & \multicolumn{2}{|c|}{ 03.02.05 Academic publishing overhaul } \\
\hline & \multicolumn{2}{|l|}{ 03.02.06 Other } \\
\hline \multicolumn{3}{|l|}{03.03 Other } \\
\hline \multicolumn{3}{|c|}{04 Research assessment } \\
\hline \multirow{4}{*}{04.01 Goal } & \multicolumn{2}{|c|}{ 04.01.01 Transparency } \\
\hline & \multicolumn{2}{|c|}{ 04.01.02 More meaningful impact } \\
\hline & \multicolumn{2}{|c|}{ 04.01.03 Measuring research quality } \\
\hline & \multicolumn{2}{|l|}{ 04.01.04 Other } \\
\hline \multirow{10}{*}{04.02 Mechanism } & \multicolumn{2}{|l|}{ 04.02.01 Metrics } \\
\hline & \multicolumn{2}{|l|}{ 04.02.02 Output type } \\
\hline & \multirow{3}{*}{$\begin{array}{l}\text { 04.02.03 Weighting } \\
\text { impact }\end{array}$} & 04.02.03.01 Should increase \\
\hline & & 04.02.03.02 Should decrease \\
\hline & & 04.02.03.03 Other \\
\hline & \multirow{4}{*}{$\begin{array}{l}\text { 04.02.04 Tailoring } \\
\text { impact to disciplines }\end{array}$} & 04.02.04.01 Impact in arts and humanities \\
\hline & & 04.02.04.02 Impact in social science \\
\hline & & 04.02.04.03 Impact in pure science \\
\hline & & 04.02.04.04 Other \\
\hline & \multicolumn{2}{|l|}{ 04.02.05 Other } \\
\hline \multicolumn{3}{|l|}{04.03 Other } \\
\hline
\end{tabular}

05.01 Brexit

05.02 World standing in research

\begin{tabular}{|l|l} 
05.03 Trust in & 05.03.01 Policymaking
\end{tabular}

research 05.03.02 Public trust

05.04 Accountability

05.05 Marketisation or quantification of research

05.06 Other

\section{Simple answers}

06.01 Yes

06.02 No

06.03 Unsure

\section{General comments}

07.01 Research system
07.01.01 Positive

07.01.02 Negative 


\begin{tabular}{|c|c|}
\hline & 07.01.03 Other \\
\hline \multirow{3}{*}{$\begin{array}{l}07.02 \text { Research } \\
\text { assessment }\end{array}$} & 07.02.01 Positive \\
\hline & 07.02.02 Negative \\
\hline & 07.02.03 Other \\
\hline \multirow{3}{*}{ 07.03 Survey } & 07.03.01 Positive \\
\hline & 07.03.02 Negative \\
\hline & 07.03.03 Other \\
\hline \multirow{3}{*}{ 07.04 Other } & 07.04.01 Positive \\
\hline & 07.04.02 Negative \\
\hline & 07.04.03 Other \\
\hline \multicolumn{2}{|c|}{08 Disciplinary context } \\
\hline \multicolumn{2}{|c|}{ 08.01 Basic research } \\
\hline \multicolumn{2}{|c|}{ 08.02 Applied research } \\
\hline \multirow{2}{*}{08.03 Science } & 08.03.01 Main Panel A \\
\hline & 08.03.02 Main Panel B \\
\hline \multirow{2}{*}{$\begin{array}{l}08.04 \text { Arts/ } \\
\text { humanities/ } \\
\text { social science }\end{array}$} & 08.04.01 Main Panel C \\
\hline & 08.04.02 Main Panel D \\
\hline \multicolumn{2}{|c|}{08.05 Interdisciplinary research } \\
\hline \multicolumn{2}{|l|}{08.06 Other } \\
\hline
\end{tabular}

09.01 Specific types of universities

09.02 Specific universities

09.03 Other

\section{Equality and Diversity and Inclusion}

10.01 Gender

10.02 Ethnicity

10.03 Disability

10.04 Other

\section{Career stage}

11.01 PhD student

11.02 Early-career researcher

11.03 Mid-career researcher

11.04 Established researcher

11.05 Retired or emeritus professor

12 Other context 


\section{Unsure}

Attributes (Coded automatically)

Main panel

UOA

Interdisciplinary by UOA

Interdisciplinary by main panel

HEI Group

Location

Career Stage

Gender 



\section{Annex F. REF 2021 Units of Assessment}

\begin{tabular}{|l|l|l|}
\hline Main Panel & \multicolumn{3}{|l}{ Unit of assessment (UOA) } \\
\hline & 1 & Clinical medicine \\
\hline & 2 & Public health, health services and primary care \\
\hline & 3 & Allied health professions, dentistry, nursing and pharmacy \\
\hline & 4 & Psychology, psychiatry and neuroscience \\
\hline 5 & Biological sciences \\
\hline 7 & Agriculture, food and veterinary sciences \\
\hline 8 & Earth systems and environmental sciences \\
\hline 9 & Physics \\
\hline 10 & Mathematical sciences \\
\hline 11 & Computer science and informatics \\
\hline 12 & Engineering \\
\hline 13 & Architecture, built environment and planning \\
\hline 14 & Geography and environmental studies \\
\hline 15 & Archaeology \\
\hline 16 & Economics and econometrics \\
\hline 17 & Business and management studies \\
\hline 18 & Law \\
\hline 19 & Politics and international studies \\
\hline 20 & Social work and social policy \\
\hline 21 & Sociology \\
\hline 22 & Anthropology and development studies \\
\hline 23 & Education \\
\hline 24 & Sport and exercise sciences, leisure and tourism \\
\hline C & & \\
\hline
\end{tabular}


Main Panel Unit of assessment (UOA)

25 Area studies

26 Modern languages and linguistics

27 English language and literature

28 History

29 Classics

D

30 Philosophy

31 Theology and religious studies

32 Art and design: history, practice and theory

33 Music, drama, dance, performing arts, film and screen studies

34 Communication, cultural and media studies, library and information management

These are taken from https://www.ref.ac.uk/panels/units-of-assessment 


\section{Annex G. Workshop participants}

\begin{tabular}{|c|c|c|}
\hline Participant & Affiliation & Workshop \\
\hline Morag Campbell & Scottish Funding Council & Purpose of research assessment \\
\hline Dr Jenn Chubb & University of Sheffield & Purpose of research assessment \\
\hline $\begin{array}{l}\text { Professor Jonathan } \\
\text { Grant }\end{array}$ & Kings College London & Purpose of research assessment \\
\hline Dr Chonnettia Jones & Wellcome & Purpose of research assessment \\
\hline Paola Quattroni & Cancer Research UK & Purpose of research assessment \\
\hline Sue Smart & $\begin{array}{l}\text { Engineering and Physical Sciences } \\
\text { Research Council }\end{array}$ & Purpose of research assessment \\
\hline Fiona Goff & Natural Environment Research Council & Purpose of research assessment \\
\hline Dr Carolyn Reeve & $\begin{array}{l}\text { Department for Business, Energy and } \\
\text { Industrial Strategy }\end{array}$ & Purpose of research assessment \\
\hline Prof Alison Park & Economic and Social Research Council & Peer review \\
\hline Prof Maria Delgado & $\begin{array}{l}\text { The Royal Central School of Speech and } \\
\text { Drama }\end{array}$ & Peer review \\
\hline Prof Jane Millar & University of Bath & Peer review \\
\hline Prof Claire Squires & University of Stirling & Peer review \\
\hline Dr Andrew Clark & Royal Academy of Engineering & Peer review \\
\hline Prof Aileen Fyfe & St Andrews & Peer review \\
\hline Dr Ed Gerstner & Springer & Peer review \\
\hline Dr Ken Emond & British Academy & Peer review \\
\hline Dr Damian Pattinson & Research Square & Peer review \\
\hline Prof Margot Finn & Royal Historical Society & Peer review \\
\hline Dr Joris van Rossum & Digital Science & $\begin{array}{l}\text { Peer review } \\
\text { Emerging technologies }\end{array}$ \\
\hline Dr Liz Allen & F1000 & $\begin{array}{l}\text { Peer review } \\
\text { Emerging technologies }\end{array}$ \\
\hline
\end{tabular}




\begin{tabular}{|l|l|l|}
\hline Participant & Affiliation & Workshop \\
\hline $\begin{array}{l}\text { Dr Elizabeth Gadd } \\
\text { Professor John } \\
\text { Domingue }\end{array}$ & Loughborough University & Emerging technologies \\
\hline Simon Thomson & Clarivate & Emerging technologies \\
\hline Lucy Davies & Vertigo Ventures & Emerging technologies \\
\hline Dr Lotte Boon & University of Oxford & Emerging technologies \\
\hline Tamsin Burland & JISC & Emerging technologies \\
\hline Dr Steven Wooding & $\begin{array}{l}\text { Centre for Science and Policy, University } \\
\text { of Cambridge }\end{array}$ & Emerging technologies \\
\hline Dimity Flanagan & The British Library & Emerging technologies \\
\hline Dr Beverly Sherbon & Research Fish & Emerging technologies \\
\hline Simon Porter & Digital Science & Emerging technologies \\
\hline Tom Letcher & Symplectic & Emerging technologies \\
\hline
\end{tabular}

